Portland State University

PDXScholar

\title{
Teaching Mathematical Problem Solving in the Context of Oregon's Educational Reform
}

Nicole R. Rigelman

Portland State University

Follow this and additional works at: https://pdxscholar.library.pdx.edu/open_access_etds

Part of the Curriculum and Instruction Commons, Educational Leadership Commons, and the Science and Mathematics Education Commons

Let us know how access to this document benefits you.

\section{Recommended Citation}

Rigelman, Nicole R., "Teaching Mathematical Problem Solving in the Context of Oregon's Educational Reform" (2002). Dissertations and Theses. Paper 1760.

https://doi.org/10.15760/etd.1759

This Dissertation is brought to you for free and open access. It has been accepted for inclusion in Dissertations and Theses by an authorized administrator of PDXScholar. Please contact us if we can make this document more accessible: pdxscholar@pdx.edu. 


\section{TEACHING MATHEMATICAL PROBLEM SOLVING \\ IN THE CONTEXT OF OREGON'S \\ EDUCATIONAL REFORM}

by

NICOLE RENÉ MILLER RIGELMAN

A dissertation submitted in partial fulfillment of the requirements for the degree of

\section{DOCTOR OF EDUCATION in \\ EDUCATIONAL LEADERSHIP: CURRICULUM AND INSTRUCTION}

Portland State University

(C)2002 


\section{DISSERTATION APPROVAL}

The abstract and dissertation of Nicole René Miller Rigelman for the Doctor of

Education in Educational Leadership: Curriculum and Instruction were presented

May 29, 2002, and accepted by the dissertation committee and the doctoral program.

COMMITTEE APPROVALS:

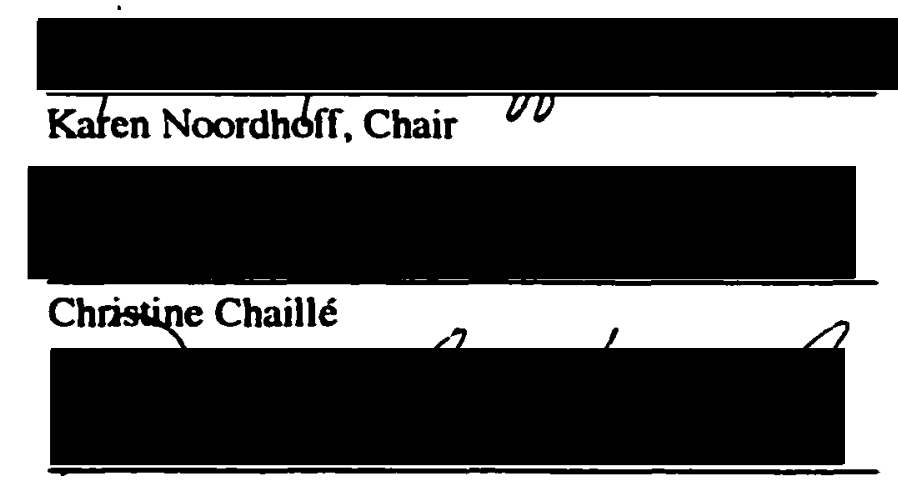

$$
\text { Ronald Narode }
$$

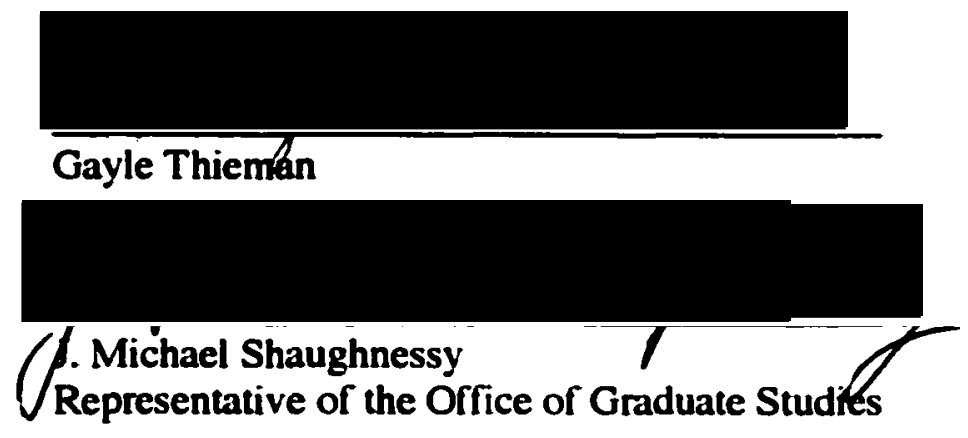

DOCTORAL PROGRAM APPROVAL:

Phyllats J. Eämundson, Dean

Graduate School of Education 


\begin{abstract}
An abstract of the dissertation of Nicole René Miller Rigelman for the Doctor of Education in Educational Leadership: Curriculum and Instruction presented May 29, 2002.
\end{abstract}

Title: Teaching Mathematical Problem Solving in the Context of Oregon's Educational Reform

Implementation of Oregon's Educational Reform Act (HB 3565 and HB 2991) provides the context for this inquiry as its emphasis on problem solving has impacted mathematics teaching and learning throughout the state. Even though all Oregon teachers are responding to the same policy, their goals in teaching problem solving vary. These goals and these practices are influenced by the way teachers view the role of problem solving in the curriculum. Further, their practice is influenced by their knowledge and beliefs about mathematics content, teaching, learning, and the reform policy. The questions addressed in this study are: (1) What do exemplary middle school math teachers do to engage students in mathematical problem solving? and (2) On what bases do these teachers make decisions about what to emphasize when teaching problem solving? how to teach problem solving?, and when to teach problem solving? 
This qualitative study provides a fuller description of Standards-based classroom practice than presently represented in the literature by offering both examples of problem solving practice and the related influences on that practice. It considers the influences of policy, curriculum, professional development, administrators, and colleagues on teachers' developing practice. The study also grounds the implementation of the Principles and Standards for School Mathematics (National Council of Teachers of Mathematics [NCTM], 2000) in the work of practicing middle school teachers. Finally, the study shows how, for these teachers, their curriculum has played a significant role in developing their perspectives on learning, teaching, and the nature of math, which has in turn, influenced their knowledge, beliefs, and instructional practice.

This study demonstrates that teachers are able to teach in ways consistent with the NCTM Standards when their knowledge and beliefs about practice align with the recommendations. Further, they teach in this manner when professional development experiences are geared toward understanding and developing Standards-based instructional practice, curriculum is consistent with this vision of practice, and administrators and school cultures are supportive of such practice. When these internal and external conditions exist within and for teachers, their students have the opportunity to learn to become "problem solvers," not just "problem performers." 


\section{ACKNOWLEDGEMENTS}

So many have encouraged me along this journey in completing my doctorate. There are many to thank. First, I want to thank Karen Noordhoff, my doctoral advisor, who helped me ask the deeper questions so that I could grow and learn more about what it means to be a teacher educator and scholar. I shall never forget her words of encouragement and careful reading of my writing. I want to thank my doctoral committee-Christine Chaillé, Ron Narode, Mike Shaughnessy, and Gayle Thieman for their support, feedback, and thoughtful questions.

I am thankful and appreciative of what I learned through the stories of the four exemplary middle school math teachers who participated in my research. They gave generously of their time and ideas, I am proud of their commitment to the profession. My work has also benefited from conversations with colleagues and former teachers. For their generous help, I am grateful to Cathy Brown, Lisa Byrd-Adajian, Rick Dills, Mark Endsley, Linda Foreman, Gene Maier, Heather Nelson, Ted Nelson, Claudia Noldge, Kathy Praendler, and Patty Quan. To my friends in the Gresham-Barlow School District and my new friends at George Fox University, particularly Scot Headley, Beth LaForce, Margi Macy, Jayne Sowers and Diane Wood, thank you for your support and encouragement. 
My family has always been encouraging, even if they doubted I would ever say, "I' $m$ done." My husband, Marc, has unwavering faith in my work and me. I could not have completed this program without his love, patience, sacrifice, and support. My daughters, Isabella and Gabrielle, are so happy to have their mom back. Thank you for always understanding and "yes, I can play with you now." I would also like to express appreciation to my father-in-law, Arden Benson, for his willingness to proofread for me. Finally, to my mom, dad, sisters and their families, no one could ask for better friends and supporters in life than they have been to me. 
TABLE OF CONTENTS

PAGE

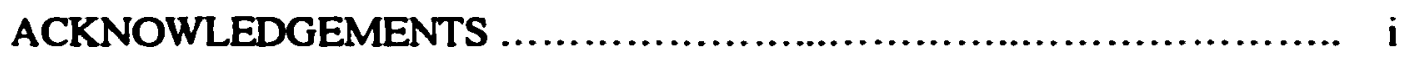

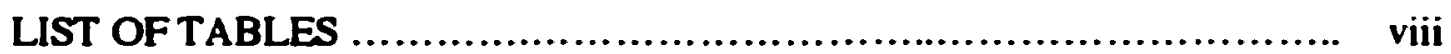

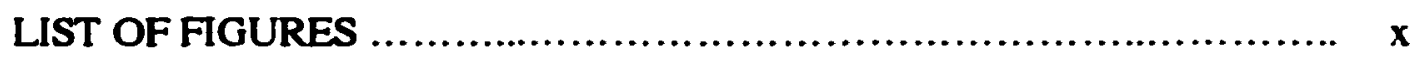

\section{CHAPTER}

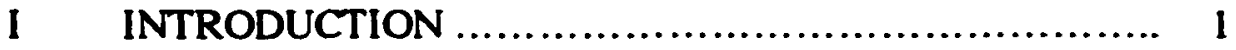

Problem Statement ................................ 4

Policy Background $\ldots \ldots \ldots \ldots \ldots \ldots \ldots \ldots \ldots \ldots \ldots, 6$

Interactions Between the Reform Policy and Views of Teaching and Learning ......................... 10

Comparing Classroom A to Classroom B

Learning Theories Informing the Policy

Conceptual Framework ......................... 16

Research Questions .............................. 20

Educational Significance $\ldots \ldots \ldots \ldots \ldots \ldots \ldots \ldots \ldots \ldots, 21$

Delimitations .................................. 23

Definitions ..................................... $\quad 24$

II LITERATURE REVIEW ............................... 26

Math Reform Context ............................ 28

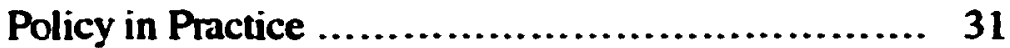


Defining Problem Solving .......................... 35

Problem Solving as a Focus in the Curriculum ....... 45

Historical Views of Problem Solving, Mathematics, and Learning

Recent Views of Mathematics and Learning

Views on the Role of Problem Solving in the

Curriculum

Problem Solving as Context

Problem Solving as Skill

Problem Solving as Art

Considerations for Problem Solving Instruction

Clarity for Instructional Outcomes

Guidance for Instruction

Habits and Dispositions of Expert Problem Solvers

The Influence of Teachers' Knowledge and Beliefs

on Problem Solving Instruction ....................

Knowledge of Mathematics Content and Pedagogy

Beliefs about Mathematics Content, Pedagogy, and Learning

Relationship of Teachers' Knowledge and Beliefs to Practice

Necessary Support Conditions for Teachers

Developing Their Practice

Importance of Understanding the Change Process and What is Called For By the Reform

Role of Professional Development

Role of the Principal and Teacher Leaders

Role of Collegial Support and Collaboration 
METHODOLOGY ......................................... 95

Research Questions .............................. 95

Considerations Leading to the Design of the Study ... 97

Criteria for Selection $\ldots \ldots \ldots \ldots \ldots \ldots \ldots \ldots \ldots \ldots \ldots, 102$

Process for Identification and Selection ............. 105

Data Collection ................................. 106

Questionnaire

Initial Interview

Prompted-Response Interview

Observations and Pre- and Post-Observation Interview

Follow-Up Interview

Data Reduction and Analysis

Summary

IV FINDINGS

Participant Profiles

Darrin Akers (DA)

Danielle Miller (DM)

Michelle Daniels (MD)

Quenton Forest (QF)

Engaging Students in Mathematical Problem Solving

Role of the Teacher

Role of the Student

Interrelationships among Teachers, Students, and Mathematical Problem Solving

Bases for Decision-Making about Problem Solving

Instruction

Internal Influences

External Influences

Summary and Discussion of the Data 
V CONCLUSION, FURTHER DISCUSSION, AND

IMPLICATIONS .................................. 245

Review of Research Questions and Research

Methodology ................................ 246

Summary and Conclusions ....................... 249

Further Discussion .............................. 251

Reconceptualizing the Conceptual Framework Internal Influences on Problem Solving Instruction

External Influences on Problem Solving Instruction

Implications and Recommendations ....

Teacher Educators and Professional

Developers

Teachers

Curriculum Developers

Policymakers

Suggestions for Further Research

Conclusion

\section{APPENDICES}

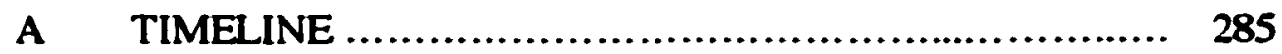

B INFORMED CONSENT ................................. 287

C MATHEMATICS TEACHER QUESTIONNAIRE .......... 289

D INITIAL INTERVIEW PROTOCOL ....................... 294

E PROMPTED-RESPONSE INTERVIEW PROTOCOL ........ 296

F TASKS FOR SORTING ................................. 298 
vii

G CLASSROOM OBSERVATION SCALES

303

H RE- AND POST -OBSERVATION INTERVIEW PROTOCOL

307

I CHARACTERISTICS OF MATHEMATICAL INSTRUCTIONAL TASKS

309

J FOLLOW-UP INTERVIEW PROTOCOL

311

K CURRICULUM SAMPLES FOR FOLLOW-UP INTERVIEW

313

L RESEARCH QUESTION AND METHODS ALIGNMENT MATRIX

316 


\section{LIST OF TABLES}

TABLE

PAGE

1. Oregon Mathematics Problem Solving Scoring Guide

8

2. Knowledge and Behavior Necessary for an Adequate Characterization of Mathematical Problem

Solving Performance

42

3. Connection between Schoenfeld's Problem Solving

Performance and Oregon's Mathematics

Problem Solving Scoring Guide

4. An Agenda for Action Recommendations for School

Mathematics of the $1980 \mathrm{~s}$

5. A Guide to Problem Solving Techniques

6. Components of the Role of the Teacher in a Reformed Classroom and Related Beliefs about the Teaching and Learning of Mathematics

7. Ten Important Principles of Professional Development

8. Goal-Specific Versus Non-Goal-Specific Problems

92

9. Summary of Data Sources and Central Purposes

113

10. Role of Teacher and Student While Engaging in Problem

Solving

11. Summary Background Information and Teaching Context by Teacher

12. Observations About Solution Strategies

13. Factors Influencing Effective Instruction According to Darrin

Akers 
14. Factors Influencing Effective Instruction According to Danielle Miller ..................................................... 130

15. Factors Influencing Effective Instruction According to Michelle Daniels .........................................................

16. Factors Influencing Effective Instruction According to Quenton Forrest.......................................................

17. Interrelationships Between Teachers' Goals, Beliefs, and Actions Regarding Problems and Problem Solving ............

18. Relationships Between Teachers' Beliefs and Chosen Strategies for Supporting Students ...................................... 197

19. Relationships of Internal Influences to Problem Solving Practice 210

20. Comparing Visual Mathematics to Two Other Standards-based Curricula ................................................... $\quad 219$

21. Relationships of External Influences to Problem Solving

Practice 


\section{LIST OF FIGURES}

FIGUEE

PAGE

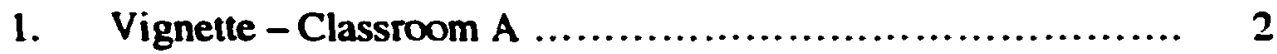

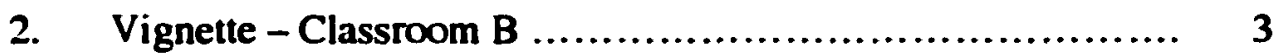

3. Model for Research and Curriculum Development ............. 17

4. Instructional Triangle .................................... 18

5. Revised Model for Research and Curriculum Development .... $\quad 19$

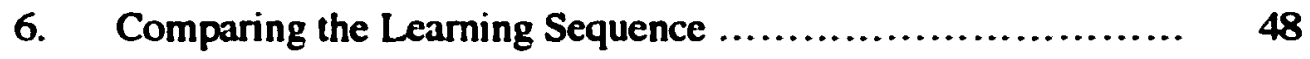

7. Teachers' Knowledge Developing in Context ................. 81

8. Mathematical Thinking and Problem Solving ................. 140

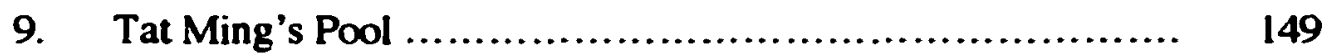

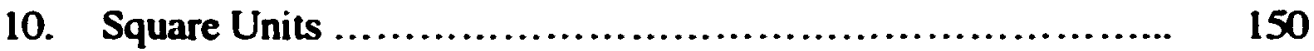

11. Frequency of Question Types (\%) ....................... 166

12. Frequency of Interaction Types (\%) indicating Role of Teacher 169

13. Completing the Square ................................... 173

14. Arithmetic Sequences .................................. 174

15. Algebraic Representations ................................ 176

16. Integer Multiplication .................................... in

17. Frequency of Interaction Types (\%) indicating Role of Student 180

18. Frequency of Problem Solving Behaviors (\%) ................ 182

19. Mathematical Problem Solving Process ...................... 184 
20. Revised Model for Research and Curriculum Development Revisited

21. Revised Instructional Triangle

22. Instructional Triangle Specifying Interactions Within and Influences on the Teaching and Learning Process

23. Instructional Triangle Specifying Interactions While Engaging in Problem Solving .........................................

24. Instructional Triangle Specifying Interactions Within and Influences (Internal) On the Teaching and Learning Process

25. Instructional Triangle Specifying Interactions Within and Influences (Internal and External) On the Teaching and Learning Process 


\section{CHAPTER I}

\section{INTRODUCTION}

Effective mathematical problem solvers are flexible and fluent thinkers. They are confident in their use of knowledge and processes. They are willing to take on a challenge and persevere in their quest to make sense of a situation and solve a problem. They are curious, seek patterns and connections, and are reflective in their thinking. These characteristics are not limited to problem solvers in mathematics or even in schools; they are characteristics desired for all individuals in both their professional and personal lives (National Research Council [NRC], 1985; Steen, 1990). These characteristics not only make it easier for individuals to learn new things but also help them in making sense of existing knowledge. Problem solving "habits of mind" prepare individuals for "real" problems: situations requiring effort and thought, lacking an immediately obvious strategy or solution. To develop problem solving habits of mind, students need experiences working with situations that they "problematize with the goal of understanding and developing solution methods that make sense for them" (Hiebert et al., 1996, p. 19).

The current mathematics educational reforms at both the state and national levels suggest that students should have such learning opportunities and recommend increased attention to problem solving in the curriculum (Oregon Department of 
Education [ODE], 2001; National Council for Teachers of Mathematics [NCTM], $1989,2000)$. However, simply asking teachers to increase attention given to problem solving does not ensure a focus on student understanding. Following are two vignettes, (Figures 1 and 2) each offering a picture of problem solving instruction. While both teachers are responding to the same recommendations for a focus on problem solving, they offer students very different learning opportunities.

How many tiles are in the $25^{\text {th }}$ figure of this pattern?

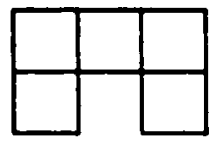

$1^{\text {n }}$ Figure

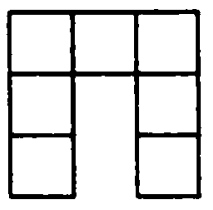

$2^{\text {nd }}$ Figure

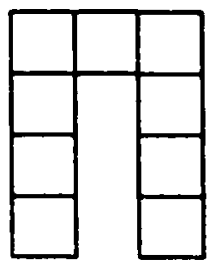

$3^{\text {rd }}$ Figure

$T_{1}: \quad$ Today we are going to practice problem solving. I'd like you to work on answering this question. You need to be sure to restate the question, explain your process, and check your work. What is the question asking us to do?

$S_{1}$ : Find out how many tiles are in the $25^{\text {th }}$ figure.

$T_{1}$ : Good. How are we going to find out?

$S_{2}$ : Just keep adding two tiles until we get to the $25^{\text {th }}$ figure.

$S_{1}$ : We need to add two tile 23 more times.

$T_{1}$ : $\quad$ OK. On your paper explain how you'll find the answer and don't forget to check your work.

Figure 1. Vignette - Classroom A 
Investigate and report all you can about this pattern.

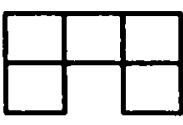

$1^{n}$ Fieure

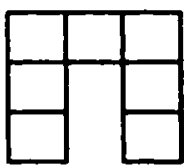

$2^{\text {nd }}$ Figure

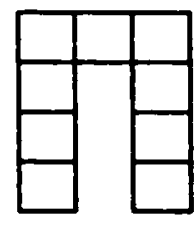

$3^{\text {rd }}$ Figure

$\mathrm{T}_{2}$ : $\quad$ Please take out your problem solving journal and begin work on this problem [Teacher places problem on the overhead. Teacher circulates as student begin work. After seven minutes the teacher asks...] What do you notice about this pattern?

S: It looks like a table whose legs are getting longer and longer.

$S_{4}$ : The legs are getting longer by one tile...

$S_{3}: \quad \ldots$ and there are two tiles added for each figure.

$S_{s:} \quad$ There are always three tiles on the top of the figure.

$S_{6}: \quad$ The legs are always the same as the figure number.

$T_{2}$ : Would you come and show how you see that?

$S_{6}$ : [Student goes to the overhead.] See, the legs are always the same as the figure number. In the first figure there is one in each leg, in the second there is two, in the third, three, and so on.

$S_{7}$ : [Student goes to the overhead.] I saw the legs as the whole side. So the legs are longer than the figure number and there is one in the middle instead of three on top. In the first figure, I see two in each leg, three in the second, four in the third, and there's always one left to count in the middle.

$\mathrm{T}_{2}$ : Did anyone see it in a different way?

$S_{8}$ : I saw a "three-by" rectangle with empty spaces in the middle. [Student walks to the overhead while talking.] There are always three tiles in the dimension [points along the top dimension of each figure]. There is always one more than the figure on this dimension... first there is two, then three, then four... so in the $10^{\text {th }}$ figure there would be eleven, it's a 3-by-11 with ten empty spaces in the middle.

$S_{6}$ : Oh! So the empty space is the same as the figure number.

$S_{3}$ : You could move that outside leg of the table over by the other leg and make a "two-by" rectangle with one extra tile sticking out. [Student goes to the overhead and shows how the right leg can slide to the left to fill the empty space.]

$T_{2}$ : I can see you all have done some good thinking about this. I'd like you to take some private think-time now and record your thoughts about some different ways that you might find the total number of tiles in any figure that is in this pattern. Also, how might you convince someone else that you are correct?

Figure 2. Vignette - Classroom B 
These classrooms present two very different approaches to problem solving. The focus in Classroom A (Figure 1) is on finding a single strategy to obtain the answer to the problem. This is preceded by writing-up the response to the problem following specified criteria: restating, explaining, and verifying. This teacher's view of problem solving, and perhaps mathematics, is that there is one way to correctly solve the problem and one way to write-up a response to a problem. The instructional focus in Classroom B (Figure 2) is on exploring the relationships within the problem, sharing the possibilities, and considering how this thinking may extend to any figure in the pattern. This teacher's view of problem solving is that there are multiple ways to solve a problem and that problem solving is a process of exploring, developing methods, discussing methods, and generalizing results. Students in Classroom B at first have a chance to explore the problem individually, they then share their ideas and thinking, and finally individuals have an opportunity to reflect on what had been shared, explore to see if they can create general statements and/or formulas, and generally make meaning of the information for themselves.

\section{Problem Statement}

Standards implementation, specifically the teaching of mathematical problem solving, provides the context for this study. Developing students as problem solvers is the vision of national and state policymakers. This vision, articulated in the Principles and Standards for School Mathematics (NCTM, 2000), describes the desire to create students with problem solving habits of mind. In this view, successful problem 
solvers exhibit curiosity, flexibility, and interconnected understandings of mathematical content and processes. Unfortunately, many Oregon teachers in response to the educational reform are training their students with "how-to" approaches to problem solving. They teach their students how to perform well based on the criteria defined in the state problem solving scoring guide. They present only "state-like" problems to their students, those that have a single answer and can be solved within a 45-minute time period. They develop students as "problem performers" as opposed to "problem solvers." They provide their students with specific formats for their write-up to a problem, and in many cases a strategy for developing a solution to a problem. Despite what the educational reform encourages regarding problem solving instruction and goals, students are receiving narrowly defined instruction. These current instructional practices leave students dependent on prescribed processes and unable to readily face problems without an immediately obvious strategy. The short-term goal of developing students who meet or exceed the standard (problem performers) may be attained, but the more important long-term goal of developing flexible and fluent thinkers (problem solvers), may not be.

The policies informing mathematics teacher's practice in Oregon include both national and state standards. These policies offer a broad range of recommendations regarding content, teaching methods, and assessment techniques. While the policies provide some guidance, they leave teachers to their own interpretations and decisionmaking responsibility regarding their practice. 


\section{Policy Background}

In June 1991, the Oregon Legislative Assembly in response to A Nation at Risk (National Commission on Educational Excellence, 1983) enacted the Oregon Educational Act for the 21st Century. The Act was developed by the Department of Education in conjunction with the Oregon State Legislature. The plan, while not the first state-level attempt to establish higher standards for student learning, represents Oregon's move toward a comprehensive restructuring of schools pre-K through 14 . In general, major components of the plan include (a) expansion of the waiver process, (b) broadened authority of school site councils, (c) required altemative learning environments, and (d) mandated development of content and performance standards for Certificates of Initial and Advanced Mastery (CIM and CAM) with accompanying assessments. The content and performance standards were intended to guide districts' instructional and assessment programs in districts resulting in a connected educational pathway for students from their pre-K experience through their transition into the workforce as a young adult. The content and performance standards along with the assessments specific to mathematics are the focus for this study.

The statewide reform initiative outlines content expectations for students in the core subjects, including mathematics. The mathematics content standards are based on work from National Council of Teachers of Mathematics (1989, 1991, 1995, 2000) and the National Research Council (1985). The expectations represent a broad range of content (including calculations and estimations, algebra, geometry, measurement, 
statistics and probability) and are more rigorous than they had been in the past. This reform focuses on the improvement of teaching and learning in mathematics, and while it offers explicit guidance in terms of content, the guidance for teaching practice is implicit.

The state assessments in mathematics - a multiple-choice assessment, a performance assessment, and a classroom worksample - are used to provide evidence of improved teaching and learning. The multiple-choice and performance (problem solving) assessments are each on-demand individual assessments while the classroom worksample and its administration varies. Since the policy emphasizes the need to develop mathematically proficient students, the assessment system measures student proficiency relative to a cut score for the multiple-choice test and problem solving scores for the performance assessment and the classroom worksample. A student, to meet standard, must show evidence of proficiency on all three measures.

In 1996, the Oregon State Board of Education adopted the Mathematics Content Standards that identify what students should know and be able to do. For each Content Standard there are benchmarks for grades three, five, eight, ten (Certificate of Initial Mastery, CIM), and twelve (Certificate of Advanced Mastery, CAM/PASS). The benchmarks specify the content expectations and required proficiencies for the particular grade level. Performance standards measure the progress toward the benchmark. While no specific instructional strategies are advocated by the policy, the problem solving scoring guide implicitly communicates the types of learning opportunities that ensure student success in meeting the standards 
on the problem solving assessment. The guide has four traits: conceptual understanding, processes and strategies, verification, and communication, as well as a separate accuracy component. To meet the standard, students must (1) show an understanding of the problem or task and obtain at least an essentially correct solution, (2) choose and use an appropriate strategy, (3) convince the reader that both the strategy and solution are correct, as well as (4) clearly communicate all aspects of the work. Shown in Table 1 is the Oregon Mathematics Problem Solving Scoring Guide (ODE, 2001). Students must score at least a four on each dimension of the scoring guide and at least a four in Accuracy to meet the standard. Scores of five and six are judged to exceed the standard. The scoring guide communicates the valued cognitive actions and processes, as well as cognitive product.

Table 1

Oregon Mathematics Problem Solving Scoring Guide

\begin{tabular}{|c|c|c|c|}
\hline $\begin{array}{l}\text { Concepplual } \\
\text { Understanding } \\
\text { Interpreting the } \\
\text { concepts of the lask } \\
\text { and translating them } \\
\text { into mathematics }\end{array}$ & $\begin{array}{l}\text { Processes \& } \\
\text { Strategies } \\
\text { Choosing strategies } \\
\text { that can work. and } \\
\text { then carrying out the } \\
\text { strategies chosen } \\
\text { HOW? }\end{array}$ & $\begin{array}{l}\text { Verification } \\
\text { In addition to solving } \\
\text { the task, evidence of a } \\
\text { second look at the } \\
\text { concepts/stralegies/ } \\
\text { calculations to defend } \\
\text { a solution } \\
\text { DEFEND! }\end{array}$ & $\begin{array}{l}\text { Communication } \\
\text { Using pictures, } \\
\text { symbols, and/or } \\
\text { vocabulary to convey } \\
\text { the path to the } \\
\text { identified solution } \\
\text { THE CONNECTING } \\
\text { PATH! }\end{array}$ \\
\hline $\begin{array}{l}\text { The translation of the } \\
\text { task is enhanced } \\
\text { through connections } \\
\text { and/or extensions to } \\
\text { other mathematical } \\
\text { ideas }\end{array}$ & $\begin{array}{l}\text { Elegant, complex } \\
\text { and/or enhanced } \\
\text { mathematical } \\
\text { processes/strategies } \\
\text { are completed }\end{array}$ & $\begin{array}{l}\text { The review is related } \\
\text { to the task, and } \\
\text { enhanced, possibly by } \\
\text { using a different } \\
\text { perspective as the } \\
\text { defense }\end{array}$ & $\begin{array}{l}\text { The connecting path } \\
\text { is enhanced (e.g.. } \\
\text { graphics. examples) } \\
\text { allowing the reader to } \\
\text { move casily and make } \\
\text { comnections from one } \\
\text { thought to another }\end{array}$ \\
\hline
\end{tabular}


Table 1

(continued)

\section{Oregon Mathematics Problem Solving Scoring Guide}

\begin{tabular}{|c|c|c|c|c|}
\hline 5 & $\begin{array}{l}\text { The translation of the } \\
\text { task into } \\
\text { mathematical } \\
\text { concepts is } \\
\text { thoroughly developed }\end{array}$ & $\begin{array}{l}\text { Pictures, models, } \\
\text { diagrams, and/or } \\
\text { symbols used to solve } \\
\text { the lask are } \\
\text { thoroughly developed }\end{array}$ & $\begin{array}{l}\text { The review is a } \\
\text { thoroughly developed } \\
\text { look at the concepts/ } \\
\text { strategies/calculations } \\
\text { in relation to the task }\end{array}$ & $\begin{array}{l}\text { The path connecting } \\
\text { concepts, strategies, } \\
\text { and/or verification to } \\
\text { the identified solution } \\
\text { is thoroughly } \\
\text { developed }\end{array}$ \\
\hline 4 & $\begin{array}{l}\text { The translation of the } \\
\text { lask into adequate } \\
\text { mathematical } \\
\text { concepts using } \\
\text { relevant information } \\
\text { is completed }\end{array}$ & $\begin{array}{l}\text { Pictures, models, } \\
\text { diagrams, and/or } \\
\text { symbols are complete }\end{array}$ & $\begin{array}{l}\text { The review is } \\
\text { completed } \\
\text { (concepts/stralegies/ } \\
\text { calculations), and } \\
\text { supports a solution }\end{array}$ & $\begin{array}{l}\text { The path connecting } \\
\text { concepts. strategies, } \\
\text { and/or verification to } \\
\text { the identified solution } \\
\text { is complete }\end{array}$ \\
\hline 3 & $\begin{array}{l}\text { The translation of the } \\
\text { major concepts of the } \\
\text { task is partially } \\
\text { completed and/or } \\
\text { partially displayed }\end{array}$ & $\begin{array}{l}\text { Pictures, models, } \\
\text { diagrams, and/or } \\
\text { symbols may be only } \\
\text { partially useful and/or } \\
\text { partially recorded }\end{array}$ & $\begin{array}{l}\text { The review is } \\
\text { partially completed, } \\
\text { partially recorded. } \\
\text { and/or partially } \\
\text { effective }\end{array}$ & $\begin{array}{l}\text { The path connecting } \\
\text { concepts, strategies, } \\
\text { and/or verification to } \\
\text { the solution is } \\
\text { partially complete. } \\
\text { and/or partially } \\
\text { displayed with } \\
\text { significant gaps that } \\
\text { have to be inferred }\end{array}$ \\
\hline 2 & $\begin{array}{l}\text { The translation of the } \\
\text { lask is } \\
\text { underdeveloped, } \\
\text { sketchy and/or may } \\
\text { be flawed }\end{array}$ & $\begin{array}{l}\text { Pictures, models, } \\
\text { diagrams, and/or } \\
\text { symbols used are } \\
\text { underdeveloped or } \\
\text { sketchy }\end{array}$ & $\begin{array}{l}\text { The review is } \\
\text { underdeveloped or } \\
\text { sketchy (e.g., } \\
\text { focusing only on their } \\
\text { answer or its } \\
\text { reasonableness) }\end{array}$ & $\begin{array}{l}\text { The path comnecting } \\
\text { concepts, strategies, } \\
\text { and/or verification } \\
\text { toward a solution is } \\
\text { underdeveloped or } \\
\text { sketchy. }\end{array}$ \\
\hline 1 & $\begin{array}{l}\text { The translation of the } \\
\text { task uses } \\
\text { inappropriate } \\
\text { concepts or is } \\
\text { minimal or not } \\
\text { evident }\end{array}$ & $\begin{array}{l}\text { Pictures, models, } \\
\text { diagrams, and/or } \\
\text { symbols are } \\
\text { ineffective, minimal, } \\
\text { not evident, or may } \\
\text { conflict with their } \\
\text { solution }\end{array}$ & $\begin{array}{l}\text { The review is } \\
\text { ineffective, minimal. } \\
\text { inappropriate and/or } \\
\text { not evident }\end{array}$ & $\begin{array}{l}\text { The path connecting } \\
\text { concepts, strategies, } \\
\text { and/or verification } \\
\text { loward a solution is } \\
\text { ineffective, minimal } \\
\text { or not evident }\end{array}$ \\
\hline
\end{tabular}

Accuracy

\begin{tabular}{|c|c|c|c|c|}
\hline 5) & $\begin{array}{l}\text { The answer given is } \\
\text { mathematically } \\
\text { justifiabie and supported } \\
\text { by the work }\end{array}$ & 4) & $\begin{array}{l}\text { The answer given is } \\
\text { adequate and/or it may } \\
\text { contain a minor error, but } \\
\text { no additional instruction } \\
\text { appears necessary }\end{array}$ & $\begin{array}{l}\text { 1) The answer given is } \\
\text { incorrect, incomplete or } \\
\text { correct but conflicts with } \\
\text { the work }\end{array}$ \\
\hline
\end{tabular}

From ODE (2001) 
Implementation of Oregon's Educational Reform Act (HB 3565 and HB 2991) provides the context for this inquiry given that the reform's emphasis on problem solving has impacted mathematics teaching and learning throughout the state. Even though all Oregon teachers are responding to the same policy, their goals and instructional practice in teaching problem solving vary. Their goals and practice are influenced by the way teachers view the role of problem solving in the curriculum. Further their practice is influenced by their knowledge and beliefs about mathematics content, teaching, learning, and the relorm policy.

Interactions between the Reform Policy and Views of Teaching and Learning

This section explores the connections between the characteristics of the classrooms in the opening vignettes and the teaching, learning, and assessment outcomes likely in classrooms with such interactions. It continues with a look at the brief look at the learning theories informing the state and national policies.

\section{Comparing Classroom A to Classroom B}

When comparing Classroom A (Figure 1) to Classroom B (Figure 2) we can see some similarities. The teachers pose similar problems and they ask students for ideas about the problem. We see evidence of students interacting with each other by building on each other's ideas. We can also see some differences, differences that can be significant when viewing problem solving beyond the state's problem solving scoring guide. While the teacher in Classroom A may be preparing students to 
respond to a set of questions aligned to the dimensions of the scoring guide (e.g., restating the problem is conceptual understanding, explaining how you found the answer is communication, checking your work is verification), is she preparing students to problematize and make sense of situations and invent solution methods? Is there evidence that students are thinking flexibly and fluently about the problem and considering alternate strategies? The students in Classroom $A$ are not engaged in the same level of thinking and reflection as the students in Classroom B. These learning opportunities in these classrooms do not yield the same educational outcomes. The main differences and their corresponding outcomes are described more fully below.

The Problem. The problem posed in Classroom A is a state-like problem, asking how many tiles are in the $25^{\text {th }}$ figure of this pattern. It is a problem that yields only one correct solution. The problem posed in Classroom B differs in that it the task itself encourages exploration of the pattern and naturally yields a generalization from students.

Eliciting Student Thinking. The questions posed from the teacher in Classroom A (What is the question asking us to do? How are we going to find out?) yield responses that simply answer the question asked and communicate little about how the student decided on the solution and/or what the student sees in the model. In Classroom B the questions (What do you notice about the pattern? Would you come and show how you see that? Did anyone see that in a different way?) suggest that this teacher values both the process and the product. In addition to sharing a solution, the students share their reasoning (how they see it in the model), build on others' ideas, 
consider more than one approach, and make sense of each others' approaches. They are problematizing and making sense of the situation.

Reflection and Sensemaking. Students in Classroom A were not given an opportunity for reflection and sensemaking. They move from the task to a focus on the product. Students in Classroom B had several points of reflection and sensemaking. The interchange opens with students individually exploring this openended problem in their journals. It next moves through several students sharing observations and informal generalizations. There is evidence that students are actively considering the ideas of others, as in the cases of $S_{6}$ and $S_{3}$. Students, having already shared their ideas, build on their peers' ideas as the conversation unfolds. Finally, the teacher asks the students to individually consider all these ideas and now formulate some thoughts about more formal generalizations and proof. Students in both Classroom A and B are inventing solution strategies; however, in Classroom B students also explore multiple strategies and analyze these strategies, considering how they might lead to generalizations.

Cohen (1988) suggests that in a traditional classroom knowledge is objective and stable, consisting of facts, laws, and procedures that are true; while in a reformed classroom knowledge is emergent, uncertain, and subject to revision. The teacher in Classroom A, while attempting to engage the students in a discussion about the problem, asks questions that do not elicit much discussion. Once she hears the response she was looking for from students, the focus quickly turns to the procedure the students need to follow in writing-up a response to the problem. Alternatively, in 
Classroom B the teacher guides the inquiry through posing open-ended tasks, encouraging reflection, asking questions, generally helping students learn how to construct knowledge through interacting with the problem (Cohen, 1988) and each other (Leinhardt, 1992).

\section{Learning Theories Informing the Policy}

The Curriculum and Evaluation Standards (NCTM, 1989) state that instructional activities must allow students to enter at varying conceptual levels and with existing schema. This statement implies that knowledge does not develop in the same way or at the same time for all students. In the classroom, while all students are receiving the same instruction, the outcomes are not the same for all. The students' varying levels of mathematical understanding are a starting point, and the instructional strategies, including hands-on exploration, inquiry, discourse, and reflection, are used to create the desire to grow and learn more in mathematics. Students experiencing this instruction take what they need from the classroom interactions, what is appropriate to their conceptual readiness. Students express their ideas and opinions. Their peers actively listen as the sharing benefits the learning of all. The community within the classroom works collectively to construct understanding. Students share their insights and expertise for the common good. Teachers orchestrate this experience through posing problems, asking questions, and encouraging discourse and reflection. Constructivist learning theory, as described by Piaget (as cited in Confrey, 1990), von Glasersfeld (1990), Vygotsky (1978), and others, guides these statements. 
Constructivism rejects the ideas that students are blank slates. They do not absorb ideas as teachers present them. Rather, they are creators of their own knowledge and understanding. As students approach a learning situation they bring differing knowledge and experiences and because of this often see a mathematical or scientific idea in a different way than adults who have experience with the idea (Piaget as cited in Confrey, 1990). These differences are not simply a result of lack of techniques or method; instead, students possess "a different form of argument, [their ideas] are built from different materials, and are based on different experiences," (Confrey, 1990, p. 109). Before students will change what they understand or believe to be true, they must be confronted with the fact that their thinking has a flaw, is no longer effective, or that another alternative is preferable. This stage is part of the learning process, wherein learners face "cognitive conflict" or disequilibrium by reflecting on what they believe to be true, and then reorganizing their knowledge and/or beliefs in an attempt to retum to a state of equilibrium. Confrey suggests that a fundamental quality of powerful knowledge construction is believing what you know. It is the process of reaching a state of equilibrium with a concept that moves students from knowledge of the concept to belief in that concept.

While constructivists agree that learners should take an active role in making sense of the world around them, there are differing views about what experiences advance new learning from knowing to believing. Ernst von Glasersfeld (1990) would argue that it is the cognitive effort of the individual that results in the construction of knowledge, arguing that "reality" lies within the learner and that the leamer pays little 
attention to the social processes of knowledge construction. On the contrary, Vygotsky (1978) identifies social interaction as playing a crucial role in the learning process. He claims that it is dialogue and collaboration with more capable peers that advances knowledge construction, as the learner can learn more in collaboration than he/she can independently. This discrepancy between the radical constructivist and social constructivist paradigms does not necessarily imply that a teacher must chose between these two perspectives. Cobb (1994) argues that mathematics learning "should be viewed as both a process of active individual construction and a process of enculturation into the mathematical practices of wider society" (p. 13). Essentially, he describes how both processes shape learning; the social constructivist perspective defines the conditions for the learning, while the radical constructivist perspective shapes the processes by which learning takes place.

Building a classroom environment in which constructivist beliefs are evident implies that the role of the teacher and students must change (Cohen, 1988). This approach causes students to become increasingly involved in directing their own learning. The teacher becomes a facilitator instead of a dispenser of information. The constructivist approach acknowledges and nurtures the fact that individual students interpret instructional situations in different ways and gives students opportunities for students to collaborate with their peers. As students share their thinking, justify their strategies and solutions, and reflect on the learning overall, they construct new understanding, just as was observed in Classroom B. 


\section{Conceptual Framework}

Teaching, like problem solving, is an art. It requires more than mechanized teaching skills and/or content knowledge. The teacher must be aware of the multiple approaches and multiple representations that could be used to teach a topic and make decisions regarding what is best for his/her students (Shulman, 1986a; Grossman, Wilson, \& Shulman, 1989; Cohen \& Ball, 2000). A teacher using a Standards-based approach to instruction takes on the role of a facilitator in the classroom. He/she must make choices about the right problem to pose, about when to let students struggle, about when to intervene (Henningson \& Stein, 1997; Smith \& Stein, 1998). There are many factors that influence a teacher's decision-making in the classroom. These include a teacher's knowledge and beliefs about mathematics (Cooney, 1985; Grossman et al., 1989; Raymond, 1997), mathematics teaching and learning, and students (Haimes, 1996; Grossman et al., 1989; Jennings-Wiemers, 1990). Also shaping a classroom teacher's instruction is the knowledge and beliefs the teacher holds regarding the policies they are to implement (Clarke, 1997; Cohen, 1990; Cohen \& Ball, 1990).

Reflecting such factors, a conceptual framework offered by Carpenter (1989) guided this study. This model, developed in conjunction with Carpenter, Fennema, and Peterson (Figure 3), treats teaching as problem solving, suggesting that while teaching a teacher engages in a form of problem solving. For example, while interacting with students during classroom instruction a teacher must make decisions 
regarding what task to pose and how to pose it, how to respond to students' questions, who to call on, in what order students should present their ideas, how to deal with mistakes, and/or whether to pursue a students' idea. Influencing these decisions are the teacher's knowledge and beliefs. Carpenters' model assigns a central role to both teachesrs' and students' thinking. The influences on the teachers' decisions, and therefore, teachers' instructional practice are the focus of this study.

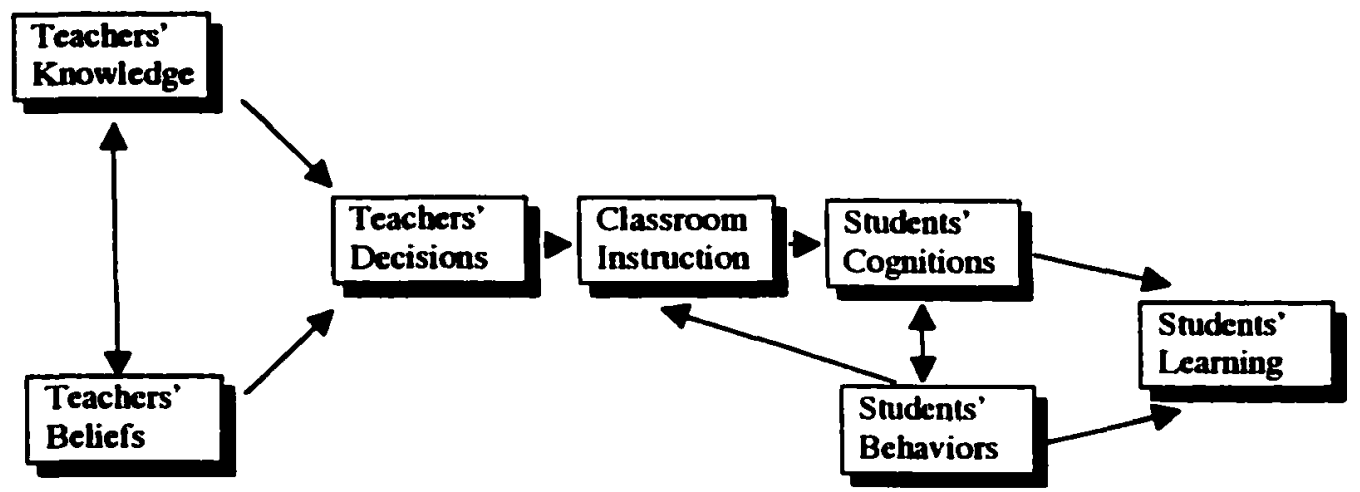

Figure 3. Model for research and curriculum development. From Carpenter (1989, p. 193).

Like Carpenter et al., Hawkins (1974) recognizes that classroom instruction is constructed through interactions between teachers and students. His model, shown in Figure 4, differs from Carpenter's in that content is central to the interactions in the classroom. Hawkins describes classroom instruction as reciprocal interactions between I, thou, and it. "I" represents the teacher, "thou" the students, and "it" the subject. He describes the need for teachers to engross the students in the subject, so the student comes alive and the teacher and the student have a common theme for discussion. This framework suggests that within a problem solving leaming 
environment, both the teacher and student act as learners, engaging in solving a problem, and from their experiences interacting with the problem and each other, learning takes place. The relationship is reciprocal as both the teacher and the student learn by taking part in the problem solving investigation.

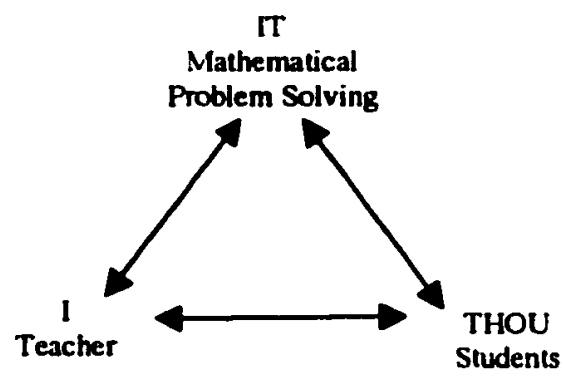

Figure 4. Instructional triangle.

Considering both models together suggests some revision to Carpenter's model to adequately capture classroom interactions. For example, what happens in classrooms as a result of teachers' decisions will likely impact the teachers' knowledge and/or beliefs. To accommodate these additional perceived relationships, this researcher proposed the addition of the dashed arrows in Figure 5 since there are reciprocal relationships among teachers' decisions, knowledge, and beliefs. Also, from an instructional practice standpoint, student behaviors influence teachers' decisions and vice versa. 


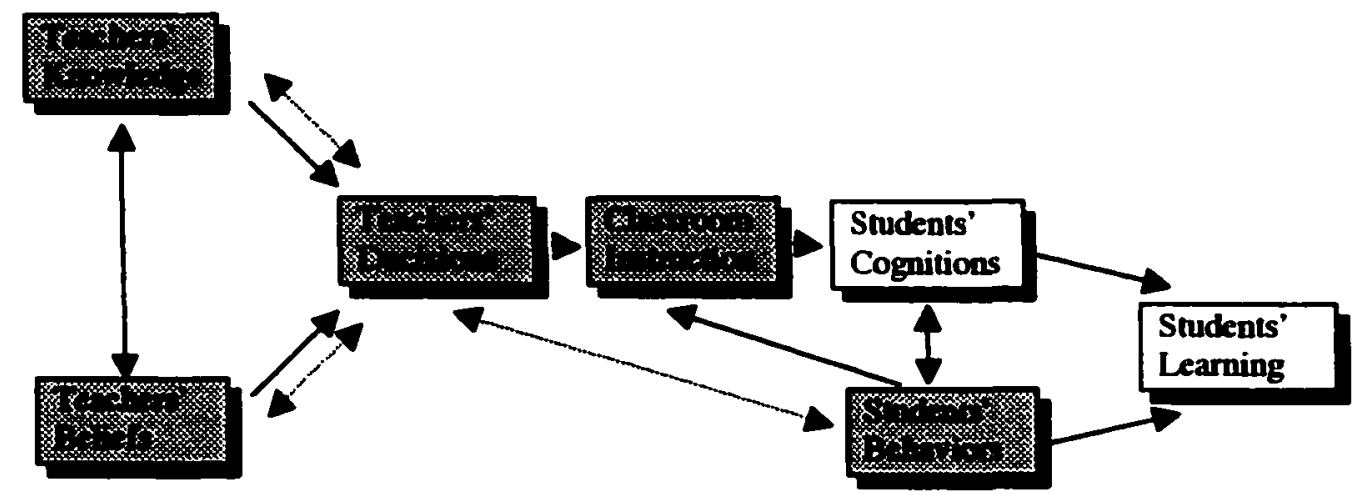

Figure 5. Revised model for research and curriculum development. (Shaded items indicate the focus for the present study and dashed arrows are added to show additional relationships.)

In conclusion, as seen in the opening classroom vignettes, what it means to problem solve in mathematics differs from classroom to classroom. If policymakers were hoping that in response to the policy all teachers would develop students into problem solvers, they may be surprised by the differences in the levels of thinking that students are engaged in, all under the guise of problem solving. The teacher in Classroom B better represents a teacher that is engaging students in problem solving. In contrast, the teacher in Classroom A seems to be complying with the reform by training students to perform well on the state assessment, controlling their problem solving through a focus on the dimensions of the scoring guide. Teachers, like the one represented in Classroom B, were the focus of the present study so that positive problem solving instruction and its influences could be studied in depth. 


\section{Research Questions}

Two main questions were addressed in this study:

1. What do exemplary middle school mathematics teachers do to engage students in mathematical problem solving?

In answering this question, the researcher looks at relationships among the teacher, student, and the content, specifically, mathematical problem solving. The researcher

describes what teachers and students are doing as they engage in problem solving and describes what teachers emphasize as they teach problem solving, the role problem solving plays in their curriculum, and how teachers choose the problems they do.

2. On what bases do teachers make decisions about

-what to emphasize when teaching problem solving?

-how to teach problem solving?, and

-when to teach problem solving?

In answering this question the researcher looks at the internal and external conditions influencing teachers as they make decisions about what to emphasize as they teach problem solving, how to teach problem solving, and when to teach problem solving. This study allowed the researcher to account for and explain the internal (knowledge, beliefs, and thinking) and extemal (curriculum, policy, professional development) conditions that influence teachers' problem solving practice. It provides stories of how and why teachers come to teach problem solving the way they do. 


\section{Educational Significance}

Silver (1985) reviews the literature on the teaching and learning of problem solving. He discovers a lack of information about the role of the teacher during problem solving. He feels the research lacks a good description of what actually happens in the classroom when problem solving is taught. Prior to 1985 , studies systematically controlled for the "teacher variable" and do not assess the direct effectiveness of the instruction. Grouws (1985) argues for more information on (1) how teachers conceptualize problem solving, (2) how teachers attempt to teach problem solving, (3) the amount of time devoted to problem solving and the number and types of problems students are asked to solve, and (4) the types of teacher-student and student-student interactions.

Since 1985, studies have looked at mathematics instruction that emphasizes reasoning, problem solving, and understanding and have linked student success on performance assessments to instructional approaches that emphasize the development of conceptual understanding (Silver \& Lane, 1995, Ben-Chaim, Fey, Fitzgerald, Benedetto, \& Miller, 1997; Sawada, 1997). Studies have also shown how teacher goals when using problem-oriented curricula, when not aligned with the curricula, can prevent and/or limit student learning (Rickard, 1995; Henningsen \& Stein, 1997). Studies explained the influence of teachers' subject matter knowledge and explicit beliefs about teaching and learning on the ways teachers teach mathematics (Shulman, 1986a; Grossman et al., 1989) and implement the NCTM Standards (Borko \& Elliott, 
1998; Fernandez, 1997). Only Borko and Elliott (1998) and Fernandez (1997) purposefully study several exemplary teachers and their instructional practices, describing what these teachers can do and how they put reform policies into practice.

To some extent the research community has responded to the needs identified by Silver (1985) and Grouws (1985). There are now descriptions of what is happening in classrooms wherein teachers are implementing the NCTM Standards, which includes the teaching of problem solving. The studies listed above provide examples of what the teacher is doing, what the students are doing, and how students are performing as a result of the experiences. Some studies begin to account for the influences on the teachers' practices, but use these influences to explain why the instructional practices are not what they should be. Borko and Elliott (1998), Fernandez (1997), and Henningsen and Stein (1997) provide cases of the positive possibilities for Standards-based instruction and teacher-student and student-student interactions. Still lacking are descriptions specific to problem solving instruction. Such descriptions are important since state-level interpretations of the Standards have resulted in an emphasis on problem solving teaching, learning, and assessment. Also lacking is information regarding how teachers conceptualize problem solving, specifically how teacher knowledge and beliefs impact conceptions and instruction of "problem solving". The current study fits into this line of research and builds on it by filling the gaps and providing descriptions of problem solving instruction within a state in which problem solving is central to the assessment system. Additionally, this 
study considers the relationships among and the influences on teacher knowledge and beliefs about problem solving.

From this study comes a description of what is happening in the classrooms of exemplary middle school math teachers. It describes how these teachers view problem solving, how they teach problem solving, and how teachers and students interact as they engage in problem solving. This study benefits teachers and teacher educators by helping them to better understand the positive possibilities for problem solving teaching and learning. Also developed through this study is a better understanding of what influences a teacher's instructional practice, as well as the relative power of those influences. Recognizing these influences benefits teacher educators and administrators by helping them know how to plan experiences likely to impact teachers' knowledge and beliefs, and therefore their practice.

\section{Delimitations}

The goal of the present study is to describe the problem solving instruction of exemplary middle school math teachers' classrooms and account for influences on their instructional practice. The sample is a purposefully selected group of four mathematics teachers in a large metropolitan area in Oregon, teachers whose classroom practice reflects the vision of the NCTM Principles and Standards (2000).

A qualitative case study approach is used to explore and explain the nature of problem solving instruction in four exemplary middle school mathematics teachers' classrooms. The teachers were chosen based on recommendations by the researcher's 
dissertation committee members and mathematics curriculum specialists and the completion of a screening observation. Those teachers exhibiting characteristics such as a rich understanding of math content, a pedagogy centered on student understanding, and a belief that all students can do math. The primary data sources were three consecutive classroom observations and five individual teacher interviews. Supplemental data included classroom artifacts (e.g., tasks/problems) and district/state documents (e.g., curriculum frameworks, task banks, professional development plans and calendars).

The case study approach is used because only qualitative approaches accommodate the detailed descriptions of the relationships among knowledge, beliefs, and practice called for by the research questions. Multiple methods were used to tell a more complete story of what informs the teachers' practices. Exemplary teachers were chosen because it is their stories that can help teachers, teacher educators, and administrators develop a better understanding of what is possible in a problem solving environment and develop a clearer sense of strategies to support, sustain, and cultivate teachers' problem solving practice.

\section{Definitions}

Based on the previous discussion and the purposes of this dissertation, the following definitions are offered.

Benchmarks: Checkpoints during grades 3, 5, 8, and 10 when students' progress toward the Certificate of Initial Mastery (CIM) is formally measured (ODE, 2001). 
Content Standard: These standards define what students are expected to know and be able to do in English, mathematics, science, social students, the arts, and a second language (ODE, 2001).

Performance Standard: The standards define the minimum scores expected of students on state tests and classroom assignments to achieve the benchmarks at grades 3, 5, 8, and 10 (ODE, 2001).

Problem: A situation lacking an immediately obvious strategy or solution. Knowledge must be put together in a new way to solve the problem.

Problem Solving: The process of engaging in a problem (making observations, conjectures, and generalizations) and making use of mathematical knowledge, strategies/techniques, metacognitive skills, and beliefs.

Reform: (Oregon Educational Reform Act for the $21^{\text {st }}$ Century) Sets standards for students to prepare them for the challenges they will face after high school. The goal is to have curriculum, instruction, and assessment articulated and aligned to help students achieve the desired standards. Teams of teachers and other experts regularly review and refine the standards and assessment to assure alignment, appropriate rigor, etc.

Scoring Guide: Specific, consistent criteria on a 1-6 point scale against which teachers score students' classroom work (ODE, 2001).

Visual Mathematics/Math Alive!: A National Science Foundation (NSF) funded Standards-based comprehensive middle school curriculum focused on student-driven exploration of complex problems. The materials provide experiences with models and manipulatives to help students understand and invent math ideas. 


\section{CHAPTER II}

\section{LITERATURE REVIEW}

Oregon's Educational Reform Act (HB 3565 and HB 2991) sets academic learning standards for students and focuses on the improving the alignment of teaching, leaming, and assessment. The policy offers implicit guidance for teaching practice through its content and performance expectations. The evidence of improved student learning is provided by a three-pronged assessment system comprised of an on-demand multiple-choice assessment, a performance assessment, and a classroom worksample. Each of these assessments emphasizes an understanding of mathematics instead of just the ability to do math. As described in Chapter 1 , the assessment system measures student proficiency relative to a passing score for the multiple choice test, and problem solving scores for performance assessment and the classroom worksample. The problem solving scores are generated from a trait-based scoring guide focused on five dimensions: conceptual understanding, processes and strategies, verification, communication, and accuracy. This three-pronged assessment system provides a more complete picture of a student's mathematical understanding than does a percentile score on a standardized assessment (ODE, 2000). The classroom teacher is responsible for preparing students to meet or exceed these standards relative to math content and problem solving ability. 
There are many factors shaping teachers' problem solving practice. These factors include teacher knowledge and beliefs about mathematics, about problem solving, about students, and about the reform expectations (Thompson, 1989; Cohen \& Ball, 1990). As a teacher educator, I have worked to help teachers incorporate problem solving into their practice. I have facilitated workshops, for several hundreds of teachers on scoring using the state scoring guide, developing "good" problems and tasks, enhancing students' problem solving expertise, and considering what we learn about students based on their responses to a given problem. From my work in these areas, I have heard stories of teachers' problem solving practices that, in my opinion, do not reflect the intentions of the policymakers. The original intent of the policy was to prepare students for the 21 st century (ODE, 2001). According to this policy, teachers need to attend to higher and broader content standards in mathematics that include strands such as geometry, measurement, algebra, probability and statistics, and calculations and estimations. As a result, teachers should teach content from each of these strand areas every year, instead of reserving work with algebra and geometry for high school. The policy also gives attention to mathematical processes including reasoning and proof, communication, and the focus of this present study, mathematical problem solving.

In listening to teachers describe their problem solving practice; I feel their practice often tells a different story. Teachers are training their students to perform well based on the criteria defined in the state problem solving scoring guide. In other words, they provide students with specific formats for their write-up to a problem, and 
in many cases provide a format for developing a solution to a problem. They may tell their students to solve the problem with a particular "preferred" strategy or control the problem solving process by asking students to develop their response in a setting, controlling for the dimensions of the scoring guide, as in Classroom A (Figure 1). Rather, the Classroom B (Figure 2) teachers facilitate "problem solving” as envisioned by the policymakers. They actively engage students in a problem, and a solution is found through a combination of individual and social knowledge construction.

A frame for this investigation is offered in the following review of the literature. This review provides a structure for analysis of problem solving teaching by (1) providing the mathematics reform context, (2) offering descriptions of similar policies in practice, (3) defining problem solving, (4) reviewing why problem solving should be a focus in the curriculum, (5) outlining the various views on the role of problem solving in the curriculum, (6) exploring considerations for problem solving instruction, (7) reflecting how teacher knowledge and beliefs shape problem solving instruction, and (8) determining the necessary conditions for supporting teachers in developing their practice.

\section{Mathematics Reform Context}

Problem solving has been emphasized in the mathematics curriculum during the past two decades (NRC, 1985; NCTM, 1980, 1989, 1991, 1995, and 2000). However, the role problem solving should take in the curriculum continues to be a question for teachers. Is problem solving a justification for teaching mathematics? 
Does it represent the vehicle for motivating students? Should it be used to teach new concepts or practice previously learned concepts? Does problem solving represent another skill which teachers are responsible for teaching? Does it represent all of the above? The way in which a teacher answers these questions reveals his/her beliefs and knowledge about the nature of problem solving and its role in the math curriculum.

NCTM's Principles and Standards (2000) describe problem solving as both a purpose and a means for mathematics learning. This document describes a need for all students (1) to build new mathematical knowledge through work with problems, (2) to develop a disposition to formulate, represent, abstract, and generalize in situations both within and outside mathematics, (3) to apply a wide variety of strategies and to adapt these strategies to new situations, and (4) to monitor and reflect on mathematical thinking. However, like Oregon's Content Standards, there is not much explicit guidance to teachers with strategies for enacting these goals in their practice.

Teachers are left to make their own decisions about their problem solving instruction. These decisions about how to implement the reform expectations are influenced by their knowledge and beliefs about the reform, (Thompson, 1989; Cohen \& Ball, 1990) as well as the available curricular resources (Clarke, 1997).

An earlier set of recommendations about reforming mathematics teaching practice also came from the National Council of Teachers of Mathematics. An Agenda for Action (NCTM, 1980) directly states that problem solving should be the focus of school mathematics. This call for change indirectly recommended a need for 
change in the curricular resources available for teachers. As a response to the release of An Agenda for Action, numerous problem solving resources have been published including: Problem Solving in Mathematics(Schaff \& Brannan, 1983), The Problem Solver. Activities for Leaming Problem-Solving Strategies (Scanlin, Hoogeboom, \& Goodnow, 1998), Daily Problems and Weekly Puzzlers (Callahan, 1996), and Problem of the Week: A Fresh Approach to Problem Solving (Griffin \& Demoss, 1998). These problem solving resources reflect both "teacher presenting" and "student developing" approaches to problem solving. The teacher presenting strategy is characterized by the teacher modeling problem solving for the students to imitate and/or the teacher instructing students in a problem solving strategy followed by students practicing that strategy. The student developing strategy is characterized by teachers providing students with problems and allowing them to engage in problem solving, refining and defending ideas, and reflecting on their work. While there may be advantages and disadvantages to both methods of teaching and learning, consideration should be given to what students are learning about problem solving and mathematics given each method and how this leaming aligns with the vision of the NCTM Standards (1989, 1991, 1995, and 2000).

Teachers need to step back and consider what problem solving means to them. They need to consider if the opportunities they offer their students represent true problem solving situations. They need to take a position about the role probiem solving plays in the curriculum if they are to effectively review and/or use the numerous problem solving and curricular resources available. 
The following review begins with examples of what has happened as similar reform policies were implemented. It then offers a variety of definitions of problem solving, positions on role of problem solving in the mathematics curriculum, and suggestions for problem solving instructional strategies. Finally, it considers how teacher knowledge and beliefs shape problem solving instruction as well as how teachers can be best supported in developing their instructional practice to reflect the intentions of Oregon's educational reform.

\section{Policy in Practice}

Policymakers have worked to change schools and school practices for years. Oregon's reform efforts are informed by previous attempts at policy implementation. An early policy that emphasized teaching mathematics for understanding was the Mathematics Framework for Califomia Public Schools (California State Department of Education, 1985), a precursor to the NCTM Curriculum and Evaluation Standards (1989) and the Principles and Standards for School Mathematics (2000). Implementation of the Framework was studied during the 1988-1989 school year (Cohen, 1990; Peterson, 1990; Sykes, 1990; Wilson, 1990; Darling-Hammond, 1990; Ball, 1990; Jennings-Wiemers, 1990). These researchers describe the shifts in thinking that had taken place to implement the curriculum guidelines. They found that the policy prompted most teachers to change their practice, but practice, in many cases redefined the policy (Cohen \& Ball, 1990). Teachers felt they were aligning their 
practice to the new expectations but in many cases the changes were superficial, thus altering the instructional practices intended by the policy.

Some teachers were using innovative instructional materials in traditional ways by teaching students how to use the manipulatives to solve the problems and/or teachers telling students what connections they should see between the manipulatives and the algorithm (Cohen, 1990; Ball, 1990). Other teachers were using curricular materials that caused some rethinking of beliefs and knowledge about the role of problem solving and modeling (Jennings-Wiemers, 1990). Still, others were facing conflicting paradigms between district and state policies regarding (1) pressure for an instructional approach concerned with pacing, content coverage, time on task, testing, and reteaching traditional testing, and (2) perceived pressure from parents and state testing practices to maintain traditional approaches to teaching (Peterson, 1990; Wilson, 1990). Generally, the teachers in this study did not know much about what the Framework advocated and were mixing the old with the new, as they were integrating the policy into existing practice, knowledge, and beliefs.

Cohen and Ball (1990) state that "so far teachers have been asked to make great changes, but they have not been offered many of the resources that might support such change" (p. 336). This policy analysis provides evidence of how the level of understanding of the policy can influence a teacher's actions and therefore implementation of a policy. It also shows how educational context impacts implementation, especially for teachers working within structures where competing policies were in place. The small changes evident in these case studies could represent 
major changes in those teachers' thinking in the long term. "Most of the teachers are experimenting some and questioning more; ... they are looking at students' thinking and learning with a new lens, though they may not now understand what they see" (Darling-Hammond, 1990, pp. 345-346).

Haimes (1996) conducted a study of a teacher's implementation of a reformed curriculum and like the California studies, found differences between the intended and the implemented curriculum. The findings indicate that the teacher's pedagogical practices were not representative of those recommended for the new curriculum; "Her previous experiences, namely the practices she had adopted in teaching the earlier curriculum, her background as a student, and her pedagogical training, emerged as factors that influenced her current pedagogical practices" (p. 600). This teacher was also mixing the old with the new, demonstrating that the impact of the curriculum on this teacher's actions was found to be minimal. Haimes suggests that changes can be expected to be gradual, the teacher must be convinced the change is beneficial, and the support materials and inservice must be meaningful and accessible to the teacher.

Clarke (1997) conducted a study of two teachers implementing innovative curriculum materials. He identified a list of factors that influenced the process of changing roles for these teachers. These factors include:

- The reform movement in general

- The principal and the school community

- The grade-level team of teachers

- The spirit of collegiality, collaboration, and experimentation 
- Innovative curriculum materials The inservice program

- External support personnel

- The researcher as an audience and critical friend

- Day-to-day conditions under which teachers work

- Internal support personnel

- Outcomes valued by the teacher

- Teacher knowledge (p. 296)

While there are similarities between this list and the findings from the previously cited studies, Clarke also identifies the factors with the greatest influence on the change process. He discovered that the availability of innovative curriculum materials and the daily opportunity to reflect on classroom events were the factors that were most beneficial for these teachers who were working to change their practice. Policymakers would be wise to consider the type of support that teachers need in developing instructional practices that align with the intent of the educational reform.

Change is a process, and innovations are not institutionalized simply because someone says this is now the way things are done. The external policies confronted by mathematics teachers may or may not have an impact on a teacher's practice. There are also internal influences; teachers have their existing knowledge, strong beliefs, and their classroom experience. They teach as they do because they feel it is what is best or it was what they experienced. Teachers value their own educational experiences, both as a teacher and as a leamer. They do not easily give up what they believe is best. They themselves need to experience something better both as a teacher 
and as a learner. As teachers face situations wherein their current practice is problematic, they are likely to reconsider what they thought they knew (Cobb, Wood, \& Yackel, 1990).

Teachers need to experience the cognitive conflict associated with new learning if they are to reconceptualize their practice. Administration of the statewide mathematics performance assessment in problem solving caused such conflict, as when first administered, only a few teachers had responded to the policy. The assessment did not align with teaching practices of most teachers at the time; teachers realized that their practice was problematic in preparing students to be "problem solvers." This move on the part of the state did not attend to the fact that it takes time for teachers to understand the need for change and then become capable users of the innovation. Teachers were in no way "experts" in the use of the innovation before they were "assessed." The performance assessment has essentially acted as a lever to change practice; teachers are now including problem solving in their mathematics curriculum. However, as we consider Classrooms A and B and these teachers' attempts to develop problem solving expertise in their students, it is clear that these teachers' decisions about instructional practice influence the educational outcomes.

\section{Defining Problem Solving}

There are a variety of definitions of a problem that should be considered before defining problem solving. A few include: 
A problem is a situation for which the individual who confronts it has no algorithm that will guarantee a solution. That person's relevant knowledge must be put together in a new way to solve the problem. (Kantowski, 1980, p. 195)

A real problem involves a question that cannot be immediately answered; it requires some effort in making appropriate use of previously learned concepts and skills for its solution. (Bruni, 1982, p. 10)

[A problem] is a situation in which an individual or group accepts the challenge of performing a task for which there is not an immediately obvious way to determine a solution. Frequently, the problem can be approached in many ways. Occasionally, the resulting investigations are nonproductive. Sometimes they are so productive that they lead to many different solutions or suggest more problems than they solve. (Brannan \& Schaaf, 1983, p. 43)

Dewey (1933/1970) describes thinking as an adjustive mechanism brought into play by felt difficulties or problems in the environment. He claims that a normal child naturally responds to a difficulty or problem by functioning to overcome it. Therefore, a normal child would naturally attempt to independently solve a problem if it is perceived as a problem.

If problem solving is a natural response for students when they are posed with a problem or difficulty, then it seems unnecessary to provide an algorithm, as students are eager to develop a solution on their own. These definitions for a problem raise questions about the teaching strategies communicated in many problem solving resources in which teachers simply present a problem solving approach to students and students apply that approach to all such problems. Students, instead of facing a problem without an immediately applicable rule, are supplied with an algorithm making the problem little more than an exercise. 
Dewey (1933/1970) describes the central task in teaching as preparing children to think, which in many ways can be likened to teaching them to problem solve. Dewey describes the "complete act of thought" in five steps or states. These steps fall between "pre-reflective" doubt and "post-reflective" satisfaction. Pre-reflective doubt is the state wherein the student is perplexed, troubled, or confused. Out of this feeling grows the question that reflection has to answer. Post-reflective satisfaction is the state wherein the student has cleared-up, unified, resolved situation at the end; the doubt has been dispelled resulting in satisfaction, and enjoyment. Following are the five steps in the complete act of thought.

1. Suggestion is when the mind leaps forward to a possible solution, including ideas of what to do and thoughts about possible actions.

2. Intellectualization of the difficulty or perplexity that has been felt (directly experienced) into a problem to be solved. It is the emotional quality of the whole situation.

3. Use of one suggestion after another as a leading idea, or hypothesis, to initiate and guide observation and other operations in collection of factual material. The working hypothesis is used to make more observations, collect more facts, reasons that if... then...

4. Mental Elaboration of the idea or supposition (reasoning) that helps extend knowledge while at the same time relies on what is already known. 
5. Testing the Hypothesis by overt or imaginative action including experimental corroboration or verification. The learning occurs even if there is failure to confirm the hypothesis.

Dewey (1933/1970) argues that the sequence of the five phases is not fixed. Learning takes place even when the end result is incorrect, placing value on the process, value in struggling with a problem.

The person who really thinks learns quite as much from his failures as from his successes. For a failure indicates to the person whose thinking has been involved in it, and who has not come to it by mere blind chance, what further observations should be made. It suggests to him what modifications should be introduced in the hypothesis upon which he has been operating. It either brings to light a new problem or helps to define and clarify the problem on which he has been engaged. Nothing shows the trained thinker better than the uses he makes of his errors and mistakes. (p. 79)

Pólya (1980), like Dewey, sees problem solving as a process. He suggests that problem solving is the process of finding the unknown means to a distinctly conceived end.

If the end by its simple presence does not instantaneously suggest the means, if, therefore, we have to search for the means, reflecting consciously how to attain the end, we have to solve a problem. To solve a problem is to find a way where no way is known off-hand, to find a way out of a difficulty, to find a way around an obstacle, to attain a desired end, that is not immediately attainable, by appropriate means. (Pólya. 1980, p. 1)

Likewise, House, Wallace, and Johnson (1983) describe problem solving as a process, not a step-by-step procedure or an answer to be found. They see it as a journey, not a destination. From the work of Dewey (1933/1970), Pólya (1980) and House et al. (1983), we can define problem solving as the process of engaging in a problem (a 
situation lacking an immediately obvious strategy or solution, therefore, requiring effort to solve) and making use of mathematical knowledge, strategies/techniques, metacognitive skills, and beliefs in a new way to solve the problem. Even though there may be struggles along the way, learning takes place through engaging in the process.

As students engage in problem solving there are differing levels of effort needed based on what the student brings to the problem. Goldin (1982) describes several possible situations that may be evident in the problem solving process. These situations include:

1. The subject "knows the answer" or is already at the goal when the task is posed.

2. The subject does not "know the answer," but "possesses a correct procedure" for arriving at the answer and furthermore "knows" that he or she possesses the procedure and is able to describe the procedure verbally before carrying it out.

3. Same as two, but the subject is unable to describe the procedure in advance of carrying it out.

4. Same as three, but the subject "does not know for sure" that he or she possesses the procedure until after the problem has been attempted.

5. The subject does not arrive at the answer through correct processes at the answer or goal until additional information or assistance is provided. (p. 95)

Goldin (1982) considers cases two through five all within the domain of problem solving for research purposes. He essentially defines problem solving as a situation in which the subject does not know the answer, but is somewhere along a continuum of confidence that he/she knows how to complete the problem, as well as an instance in which the subject does not arrive at the answer without additional assistance, similar 
to Vygotsky (1978). Depending on what is meant by "assistance," Pólya (1980) and House et al. (1983) may not agree that both cases two through four and case five constitute problem solving. They may determine that a subject in case five is only applying the rule or algorithm supplied through the assistance. However, these researchers do agree that problem solving occurs only when the subject does not immediately know the answer.

Schoenfeld (1985) notes important areas that may be lacking in some definitions of problem solving. He describes four categories of knowledge and behavior that "explain" human problem solving behavior. The categories are:

- resources - the foundation of basic mathematical knowledge

- heuristics - general problem solving techniques

- control - how one selects and deploys the resources at one's disposal, choosing appropriate solution methods

- belief systems - one does not perceive that his/her mathematical knowledge is useful, and consequently does not call upon it... establishing a psychological context within which he/she does mathematics. (pp. 14-16).

Schoenfeld believes that a definition lacking consideration of these areas does not capture the complex nature of problem solving. He feels that attempts to operationalize problem solving result in definitions that are too narrow; creating definitions that may not consider what knowledge, experiences, and strategies the student brings to the problem. He also takes issue with the positivist view that considers teaching problem solving to be equivalent to providing a set of prescriptions for students' productive behavior, similar to the teacher in Classroom A and other teachers preparing students to be problem performers. He states that: 
... whether one wishes to explain problem solving performance, or to teach it, the issues are more complex. One must deal with (1) whatever mathematical information problem solvers understand or misunderstand, and might bring to bear on a problem; (2) techniques they have (or lack) for making progress when things look bleak; (3) the way they use, or fail to use, the information at their disposal; and (4) their mathematical world view which determine the ways that the knowledge of the first three categories is used. (1985, p. 14)

Table 2 summarizes the characteristics of problem solving knowledge and behavior that Schoenfeld deems important to problem solving performance. A portion of these characteristics are closely aligned with the previously of fered definitions for problem solving and Oregon's expectations for problem solving as communicated in the Problem Solving Scoring Guide (presented in Chapter 1, Table 1). Included in the scoring guide are the elements of resources and heuristics characteristics. Lacking is explicit mention of the control and belief systems characteristics described by Schoenfeld. 
Table 2

\section{Knowledge and Behavior Necessary for an Adequate Characterization of Mathematical Problem Solving Performance}

Resources: Mathematical knowledge possessed by the individual that can be brought to bear on the
problem at hand
Intuitions and informal knowledge regarding the domain
Facts
Algorithmic procedures
'Routine" nonalgorithmic procedures
Understandings (propositional knowledge) about the agreed-upon rules for working in the
domain
Heuristics: Strategies and techniques for malking progress on unfamiliar or nonstandard problems; rules
of thumb for effective problem solving, including
Drawing figures, introducing suitable notation
Exploiting related problems
Reformulating problems, working backwards
Testing and verification procedures
Control: Global decisions regarding the selection and implementation of resources and strategies
Planning
Monitoring and assessment
Decision-making
Conscious metacognitive acts
Belief Systems: One's "mathematical world view." the set of (not necessarily conscious) determinants
of an individual's behavior
About self
About the environment
About the topic
About mathematics From Schoenfeld (1985, p. 15).

Table 3 presents the connections between Schoenfeld's knowledge and behaviors and Oregon's Problem Solving Scoring Guide. While not mentioned explicitly in the scoring guide, the students receiving the highest scores when assessed with the state-scoring guide are showing evidence of the characteristic Schoenfeld describes as control. For example, by enhancing his/her work through offering connections or extensions (a level six in Conceptual Understanding), a student shows evidence of control by making sense of the work through conscious metacognitive 
acts ${ }^{1}$. When reviewing his/her work through using a different perspective (a level six in Verification), a student shows evidence of control though deciding to monitor and assess the work. Finally, a student shows evidence of planning when he/she communicates in such a way that the reader moves easily and makes connections from one thought to another (a level six in Communication).

Table 3

Connection between Schoenfeld's Problem Solving Performance and Oregon's Mathematics Problem Solving Scoring Guide

\begin{tabular}{|c|c|}
\hline Schoenfeld's Problem Solving Performance & Oregon's Problem Solving Scoring Guide \\
\hline \multirow{2}{*}{$\begin{array}{l}\text { Resources: Mathematical knowledge possessed } \\
\text { by the individual that can be brought to bear on } \\
\text { the problem at hand } \\
\text { - Intuitions and informal knowledge regarding } \\
\text { the domain } \\
\text { - Facts } \\
\text { - Algorithmic procedures } \\
\text { - Routine" nonalgorithmic procedures } \\
\text { - Understandings (propositional knowledge) } \\
\text { about the agreed-upon nules for working in } \\
\text { the domain }\end{array}$} & $\begin{array}{l}\text { Conceptual Understanding: Interpreting the } \\
\text { concepts of the task and translating them into } \\
\text { mathematics. "What?" } \\
\text { 4. The translation of the task into adequate } \\
\text { mathematical concepts using relevant } \\
\text { information is completed. } \\
\text { 5. The translation of the task into mathematical } \\
\text { concepts is thoroughly developed. }\end{array}$ \\
\hline & $\begin{array}{l}\text { Communication: Using pictures, symbols, and/or } \\
\text { vocabulary to convey the path to the identified } \\
\text { solution. "The connecting path!" } \\
\text { 4. The path connecting concepts, strategies. } \\
\text { and/or verification to the identified solution } \\
\text { is complete. } \\
\text { 5. The path connecting concepts, strategies. } \\
\text { and/or verification to the identified solution } \\
\text { is thoroughly developed. }\end{array}$ \\
\hline
\end{tabular}

\footnotetext{
'Metacognition is thinking about one's own thinking. A student when performing at a level six is considering his/her work from multiple perspectives and looking back at his/her thinking to determine if it makes sense.
} 
Table 3

(continued)

\section{Connection between Schoenfeld's Problem Solving Performance and Oregon's Mathematics Problem Solving Scoring Guide}

\begin{tabular}{|c|c|}
\hline Schoenfeld's Problem Solving Performance & Oregon's Problem Solving Scoring Guide \\
\hline $\begin{array}{l}\text { Heuristics: Strategies and techniques for making } \\
\text { progress on unfamiliar or nonstandard problems; } \\
\text { nules of thumb for effective problem solving. } \\
\text { including } \\
\text { - Drawing figures, introducing suitable } \\
\text { notation } \\
\text { - Exploiting related problems } \\
\text { - Reformulating problems, wotking } \\
\text { backwards } \\
\text { - Testing and verification procedures }\end{array}$ & $\begin{array}{l}\text { Processes and Strategies: Choosing strategies that } \\
\text { can work, and then carrying out the strategies } \\
\text { chosen. "How?" } \\
\text { 4. Pictures, models, diagrams, and/or symbols } \\
\text { are complete. } \\
\text { 5. Pictures, models, diagrams, and/or symbols } \\
\text { used to solve the task are thoroughly } \\
\text { developed. } \\
\text { 6. Elegant, complex and/or enhanced } \\
\text { mathematical processes/strategies are } \\
\text { completed. } \\
\text { Verification: In addition to solving the task. } \\
\text { evidence of a second look at the } \\
\text { concepts/strategies/ calculations to defend a } \\
\text { solution. "Defend!" } \\
\text { 4. The review is completed (concepts/ } \\
\text { strategies/calculations) and supports a } \\
\text { solution. } \\
\text { The review is a thoroughly developed look at } \\
\text { the concepts/strategies/ calculations in } \\
\text { relation to the task. }\end{array}$ \\
\hline $\begin{array}{l}\text { Control: Global decisions regarding the selection } \\
\text { and implementation of resources and strategies } \\
\text { - Planning } \\
\text { - Monitoring and assessment } \\
\text { - Decision-maling } \\
\text { - Conscious metacognitive acts }\end{array}$ & $\begin{array}{l}\text { Conceptual Understanding (continued) } \\
6 \text {. The translation of the task into enhanced } \\
\text { through connections and/or extensions to } \\
\text { other mathematical ideas. } \\
\text { Verification (continued) } \\
6 \text {. The review is related to the task and enhanced } \\
\text { possibly by using a different perspective as } \\
\text { the defense. } \\
\text { Communication (continued) } \\
6 \text {. The connecting path is cnhanced (e.g., } \\
\text { graphics, examples) allowing the reader to } \\
\text { move easily and make connections from one } \\
\text { thought to another. }\end{array}$ \\
\hline $\begin{array}{l}\text { Belief Systems: One's 'mathematical world } \\
\text { view," the set of (not necessarily conscious) } \\
\text { determinants of an individual's behavior } \\
\text { - About self } \\
\text { - About the environment } \\
\text { - About the topic } \\
\text { - About mathematics }\end{array}$ & \\
\hline
\end{tabular}

From Schoenfeld (1985, p. 15) and ODE (2001). 
The state problem solving scoring guide influences Oregon's teachers in their decision-making about what to emphasize in problem solving instruction. What is not clear is, what conditions help a teacher to teach beyond the scoring guide and develop problem solvers who attend to control and belief systems as well as resources and heuristics. What do Classroom B teachers know and believe about the importance of problem solving and role of problem solving in the curriculum?

Problem Solving as a Focus in the Curriculum

Before answering the question "why should problem solving be a focus in the curriculum?" it becomes necessary to consider the question "what are the goals of math education?" The latter question has been asked throughout the 20th century (NCTM, 1970) and continues to be asked today. The common responses have been to view math as a mental discipline, an exercise to improve the learner's ability to think, to reason, to solve problems; to view math as utility, wherein a person studies that which was directly functional to his/her future societal needs and to view math as beauty of mathematics are emphasized (Bidwell \& Clason, 1970; NCTM, 1970). Romberg (1992) describes how these philosophic shifts in the discipline of mathematics provide different justifications for teaching math and what math children should study. These differing beliefs - along with societal forces, learning theories, and committee reports/policies - impact the choices teachers make regarding the role of and emphasis on problem solving in the curriculum. 
To put the question of "why focus on problem solving" into context, it is helpful to take a brief look at the history of mathematics education in the United States and consider the role of problem solving and its relationship to the views of mathematics and learning held at the time.

\section{Historical Views of Problem Solving.} Mathematics, and Learning

Prior to the 20th century, mathematics was seen as a mental discipline but as schools changed to become more inclusive, questions arose regarding the achievability of mental discipline as a goal and the response was to teach procedures (NCTM, 1970). In the early part of the century, due to shifts in leaming theory, there was a renewed emphasis on developing understanding through appropriate content and pedagogy. But resistance to change, limited resources, and a lack of leadership kept the math as knowledge reform from taking hold (NCTM, 1970). Thorndike's stimulus-response theory gained popularity between 1917 and 1935. This theory, sometimes called "connection" theory, emphasizes establishing many "bonds" through practice. Arithmetic became fragmented into many small facts and skills to be taught and tested separately; problem solving was not an emphasis in the curriculum. Developing functional citizens was the focus of the math content; math was viewed as utility (NCTM, 1970).

In 1940, after analyzing the problem solving process, the Progressive Education Association issued a report urging that math instruction stress problem solving methods and skills at all levels of instruction. This was the first group that did 
not rely upon mental discipline to argue that math provides training in problem solving (NCTM, 1970). However, the focus for instruction throughout the 1940 s was on functional competence.

The prevalent learning theories during the 1950s come from Piaget, Gagné, and Bruner (NCTM, 1970). Each theory promoted math as knowledge, but differed in beliefs about attainment of knowledge. Piaget's theories on the development of math concepts, specifically conservation and reversibility, significantly influenced approaches to number, geometry, and logical reasoning. Gagné organized math topics into hierarchies of principles placing emphasis on sequential learning and describing how problem solving requires the learner to recall principles and combine them to achieve a solution. Bruner while supportive of discovery and hands-on teaching, differed from Piaget beliefs about readiness based on age spans. Bruner claimed that the foundation of any subject may be taught to anybody at any age in some form. Shulman (1970) described the instructional approach advocated by Gagné as expository, "characterized by a smoothly guided tour up a carefully constructed hierarchy of learning tasks" (p. 53). He described Bruner's approach as discovery in which "instruction is a roller-coaster ride of successive disequilibria and equilibria terminating in the attainment or discovery of a desired cognitive state" (p. 53). The diagram below (Figure 6) represented the learning sequences for both Gagné and Bruner, in which Gagné worked up from simple prerequisites and Bruner worked down from an initial problem solving situation. 


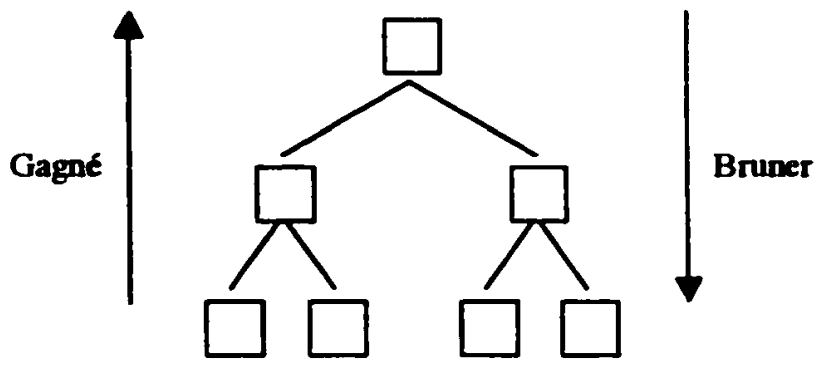

Figure 6. Comparing the learning sequence. From Shulman, 1970, p. 53.

At this same time, in response to the Soviet Union's launch of the space satellite Sputnik, came a major renewal of mathematics curricula. Scientists and mathematicians became heavily involved in the creation of new educational materials, often referred to as "new math" (Schoenfeld, 1992). The use of the materials flourished brielly in the 1960 s but were later perceived as a failure, as students failed to master the abstract ideas they grappled with in "new math" and the basic skills that were learned successfully by past generations of students. The materials were never fully implemented. In what Schoenfeld (1992) describes as a dramatic pendulum backswing, the "new math" was replaced by the "back-to-basics" movement - a decade of curricula focused on rote mechanical skills that represented a shift in the view of math back to math as utility.

\section{Recent Views of Mathematics and Learning}

The most recent major renewal of mathematics curricula took place in the 1980s. This move toward a focus on problem solving was in response to the weaknesses of the "back-to-basics" movement of the 1970s. This renewal shifted the 
focus of mathematics instruction back to math as knowledge. The first call to move toward problem solving as a basic skill came in 1977 from the National Council of Supervisors of Mathematics [NCSM]. It was followed by the publication of An Agenda for Action from NCTM in 1980 . These curricular recommendations made by NCSM and NCTM not only call for problem solving as the focus of school mathematics, but also for a broader definition of basic skills and the use of technology. These curricular recommendations - along with recommendations for instruction, assessment, and outreach - are included in Table 4. NCTM's Curriculum and Evaluation Standards (1989) maintain and extend the NCSM and early NCTM recommendations for problem solving.

\section{Table 4}

An Agenda for Action: Recommendations for School Mathematics of the 1980s

1. Problem solving must be the focus of school mathematics in the 1980 s.

2. The concept of basic skills in mathematics must encompass more than computational facility.

3. Mathematics programs must take full advantage of the power of calculators and computers at all grade levels.

4. Stringent standards of both effectiveness and efficiency must be applied to the teaching of mathematics.

5. The success of mathematics programs and student learning must be evaluated by a wider range of measures than conventional testing.

6. More mathematics study must be required for all students and a flexible curriculum with a greater range of options should be designed to accommodate the diverse needs of the student population.

7. Mathematics teachers must demand of themselves and their colleagues a high level of professionalism.

8. Public support for mathematics instruction must be raised to a level commensurate with the importance of matbematical understanding to individuals and society.

From NCTM (1980, p. 1). 
Why then, should problem solving be a focus in the school mathematics curriculum? Schoenfeld (1992) describes how what we now know about mathematical thinking, leaming, and problem solving has blocked an anticipated pendulum backswing. He argues that there are currently broader descriptions of what is mathematics and what represents doing mathematics than there were throughout most of the $20^{\text {th }}$ century. The goals of the Principles and Standards for School Mathematics (NCTM, 2000) focus on helping students know, understand, and appreciate the beauty of mathematics, calling for a view of math as knowledge. To help students develop math as knowledge, Schoenfeld (1992) argues that their classroom instruction must focus on problem solving, as problem solving serves as a tool to develop mathematical understanding. I would also suggest that viewing math as knowledge and teaching through problem solving, accomplishes having students learn the math they will need in the future (math as utility) and develops students' abilities to think (math as mental discipline).

Like Schoenfeld, Branca (1980) also feels that problem solving should be the focus of the curriculum. He sees "learning how to solve problems is the primary reason for studying mathematics" (p. 3) and claims that when problem solving is considered a goal, it is independent of specific problems, of procedures or methods, and of mathematical content. Branca distinguishes between viewing problem solving as a process and viewing it as a basic skill. When interpreting problem solving as a process, one considers methods, procedures, strategies, and heuristics involved in problem solving. When interpreting problem solving as a basic skill, one is forced to 
consider the specifics of problem content, problem types, and solution methods. The focus shifts from widely applicable processes to a set of basic skills. While a view of problem solving as a basic skill helps teachers organize the specifics of daily teaching, it does not help teachers examine what students should do with the basic skills and concepts, how they relate to each other, and what role they play in the problem solving.

Treating problem solving as a skill runs the risk of merely asking students to “do" mathematics without necessarily knowing what they are doing and why. Treating problem solving as a process is more likely to push students into providing evidence of "knowing and understanding" mathematics, seeing math as knowledge. These arguments for why problem solving should be the focus of the curriculum are based on beliefs about what mathematics is and also about what having problem solving as a focus does for both the teacher and students. It may well be that policymakers in Oregon chose problem solving as a central component to the mathematics reform in the state for similar reasons.

This section has outlined the numerous influences shaping the focus of the mathematics curriculum. Schoenfeld (1992) argues that all the factors currently point toward problem solving as a focus in the curriculum. According to Schoenfeld, problem solving as a focus is now possible (1) due to the reconceptualizing of both mathematics curricula and problem solving, and (2) based on what we now know about mathematical thinking, learning, and problem solving. 
Views on the Role of Problem Solving in the Curriculum

The purpose of problem solving activity in the classroom may vary from teacher to teacher based on his/her knowledge and beliefs about its role in the curriculum. Some teachers ask their students to engage in problem solving to leam new content and gain valuable thinking skills (Classroom B, Figure 2) while others do so simply to prepare students for the state assessment (Classroom A, Figure 1). This section outlines the various views about the role of problem solving in the mathematics curriculum and links these views to the knowledge and beliefs that may be influencing the views teachers hold about the role of problem solving in the curriculum.

Stanic and Kilpatrick (1989) identify three distinct roles: problem solving as context, problem solving as skill, and problem solving as art.

\section{Problem Solving as Context}

This view of problem solving is based on the idea that problems and the solving of problems are a means to achieve other valuable ends. In other words, teachers who believe the problem solving role is contextual make the choice to teach problem solving based on what problem solving can accomplish for them and/or their students. The purposes for problem solving identified by Stanic and Kilpatrick (1989) are justification, motivation, recreation, vehicle, and practice.

- problem solving as justification - defense for teaching mathematics,

- problem solving as motivation - aim of gaining student interest, 
- problem solving as recreation - allow students some fun with mathematics,

- problem solving as vehicle - means for learning new concepts or skills, and

- problem solving as practice - activity to reinforce skills and concepts. (p. 13)

Viewing problem solving as context could impact the perception of the relative importance of problem solving in the mathematics curriculum. For teachers holding this view, problem solving in and of itself is not the reason the teacher chooses to have students solve problems. Instead, the teacher uses problem solving to achieve another goal such as hooking students into learning new concepts. They ask students to engage in problem solving as a means of doing mathematics.

\section{Problem Solving as Skill}

A second view of problem solving is problem solving as skill. This notion places problem solving alongside the numerous other skills to be taught in the school curriculum. Stanic and Kilpatrick (1989) state that teachers holding this belief about problem solving see it as a valuable curriculum end deserving special attention, rather than simply a means to achieve other ends. To some extent, Oregon's reform act, when listing problem solving as a mathematics strand alongside calculations and estimations, measurement, algebraic relationships, etc., communicates to teachers that problem solving is yet another skill to teach, an artifact of the way that the Content Standards (ODE, 2001) are listed. 
Stanic and Kilpatrick (1989) also identify a negative consequence of putting problem solving in a hierarchy of skills to be acquired by students and that regards the issue of access. Within the general skill of problem solving, a teacher may make hierarchical distinctions between solving routine and nonroutine problems. Nonroutine problem solving is characterized as a higher level skill to be acquired after skill at solving routine problems, which for many teachers is to be acquired only after students learn basic mathematical concepts and skills. This view about problem solving teaching and learning postpones attention to nonroutine problem solving and results in exposing only certain students, those accomplishing the prerequisites, to such problems. Nonroutine problem solving becomes an activity for the especially capable students rather than for all students. An equity issue arises when not all students are exposed to nonroutine problem solving opportunities. The Principles and Standards (NCTM, 2000) argue that all students should be exposed to the same rigorous curriculum. They also suggest that with these higher expectations there must be solid support for learning for all students.

\section{Problem Solving as Art}

Unlike viewing problem solving as a context or skill, viewing problem solving as an "art" represents a deeper, more comprehensive view of problem solving in the school mathematics curriculum. This view originated from the work of George Pólya.

Polya's experience as a mathematician led him to conclude that the finished face of mathematics presented deductively in the mathematical journals and in textbooks does not do justice to the subject. Finished mathematics requires demonstrative reasoning, 
whereas mathematics in the making requires plausible reasoning. If students are to use plausible reasoning, they need to be taught how. (Stanic \& Kilpatrick, 1989, p. 16)

This view holds that real problem solving is the heart of mathematics, if not mathematics itself. Viewing problem solving as art suggests that problem solving, occurring through active engagement, discovery, social construction, and sensemaking, is central to learning (Stanic \& Kilpatrick, 1989).

Pólya (1945) argues that it is with independent problem solving that students learn to problem solve, so if general rules for solving problems were formulated and teachers shared them with students they would not be very useful. What is the role of the teacher who views problem solving as art? Pólya sees the role of the teacher in the problem solving process as key. He maintains that teachers need to pose the right kinds of problems and provide the appropriate amount of guidance. They need to place students in a position of truly solving problems, not following a recipe. Stanic and Kilpatrick (1989) found that there are those today who on the surface affiliate themselves with the work of Pólya, but who reduce the rule-of-thumb heuristics to procedural skills, almost taking an algorithmic view of heuristics (i.e., specific heuristics fit in specific situations).

The NCTM Principles and Standards (2000) state that the major goal of problem solving instruction is to enable learners to develop and apply strategies to solve problems. Across the grade levels, the goal expands to helping learners develop an increasing repertoire of strategies, approaches, and familiar problems. The Standards presume that students develop this repertoire through continued exposure to 
solving problems. The document recommends that problem solving become an integral part of instruction. The view of problem solving most evident in the Principles and Standards (2000) aligns closely with the view of Problem Solving as Art wherein students build new knowledge through problem solving, solve problems that arise in math and other contexts, apply and adapt a variety of strategies, and monitor and reflect on their process. Like those who misalign themselves with the work of Polya, there are teachers who claim alignment with the Standards, but who treat problem solving as a set of procedural skills to memorize. This may be due in part to the problem solving resources which claim alignment to the Standards, but do not give students an opportunity to develop their own strategies, refine and defend their ideas, and/or reflect on their work.

\section{Considerations for Problem Solving Instruction}

NCTM Principles and Standards (2000) describe the goal of teaching problem solving as helping all students become flexible, autonomous, and effective problem solvers. Teachers would benefit from knowing about (1) the research on successful problem solvers as this provides clarity for instructional outcomes; (2) the various perspectives on the teaching of problem solving described by Kilpatrick as well as the suggestions from Brannan and Schaaf as these offer guidance for instruction; (3) the role of metacognition and Pólya's "Guide to Problem Solving Techniques" as each engages students in utilizing the habits and dispositions of expert problem solvers. 
These recommendations equip teachers with information regarding how to better plan for and facilitate problem solving in their classroom.

\section{Clarity for Instructional Outcomes}

... becoming a good mathematical problem solver - becoming a good thinker in any domain - may be as much a matter of acquiring the habits and dispositions of interpretation and sense-making as of acquiring any particular set of skills, strategies, or knowledge.

(Resnick, 1988, p. 58)

Resnick (1988) suggests that mathematical problem solving is more than the ability to "do" a problem. It is "understanding" how to deal with a problem, how to interpret and make sense of a situation in order to solve it. An important educational outcome of problem solving instruction should be to develop the habits and dispositions of good problem solvers in our students.

House et al. (1983) found that successful problem solvers could be identified by the processes or the attitudes of mind they display. They identified four characteristics - desire, enthusiasm, facility, and ability. More specifically, successful problem solvers possess the:

1. desire to approach and solve the problem, accept a challenge, take a risk, find an answer, understand a question and discover new knowledge or create a new solution.

2. enthusiasm to proceed with the solution, willingness to accept the challenge and persevere. It means possessing the flexibility to try several methods and to look for more questions once the original problem has been solved.

3. facility in using mathematics and heuristics.

4. ability, opportunity to become better problem solvers. (pp. 10-11) 
An ongoing question then is, how do teachers support students in developing these characteristics? Kantowski (1980) recognizes that teaching for problem solving differs from all other aspects of mathematics instruction. He claims that most teachers would agree that planning instruction to help students improve their ability to solve difficult, nonroutine problems is the most challenging task facing them in the mathematics classroom. He believes that problem solving is for everyone and expertise in problem solving does not just happen. A teacher must plan instruction and experiences with solving a variety of problems and that the students' ability to solve problems develops slowly over a long period of time.

\section{Guidance for Instruction}

The Principles and Standards (NCTM, 2000) point to the different decisions that teachers make as they plan for developing their students' problem solving expertise. They suggest that students should have experience with problems that may take hours, days, and even weeks to solve. Students also need experiences with a range of problems types (from formulated to open-ended) and a variety of learning formats (from individual to cooperative small groups and whole class). The Standards view problems as tools for instruction, where knowledge emerges from the problem situation and students are forced to make sense of the situation, the mathematics, and/or the strategies used by both their peers and themselves.

Kilpatrick (1985) summarizes the various approaches to teaching problem solving that have been advocated over the years. He sorts these into five categories: 
osmosis, memorization, imitation, cooperation, and reflection. Osmosis is a strategy in which students are immersed in an environment of problems. The teacher assumes that techniques will be "absorbed through a process seldom made explicit but presumably akin to osmosis" (p. 9). In other words, as a result of exposure to many problems, problem solving ability would permeate students' thinking, like diffusion of fluids through a cell membrane during biological osmosis. Memorization relies on the process of decomposing the solution of a problem into procedures, each of which is then taught. Essentially, an algorithm is developed that will handle a class of problems, and students are programmed to follow the algorithm to obtain a solution. Imitation is the method in which students model the work of a master problem solver. Cooperation utilizes group problem solving sessions, which serve as a vehicle for instruction. Tentative ideas are put out in the open where they can be refined and defended. Reflection is based on the belief that students learn by doing and then thinking about what they do. These approaches to teaching problem solving may exist in isolation or in combination in the classroom.

Brannan and Schaaf (1983) offer some suggestions to promote the learning of problem solving. They describe ways that students can improve their problem solving abilities: (1) identify and discuss the problem solving skills they use while solving mathematical problems; (2) solve problems independently; and (3) make sense out of the mathematics they are learning. They also describe how teachers can help students improve their problem solving abilities: (1) teach a variety of problem solving skills directly; use a problem solving approach to mathematics instruction frequently with a 
variety of mathematical activities; (2) recognize that they themselves are problem solvers who share their experiences (successful and unsuccessful) with students; and (3) create a classroom atmosphere in which openness and creativity can occur.

\section{Habits and Dispositions of Expert} Problem Solvers

Another process beneficial to students in becoming mathematical problem solvers is the process of metacognition. Metacognition is defined as a driving force in cognitive performance (Schoenfeld, 1982). It includes monitoring and assessment strategies, intuitions about progress or plausibility of a solution, and a means by which conflict is resolved (Schoenfeld, 1982; Silver, 1982). Silver and Schoenfeld would likely want to add to the lists offered by a Brannan and Schaaf aspects of problem solving such as, students should (1) describe their thinking throughout the problem solving process, and (2) develop strategies for dealing with "being stuck" on a problem; teachers should (1) encourage students to be aware of their thinking processes, and (2) provide students with opportunities to discuss their processes with others, as well as share their strategies for dealing with "being stuck."

Polya (1945) holds that the teacher should help a student naturally and unobtrusively with help from the Guide to Problem Solving Techniques shown in Table 5. This guide could be used by the teacher to aid in questioning techniques or by the student to guide their work on solving the problem. The guide has four phases and helps students better conceptualize the problem, which helps them avoid mistakes in both reasoning and solution. 


\section{Table 5}

\section{A Guide to Problem Solving Techniques}

\section{UNDERSTANDING THE PROBLEM}

First. What is the unlonown? What are the data? What is the condition? Is it You have to possible to satisfy the condition? Is the condition sufficient to determine understand the problem. the unknown? Or is it insufficient? Or redundant? Or contradictory? Draw a figure. Introduce suitable notation.

Separate the various parts of the condition. Can you with them down?

\section{DEVISING A PLAN}

Second. Have you seen it before? Or have you seen the same problem in a Find the connection slightly different form?

between the data and the unknown.

You may be obliged to consider auxiliary problems if an immediate connection cannot be found.

You should oblain eventually a plan of the solution.

\section{If you cannot solve the proposed problem try to solve first some related problem. Could you imagine a more accessible related problem? A more general problem? A more special problem? An analogous problem? Could you solve a part of the problem? Keep only part of the condition, drop the other part; how far is the unknown then determined, how can it vary? Could you derive something useful from the data? Could you think of other data appropriate to determine the unknown? Could you change the unknown or the data, or both if necessary, so that the new unknown and the new data are nearer to each other? Did you use all the data? Did you use the whole condition? Have you taken into account all essential notions involved in the problem?}

\section{CARRYING OUT THE PLAN}

Third. Carrying out your plan of the solution. check each step. Can you see Carry out your plan. clearly that the step is correct? Can you prove that it is correct?

\section{LOOKING BACK}

Fourth Can you check the result? Can you check the argument? Examine the solution Can you derive the result differently? Can you see it at a glance? obtained. Can you use the result, or the method, for some other problem? 
As we reconsider the vignettes opening Chapter 1 , what evidence do we have that the teacher in Classroom B is developing problem solvers that are flexible, autonomous, and effective? We see students showing enthusiasm for approaching the problem, making sense of the situation, and considering multiple ways of seeing the pattern. We see students, both independently and collectively, investigating and analyzing a pattern to construct understanding. We see depth in the students' knowledge and understanding as they justify their thinking and form generalizations about any figure in the pattern. We see self-reflection wherein the students step back and synthesize what they have learned. We see expert problem solvers at work.

The Influence of Teachers' Knowledge and Beliefs on Problem Solving Instruction

What a teacher believes about teaching and learning mathematics and what a teacher knows about the content, methods, and materials available to teach mathematics influence the teacher's instructional decisions. (Lubinski \& Vacc, 1994, p. 476)

A teacher's knowledge and beliefs shape practice, specifically problem solving practice. Clarke (1997) outlines the role of a teacher in a reformed classroom and connects what the teacher does to specific beliefs about the teaching and learning of math. He discusses one feature of the reform, the use of nonroutine problems, as a starting point and focus of problem solving instruction. The belief that allows a teacher to use problems as a starting point or focus of instruction is the belief that students can and should have access to nonroutine problems without first being taught a procedure. Similarly, what a teacher knows about math content and pedagogy, and 
how this knowledge relates to the content and pedagogy advocated by the reform, impacts practice. These ideas are expanded further in the section that follows.

Knowledge of Mathematics Content

and Pedagogy

"One of the most widely offered explanations of why students do not learn mathematics is the inadequacy of their teachers' knowledge of mathematics" (Fennema \& Franke, 1992, p. 148). However, when the relationship of teacher knowledge of mathematics and student learning was reported in the National Longitudinal Study of Mathematical Abilities (School Mathematics Study Group, 1972), there was little correlation between the number of college mathematics courses taken by teachers to student learning. What is not measured in this type of study is the complexity of teachers' knowledge. Grossman et al. (1989) describe the numerous types of knowledge that impact instruction - these include knowledge about subject matter, learners, learning, curriculum, content, pedagogy, and subject-specific pedagogy. These researchers argue that neither standardized tests nor number of college courses accurately reflect the knowledge necessary for teachers to teach for conceptual understanding.

Shulman (1986a) also argues that measures of teacher knowledge should be conceived of differently than examining test scores or counting credit hours. Instead, the measures should reflect teachers' understanding of both content and process, as teachers need both. Shulman describes three major types of teacher knowledge: (1) subject matter content knowledge, (2) pedagogical content knowledge, and (3) 
curricular knowledge. Shulman defines subject matter content knowledge as the amount and organization of knowledge in the mind of the teacher. Grossman et al. (1989) refer to it as the "stuff" of a discipline, the factual information, organizing principles, central concepts. Pedagogical content knowledge is the knowledge about the ways of representing and formulating the subject that make it comprehensible to others. It includes an understanding of what makes the learning of specific topics easy or difficult, and the conceptions and preconceptions that students of different ages and backgrounds bring to the learning experience. Curricular knowledge is knowledge about the range of programs designed for the teaching of particular topics, the variety of instructional materials available in relation to those programs, and the set of characteristics serving as a critical lens for a teacher in deciding about the use of particular curriculum or program materials.

Informed by the work of Schwab (1978), Grossman et al. (1989) take a closer look at subject matter knowledge. They describe two structures of subject matter knowledge, substantive and syntactic. Substantive structures are the organizing frameworks, the variety of ways in which the basic concepts and principles of the discipline are organized to incorporate its facts. Syntactic structures represent the set of ways in which truth or falsehood, validity or invalidity, are established - they help the teacher know how to conduct inquiry in the discipline or bring new knowledge into the field. Grossman et al. found that teachers' subject matter knowledge affected both the content and processes of instruction, influencing both what teachers teach and how they teach it. They state that this subject matter knowledge, or lack thereof, can 
affect how teachers critique textbooks, how they select material to teach, how they structure their courses, and how they conduct instruction. The distinction between these two forms of knowledge becomes especially important as one considers teaching in the context of Oregon's reform. While substantive structures are a component of the content standards - offering an organizing framework and a focus for instruction, it is the subject-specific scoring guides that represent the syntactic structures defining the "valued" process for instruction and pressing for deeper understanding of the subject through analysis, inquiry and problem solving.

Carpenter, Fennema, Peterson and Carey (1988) are concerned with developing teachers' knowledge of both content and subject-specific pedagogy through the Cognitively Guided Instruction (CGI) project. In this project they provide training for teachers in the variety of whole number arithmetic problem types and the strategies students use to solve them. The project helps classroom teachers develop a deeper knowledge of the subject and gives them the confidence and background needed to facilitate the classroom discourse in a problem solving environment; modeling a classroom structure of posing a problem to students, listening to student responses, and determining the next steps in instruction based on the students' responses. The CGI model empowers classroom teachers through helping them understand substantive and syntactic knowledge structures in mathematics. This allows them to place emphasis on conceptual explanations from their students and use these explanations to determine where to go next. 
Schoenfeld (1985) studies his own teaching in a university level problem solving course wherein he works to develop problem solving expertise in his students. The class time was spent solving problems and discussing problem solutions. The lectures were designed to explicitly model decision-making strategies for sample solutions, where Schoenfeld represents the expert problem solver. Schoenfeld took on the role of a coach in his classroom, guiding students through the process of problem solving. Both Schoenfeld and the teachers studied by Carpenter et al. (1988) provided a rich mathematical experience for their students. The structure of their classrooms enabled their students to experience understanding mathematics as opposed to just doing mathematics.

Thompson (1989) feels that the teacher needs to not only be "knowledgeable about and feel comfortable 'doing' mathematics, but the teacher must also understand the learner and the classroom activities and arrangements most conducive to problem solving" (p. 234). Greater knowledge of the content and pedagogy allows a teacher more nexibility in decision-making. Teachers, who have knowledge of various problem types and different strategies children naturally use to solve each of these types, have the ability to plan instruction on the basis of students' thinking.

Thompson (1989) focused on the principles of heuristic teaching in her teacher education course; she wanted to "enhance the teachers' confidence and competence in solving problems, in the use of heuristics, and in the use of pedagogical techniques for enhancing students' problem solving performance and mathematical thinking skills" (p. 236). The course structure had two parts. The first part had the teachers solving 
problems and discussing solutions. These problems were used as the vehicle for discussing instructional issues around the teaching and learning of problem solving with a focus on the role of the teacher. Thompson conducted follow-up observations with 14 teachers during the following school year. She found that the teachers had not made cognitive changes but did vary in their implementation of problem solving due to obstacles they faced, such as limited mathematical resources. Grossman et al. (1989) might suggest that Thompson should also include in her course time for discussion about the syntactic structures of the discipline, as this better prepares teachers to acquire more content knowledge and to know more about the nature of knowledge, "which in turn may affect their conceptions of subject matter understanding and their educational aims"(p.31).

Beliefs about Mathematics Content. Pedagogy, and Learning

Teachers' beliefs about students' abilities greatly influence the decisions the teacher makes about the learning environment. If a teacher believes that children should solve a variety of problems at an early age (similar to Bruner), they will make different decisions than will teachers who believe that children should know basic facts before solving word problems (similar to Gagné). Teachers who believe that the textbook guides the mathematics content in their classroom make different decisions than do teachers who believe that children's interests and abilities guide the content.

Grossman et al. (1989) describe two types of beliefs that powerfully affect teaching. There are beliefs about content that impact the "how" and the "what." 
There are also beliefs defining a teacher's orientation toward subject matter.

Grossman et al. found that beliefs impact a teacher's conceptions about what is important to know and how one knows it in the subject matter. They also discovered that beliefs about the subject matter are as powerful and influential as beliefs about teaching and learning. Grossman et al. advocate for teachers having opportunities to identify and examine their beliefs about the content they teach and acknowledging that these beliefs influence both what they learn and what they teach.

Cooney (1985), when conducting a case study of a beginning math teacher, discovered conflicts between the teacher's idealism and the reality of classroom practice. He examined a teacher's beliefs about problem solving while finishing preservice training and during the first three months of teaching. The teacher reported that his students were not always responsive to changes he made in instruction from traditional approaches toward problem solving. This response from students caused the teacher to move away from his beliefs of how problem solving should be taught and toward more traditional approaches. The students had opinions about appropriate curriculum and instruction, which had a great influence on how the teacher approached the teaching of problem solving.

Raymond (1997) found that a teacher's beliefs and practice were not wholly consistent. The teacher in his study held beliefs about mathematics content more deeply than her beliefs about mathematics pedagogy. This teacher's practice was more closely related to her beliefs about mathematics content than to her beliefs about mathematics pedagogy. Her beliefs about mathematics content were highly influenced 
by her own experiences as a student and her beliefs about mathematics pedagogy were primarily shaped by her own teaching practice. Her teacher preparation program had limited influence on her beliefs and practice as when she was faced with the constraints of actual classroom teaching she tended, instead, to implement more traditional classroom practices.

The studies offered by both Cooney (1985) and Raymond (1997) point toward the fragility of beginning teachers' beliefs about mathematics teaching and learning. Grossman et al. (1989) suggest that calling attention to teachers' beliefs and encouraging teachers to examine these beliefs can make a difference in how their beliefs impact their classroom practice. However, when the realities of the classroom hit for beginning teachers, their awareness of these beliefs may not be enough. There are many influences that may in fact be more powerful, including students' beliefs (Cooney, 1985), the teachers' prior learning experience (Raymond, 1997), the teachers' knowledge about content and pedagogy (Shulman, 1986a; Grossman et al., 1989), as well as the textbook/curriculum and extemal policies (Clarke, 1997).

\section{Relationship of Teachers' Knowledge and}

\section{Beliefs to Practice}

Teacher beliefs play a significant role in shaping behavior (Thompson, 1989). One could assume that a teacher who holds that problem solving is important would tend to use inquiry-oriented instruction ${ }^{2}$. Lampert (1990) provides an illustration of

\footnotetext{
2 Inquiry-oriented instruction is a problem-centered approach to teaching and learning of mathematics that focuses on exploration, making and lesting conjectures, and forming generalizations.
} 
inquiry-oriented instruction in a study of her own practice. Lampert, a mathematician and researcher, deliberately structures her instruction to reflect her beliefs about mathematics and mathematics teaching and learning. Lampert views her students as mathematicians with the ability to discover mathematics. She examines whether and how it might be possible to bring the practice of knowing mathematics in school closer to what it means to know mathematics within the discipline. Instead of providing her students with an algorithm, she gives them opportunities to problem solve and discover mathematics as mathematicians do.

In Lampert's study (1990), the roles and responsibilities of the teacher and the students were deliberately altered. As the teacher, she utilized non-conventional mathematics activities and initiated and supported classroom interactions where students formed mathematical arguments in response to other students' conjectures. She believes that

...from the standpoint of the person doing mathematics, making a conjecture is taking a risk; it requires the admission that one's assumptions are open to revision, that one's insights may have been limited, that one's conclusions may have been inappropriate. (p. 31)

This belief is similar to Pólya's (1954) description of how the doer of mathematics must assume an inductive attitude and be willing to question both observations and generalizations, playing them off one another. He believes that there are moral qualities required to do mathematics, such as intellectual courage, intellectual honesty, and wise restraint. Intellectual courage is a willingness to revise any one of our beliefs. Intellectual honesty is changing a belief when there is a good reason to 
change it. Wise restraint is not changing a belief wantonly, only changing when there is some good reason and serious examination. Lampert thinks that courage and modesty are appropriate to participation in mathematical activity because truth remains tentative, even as the proof or conjecture evolves. The way in which Lampert constructed her classroom environment communicates her beliefs. She shifts the social norms and classroom discourse patterns by asking students to make and evaluate their assertions and those of others. Students are placed in the position of "arguing about what is mathematically true; they move around in their thinking from observations to generalizations and back to observations to refute their own ideas and those of their classmates" (1990, p. 33). The students in Lampert's class are their own locus of authority, not the teacher or the textbook.

Lampert (1990) describes a common perception of mathematics as a discipline with certainty - knowing it and being able to get the right answer quickly.

These cultural assumptions are shaped by school experience, in which doing mathematics means following the rules laid down by the teacher; knowing mathematics means remembering and applying the correct rule when the teacher asks a question; and mathematical truth is determined when the answer is ratified by the teacher. (p. 32)

Students acquire these widely held beliefs through years of watching, listening, and practicing. The reform documents (NCTM, 1989, 1991, 1995, 2000) recommend that mathematics students should be making conjectures, abstracting mathematical properties, explaining their reasoning, validating their assertions, and discussing and questioning their own thinking and the thinking of others. Lampert describes her 
teaching practice as practice congruent with ideas about what is means to do mathematics in the discipline.

Lampert's teaching in the classroom includes both the teaching of content and the teaching of how to interact and participate with the content. She describes how she set up a participation structure where students learned mathematically appropriate activities associated with the words know, think, revise, explain, problem, and answer. This structure redefines the roles and responsibilities of both the teacher and students in the classroom. At the onset of a new topic or unit, Lampert poses a problem that would expose a wide range of student thinking and engage all students. The problem implies a correct solution, but cannot be solved by the simple application of a known algorithm. There are multiple routes to the solution and these processes are emphasized more than the solution. Lampert began a discussion of the problem by having students share their answers. After all the answers are recorded, students are free to question other student's answers (hypotheses). The questioner addresses the presenter and provides reasons for their questioning of the hypothesis. The student who gave that answer is free to respond with a revision. Lampert wanted to communicate the idea that every answer was arrived at through a process of reasoning that makes sense to the person that volunteered it, so she asked others in the class if they could explain what the student may have been thinking and why it makes sense. Finally, the student who gave the answer was asked to respond.

Lampert's goal was to make thinking public and collaborative. She gave the students problems to do but did not explain how to get the answers. She expected 
students to find solutions and convince their peers that their strategies and solutions were reasonable. Lampert wanted her students to learn what it means to know mathematics; she did not simply tell them, she created a social situation where students worked and communicated as mathematicians.

In contrast, Borasi (1990) describes how dysfunctional mathematical beliefs (held by either the student or the teacher) regarding the scope and nature of mathematical activity and the nature and origin of mathematical knowledge not only represent a limited appreciation of the nature of mathematics but also they can lead teachers and students to focus on memorization rather than conceptual understanding. Dysfunctional beliefs play themselves out in the following ways:

- A dysfunctional belief about the scope of mathematical activity causes one to focus on providing correct answers to a given problem.

- A dysfunctional belief about the nature of mathematical activity causes one to focus on recall and application learned procedures.

- A dysfunctional belief about the nature of mathematical knowledge causes one to believe that everything is right or wrong, there are no gray areas where personal judgment, taste, or values can play a role.

- A dysfunctional belief about the origin of math knowledge causes one to believe that math al ways existed as finished product, at best; mathematicians at times discover new parts of it. (p. 176)

Borasi describes strategies to help students reconceive their views of mathematics similar to those utilized by Lampert. He believes that when students have opportunities to engage in and reflect on mathematical activities that generate doubt in their assumptions it causes cognitive conflict and their beliefs begin to change. 
Strong relationships exist between beliefs and practice. Clarke (1997) explores these relationships and developed a conceptual framework (Table 6) from his review of the literature on the teacher's role in the reformed mathematics classroom. He identified six key components of the role of the teacher and the related beliefs about the teaching and learning of mathematics. These components provide a useful framework for studying the role of the teacher and, in particular, the changes in this role when implementing a reformed curriculum. It is clear from his work that teacher knowledge and beliefs shape practice, specifically implementation of reformed practice. 
Table 6

\section{Components of the Role of the Teacher in a Reformed Classroom and Related Beliefs about the Teaching and Learning of Mathematics}

\begin{tabular}{|c|c|}
\hline $\begin{array}{l}\text { Components of the role } \\
\text { (What the teacher does) }\end{array}$ & $\begin{array}{l}\text { Related beliefs about the teaching } \\
\text { and learning of mathematics }\end{array}$ \\
\hline $\begin{array}{l}\text { The use of nonroutine problems as the starting } \\
\text { point and focus of instruction without the } \\
\text { provision of procedures for their solution }\end{array}$ & $\begin{array}{l}\text { Sudents can solve nonroutine problems without } \\
\text { first being taught a procedure. }\end{array}$ \\
\hline $\begin{array}{l}\text { - The adaptation of materials and instruction } \\
\text { according to local contexts and the teacher's } \\
\text { knowledge of students' interests and needs }\end{array}$ & $\begin{array}{l}\text { Mathematics needs to be studied in living } \\
\text { contexts that are meaningful and relevant to } \\
\text { students, in-cluding their languages, cultures, and } \\
\text { everyday lives. }\end{array}$ \\
\hline $\begin{array}{l}\text { The use of a variety of classroom } \\
\text { organizational styles (individual, small-group. } \\
\text { whole-class) }\end{array}$ & $\begin{array}{l}\text { Differences in mathematical tasks and preferred } \\
\text { leaming styles of individuals demand variety in } \\
\text { classroom organization. }\end{array}$ \\
\hline $\begin{array}{l}\text { The development of a "mathematical discourse } \\
\text { community" with the teacher as "fellow } \\
\text { player" who values and builds on students' } \\
\text { solutions and methods }\end{array}$ & $\begin{array}{l}\text { An atmosphere of conjecture and justification of } \\
\text { mathematical ideas enhances learning. Teachers } \\
\text { should be open about their own struggles with } \\
\text { mathematical problems. Students' solutions and } \\
\text { methods provide the basis for discussion of } \\
\text { problems. }\end{array}$ \\
\hline $\begin{array}{l}\text { - The identification and focus on the big ideas of } \\
\text { mathematics }\end{array}$ & $\begin{array}{l}\text { Important mathematical ideas are not confined to } \\
\text { specific procedures in isolated content areas; } \\
\text { rather, mathematics is seen as an integrated } \\
\text { whole, in which the processes of problem } \\
\text { solving, reasoning, and communication are } \\
\text { central. }\end{array}$ \\
\hline inform instructional decisions & $\begin{array}{l}\text { Observing and listening to students provides a } \\
\text { "window" into their thinking that can be used to } \\
\text { plan further instruction. }\end{array}$ \\
\hline
\end{tabular}

From Clarke (1997, p. 280).

\section{Necessary Support Conditions for Teachers Developing Their Practice}

Based on their research, Lovitt, Stephens, Clarke, and Romberg (1990) identify several principles which they conclude should be in place for successful reform implementation. These include: 
- Allow teachers to develop a clear vision for what the changes mean for their own personal and professional behavior - teacher actively reflects and makes a commitment to work toward an improved and expanded repertoire of teaching skills

- Exemplary curriculum materials can help teachers think about their current roles and modify the way they teach by drawing on experience of the teachers who helped develop the materials

- Teachers need access to a sustaining and well-structured environment for professional growth (p. 230)

However, even though teachers may utilize reformed curriculum, the intended and the implemented curriculum often differ dramatically, as the teacher is not a passive implementer of curricula (Thompson, 1985). Therefore, Thompson feels that teacher education programs (including both preservice and inservice teachers) must do more than train teachers to teach mathematics, they must educate them in mathematics. The programs need to provide teachers with experiences that expand their knowledge about mathematics so teachers can deal effectively with open-ended discussions and exploration of student-initiated ideas.

This section outlines several key conditions that support preservice and inservice teachers in developing their practice to reflect Standards-based teaching, learning, and assessment practices. The first necessary condition is supporting teachers through helping them developing an understanding of the policy and what it means for instructional practice to reflect this policy. A second condition is supporting teachers through professional development experiences that respond to their needs in implementing the policy. The third condition necessary in supporting teachers is active instructional leadership offered by principals and teacher leaders within the building or district. The fourth condition is supporting teachers through 
giving them opportunities to examine their practice. The organizational structure should encourage teachers to examine their practice through discussions, planning, and analysis of student work with colleagues who are also experiencing the challenges of reform implementation.

Importance of Understanding the Change Process and What is Called For By the Reform

Hall and Rutherford (1983) describe two types of change (innovations) within organizations. These changes are described as product and process innovations.

Product innovations involve the use of something tangible and concrete, such as a new set of curriculum materials, a new medication, or a new set of measures for diagnosing client needs. Process innovations are not as tangible or concrete, although they may be structured. Examples of process innovations are a change in the way teachers manage student behavior, a change from a centralized to a decentralized approach to problem solving, or a program to improve staff morale and efficiency. (p. 2)

The change prescribed by the Standards represents both product and process innovations. When the higher, more comprehensive content standards define the mathematics curriculum, a new set of materials and measures are the product impacting the work of the teacher. The processes defining the roles of teachers and students and classroom interactions change as constructivist learning theory informs teachers' instructional practices. Given the complexity of what is called for in the Standards, Hall (1992) would describe them as an Innovation "Stack" or HyperInnovation as they advocate a large number of innovations simultaneously. A teacher 
implementing the Standards would need to adopt a mix of both product and process innovations.

Hall (1986) developed a conceptual framework for identifying and talking about the change process as teachers implement innovations. The Concerns-Based Adoption Model (CBAM) has three dimensions: (1) Stages of Concern (SoC), (2) Levels of Use (LoU), and (3) Innovation Configurations. The Stages of Concern (SoC) dimension of the model answers the question "How do they feel about it?" The Levels of Use (LoU) dimension answers the question "Are they using it?" The Innovation Configuration dimension addresses "What is it?" Teachers and administrators can use these rubrics to monitor and describe the change process. As teachers are more aware of the characteristics of change, it is easier for them to understand that what they are going through is natural and expected. As administrators are more aware of the process, it is easier for them to implement strategies and provide experiences that facilitate teachers in moving to the next level.

In addition to understanding that change is a process, Rowland (1993) states that altering perceptions about change would be beneficial. He claims that we need to make change our friend. If we view change as something that is natural and necessary, it would become a kindred spirit with whom we celebrate the past and create the future. Rowland's approach to change takes the current situation and instead of predicting results, imagines the possibilities for alternative futures. His model allows the asking of "what if" questions and does not limit the results. Rowland 
believes that effective participation in this quickly changing world stems from a willingness to take on this attitude about change.

According to Hall and Rutherford, and Rowland, then, developing an understanding of the change process and proactively responding to the changes called for by the policy, can help teachers effectively deal with the changes called for in the policy. Ultimately this support helps teachers build a classroom culture and curriculum that align with the intentions of the policymakers. In the section that follows, considerations for professional development experiences that respond proactively to the changes required of teachers are outlined.

\section{Role of Professional Development}

Purposes of professional development include expanding teachers' knowledge and beliefs about mathematics, about mathematics teaching and learning, and about the roles of the teacher and students in the classroom (Loucks-Horsley, Hewson, Love, \& Stiles, 1998; Clarke, 1997; Haimes, 1990). What type of professional development experiences and opportunities are needed in order for teachers to teach mathematics as it is described in the Principles and Standards (NCTM, 2000) and Oregon's Standards (ODE, 2001)?

In hoping to provide guidance to decision makers regarding appropriate professional development experiences for teachers of mathematics, NCTM developed standards for the professional development of teachers of mathematics. These standards are: 
1. Experiencing Good Mathematics Teaching

2. Knowing Mathematics and School Mathematics

3. Knowing Students as Learners of Mathematics

4. Knowing Mathematical Pedagogy

5. Developing as a Teacher of Mathematics

6. The Teacher's Role in Professional Development (1991, p. 123)

These standards are based on several assumptions including:

(1) teachers need to understand the message in the Curriculum and Evaluation Standards; (2) teachers are influenced by the teaching they see and experience; (3) learning to teach is a process of integration; (4) learning to teach is an ongoing process; and (5) there are level-specific needs for the education of teachers of mathematics. (pp. 124-125)

These standards imply that professional development experiences for teachers should model good mathematics teaching; build knowledge of content, students, pedagogy; and place the teacher in an active learning role where they are responsible to experiment with alternative approaches and strategies in the classroom; reflect on and discuss teaching and learning issues with colleagues; and actively participate in workshops, courses, and with the professional community. Noddings (1990) sees the constructivist paradigm offered in the Professional Standards as an opportunity to think critically and imaginatively about the teaching and learning process; suggesting that teachers are constructing their understanding of their practice and judging their choices about teaching method in the context of these professional development and their classroom experiences.

Similarly, Fennema and Franke (1992) offer a dynamic model in which teacher knowledge about content, pedagogy, and student learning develops in the classroom (Figure 7). The figure shows that it is knowledge of math, pedagogy, and student 
thinking that influence what a teacher knows and can do in the classroom context.

From this work in the classroom, as indicated by the large rectangle and the interactions of these types of knowledge, teachers' beliefs develop. For example, teachers experiment with elements of the reform and in the process, transform their knowledge about student leaming. In turn, this transformation influences their beliefs about mathematics, teaching, learning, and assessment. These interrelationships are complex and Fennema and Franke (1992) suggest that more research is necessary to explain how change in one impacts the change in the others.

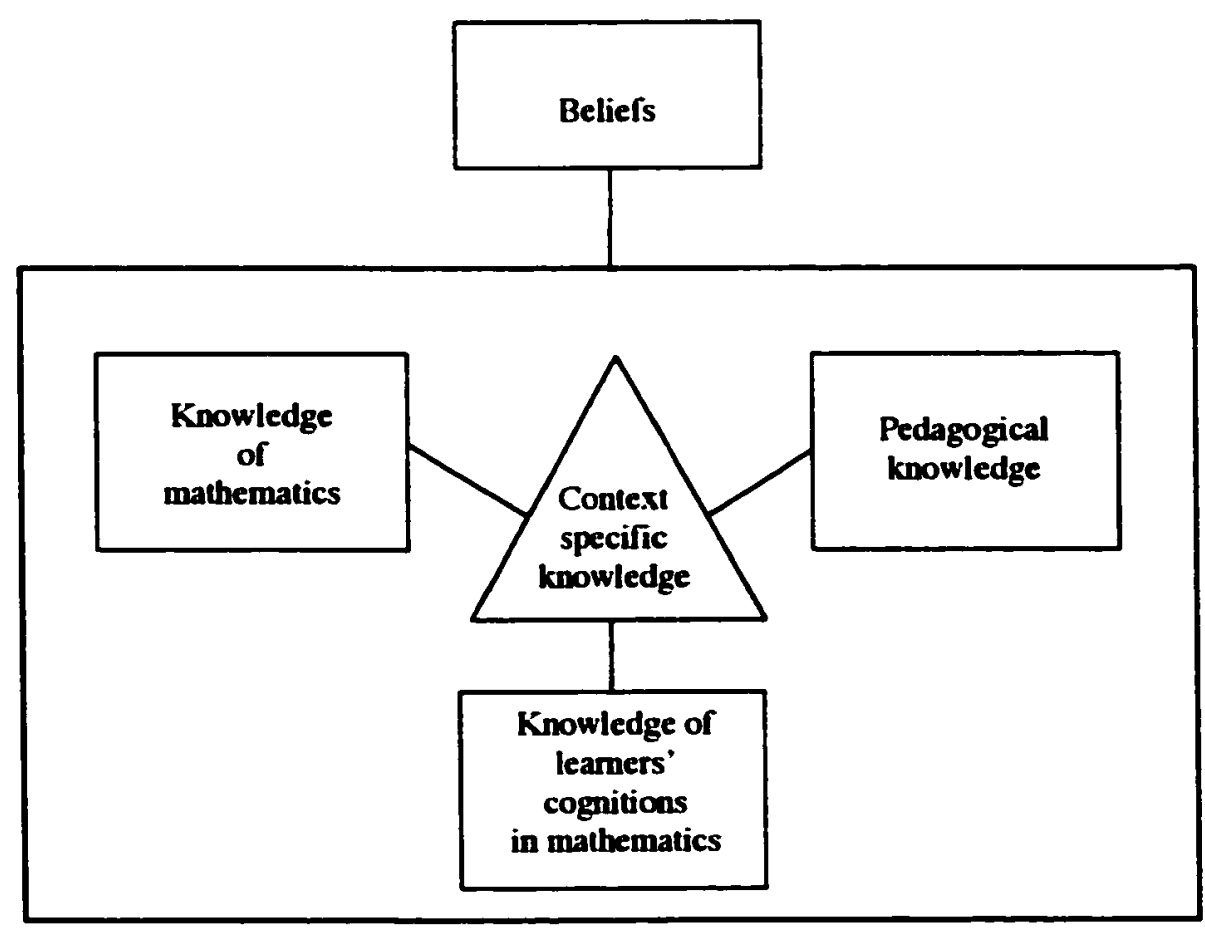

Figure 7. Teachers' knowledge developing in context. From Fennema \& Franke, 1992, p. 162. 
The work of Schifter and Fosnot (1993) confirms the dynamic relationships among types of teacher knowledge and beliefs described by Fennema and Franke. In their case studies, Schifter and Fosnot describe the transformations made by teachers following a SummerMath institute. At the institute, the teachers were engaged in learning mathematics through strategies aligned with a reformed view of mathematics. The researchers found that these experiences were not sufficient in and of themselves to change instructional practice. Teachers leave the institute with varied levels of understanding of the reform, what it means to align instruction with the vision of the Standards. For example, one teacher reported an eagerness to implement new instructional approaches through focusing on her role as a teacher. However, she did not realize that these approaches could only be sufficient if they met the needs of her students. Schifter and Fosnot report having redirected the focus of this teacher who had lost sight of this goal. The teacher confronted the necessary interactions among pedagogical knowledge, content knowledge, and knowledge of the students.

Following the redirection, the researchers found that:

[As the teacher] tumed her focus from her own behaviors toward analysis of each of her students' understandings, she could plan and modify her lessons to best support their conceptual development even if that meant departing from the day's agenda. And as the nature of her instruction changed, she began to reconceive the mathematics content she had been teaching, identifying the big ideas of the second grade curriculum. (p. 103)

The complex interactions among the forms of teacher knowledge and the impact that classroom practice has on this knowledge should be considered in planning professional development experiences. 
The "lived experiences" of teachers as both teachers and learners also help them to construct professional knowledge (Castle \& Aichele, 1994). Teachers "interact with the environment in ways that relates new knowledge to previously constructed knowledge in an attempt to make the best sense of the new knowledge" (p. 4). Castle and Aichele advocate for professional autonomy and empowerment of teachers. They believe that autonomous teachers construct personally meaningful professional knowledge, which is resistant to educational fads or external mandates. They describe how this can be fostered through allowing teachers the freedom to make choices and decisions about their practice, as well as giving them an opportunity to reflect on their practice and share their thinking with others. For teachers, the act of constructing their own knowledge helps them to better appreciate the constructive process which also better enables them to foster knowledge construction in their students.

Clarke (1994) reviews the literature on professional development from the past twenty years and reports ten important principles summarized in Table 7. He describes the need for the ideal professional development program to incorporate or address each of these principles in the planning and implementation of the change process and finds evidence supporting them (Clarke, 1997). Through a case study of two sixth grade teachers implementing a reformed curriculum, he describes the difficulty faced by teachers as they wrestle with changing their roles in the classroom. He discovers that change, while not a guarantee, could occur when these principles are in place. 
Table 7

Ten Important Principles of Professional Development

1. Address issues of concem and interest, largely (but not exclusively) identified by the teacher themselves, and involve a degree of choice for participants.

2. Involve groups of teachers rather than individuals from a number of schools, and enlist the support of the school and district administration, students, parents, and the broader school community.

3. Recognize and address the many impediments to teachers" growth at the individual, school, and district level.

4. Using teachers as participants in classroom activities or students in real situations, model desired classroom approaches during in-service sessions to project a clearer vision of the proposed changes.

5. Solicit teachers' conscious commitment to participate actively in the professional development sessions and to undertake the required readings and classtoom tasks, appropriately adapted for their own classroom.

6. Recognize that changes in teachers' belief's about teaching and learning are derived largely from classroom practice; as a result, such changes will follow the opportunity to validate, through observing positive student learning, information supplied by professional development programs.

7. Allow time and opportumities for planning, reflection, and feedback in order to report successes and failures to the group, to share "the wisdom of practice," and to discuss problems and solutions regarding individual students and new teaching approaches.

8. Enable participating teachers to gain a substantial degree of ownership by their involvement in decision-making and by being regarded as true partners in the change process.

9. Recognize that change is gradual, difficult, and often painful process, and afford opportunities for ongoing support from peers and critical friends.

10. Encourage participants to set further goals for their professional growth.

From Clarke (1994, p. 38)

Loucks-Horsley et al. (1998) developed a similar list of principles from their review of the research. They also suggest a framework for designing and identifying professional development programs. The design framework includes a continuous cycle of goal setting, planning, implementing the plan, and reflecting on and evaluating what happened. The authors also outline 15 strategies, intended to serve as a toolkit for professional developers. These strategies fall in to five categories including: (1) immersion, where teachers are immersed into solving problems and exploring mathematics; (2) curriculum, where teachers explore a curriculum and its 
implementation, the implementation of replacement units, and curriculum development and adaptation; (3) examining practice, where teachers engage in action research, case discussions, and examining student work; (4) collaborative work, where teachers form study groups, coaching/mentoring situations, partnerships and professional networks; and (5) vehicles and mechanisms, which help define the format of the learning experience, including workshops, institutes, courses, seminars, technology options (e.g., teleconferencing, television and interactive television, telecomputing), and leadership development. They suggest that every situation requires its own unique models for professional development tailored to respond to the needs of the teachers in the context of their work.

Professional development that makes a difference for developing teachers' instructional practice, accounts for developing teachers' knowledge and beliefs. It develops teachers' understanding of mathematics content and pedagogy through having them engage in math explorations that model reformed pedagogy. It furthers this learning by tying experiences to the classroom through encouraging implementation and reflecting on that implementation. It meets teachers where they are, by addressing issues that are of concem and interest to the teacher while pressing them to consider their role in developing and responding to student thinking.

\section{Role of the Principal and Teacher Leaders}

Principals powerfully impact the cultural norms in the school (Hyde, Ormiston, \& Hyde, 1994) and can make a significant difference in terms of teacher success with 
implementing curriculum innovations (Hall, 1988). Hall (1988) found that the degrees of influence toward school improvement vary among principals' leadership styles. Hord and Hall (1987) gathered data on responder, manager, and initiator leadership styles and found differences in the ways that teachers implemented the innovation under the various leadership styles. A correlation was shown between the style of the principal and implementation success. The principals that generally took a more active role in providing teachers with instructional materials, sending them to workshops, making substitutes available so teachers can observe one another, as well as making space and scheduling arrangements feasible for collaboration, were more likely to initiate and sustain school improvement. Principals monitor change efforts through asking probing questions, conferring with teachers, dropping in to classrooms, and collecting and analyzing data. Such interactions promote and encourage the use of the new curriculum and give positive support to teachers. Through these actions principals stimulate teachers' interests and develop teacher leaders within their schools (Hyde et al., 1994).

Hall (1988) states that the roles of effective administration lie not only with the principal as a change facilitator (CF), but also with a second person (2nd CF) which may be the assistant principal and a change facilitating (CF) team. This team may be comprised of a district curriculum coordinator, teachers on special assignment, and/or experienced classroom teachers implementing the innovation. Members of this team act as expert peers by assisting others with implementing the new approaches to teaching math. The functions of the team include activities such as sanctioning, 
providing resources, coaching, monitoring, training, reinforcing, pushing, telling others, and approving adaptations. Hall found that the CF team was key to successful change in a school when it addresses all of the functions on a continuing basis.

As the reform is implemented in classrooms, and the role of the teacher and student change, what an observer sees and hears while visiting the classroom also changes. This has an impact on another component of an administrator's job: classroom observation and supervision (Nolan \& Francis, 1992). In their new roles, both students and teachers are actively constructing their knowledge. For students the knowledge is of mathematics content and processes. For teachers this knowledge is of the new paradigms of teaching and learning mathematics, not to mention in some cases, mathematical content. For administrators, in addition to viewing teachers as active constructors of their knowledge, they should view themselves as collaborators in creating knowledge about teaching and learning which also impacts the data collected during classroom observations (Nolan \& Francis, 1992). Nolan and Francis (1992) feel that administrators should move past a reliance on paper-and-pencil observation instruments to capture a single period of instruction and instead use a variety of data sources to capture a lesson as it unfolds over several periods of instruction. They also describe the need for a balance between the attention given to general teaching behaviors, as identified in process-product research on classroom teacher effectiveness, as well as the content-specific issues and questions that arise as a result of implementing the reformed curriculum. Finally, Nolan and Francis suggest that supervision should shift from its individual orientation to a group process toward 
the goal of learning about and improving teaching. Through this collaboration, teachers are supported and will be more likely to risk asking the tough questions about their practice (Nolan \& Francis, 1992); leading to the final section that considers the role of collegial support and collaboration in the change process.

\section{Role of Collegial Support and Collaboration}

As teachers strive to effectively implement the innovations described in the Standards, they need to be reflective about their practice and need to be supported by colleagues. If teachers are given the opportunity to communicate with others about their experiences with the change process, both successes and failures, they will grow and learn more than they would in private reflection.

As teachers implement the reform, they discover a change in both their roles and responsibilities as math educators (Driscoll \& Lord, 1990). Driscoll and Lord (1990) describe how teachers, when implementing the reform, discover an increasing need and opportunity for collegiality. Once teachers realize this need, they open their doors to (1) discussion about the practice of teaching and learning, (2) observations of one another, (3) collaborative work on curriculum, and (4) teaching one another what they know about teaching, learning, and leading.

Virtually all of the professional development strategies described in a previous section lend themselves to collegial discussion and collaboration. In situations where teachers are examining practice (action research, case discussions, and reviewing student work and thinking, and scoring assessments), teachers deepen their 
understanding and engage in critical discussions about teaching and learning, as well as become problem-solvers who pose questions and examine alternative solutions. In situations designed with collaboration in mind (study groups, coaching and mentoring, partnerships, and professional networks), teachers involved in these relationships typically focus on issues related to their interests/needs; they collectively solve problems and consider new ideas. In situations where immersion or curriculum is the focus, teachers are typically engaged in learning the math or leaming about the curriculum as part of a group. While in this group structure, teachers often have an opportunity to discuss their new learning relative to their practice within their discussions about learning the math.

Weissglass (1994) describes a model for facilitating teachers' discussion about instructional practices and attending to the emotional struggle that is often paired with change. His model is based on the assumption that educational change requires personal transformation and improved collegial relationships. The model has four components, each essential to the change process, (1) obtaining information, (2) reflecting and planning, (3) obtaining emotional support, and (4) taking action. Weissglass has found that "constructive listening" is a structure that attends to the neglected components in the change process: reflecting and planning, as well as obtaining emotional support. Constructive listening is supportive listening in which the goal is to encourage the talker to: reflect on the meaning of the events and ideas, express and work through feelings that are interfering with thinking more clearly, construct rew meanings, and make decisions. The listener facilitates self-organization 
of the speaker when he/she becomes an audience. By taking part in constructive listening, the teacher is able to construct his or her own understanding of teaching. This communication, cooperation, and support can be beneficial for both teachers and students. Just as this process would aid teachers in constructing understanding of their practice, it would also aid students with constructing understanding of a math concept. In both cases, the interaction is aimed at achieving a state of equilibrium.

To help teachers successfully implement the reform they need to be supported through ongoing professional development and support. The professional development experiences should help teachers better understand the reform expectations as well as help teachers develop their knowledge, beliefs, and practice. Some of the support is external through workshops facilitated by "experts," while some occurs internal to the school (or district) where teachers have opportunities to work with colleagues to discuss their developing practice. Administrators play a key role with initiating and sustaining the reform implementation in their schools through providing resources as appropriate and understanding, supporting, and expecting reformed instructional practice.

\section{Conclusion}

The emphasis on mathematical problem solving in the Oregon reform policy has served as a catalyst for change in instructional practice for many teachers due to the high stakes attached to students' earning a Certificate of Initial Mastery (CIM) or meeting the state's various benchmark levels. The on-demand problem solving 
assessment has caused teachers to see the need to increase the number of problem solving opportunities offered to students in the curriculum so that students are more likely to experience success in meeting the benchmarks.

Even though all Oregon teachers are responding to the same policy, their goals in teaching problem solving are likely to vary. Teachers' views of the role of problem solving in the curriculum influence both how they teach problem solving as well as what problems they choose and what they value when they review student work. According to Pólya (1945), problem solving should include active engagement, discovery, social construction, and sensemaking on the part of the student, which offers the how. Silver (1990) cites the work of an Australian psychologist, John Sweller, who advocates the type of generative mathematical thinking that I believe is envisioned by the policymakers in terms of the what. Sweller offers two types of problems, goal-specific and non-goal-specific (Table 8)-and contrasts the students' learning from the two types of problems. In his research (as reported in Silver, 1990), Sweller found that:

(1) students are often able to leam usable knowledge and skills more effectively and efficiently through experience with non-goalspecific problems and exercises than with more traditional goalspecific versions;

(2) students solving goal-specific problems are more likely to use general strategies that are effective for solving the specific exercises or problems but are less effective for making connections among concepts and procedures or for organizing knowledge;

(3) the non-goal-specific problems offer opportunities for students to use strategies that make the important relationships more salient, thereby helping students to develop knowledge that is better organized and skills that are more usable. (p. 3) 
Table 8

Goal-Specific Versus Non-Goal-Specific Problems

\begin{tabular}{|c|c|}
\hline Goal-Specific & Non-Goal-Specific \\
\hline $\begin{array}{l}\text { Two parallel lines are cut by a transversal. as } \\
\text { sbown in the figure below. If angle } 2 \text { is } 30^{\circ} \text {. find } \\
\text { the measure of angle } 1 \text {. (See Figure A.) }\end{array}$ & $\begin{array}{l}\text { Two parallel lines are cut by a transversal, as } \\
\text { shown in the figure below. If angle } 2 \text { is } 30^{\circ} \text {, find } \\
\text { the measure of as many of the other angles as you } \\
\text { can. (See Figure A.) }\end{array}$ \\
\hline $\begin{array}{l}\text { Thu and Marina each ride their bikes to school. } \\
\text { Thu lives } 8 \text { blocks from school. Marina lives } 12 \\
\text { blocks from school. It takes Thu } 16 \text { minutes to } \\
\text { ride his bike to school each morning. How long } \\
\text { does it take Marina to ride her bike to school if } \\
\text { she rides at the same rate as Thu? }\end{array}$ & $\begin{array}{l}\text { Thu and Marina each ride their bikes to school. } \\
\text { Thu lives } 8 \text { blocks from school. Marina lives } 12 \\
\text { blocks from school. It takes Thu } 16 \text { minutes to } \\
\text { ride his bike to school each morning. Write and } \\
\text { solve as many problems as you can. }\end{array}$ \\
\hline $\begin{array}{l}\text { The radius of a circle inscribed in a square is } 6 \\
\mathrm{~cm} \text {. as shown in the figure below. Find the area } \\
\text { of the square. (See Figure B.) }\end{array}$ & $\begin{array}{l}\text { The radius of a circle inscribed in a square is } 6 \\
\mathrm{~cm} \text {, as shown in the figure below. Find out all } \\
\text { you can about the circle and the square. (See } \\
\text { Figure B.) }\end{array}$ \\
\hline Figure A & Figure B \\
\hline
\end{tabular}

From Sweller, as cited in Silver (1990, p. 4)

The type of thinking generated by the non-goal-specific problem is the type of thinking defined as problem solving, as seen in the literature I reviewed. Silver speculates that long-term engagement with non-goal-specific problems and the associated problem-posing and conjecturing activities may have a dramatic, positive effect on students' subsequent knowledge or problem solving. So as opposed to creating problem performers, students who perform well using the state scoring guide 
to guide their thinking, in posing non-goal-specific problems, we potentially create problem solvers, students who freely and enthusiastically solve problems. These students show that they can access relevant knowledge, use strategies and skills to explore the relationships in the problem, make connections, and generally show more flexibility in their thinking. The focus of problem solving is oriented to mathematical thinking and reasoning process and less on finding the answer and creating the writeup.

Students are more likely to deeply explore a concept and look for connections when a non-goal-specific problem is posed, as is shown in the example from Classroom B where students are asked to investigate and report all they can about the growing pattern. Students learn to problem solve through exposure to many different types of problems, opportunities to share and discuss the problem/strategies with others, time to reflect, and appropriate guidance. They benefit from identifying and discussing the methods they use while solving mathematical problems, solving problems independently, and making sense out of the mathematics they are learning. Additionally, self-monitoring strategies help students identify if they are on the right track or if they need to reconsider their approach.

Polya (1945) offers his Guide to Problem Solving Techniques to support both teachers and students through the problem solving process. Embedded in his four-step process is reflective thinking and verification, improving the likelihood of correct conceptualization of the problem and a correct response. Pólya's guide also helps students independently develop general approaches to problem solving and teachers 
develop general approaches to questioning. Through use of this guide, both the teacher and student take on roles, which represent closer alignment with the teaching and learning of mathematics advocated in the Standards.

Implementing the Standards is complex, so active and on-going support are necessary if we are to influence the way in which the reform policy is implemented. Attention needs to be given to the important relationships between teachers' knowledge, beliefs, and instructional practice. As we consider teacher development (both preservice and inservice) we need to understand the power of the internal influences (math content, problem solving, pedagogy, and students as leamers) and external influences (curriculum, reform policy, professional development, administrators, and colleagues) and how they shape instructional practice. 


\section{CHAPTER III}

\section{METHODOLOGY}

The focus of this study was to explore and describe in depth four Oregon teachers' problem solving practice. In the process of exploring and describing

practice, this researcher made clear the influences on the teachers' practice and relationships among these influences. The teachers included in this study were chosen because they exhibited characteristics like the teacher described in Classroom B in Chapter 1 (Figure 2).

\section{Research Questions}

There are two main questions that I address in this study.

1. What do exemplary middle school mathematics teachers do to engage students in mathematical problem solving?

In answering this question, I look at relationships among the teacher, student, and the content, specifically, mathematical problem solving. I describe what teachers and students were doing as they engage in problem solving. I also describe what teachers emphasize as they teach problem solving, the role problem solving plays in their curriculum, and how teachers choose the problems they do. 
2. On what bases do teachers make decisions about

-what to emphasize when teaching problem solving?

-how to teach problem solving?, and

-when to teach problem solving?

In answering this question I look at the internal and external conditions influencing teachers as they make decisions about what to emphasize as they teach problem solving, how to teach problem solving, and when to teach problem solving. This study allows me to account for and explain the internal (knowledge, beliefs, and thinking) and external (curriculum, policy, professional development) conditions that influence teachers' problem solving practice. It provides stories of how and why teachers come to teach problem solving the way they do.

Unpacking the two primary questions leads to several more specific subquestions, listed below.

1. What do the focus teachers do to engage students in mathematical problem solving?

a) What is the role of the teacher? How do these teachers see their role in problem solving instruction?

b) What is the role of the students? How do these teachers see the student's role?

c) What do these teachers emphasize in their problem solving instruction?

d) What role does problem solving play in their curriculum? 
e) How do teachers choose problems for classroom investigation?

2. On what bases do teachers make decisions about -what to emphasize when teaching problem solving? -how to teach problem solving? -when to teach problem solving?

a) What dimensions of teacher knowledge, beliefs, and thinking (i.e., mathematics content, problem solving, pedagogy, mathematics pedagogy, themselves as teachers and learners, students as leamers) account for the focus teachers' problem solving practice? Do these dimensions interact? If so, how and with what influence?

b) What external influences (i.e., curriculum, educational reform policies, formal and informal professional development) account for the focus teachers' problem solving practice? Do these dimensions interact? If so, how and with what influence?

Considerations Leading to the Design of the Study

Implementation of the Oregon Educational Act for the 21 st Century impacts the teaching, learning, and assessment of mathematics throughout the state. This policy not only has an impact on the role of teacher and student in the reformed classroom, but also impacts the role of the professional development and the principal 
in supporting teachers responding to the changes called for in the policy. There are many lenses through which implementation of standards can be studied. Shulman (1986b) describes how the framing of the research question "limits the range of permissible responses and prefigures the character of possible outcomes" (p. 3). The potential audience for the research also informs the question, as some research methods are more convincing to certain audiences.

Shulman (1986b) describes the opposing research paradigms that operate in mathematics education. Historically, researchers in the discipline of mathematics, a natural science, operated in a quantitative research mode, utilizing scientific method to study their questions. Education is a social science, operating with multiple paradigms and with competing schools of thought, especially in the area of mathematics education. One may assume that studying what happens to this policy in practice would also suggest the use multiple research methods.

Studying what happens with the implementation of the Standards can happen at many levels and from a variety of vantage points. As described previously, the roles of students and teachers change with implementation of the policy. Thus, a researcher may choose to study the changes in students' knowledge, beliefs, and/or understandings about mathematics or themselves. Or, research may focus on the changes in teachers' knowledge, beliefs, and/or understandings about mathematics teaching, learning, and assessment. Or research could examine changes in instructional practice or what impacts changes in practice. Also present are the changes in the potential support systems for teachers as they implement the reform 
including professional development, principals, and collegial support. A researcher also may have questions about what happens as a result of these support systems and which support systems are most influential.

In 1992, a working group from the National Center for Research in Mathematical Science Education and the Educational Development Center met to discuss strategies for studying teacher change in the reform of school mathematics. The research papers presented to this group utilized methodologies which included: observing in classrooms and reflecting on classroom practice, examining discussions during staff development meetings, analyzing teacher journals and portfolios (which included evidence of material teachers developed for use in their classrooms), examining teacher-chosen videotaped episodes of classroom practice, analyzing lesson plans, reviewing student work, developing autobiographical case studies, analyzing written tasks, and engaging in open-ended interviews. All such strategies allow the researcher to understand the participants' behavior through learning about the participants' thinking and reasoning. In only one case did the methodology include instruments generating quantitative results (Lubinski, 1992), and these were administered to determine baseline information about teacher beliefs and knowledge and used to plan staff development experiences. The instruments were readministered six months later to assess changes in beliefs and knowledge as a result of the staff development intervention. The data set for this study also included teachers' journals, videotapes, and observation records. 
Similarly, Noddings (1990) would argue that from a constructivist paradigm, research needs to focus on understanding participants' behavior. Research should explore participants' perceptions, purposes, premises, and ways of working things out. The multiple research strategies used in these studies above (National Center for Research in Mathematical Science Education \& Educational Development Center, 1992) attempt to capture the dynamics of a reformed classroom in ways that a single data source cannot. While the data from these studies may not be generalizable, due to the small sample sizes, they better tell the stories of teachers changing their practice. If a researcher wants to study the degree to which teaching and assessment practices represent the vision held by the policymakers, he/she should consider using multiple data sources where the elements are complementary, offering a more complete picture of the intended policy's implementation.

Previously, researchers noted that the research in problem solving lacks descriptions of what actually goes on in the classroom when problem solving is taught (Silver, 1985; Thompson, 1985; Grouws, 1985). In an ERIC search with limits of 1985 to the present, no empirical research was identified dealing specifically with problem solving instruction. When the search was expanded to include implementation of Standards-based practices, several large-scale research projects were identified including the QUASAR project (Henningson \& Stein, 1997; Silver \& Lane, 1995; Smith \& Stein, 1998; Stein, Smith, Henningson, \& Silver, 2000) and California's Elementary Mathematics Study (Ball, 1990; Cohen, 1990; Cohen \& Ball, 1990; Darling-Hammond, 1990; Jennings-Wiemers, 1990; Peterson, 1990; Wilson, 
1990). These projects have utilized descriptive approaches and their methodologies informed the methodology for this study. This researcher wanted to describe what is happening in classrooms around problem solving instruction and explore why it looks the way it does for teachers responding to Oregon's educational reform. Only qualitative approaches will accommodate the detailed descriptions of the relationships among knowledge, beliefs, and practice.

A qualitative case study approach was used to explore and explain the nature of problem solving instruction in four Oregon mathematics classrooms. The primary data sources included classroom observations and individual semi-structured interviews with middle school mathematics teachers. Throughout the study, the interviews were guided by protocols which allowed the researcher to determine the important topics and issues in advance while also providing the flexibility to ask questions that were relevant to the teacher's circumstances helping to maintain a conversational tone for the interview (Fraenkel \& Wallen, 1996). Supplemental data sources included classroom artifacts (e.g., tasks/problems) and district/state documents (e.g., curriculum frameworks, task banks, professional development plans and calendars).

The study gains power and validity through triangulation of the data. The use of interviews, classroom observations, and classroom artifacts helps the researcher capture both what these teachers plan to do and what they actually do to promote mathematical thinking and problem solving. The teachers add interpretation to these descriptions through explaining the influences on their decision-making and practice. 
Due to the depth of the data collected, the sample was limited to four teachers suggesting that the data may be less reliable. However, as will be seen in chapter four the data is, for the most part, consistent across the four teachers. The study's timeline is included in Appendix A.

\section{Criteria for Selection}

Presented in the opening chapter are two classroom episodes exhibiting two very different approaches to problem solving. The teacher in Classroom B facilitates mathematical thinking and problem solving through posing a worthwhile task, encouraging discussion about strategies and reasoning, and providing challenge and support for all students. This teacher actively engaged students with the content while pressing for understanding by asking the students not only what they did but also how they decided to do what they did. While the NCTM Principles and Standards state "there is no one "right way" to teach" $(2000$, p. 18$)$ but are very specific about the critical characteristics of effective teachers. Effective teachers:

- possess a rich understanding of math content which includes how knowledge is created in the discipline.

- utilize pedagogical approaches that help students make sense of mathematics content, through confronting existing conceptions, and realizing connections both within and outside the field of mathematics.

- believe that all students can understand mathematics and should have access to meaningful mathematics curriculum. 
- are confident and flexible in their teaching and are curious about student thinking and the subject.

Teachers exhibiting the above characteristics work to develop classroom environments in which the following are observable behaviors:

- Use of Mathematical Analysis - Most students, for most of the time, are engaged in mathematical analysis (e.g., searching for mathematical patterns, making conjectures, and justifying those conjectures).

- Depth of Knowledge and Student Understanding - Knowledge is very deep because the teacher successfully structures the lesson so that almost all students do at least one of the following: sustain a focus on a significant topic; or demonstrate their understanding of the problematic nature of information and/or ideas; or demonstrate complex understanding by arriving at a reasoned, supported conclusion; or explain how they solved a complex problem. In general, students' reasoning, explanations and arguments demonstrate fullness and complexity of understanding.

- Mathematical Discourse and Communication - Talking is used to understand math. The creation of and maintenance of collective understandings permeates the entire lesson. This could include the use of common terminology and the careful negotiation of meanings. Almost everyone participates.

- Locus of Mathematical Authority - Almost all the students share in the mathematical authority for the class. Students rely on the soundness of their own arguments and reasoning. The teacher almost always answers a question with a question. It is not uncommon to see students leaving a class still arguing about one or more mathematical points in their lesson.

- Intellectual/Social Support - Social support is strong; the class is characterized by high expectations, challenging work, strong effort, mutual respect and assistance in achievement for all students. Both teacher and students demonstrate a number of these attitudes by soliciting and welcoming contributions from all students who are expected to put forth their best efforts. Broad 
participation may be an indication that low achieving students receive social support for learning.

- Student Engagement in Mathematics - Serious engagement; almost all students are deeply involved, almost all of the time, in pursuing the substance of the lesson. (Evidence of engagement is shown though attentiveness, doing the assigned work, showing enthusiasm for work by taking initiative to raise questions, contribute to group tasks and help peers.) (Secada \& Byrd, 1993)

The top ratings on the 5-point Secada and Byrd (1993) Classroom Observation Scales describe the behaviors desired while students engage in problem solving. These scales represent a tight link between NCTM's description of effective teachers and what classroom instruction looks and sounds like when effective teaching occurs. For example, a teacher who understands how knowledge is created in the discipline will ask students to engage in mathematical analysis recognizing that they too, are mathematicians. A teacher who utilizes pedagogical approaches that promote sensemaking presses students for depth of understanding, encourages mathematical discourse and communication, and recognizes that students should rely on their own thinking and share in the mathematical authority for the class. A teacher who believes that all students can understand and should be exposed to meaningful mathematics provides intellectual/social support through setting high expectations for all and expecting broad participation and serious student engagement in the mathematics. The NCTM descriptors of effective teachers and the Secada and Byrd (1993) observation scales informed the identification and selection of teachers for this study. Teachers who exhibited these characteristics themselves and in their classrooms were determined to be "exemplary" middle school math teachers and were invited to be part 
of the present study. Described in the next section was the process used to identify and select participants.

\section{Process of Identification and Selection}

Based on the criteria listed above, university faculty researchers working directly with practicing teachers (members of the researcher's dissertation research committee) along with mathematics curriculum specialists from Teachers Development Group (TDG) recommended teachers for initial screening. The TDG curriculum specialists, like the committee members, offered helpful advice for selection because they have a sense for what it looks like when teachers teach like the teacher in Classroom B. They have also had opportunities to work closely with teachers (instructing, developing and observing) in many school districts around the state. In recommending teachers for this study, the university committee members and TDG specialists were asked to consider how long the teachers had been teaching using these "effective practices" and how easily they believe the teachers could be swayed in their thinking. This was a concern in this study because this researcher wanted teachers that persevere in developing a classroom culture that reflects the descriptors above, even in the face of challenge.

The recommended teachers were told that their name was given to this researcher because they were identified as exemplary middle school math teachers. They were told that the present study was being conducted to learn more about what exemplary middle school math teachers do to promote mathematical thinking and 
problem solving in their classrooms. They were asked if they would allow this researcher into their classroom for an observation. This classroom observation served as the initial screening, providing information used to determine which teachers would be asked to be part of the larger study. The Classroom Observational Scales from Secada and Byrd (1993) were used to score the observed lesson. Of the fifteen teachers screened, the four teachers earning the highest scores were asked to take part in the study. The screening observations took place in late September through early November, following the researcher's training in the use of the Observation Scales. Due to the fact that the observations took place early in the year, some teachers may not have scored as well on the scales as they would later in the school year because of the time it takes to build a classroom culture focused on mathematical thinking and problem solving. Once the teachers agreed to take part, they were asked to sign the informed consent form (Appendix B) and the initial interview was scheduled.

\section{Data Collection}

Described in this section are the data collection methods used in this study along with the intended information to be gathered with each tool. The tools include a questionnaire, an initial interview, a prompted-response interview, three classroom observations with pre-and post-observation interviews, and a follow-up interview. 


\section{Questionnaire}

Prior to the initial interview, teachers were asked to complete the Mathematics Teacher Questionnaire (Appendix C). The questionnaire gathered information on each teacher's demographics, his/her instructional influences, the demographics for the class to be observed, and his/her professional development experiences and their impact on their thinking and practice. This data was gathered efficiently through the use of the questionnaire and generated an awareness on the part of the participants regarding the influences on their instructional practices and change in those practices. This awareness helped to deepen the teachers' responses on the initial interview as they were thinking about the influences on their practice prior to the interview. The questionnaire may have broadened some participants' perspectives on what constituted professional development. The data gathered was helpful in creating participant profiles and in using for comparison between the question responses and the stated influences on instructional practice.

\section{Initial Interview}

Prior to the initial interview, the researcher contacted the teachers and requested that they bring an example of a "good problem" they had used or intended to use to the initial interview. The good problem they chose served as a basis of discussion for the initial interview, providing an illustration from the teacher's perspective of both what makes a good problem and what represents problem solving. The discussion centered on the teacher-defined characteristics of a good problem, the 
student thinking such problems elicit, the problem's alignment with state standards, and the opportunity for assessment provided by the problem.

The initial interviews, designed to find out about the teacher's knowledge and beliefs occurred in early January through early March 2001. The interview guide for the initial interview (Appendix D) posed questions related to the teacher's knowledge and beliefs: including a baseline definition of problem solving, the role problem solving takes in the teacher's curriculum, and discussion about how that role might be different if the reform were not in place. Additionally, the teachers describes the support they received in changing their practice as well as what has had the most influence on their practice.

This interview was designed to acquire a good sense of the knowledge and beliefs that guided the participant teachers' decision-making and, therefore, their classroom practice. Additionally, questions were posed to leam about the support conditions that teachers experienced as well as those that the teachers believe are most influential in developing instructional practices focused on problem solving. The initial interviews were audiotaped for transcription and coding.

\section{Prompted-Response Interview}

The prompted-response interviews (Appendix E) were conducted in January through early March. During these interviews the teachers were asked to review a set of tasks (Appendix F) and determine a way in which the tasks could be grouped together. Once the tasks were sorted the teachers were asked to talk about both what 
the categories were and how they decided upon the categories. The discussion about these tasks was designed to get at deeper knowledge and beliefs about problem solving than those shared in the initial interview. Instead of a participant responding with what he/she thought I wanted to hear, the teacher was placed in a situation where he/she was asked to indicate the relative cognitive demand of tasks, determine the content of the tasks, and suggest the contexts in which they may use the various tasks. Once teachers sorted the tasks in one way, they were asked to find a second sorting method and again discuss the criteria. This researcher speculated that attributes teachers attend to in a problem communicate something about what the teacher values when choosing a problem. Once the teacher completed the sorts, if he/she had not discussed this already, the teacher was asked to identify a problem(s) that he/she would use in the classroom and why he/she would use it and in what context, as weil as what he/she would hope to learn from students as a result of giving the task. Finally, the teachers were asked to talk aloud while solving two or more of the problems they suggested they might give their students. In each case they were asked for several approaches or ways to think about the problem. From this, the researcher was able observe the teachers' personal problem solving preferences: their fluency (problem solving effortlessly), flexibility (problem solving with multiple approaches), and orientation (direction of problem solving tendencies, i.e., algebraic, visual). The prompted-response interviews were audiotaped for later transcription and coding. 
Observations and Pre- and Post-

Observation Interview

The teachers were asked to identify and teach lessons over three consecutive class sessions. They were asked to choose lessons that exemplify their work in promoting mathematical thinking and problem solving with their students. The researcher acted as a nonparticipant observer taking field notes throughout the lesson. The observations were naturalistic as teachers and students were in their natural settings. The researcher did not attempt to manipulate variables or control the activities of individuals, as the researcher wanted to capture what naturally occurs in these classrooms. Immediately following the lessons, the Classroom Observation Scales (Secada \& Byrd, 1993), described previously, were used to review and generally describe the data. These scales are well aligned with both the curriculum and instruction recommendations in the NCTM Standards $(1989,2000)$. The field notes were detailed enough to justify the ratings and give another reader a sense of what happened in the lesson. For more detailed ratings, see Appendix G.

Prior to and following the three observation sessions the researcher conducted pre- and post-observation interviews from an interview guide (Appendix $\mathrm{H}$ ). The interviews were audiotaped for later transcription and coding. The observations and pre- and post-observation interviews took place beginning in late March through April. This window was chosen because the classroom norms were well established by this time in the year, making it more likely that the students would be accustomed to the culture of mathematical thinking and problem solving. 
The classroom observations and pre- and post-observation interviews allowed the researcher to further explore the knowledge and beliefs that guide the participants' decision-making in the classroom and determine the degree to which the participants' knowledge, beliefs, and practice are aligned. The observations allowed the researcher to see the interactions between teacher and student and to explore the decision-making in action. During the post-observation interview the teachers were asked about the challenges they faced when implementing the lessons as well as what support they feel would help them in dealing with these challenges.

\section{Follow-Up Interview}

Follow-up interviews were conducted in May through early June 2001 (Appendix J). The intent of the interview was to learn more about several themes that emerged in preliminary analyses of the data, specifically the influence of a curriculum on these teachers' thinking and teaching as well as their own learning. Teachers were asked to reflect on the influence the Visual Mathematics/Math Alive! (Foreman \& Bennett, 1995, 1996, and 1998) curriculum had on their thinking and teaching, and knowledge and beliefs about math, students, student learning, problem solving, etc. Similar to the prompted-response interview, teachers were also asked to respond to two curriculum samples exploring the concept of scale factor, to discuss similarities and differences they noticed, and to offer an approach that they might use to teach the same concept. This interview also gave the teachers an opportunity to review and respond to the transcripts of their interviews and observations. They were asked to 
discuss what stood out for them in the data and to identify classroom interactions that reflected what they strive for in their classroom. This interview was also audiotaped.

Summarized below (Table 9) are the data sources and their central purposes in this study. Appendix L contains a more detailed review of the alignment between the data sources and the research questions answered through these sources. This researcher recognizes that the listed sources are not the only place in which evidence exists that informs the answer to the question, but these were the most likely places for the evidence to exist. 
Table 9

\section{Summary of Data Sources and Central Purposes}

\begin{tabular}{|c|c|}
\hline Data Source & Central Purpose \\
\hline Questionnaire & $\begin{array}{l}\text { - determine participants' demographics and demographics for observed class } \\
\text { - deepen participants' thinking about the influences on their practice prior to the } \\
\text { initial interview }\end{array}$ \\
\hline Initial Intervien & $\begin{array}{l}\text { - uncover the knowledge and beliefs that guide the participants' decision-making } \\
\text { and,therefore, their classroom practice } \\
\text { leam about support conditions teachers have experienced as well as those that } \\
\text { were most influential in causing change in instructional practices }\end{array}$ \\
\hline $\begin{array}{l}\text { Prompled- } \\
\text { Response } \\
\text { Intervicw }\end{array}$ & $\begin{array}{l}\text { - further explore the knowledge and beliefs that guide the participants' decision- } \\
\text { making and, therefore, their classroom practice } \\
\text { determine the knowledge and beliefs that are held most deeply by the participant } \\
\text { explore the participants' problem solving preferences, fluency, flexibility, and } \\
\text { orientation. }\end{array}$ \\
\hline $\begin{array}{l}\text { Observations } \\
\text { - classroom } \\
\text { lessons/ } \\
\text { interactions } \\
\text { - pre- and post } \\
\text { interviews }\end{array}$ & $\begin{array}{l}\text { further explore the knowledge and beliefs that guide the participants' decision- } \\
\text { making and, therefore, their classroom practice } \\
\text { observe the interactions between teacher and student and in-action decision- } \\
\text { making } \\
\text { determine the degree to which the participants' beliefs, knowledge, and practice } \\
\text { are aligned } \\
\text { leam about the challenges a teacher faces when implementing the reform as well } \\
\text { as what support teachers perceive to be the most beneficial }\end{array}$ \\
\hline Artifacts & $\begin{array}{l}\text { - understand the support that has been provided to the teachers through print } \\
\text { resources (i.e., curricular resources, task banks, instructional frameworks, leacher } \\
\text { generated materials), professional development, planning time, etc. }\end{array}$ \\
\hline $\begin{array}{l}\text { Follow-up } \\
\text { Interview }\end{array}$ & $\begin{array}{l}\text { - give participants the opportumity to review and respond to the transcripts } \\
\text { - leam more about why participants use the Visual Mathematics (1996 \& 1998) } \\
\text { curriculum through direct questioning and through their responses to other } \\
\text { Standards-based curricula }\end{array}$ \\
\hline
\end{tabular}




\section{Data Reduction and Analysis}

All interviews and observations were transcribed. Prior to the follow-up interview, all transcripts were reviewed to determine areas to explore further in this interview, and initial impressions were noted. A second review of the data was completed to tentatively identify coding categories related to the research questions and sub-questions. These categories were tested on the initial interview for all the participants and were refined as needed. Finally, the categories were used to complete a first round of coding and analysis of all the data for patterns and themes across teachers.

The data collection, analysis, and theory building occurred simultaneously using constant comparative methods for coding, comparing, and analyzing data (Glaser \& Strauss, 1967, cited in Strauss \& Corbin, 1990). The research questions were used to develop initial conceptual categories for the data analysis that were then refined to include more specific sub-categories based on the teachers' responses. This design allowed for the development of grounded theory, further explaining what is happening for the teacher and the students when engaged in problem solving and what influences the teachers' decision-making related to problem solving.

The raw data was read and re-read to confirm 20 different categories in the data (elements of the research questions) under the four main headings: engaging students in problem solving, decision-making regarding problem solving, dimensions of knowledge and beliefs influencing problem solving instruction, and external 
influences on knowledge and beliefs influencing problem solving instruction. In the process of coding, seven new categories were defined, increasing the total to 27 categories.

The transcribed data were transferred into and indexed using Q.S.R. NUD.IST Qualitative Data Analysis Software (Richards \& Richards, 1994). NUDoIST (Nonnumerical, Unstructured, Data-Indexing, Searching and Theorizing) software allowed for the transcribed interview and observation data to be indexed, searched, and organized through the used of nodes organized as a tree diagram. The node tree used the following:

Data Source

1.1 Initial Interview

1.2 Prompted-Response Interview

1.3 Pre-Observation Interview

Participants

2.1 Darrin Akers

2.2 Danielle Miller

Engaging Students in Problem Solving

3.1 Role of Teacher

3.2 Role of Student

3.3 Emphasis while Problem Solving
1.4 Observation

1.5 Post-Observation Interview

1.6 Follow-Up Interview

2.3 Michelle Daniels

2.4 Quenton Forrest

3.4 Role of Problem Solving

3.5 Choosing Problems

3.6 Changing Beliefs 
Decision-making regarding Problem Solving

4.1 What to emphasize when teaching Problem Solving

4.2 How to teach Problem Solving

Dimensions of Knowledge and Beliefs

5.1 Mathematical Content

5.2 Problem Solving

5.3 Pedagogy

5.4 Mathematics Pedagogy
4.3 When to teach Problem Solving

4.4 Pacing*

Extermal Influences on Knowledge and Beliefs
6.1 Curriculum
6.6 Colleagues*
6.2 Reform Policy
6.7Environment*
6.3 Formal Professional Development
6.8Students and Parents*
6.4 Informal Professional Development
6.9Time*

\subsection{Administrator*}
*indicates categories added during the coding process

Once the coding and sorting was completed the data in each category was read and re-read to form assertions, identify representative examples, and determine variations in the data. Within the main heading of engaging students in problem solving, two of the categories - role of teacher and role of student were further analyzed to create subcategories. This was due to the particularly large portions of the data that fell into these broad headings. The subcategories gave a way to better describe the comments and actions represented within this category and drew upon 
both how the teacher described his/her role and student roles, as well as the observed roles for both groups (see Table 10). For example, one component of the role of the student is to interact with other students and/or the teacher; evidence of this is found in both what the teachers says students should be doing and what the students are actually doing as observed in the classroom. These sub-codes were used to further review the classroom observation transcripts, tracking the frequency of the actions taken by the teacher and actions taken by the student.

\section{Table 10}

\section{Role of Teacher and Student While Engaging in Problem Solving}

\begin{tabular}{|c|c|}
\hline Role of Teacher & Role of Student \\
\hline $\begin{array}{l}\text { - } \quad \text { Posing problem } \\
\text { - Clarifying the task } \\
\text { - } \quad \text { Providing manipulatives } \\
\text { - } \text { Offering praise or encouragement } \\
\text { - Asling questions } \\
\text { - } \quad \text { g get an answer } \\
\text { - to find out student thinling } \\
\text { - to press for more thinking } \\
\text { - } \quad \text { observing up a misconception } \\
\text { - Encouraging reflection } \\
\text { - Encouraging multiple approaches } \\
\text { - Encouraging a specific strategy } \\
\text { - Encouraging reasoning and/or proof } \\
\text { - Presenting a strategy } \\
\text { - Encouraging participation }\end{array}$ & $\begin{array}{l}\text { Problem solving behaviors (observing. } \\
\text { conjecturing. predicting. generalizing, testing } \\
\text { generalizations, verifying) } \\
\text { Interactions with other students and/or the } \\
\text { Ieacher } \\
\text { - Asking questions of other students } \\
\text { - Asking questions of the teacher } \\
\text { - Aresenting Results } \\
\text { Answering questions with both a solution } \\
\text { and reasoning } \\
\text { Answering questions with a solution }\end{array}$ \\
\hline
\end{tabular}

Additional data were gathered through the review of the "good problem" the teacher brought to the initial interview and the problems posed to students during the classroom observation. These were rated using the Characteristics of Mathematical 
Tasks framework (Smith \& Stein, 1998) (see Appendix I) that represents a continuum with four different problem types ranging from "Memorization" to "Doing Mathematics". This framework for task review was chosen because its descriptors capture the important aspects of mathematical thinking and problem solving behavior described in Chapter 2 (Pólya, 1980; Schoenfeld, 1985; and others). These include the extent to which students are engaged in exploring the math ideas, using of relevant knowledge and processes, analyzing their thinking and strategies, and monitoring their cognitive processes. This researcher expected, based on screening observations, that the problems posed by these teachers would likely fit into the categories "Procedures with Connections" and "Doing Mathematics," as opposed to "Memorization" and "Procedures without Connections." The former categories are well aligned with the vision for problem solving articulated in the NCTM Principles and Standards (2000), as illustrated by Classroom B. The researcher also observed for whether or not the teacher maintained the cognitive demand of the task during the set-up and implementation phases (as in Stein, 1998) as the opportunities for student learning change as the teacher makes decisions about what to focus on, how to respond to student confusion, etc.

The intent of the research analysis was to search for and describe common themes across the four teachers in the study and to develop profiles that emphasize the individual teacher's unique experience. The participant teachers' stories have been analyzed both individually and collectively, describing what these teachers do to promote mathematical thinking. The analysis has considered both what these 
exemplary teachers have in common and how they differ. Likewise, the influences on these teachers' problem solving practice were compared and contrasted in an attempt to establish a "range of generality" (Merriam, 1988) or broad statements about the problem solving practice of these exemplary middle school math teachers. Using the conceptual frames drawn from prior research on problem solving, and the relationships among knowledge, beliefs and practice, as well as the data from the present study suggest grounded theory which describes, explains, and accounts for four middle school math teachers problem solving instruction in the context of Oregon's Educational Reform.

\section{Summary}

This chapter has explained the methods that were used in this qualitative study exploring the mathematical thinking and problem solving that occurred in the classrooms of four exemplary middle school mathematics teachers. The multiple data sources allowed for exploration of what the teachers think they are doing, what they say they are doing, and what they are actually doing. The triangulated data not only provided a more complete picture of how teachers come to teach problem solving the way they do than would a single data source, but also confirmed relationships among the findings, informing educational research. 


\section{CHAPTER IV}

\section{FINDINGS}

Even though recommendations regarding the inclusion of problem solving in the mathematics curriculum have been around for more than 22 years (NCTM, 1980), when asked to engage students in problem solving different teachers respond to this expectation in different ways. The vignettes in Chapter 1 offered the picture of two teachers' strategies for engaging students in problem solving. The study reported here examined, in depth, the problem solving practice of four exemplary middle school math teachers, the influences on these teachers' practice, and the relationships among these influences. Findings show that there are more similarities than there are differences among the four participant teachers. Although there are some differences in their practice most can be accounted for through examining the influences on their practice. For example, one teacher describes specific classroom practices that can be perceived as algorithmic with a low cognitive demand, but this approach can be explained by what she believes students are able to do without her help.

This chapter begins with a brief profile of the four middle school teachers who were participants in the study. The profiles offer a context in which to consider each participant's comments and actions. The remainder of the chapter presents the results of the data analysis and is organized in terms of the two specific research questions 
posed in Chapter 1. The results section first reports on what the focus teachers do to engage students in mathematical problem solving. Then, it describes on what bases these teachers make decisions about what to emphasize when teaching problem solving, how to teach problem solving, and when to teach problem solving, and finally it accounts for the influences (both internal and external) on these teachers' decisionmaking.

\section{Participant Profiles}

The four teachers in this study represent four different middle schools in four different school districts in a large metropolitan area in Oregon. They were chosen to be part of the study because of their ability to promote mathematical thinking and problem solving in their classrooms. This section begins with a summary of the teachers' preservice and inservice mathematical background and observations about the teachers' content knowledge. Following this descriptions are profiles that follow offer a brief summary of each teacher's teaching background, and current teaching context. They also present factors the teacher believes are influencing effective instruction including state/district standards, state/district policies, instructional materials, access to technology, time, funding, and professional development. The information in the profiles is compiled both from the completed teacher questionnaires and the interviews. The names of the teachers and students are pseudonyms.

Background information about these teachers and information regarding their teaching context can provide a better understanding of these teachers' developing 
perspectives on math content, teaching and leaming. Table 11 summarizes the four teachers' certification levels, mathematical backgrounds, professional development experiences, and teaching contexts. There are many similarities among these teachers' educational backgrounds. Three of these teachers have taken more than ten college courses in mathematics, two of whom have completed math coursework within the last five years. All have taken courses in number systems, algebra, and geometry which represents a large portion of the content they teach. Three of the teachers hold elementary certificates combined with a middle school math endorsement ${ }^{3}$. One holds a secondary certificate and with a middle school math endorsement. The table also provides information about the teachers' numbers of years teaching and their specific teaching context. Their experience ranges from a first-year teacher to a teacher in her $27^{\text {th }}$ year of teaching. The student ethnicity of these teachers' schools is very much the same, with populations that are predominately white, with either Hispanics or Asians as the second largest group. The demographics, as represented with Socioeconomic Status (SES) rankings, indicate that Darrin's and Quenton's schools are comparable (with a difference of 13), and Michelle's and Danielle's schools are almost comparable (with a difference of 28); meaning, the student populations' background and needs at the two pairs of schools are similar. Due to this similarity, these schools share comparison groups for analyzing school-based and statewide assessment data.

\footnotetext{
${ }^{3}$ The Middle School Math Endorsement Program gives teachers an opportunity to enrich and broaden their mathematics background and to experience an environment that models teaching/learning environment congruent with NCTM recommendations. The program consists of eight 3-quarter hour courses that include Computing in Mathematics, Experimental Probability and Statistics, Problem Solving, Geometry, Arithmetic and Algebraic Structures, Historical Topics in Mathematics, Concepts of Calculus, and Teaching and Leaming in the Middle School Mathematics Classroom.
} 
Table 11

\section{Summary Background Information and Teaching Context by Teacher}

\begin{tabular}{|c|c|c|c|c|}
\hline & Darrin Akers & Danielle Miller & Michelle Daniels & Quenton Forrest \\
\hline $\begin{array}{l}\text { Number of years teaching. } \\
\text { including present year }\end{array}$ & 1 & 9 & 27 & 23 \\
\hline $\begin{array}{l}\text { Number of College Math } \\
\text { Courses Completed } \\
\text { (semester) }\end{array}$ & $2-3$ & $10+$ & $10+$ & $10+$ \\
\hline $\begin{array}{l}\text { Number of years ago math } \\
\text { course completed }\end{array}$ & $<5$ & $<5$ & $<5$ & $6-10$ \\
\hline $\begin{array}{l}\text { Coursework in } \\
\text { - number systems } \\
\text { - algebra } \\
\text { - geometry }\end{array}$ & $\begin{array}{l}\text { yes } \\
\text { yes } \\
\text { yes }\end{array}$ & $\begin{array}{l}\text { yes } \\
\text { yes } \\
\text { yes }\end{array}$ & $\begin{array}{l}\text { yes } \\
\text { yes } \\
\text { yes }\end{array}$ & $\begin{array}{l}\text { yes } \\
\text { yes } \\
\text { yes }\end{array}$ \\
\hline Educational Background & $\begin{array}{l}\text { UG Psychology } \\
\text { MAT Secondary } \\
\text { mid mth endorse }\end{array}$ & $\begin{array}{l}\text { UG math minor } \\
\text { elem tch cert } \\
\text { mid mth endorse }\end{array}$ & $\begin{array}{l}\text { UG math minor } \\
\text { elem tch cert } \\
\text { mid mth endorse }\end{array}$ & $\begin{array}{l}\text { UG engineering } \\
\text { elem tch cent } \\
\text { mid mth endorse }\end{array}$ \\
\hline $\begin{array}{l}\text { Number of hours spent in } \\
\text { formal math professional } \\
\text { development during the } \\
\text { past two years }\end{array}$ & $20-39$ & $80+$ & $80+$ & $80+$ \\
\hline Teaching Assignment & $8^{\text {th }}$ grade & $8^{\text {th }}$ grade & $8^{\text {th }}$ grade & $5^{\text {th }}-8^{\text {th }}$ grade \\
\hline $\begin{array}{l}\text { Ability grouping students for } \\
\text { mathematics }\end{array}$ & yes, 2 levels & yes, 2 levels & yes. 3 levels & no \\
\hline Curriculum Used by Choice* & $\begin{array}{l}\text { Visual Math/ } \\
\text { Math Alive! } \\
\text { Course III }\end{array}$ & $\begin{array}{l}\text { Visual Math/ } \\
\text { Math Alive! } \\
\text { Course II }\end{array}$ & $\begin{array}{l}\text { Visual Math/ } \\
\text { Math Alive! } \\
\text { Course II }\end{array}$ & $\begin{array}{l}\text { Visual Math } \\
\text { Math Alive! } \\
\text { Course I-III }\end{array}$ \\
\hline Enrollment by ethnicity (\%): & 388 & 307 & 279 & 401 \\
\hline $\begin{array}{ll}\text { - } & \text { Amer Indian/AK } \\
\text { Native } \\
\text { - } & \text { Asian/Pacific Islander } \\
\text { - } & \text { Black } \\
\text { - } & \text { Hispanic } \\
\text { - White }\end{array}$ & $\begin{array}{l}0.5 \\
2.9 \\
1.0 \\
7.8 \\
87.8\end{array}$ & $\begin{array}{l}0.4 \\
2.9 \\
1.7 \\
5.9 \\
89.1\end{array}$ & $\begin{array}{l}1.0 \\
4.8 \\
2.4 \\
4.3 \\
87.5\end{array}$ & $\begin{array}{l}1.3 \\
5.7 \\
2.5 \\
1.3 \\
89.3\end{array}$ \\
\hline
\end{tabular}

From Mathematics Teacher Questionnaire. Oregon Department of Education (2002), and National Center for Education Statistics (2002).

- The teachers all use the Visual Mathematics/Math Alive! Curriculum even though this differs from their district-adopted curriculum.

** Socioeconomic Status (SES) is based on percent of students on free-and-reduced lunch, student mobility, student attendance, and level of education of the most educated parent. For eighth grade the scale is from one to 412 , with schools considered similar at $+i-25$. 
Additionally, the prompted-response interview gave the interviewer an opportunity to learn about each teacher's content knowledge, more than what can be learned through simply gathering information about the teachers' certification, mathematical background, and professional development experiences. The interviewer asked the teachers to talk aloud about their solution strategies and thinking about several math tasks from the set of tasks in Appendix F. Teachers were asked to solve only those that they said they would pose to their students. The observations from listening and asking questions about their thinking throughout the problem solving process are summarized in Table 12. All of the teachers describe visual solution strategies as they describe solving the problems. Danielle, Michelle, and Quenton suggest a visual approach as a first approach, while Darrin offers a visual approach upon further prompting. Quenton describes the models his students would use to solve the problems tying models and tasks to particular lessons from the curriculum. Michelle moves flexibly from one solution strategy to the next, without being prompted to do so. She was curious about finding other methods and considering what various students might do with the problem. Danielle, while she could come up with more than one approach, not only had to be prompted to do so, but on more than one occasion she struggled to do so. This struggle did yield AHA!s as well. For both problems, Darrin first describes, a numeric/algebraic approach to solving the problems; he turns to a visual approach only when asked what he thought his students might do. Developing the visual methods took him some time, but he was able to generate several methods once he began. Both Quenton and Michelle were 
comfortable with the problems and multiple approaches to solving them. Darrin, while comfortable with the content of the problems, struggled somewhat to consider approaches beyond his initial thinking. Danielle seemed to struggle more than the other teachers with the content of the problems, particularly Task A which addressed fraction multiplication with a model.

Table 12

Observations About Solution Strategies

\begin{tabular}{|c|c|c|c|}
\hline Darrin Akers & Danielle Miller & Michelle Daniels & Quenton Forrest \\
\hline $\begin{array}{l}\text { Task M } \\
\text { - Solved problem } \\
\text { using algebra } \\
\text { - Solved with diagram } \\
\text { after further } \\
\text { questioning about } \\
\text { methods students } \\
\text { might use } \\
\text { Task H } \\
\text { - Solved by extending } \\
\text { numeric pattern } \\
\text { - Solved with visual } \\
\text { after questioning } \\
\text { about how it may } \\
\text { help or could be used } \\
\text { - Once exploring with } \\
\text { visual model, was } \\
\text { able to see more than } \\
\text { one approach }\end{array}$ & $\begin{array}{l}\text { Task S } \\
\text { - Uses a visual model } \\
\text { and explains what she } \\
\text { has seen students do } \\
\text { - Solved with multiple } \\
\text { methods after further } \\
\text { questioning } \\
\text { Task J } \\
\text { - Had an AHA! with this } \\
\text { problem, could now } \\
\text { "see" why the mental } \\
\text { math strategy/ } \\
\text { distributive property } \\
\text { works } \\
\text { Task A } \\
\text { - At first, saw a } \\
\text { comection to } \\
\text { proportional growth but } \\
\text { then had difficulty } \\
\text { articulating what she } \\
\text { was seeing } \\
\text { - Kept switching back- } \\
\text { and-forth between a } \\
\text { ratio and a part-to- } \\
\text { whole model for } \\
\text { fractions, could not use } \\
\text { either one consistently }\end{array}$ & $\begin{array}{l}\text { Task B } \\
\text { - Solved using a visual } \\
\text { first, naturally moves } \\
\text { to a second approach } \\
\text { - Very flexible in her } \\
\text { thinking about this } \\
\text { problem, uses } 4 \\
\text { different approaches } \\
\text { Task M } \\
\text { - Thought, at first, that } \\
\text { students would need to } \\
\text { use the distance } \\
\text { formula to solve then } \\
\text { decided not and that it } \\
\text { was not too hard a } \\
\text { problem, perhaps she } \\
\text { would change the } \\
\text { numbers to harder } \\
\text { numbers } \\
\text { - Thought that students } \\
\text { would solve by } \\
\text { drawing a picture or } \\
\text { working backwards }\end{array}$ & $\begin{array}{l}\text { Tasks A. E. O. F. D. I } \\
\text { and J... N. R. T... M, } \\
\text { - Did not ever talk about } \\
\text { how be'd solve the } \\
\text { problems instead. kept } \\
\text { tying the problems to } \\
\text { specific lessons in the } \\
\text { curniculum where be } \\
\text { thought he might use } \\
\text { the problems to see } \\
\text { what strategies his } \\
\text { students might use. } \\
\text { Would pose the } \\
\text { problems after doing } \\
\text { the unit and looking at } \\
\text { the model and watch } \\
\text { to see if students apply } \\
\text { the models explored in } \\
\text { the lessons } \\
\text { Did not feel that any } \\
\text { of the problems would } \\
\text { be too difficult for his } \\
\text { students }\end{array}$ \\
\hline
\end{tabular}

From Prompted-Response Interview. 


\section{Darrin Akers (DA)}

Darrin was a first-year teacher when this study was conducted. He was teaching math to three groups of heterogeneously grouped eighth graders. All of his classes, entitled Algebra, met for $\mathbf{8 0}$ minutes a day, five days a week. His observed class was third period. The instructional materials utilized with this group were Math Alive!: Course III [formerly Visual Mathematics] (Foreman \& Bennett, 1998). Darrin structured his classroom in groups of three or four desks in rows, facing the front of the room. Even though this was Darrin's first year teaching, he became familiar with and used these instructional materials during his full time student teaching placement in the year before this study.

Darrin has experienced between 20 and 39 hours of formal professional development in the last two years with only $1 \%$ to $9 \%$ of the support occurring within his district. His additional hours were during graduate school. Most of his professional development was informal as he received assistance from a "lead teacher" in his school and assistance from a staff person in his district. To a great extent, he feels supported as he implements his new learning in the classroom. Darrin has found that his professional development experiences have increased his math content and pedagogical knowledge. Impacted by his professional development experiences, but less so, was his understanding of educational reform, ability to implement instructional materials, and understanding of how students think about/learn mathematics (teacher questionnaire). 
Summarized in Table 13 are the factors Darrin has found influencing his

effective instruction. With Darrin's current teaching situation he has support from his state and district curriculum frameworks, through the importance that his school placed on mathematics instruction, and with the availability of high quality instructional materials and manipulatives. He also has time to work with colleagues as well as to plan and prepare lessons. From his perspective, inhibiting his instruction are public attitudes toward reform.

\section{Table 13}

Factors Influencing Effective Instruction According to Darrin Akers

\begin{tabular}{ll}
\hline Type of Influence & Factors \\
\hline Encourages & - State and/or district curriculum frameworks \\
& - Quality of available instructional materials \\
& - Access to calculators for mathematics instruction \\
& - Instructional materials at the district or school level \\
& - Time available for teachers to plan and prepare lessons \\
& - Time available for teachers to work with other teachers \\
& - Time available for professional development \\
Neutral or Mixed & - Consistency of mathematics reform efforts with other educational reforms \\
& - State and/or district testing policies and practices \\
Inhibits & - Access to computers for mathematics instruction \\
\hline
\end{tabular}

From Mathematics Teacher Questionnaire.

A critical moment influencing his thinking and teaching was his student teaching experience. Darrin commented about his cooperating teacher "he was an incredible influence just to watch everyday... he's so good at getting thinking out of 
kids... really making kids do all the legwork by asking really good questions" (initial interview, $2 / 13 / 01$, section 7). Darrin found that it was helpful seeing this practice modeled and watching how students responded. He also stated that critical to his developing practice was using the Visual Mathematics curriculum. "[Visual Math] makes it easier to really push for thinking," (initial interview, 2/13/01, section 7 ) and "it makes [teaching] a lot more interesting if I can find out what [students] are thinking" (initial interview, 2/13/01, section 11).

Darrin has experienced learning formats similar to his student teaching experience in his professional development experiences. Darrin was asked to engage in problems, discover concepts/algorithms, and explain his reasoning to others. As he describes his teacher development experiences in mathematics he states:

The first day [our professor] gave us all these number systems and we had to crack the code. And it was just so much fun trying to crack the code and figure it out. It was such a great way to introduce you to these other styles. I just enjoyed it so much, it brought out the best of what math can be. (initial interview, 2/13/01, section 200)

From this statement it is clear that Darrin really enjoys learning math through an inquiry approach. This may influence the types of experiences he provides for his students. The relationship between Darrin's beliefs and practice are explored in upcoming sections.

\section{Danielle Miller (DM)}

Danielle had been teaching for 8 years when this study was conducted. She was teaching math to five groups of homogeneously grouped $8^{\text {th }}$ graders. Her students 
were tracked to create one section of Algebra with her four other sections considered Pre-Algebra. Her classes met for 45 minutes a day, five days a week. Her observed class was her third period class, Pre-Algebra. The instructional materials utilized with this group were Visual Mathematics: Course Il (Foreman \& Bennett, 1996). Danielle structured her classroom so that the desks were in clusters of four. This was Danielle's first year to use these materials as her primary teaching resource; she had dabbled with their use for 3 years before this study, using it to supplement her districtadopted textbook.

Danielle has experienced more than 80 hours of formal professional development in the last two years with $20 \%$ to $39 \%$ of the support occurring within her district. She is involved to a great extent in planning her professional development and has received support as she implements what she has learned. Danielle's professional development experiences have increased her math content knowledge, understanding of how students think about/learn mathematics, ability to implement instructional materials, and ability to develop students' problem solving abilities. Impacted by her professional development experiences, but less so, was her pedagogical knowledge and understanding of educational reform (teacher questionnaire).

Summarized in Table 14 are the factors Danielle has found influencing her effective instruction. Similar to Darrin, in Danielle's current teaching situation, she perceives support from her state and district curriculum frameworks, through the importance placed on mathematics instruction, and with the availability of high quality 
instructional materials and manipulatives. Unlike Darrin, from her perspective, she does not have opportunities to work with colleagues nor does she perceive that she has enough time to plan and prepare lessons. In fact, this lack of time inhibits her instruction, as do public attitudes toward reform.

Table 14

Factors Influencing Effective Instruction According to Danielle Miller

\begin{tabular}{ll}
\hline Type of Influence & Factors \\
\hline Encourages & - State and/or district curriculum frameworks \\
& - Quality of available instructional materials \\
& - Access to calculators for mathematics instruction \\
& - Access to computers for mathematics instruction \\
& - Instructional materials at the district or school level \\
Neutral or Mixed & - Impontance that the school places on mathematics \\
& - State and/or district testing policies and practices \\
Inhibits & - Time available for professional development \\
& - Tublic attitudes toward educational reform \\
& - Time available for teachers to work with other teachers \\
\hline
\end{tabular}

From Mathematics Teacher Questionnaire.

For Danielle, the critical moment impacting her thinking and teaching was when she participated in her Mathematics for Elementary Teachers courses at the local university. It was in that course that she realized that she really did not understand the math that she had always been able to do. She commented, "I got pretty angry that I didn't really understand" (initial interview, 1/9/01, section 168). She states that what made the experience so powerful was "the hands-on developing. It was at that point 
where I gave up something that I've seen forever and have used for a long time, to be able to figure out how those formulas were actually developed" (initial interview, 1/9/01, section 176). Also influencing Danielle's thinking and teaching was "working with really strong people... watching their excitement, feeling uncomfortable working in a standardized classroom. By standardized, I mean the way I was taught, you know that memorization method" (initial interview, 1/9/01, section 7).

\section{Michelle Daniels (MD)}

Michelle had been teaching for 26 years when this study was conducted. She was teaching math and science to three groups of homogeneously grouped eighth graders. Her eighth graders were grouped to create three levels: Algebra, Pre-Algebra, and Math 100. Michelle taught one group of each level. Her classes met for 80 minutes a day, five days a week altemating content focus daily between math and science. Her observed class was her first period class, which took part in school-wide Silent Sustained Reading (SSR) for the first 20 minutes of the day, increasing their time with her to 100 minutes. The instructional materials utilized with this group for math were Visual Mathematics: Course II (Foreman \& Bennett, 1996). Michelle structured her classroom so that the desks were in clusters of four. This was Michelle's first year to use these materials as her primary teaching resource, she had dabbled with their use for about eight years and increased use to about $60 \%$ in the year prior to this study. 
Michelle has experienced more than 80 hours of formal professional development in the last two years with $100 \%$ of the support occurring within her district. Like Danielle, she is involved to a great extent in planning her professional development and receives support as she implements what she has learned. Michelle's professional development experiences have increased her math content knowledge and understanding of educational reform. Impacted by her professional development experiences, but less so, was her pedagogical knowledge, understanding of how students think about/learn mathematics, ability to implement instructional materials, and ability to develop students' problem solving abilities (teacher questionnaire).

Summarized in Table 15 are the factors Michelle has found influencing her effective instruction. Similar to Darrin and Danielle, in Michelle's current teaching situation she perceives support from her state and district curriculum frameworks, through the importance placed on mathematics instruction. Unlike the others, she perceives support for effective instruction through the state and/or district testing policies and feels that the availability of high quality instructional materials and public attitudes toward reform is less important in encouraging effective instruction. Inhibiting her instruction is a lack of computer access and lack of time to work with colleagues. 
Table 15

Factors Influencing Effective Instruction

According to Michelle Daniels

\begin{tabular}{|c|c|}
\hline Type of Influence & Factors \\
\hline Encourages & $\begin{array}{l}\text { - State and/or district curriculum frameworks } \\
\text { - State and/or district testing policies and practices } \\
\text { - Funds for purchasing math materials and mamipulatives } \\
\text { - Instructional materials at the district or school level } \\
\text { - Imponance that the school places on mathematics }\end{array}$ \\
\hline Neutral or Mixed & $\begin{array}{l}\text { - Quality of available instructional materials } \\
\text { - Access to calculators for mathematics instruction } \\
\text { - Time available for teachers to plan and prepare lessons } \\
\text { - Time available for professional development } \\
\text { - Consistency of mathematics reform efforts with other educational reforms } \\
\text { - Public attitudes toward educational reform }\end{array}$ \\
\hline Inhibits & $\begin{array}{l}\text { - Access to computers for mathematics instruction } \\
\text { - Time available for teachers to work with other teachers }\end{array}$ \\
\hline
\end{tabular}

From Mathematics Teacher Questionnaire.

A critical moment impacting Michelle's thinking and teaching was when she and a colleague attended their very first Visual Math class. The course helped her see a remedy to the boredom she was feeling with what they were doing in math class. "We were doing the same old thing and the kids just mimic what you do and we didn't feel like we were helping them understand it. We were just pencil pushing" (initial interview, 2/26/01, section 7). What made the experience powerful was the fact that "it put meaning behind what you were teaching and meaning behind what the kids were learning and a way of understanding rather than thinking this is something that is just done" (initial interview, 1/9/01, section 285). Also influencing Michelle's thinking and teaching was being part of her district's Math Leadership Team. This team formed a study group that met periodically throughout the year to discuss the 
NCTM Principles and Standards (2000). She comments that this is different for her because

In the past we always got a list of teach this, this, this, and this... or a list of what the students will be able to do by the end of eighth grade... but NCTM emphasizes pedagogy more than just content strands which of course is what we are doing in the Visual Math... IIf other teachers would] read the NCTM Standards it would validate what they need to do to change their teaching. (initial interview, 1/9/01, section 257)

\section{Quenton Forrest (OF)}

Quenton had been teaching for 22 years when this study was conducted. He was teaching math to heterogeneously grouped fifth through eighth graders in a Math/Science magnet school. He taught all the math classes, with one section of homogeneously grouped students at each grade level, and one technology class. Students enter this magnet school through an application and interview process. Even though the school is open to all students the applicants tend to be those students seeking a rigorous academic program and are often identified as Talented and Gifted ( $80 \%)$. His classes met for 60 minutes a day, five days a week. His observed class was his third period class. The observed class was his seventh grade class, chosen because the mathematical experiences of this group most closely represent his vision for what is possible with the math program at this school. The instructional materials utilized with this group were Math Alive!: Course III (Foreman \& Bennett, 1998). Quenton structured his classroom so that the desks were in clusters of four or five. 
Quenton had been using Math Learning Center materials as his primary teaching resource for more than ten years".

Quenton has experienced more than $\mathbf{8 0}$ hours of formal professional development in the last two years with $10 \%$ to $19 \%$ occurring within his district. He is not involved in planning his professional development, nor does he have opportunities to work with other teachers. This is related to the fact that he is the only middle school math teacher in his building. He also feels as though he receives support as he implements what he has leamed through his professional development experiences. Quenton's district-provided professional development experiences have not impacted his knowledge, his understanding, or his abilities (teacher questionnaire). He describes these experiences as a chance to "see [his] old math buddies;" he does not perceive that he was there as a colleague (initial interview).

Summarized in Table 16 are the factors Quenton has found influencing his effective instruction. Unlike the others, his perceptions toward the state and/or district curriculum frameworks and testing policies are neutral or mixed. From his perspective, encouraging his effective instruction are high quality materials, availability of manipulatives, and the importance placed on mathematics instruction. Inhibiting his instruction is a lack of computer access and lack of time: to plan, to prepare, to work with others, and to engage in professional development.

\footnotetext{
4 In addition to using the Math Learning Center materials with his students in the classroom. Quenton also provides professional development centered on the use of the materials to inservice teachers nationally.
} 
Table 16

Factors Influencing Effective Instruction According to Quenton Forrest

\begin{tabular}{|c|c|}
\hline Type of Influence & Factors \\
\hline Encournges & $\begin{array}{l}\text { - Quality of available instructional materials } \\
\text { - Access to calculators for mathematics instruction } \\
\text { - Funds for purchasing math materials and manipulatives } \\
\text { - Instructional materials at the district or school level } \\
\text { - Importance that the school places on mathematics } \\
\text { - Consistency of mathematics reform efforts with other educational reforms }\end{array}$ \\
\hline Neutral or Mixed & $\begin{array}{l}\text { - State and/or district curriculum frameworks } \\
\text { - State and/or district testing policies and practices } \\
\text { - Public attitudes toward educational reform }\end{array}$ \\
\hline Inhibits & $\begin{array}{l}\text { - Access to computers for mathematics instruction } \\
\text { - Time available for teachers to plan and prepare lessons } \\
\text { - Time available for teachers to work with other teachers } \\
\text { - Time available for professional development }\end{array}$ \\
\hline
\end{tabular}

From Mathematics Teacher Questionnaire

For Quenton, a critical moment impacting his thinking and teaching was when he met Linda Foreman, author of Visual Mathematics. He was a Title I teacher and knew that his students were smart enough to do math. He was finding that he would work with them for a while and they were successful so they would return to their regular classroom, but within a couple of quarters or a year they would return to his room. "Whatever was happening in our room was not transferring to the regular classroom... I began to realize that it wasn't [as] important what we were doing as what was going on in their regular classroom" (initial interview, 2/23/01, section 7). Quenton recognized a need for a change. Linda was presenting an activity on pattem block trains and one on averaging at a regional math conference, he comments that he 
thought what she was doing was "cool" and that he immediately knew that these

lessons represented what he wanted to do with students (initial interview, 2/23/01).

Quenton feels that the experience with meeting Linda Foreman was

particularly powerful for him because

I understood enough mathematics to see the value in what in what she was doing, especially with the pattern block trains thing and the algebra connection to it. I could just see right there an activity that every kid could do. No matter who they were they could do that activity. They could really get some solid mathematics out of it. I had never experienced anything like that; I mean I got my degree in engineering without really understanding any math. So it was kind of a revelation for me that it could be fun and colorful and kind of interesting and still get to the same place... I was really tired of what I was doing. I was tired of the revolving door between Title I and the regular classroom and every year, the same kids in and out. So it was just like... an epiphany. It was just like I went "wow this is cool." Then, I of course started the middle school [math endorsement program] right away and just really liked what I was doing there and was excited to use it with kids. (initial interview, 2/23/01, section 218)

\section{Engaging Students in Mathematical Problem Solving}

For these teachers, engaging students in problem solving is not asking them to solve a routine problem and write-up their response in a template that asks them to restate the problem, solve the problem, check your work, and explain your process, a common heuristic. Instead, these teachers see engaging students in problem solving as both the how and the why students learn math. These teachers pose problems with the intent of helping students leam something new. This view of problem solving permeates the curriculum used by these teachers (Foreman \& Bennett, 1996, 1998) and influences the classroom culture and the teachers' decisions and actions. This 
section includes a description of how these teachers view their role in the classroom and how they view the role of their students. The discussion includes both the stated and the observed roles. Finally, there is a discussion of the interrelationships among the teachers, students, and the content, in this case, mathematical problem solving.

\section{Role of the Teacher}

There are three parts to this section examining the role of the teacher. It begins with a description of these teachers' mindsets about problem solving and problem solving instruction including: the role of problem solving in their curriculum, their goals in teaching problem solving, and their decision-making with regard to problem solving instruction. Next it illustrates the classroom actions that are typical in these exemplary teachers' classrooms. It is concluded by a discussion of the interrelationships between these teachers' beliefs and actions.

\section{Mindset about Problem Solving and Problem Solving Instruction. For these} teachers, problem solving is both the how and the why behind their teaching; problem solving therefore plays a significant role in these teachers' curriculum and impacts the decisions these teachers make. This section explores how these teachers see the role of problem solving in their curriculum and their goals in teaching problem solving. It continues by considering the bases upon which these teachers make decisions about the problems they pose, what they emphasize, and both how and when they teach problem solving. 
Role of Problem Solving in the Curriculum. When considering the role of

problem solving, it was helpful to begin with finding out about how these teachers

think about problem solving. They were asked, "what does mathematical thinking and

problem solving mean to you?" These were their responses:

I sort of think of them together. They are almost synonymous. All of math is problem solving... you are always solving problems... If you are in class and you are doing the next step it doesn't always seem to be doing problem solving. It's just math, but math is always problem solving. Just giving them different problems and seeing if they can get the answer and how they go about it. How is that different or the same as mathematical thinking? I guess I would think that mathematical thinking is a little bit more broad. To be a good mathematical thinker you need to be able to problem solve but you also need to understand your algebraic thought, you need to understand how to do computation, you need to understand abstraction, understand your formulas. (Darrin, initial interview, 2/13/01, section 152-160)

That is such a huge... I look at problem solving as the whole basis for mathematics. To me it is the life-long skill that you've got to learn. Problem solving says that I have this situation that I need to analyze and I have to be comfortable with my results. I have to feel in my gut that it is right. The mathematics comes in because we need that concrete proof that what you have done is correct. That you can present your ideas to somebody else and it will be accepted and believed. The problem solving really starts to occur when the student starts to make observations about the problem and develop linear logical thought about the problem of what the problem is doing...From there they can make generalizations from there they can make predictions and then prove mathematically that those predictions will come true. You have to be able to look at a situation and develop a thought pattern. That is not going to happen the first time. (Danielle, initial interview, 1/9/01, section 8492)

[M]athematical thinking would be how are you thinking about the problem, how are you arriving at your ideas about math. Problem solving to me is probably more focused on a particular problem and the different techniques they use to solve them. [T] me mathematical thinking is every little bit along the way. Their sharing their ideas and trying to verbalize how they are figuring something out, how they are 
thinking about it. Problem solving I think is more specific to a problem. (Michelle, initial interview, 2/26/01, section 134)

Quenton offers an example (Figure 8) of mathematical thinking and problem solving.

Math looks very different than it did when I was in school. I want kids to have a chance to look at what each other is doing and see the multiple approaches. Instead of just looking at methods that are correct. So kids learn from mistakes that they see or errors that people make... lots of ways to solve a problem. I saw [an example of] that today. Actually it was really kind of interesting when the kids did that thing where they have to invent ways of approximating the area of a circle. There's the problem with the pizza crusts where they have the wrong pizza and what should they charge for a square pizza. She used that model to figure out the problem instead of $\pi r^{2}$ and all that, she just divided the pizza up and said that each of those little wedges was a certain amount and decided that the square would have 8 more of those than the circle did.

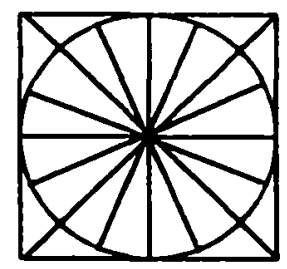

...she is saying that the little piece on the outside of the circle is the same approximate size as the ones inside the circle. Actually they are a little bigger. That's the first time anyone has used that method of approximating and this is the first class that I have ever had that has used their approximating methods in problem solving. The other kids have always just gone $\pi^{2}$ once they've seen the formula... (initial interview, 2/23/01, section 118-140)

Figure 8. Mathematical thinking and problem solving.

The definitions offered by these teachers and Quenton's example suggest that these teachers have somewhat different views about what constitutes problem solving 
and the nature of problem solving. These teachers do not consider problem solving as an application following new learning; they instead see problem solving as a means for new learning. As is shown in Quenton's example, they use real world problems as opportunities for application of new learning that took place in prior problem solving opportunities. Darrin suggests that giving students different problems and seeing what they do with them is problem solving. His comments also suggest that he is considering whether or not the problem is really a problem for the students. Danielle views problem solving as a process, beginning with observations and ending with a convincing argument to support your thinking. Michelle feels that problem solving is focused on a particular problem and techniques one might use to solve it. Quenton offers, through example, those aspects that he believes are most important in problem solving like collaborating with others, seeing multiple approaches, learning from mistakes, and inventing your own methods. Darrin, Danielle, and Quenton describe problem solving as a process, while Michelle holds a strategic view of problem solving. The relationships between these views of problem solving and the resulting classroom practice are considered in upcoming sections.

As previously mentioned, all of these teachers use the Visual Mathematics $(1996,1998)$ curriculum. Learning with this curriculum involves interaction with models and manipulatives, peers, and the teacher, all to help students make sense of mathematical ideas and procedures. When these teachers were asked about the role that problem solving takes in their curriculum, Darrin suggests that problem solving is how the students learn mathematics in the Visual Mathematics program. 
I think a very big role. Visual Math is set up in a way that it is a lot of problem solving. Instead of telling them how to do the problem and having them do it over and over again, it's more presenting them with a problem and seeing if they can solve it. Also, I start every day with some sort of starter. Mondays are extensions where I gave them this logic problem (The Gossips). I've just started giving them some really different things like logic problems. Tuesdays and Thursdays, I just give them a problem and it can be pretty traditional or not. It's something where they all work on it so it might be like, "here is a trapezoid, find the area." Or it can be more similar to this, where today it was "balls in boxes and they had to figure out how many were in each one." So I really like that, total problem solving, and it's out of context. So it's like okay, last time we covered this area of a trapezoid we did it right in order, now I want to see if you can get back to it. (Darrin, initial interview, 2/13/01, section 164)

He also describes how he begins class with a problem solving opportunity unrelated to the current math topic; he instead may pose a logic problem or a problem that expects the students to draw upon prior leaming in order to solve. Similarly, Danielle comments that students do not have to be exploring a task to engaged in problem solving. They problem solve anytime they are making observations, conjectures, and generalizations.

I think it takes a really high role in my curriculum. I think even if we are not looking at what a student would understand as a task with the students I'm asking. "Can you make a conjecture? What are your observations? Can you summarize what you've done? Can you make a general statement?" I'm just thinking today in class, we were looking at vertical angles. We started with a straight angle. From there I drew several vertical angles on the board and stepped back. "What do you see? Can you make some observations? I wonder if anyone can make a conjecture about that vertical angle?" You know that kind of thing. I feel that I introduce that all the time in the classroom. (Danielle, initial interview, 1/9/01, section 96)

Danielle suggests that problem solving is more than completing a particular task; it is pondering and answering the questions that she poses about any mathematical 
situation. The example questions that Danielle offers pick up on the various steps of the problem solving process she described previously. While Michelle concurs that students are constantly engaged in problem solving, her description of problem solving behaviors is strongly linked to the problem solving scoring guide.

We are really doing all the parts of problem solving on a daily basis. Students are communicating their conceptual understanding, they are learning procedures, and they are doing verification through all the different ways of thinking about the problem. (Michelle, initial interview, $2 / 26 / 01$, section 154 )

Michelle's description of problem solving suggests that her view of problem solving is perhaps more tightly linked to the expectations on the state scoring guide than the views held by the other teachers. This may suggest that Michelle holds lower cognitive demands for students. If she is expecting students to perform "at standard" or with the score of four on the scoring guide, this work is termed "adequate;" while Darrin and Danielle use words such as conjecture and generalization to describe what students do on a daily basis. These actions or level of work would be "enhanced" and "complex" and would receive the score of 6 on the scoring guide.

Similar to Darrin, Quenton articulates that problem solving is the means by which the students come to learn mathematics in the curriculum. He states that even when his class explores concepts for the first time there is something that students need to find out or some connection they need to make. He sees it as the whole point of mathematics (initial interview, 2/23/01, section 154 ).

All of the teachers suggest that through use of the Visual Math curriculum, students are engaged in problem solving on a daily basis. While not all the teachers 
articulate that problem solving is the means by which students learn math in their classrooms, the teachers' statements suggest that problem solving is a significant component of classroom instruction.

Goals in Teaching Problem Solving. As described in the previous section, these teachers regularly pose problems for the students to solve. In doing so, they trust students to develop and/or apply their understanding. While students are engaged in problem solving, these teachers want students to exhibit specific characteristics.

These include:

- confidence/eagemess in approaching a problem,

- metacognition skills,

- oral and written communication skills, and

- multiple solution strategies.

Two of these teachers also describe how they seek to develop flexible and fluent understanding of concepts through engaging in problem solving.

The following excerpt from Danielle shows that she is looking to enhance confidence, encourage metacognition, and develop communication skills in her students.

For my eighth graders, my goal is that when a child is faced with a problem, they know where to start. And they also know that when they start at a particular point, "can I recognize when I get lost?" They ask, "do I need to start again? If I start again and I try the same thing three times who can I ask? Which again is part of problem solving. I'm not getting anywhere with this. I know it is not right, I keep running in to this wall. Who can I ask? What can I do? What are my other resources?" One of the things I work for is for the student to be able to explain what they have done. I really do want them to be able 
to develop their communication skills. It is an area where they are really lacking. (Danielle, 1/9/01, initial interview, section 132-139)

Both Danielle and Michelle discuss wanting to develop their students' communication skills, however Michelle's comments seem to again be linked specifically to performance using the state scoring guide. Michelle describes how she also works to develop students' skills with specific problem solving strategies.

I want to make sure that the kids are clear in communicating their verification. Often times their verification is mixed in with communication. I want to know what they can verbally tell me and what can they put on paper as their communication. Another thing is just working on the different strategies and saying that there are multiple ways to solve the problems and that they don't have to do it one way. It is okay to do it and think about it differently. Maybe you can even use two different ways to solve the problem. As we are going along in the Visual Math sometimes when we are looking at patterns I try to get them to organize it by putting it into a table, or to draw diagrams, you know use the equations to solve the problems. I also use the Lane County stuff to help them understand what all the different problem solving strategies they have to choose from. We also have the Problem Solver books, I use problems out of there too. (Michelle, initial interview, 2/26/01, section 158-162)

Quenton's goals in teaching problem solving focus on understanding the

content. He describes his desire for students to adapt and use their knowledge;

applying their knowledge through exploration to situations that are unfamiliar.

I want kids to be able to use their knowledge flexibly and to approach problems they don't know how to do. Like uh, my kids that are in the seventh grade, we're working on course 3 , this is an example of some of the problems that I use now that they've done that focus 3.3 stuff. I have a bunch of circle geometry problems from the secondary Oregon Mathematics Teacher and from the NCTM journal. Like some of these are just regular..., like the Kris and Bjorn thing [characters in the problem box problems in The Oregon Math Teacher journal] is just circumference and distance and stuff. But some of them, like the area of a lune on the back of that page and the on the front of the other one 
are problems like these that really are not part of the content of the lesson but can be solved using what the kids know. They have enough geometry to solve them all. Those are really good, this one [area of the lune] especially, it looks complicated but you can solve it using Pythagorean Theorem and circle geometry. You don't have to know anything special you have to really explore it and look at it and try some things out and draw, put the missing parts in. Once you put the missing parts in it all falls into place. (Quenton, initial interview, 2/23/01, section 158)

Similarly, Danielle talks about her desire for students to leam more than the rules; when she poses the problems to students, she wants students to show evidence of understanding the content. In this case, she wants to see that they understand both the meaning of the operations and the impact of the signs in the problem on the sign of the solution.

What I'm really asking kids to do is asking them to understand conceptually what occurs when we are looking at positive and negative integers so they will have a stronger understanding and not just "know the rules." They'll have some foundation behind the actions of the operations. (Danielle, pre-observation interview, 4/10/01, section 39)

A related conflict that Darrin faces when developing understanding in the problem solving context is with his students' reactions to completing the tasks with speed versus understanding. His students want to just do mathematics and not take time to understand.

I feel the battle often times between them wanting to see it and understand it but also wanting to do it as quickly as possible. If they can just do it quickly, they just want to get it out there and get it done which I totally understand. That's sort of how I do stuff but it's a hard issue. If you don't have them get down to the real fundamentals of this, it's going to be harder when you get up to a chapter like this. On the other hand, Visual Math has such a push on doing things in different ways, if their way works, I want to support that as well. So, what I really focused on in the other chapter was making sure they 
could see the sequences and so that they could find sequences, see them, graph them and then really focused on balancing equations in which ever way they could. Just as long as they could do it, I just wanted them to be able to do it. (Darrin, pre-observation interview, 4/13/01, section 27)

There are two types of goals that that these teachers have for the students relative to problem solving. These goals relate to both process and content. The process goals these teachers define are closely related to the four characteristics of successful problem solvers offered by House, Wallace, and Johnson (1983). House, et. al. describe the desire, enthusiasm, facility and ability (see Chapter 2 for further discussion) which link to confidence and eagerness in approaching a problem, willingness to explore multiple strategies, and the self-monitoring and regulation skills suggested as important to these teachers. Students in these classrooms are immersed in a problem solving environment where they learn math through engaging in problem solving; a portion of their skill develops through what Kilpatrick (1985) describes as osmosis, while imitation, cooperation, and reflection are also apparent.

Choosing Problems. During the initial interview these teachers were asked to select a problem that they had given to their students that they feel is a "good problem." They shared the problem and discussed what makes the problem a good one. These comments suggest something about the criteria these teachers use when choosing problems. Common criteria included the problem having a variety of ways to solve and asking students to provide their reasoning and/or proof. 
Darrin discussed a problem he had used as a warm-up earlier in the week called "The Gossips." This problem is one that Darrin found to have multiple solution strategies.

Each evening in a certain village, the elders gather in pairs to exchange gossip about the village activities. At each exchange, each man passes off all that he has learned about the day's events. What is the fewest number of exchanges needed so that everybody is up to date?

When he posed the problem to his first two classes, he posed questions like "so what if there is five? Let's say there is ten? Let's say there is n." When he later posed the problem to his third period class, he covered up the question and asked the students, "what do you guys think?" One student said, "what if there is $n$ ?" Darrin appreciated that his students could take an open-ended situation and move toward a generalization without his asking them to do so. He went on to describe several methods the students used to solve the problem illustrating the variety of possible strategies for solving the problem. From this we see that, even though the students were not asked to provide their reasoning, proof, or generalization, they were naturally doing so when the situation was posed.

Danielle brought an algebra problem to the discussion. The problem is shown in Figure 9 below. She likes this problem because it looks at both linear growth and area growth. The students are asked to begin with observations, then represent the relationship in multiple forms, and finally moving them to making generalizations. This problem is well aligned with her goals in teaching problem solving. She also 
feels this task is well aligned with the state standards and serves her well as a final assessment for her work with algebra.

Tat Ming is designing square swimming pools. Each pool has a square center that is the area of the water. Tat Ming uses black tiles to represent the water. Around each pool there is a border of white tiles. Here are pictures of the three smallest square pools that be can design with black tiles for the interior and white tiles for the border.

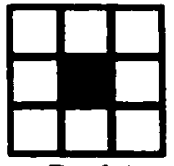

Pool 1

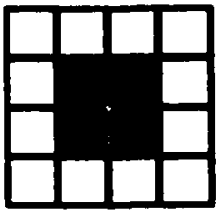

Pool 2

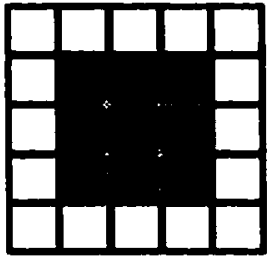

Pool 3

On separate paper:

- Describe what you see in the first three pools.

- Build the next three pools.

- Make a table showing the pool number, the number of black tiles, the number of white tiles, and the total number of tiles (black and white).

- What are the variables in the problem? How are they related? How can you describe this relationship in words?

- On a coortinate plane make three graphs:

a) One that shows the number of black tiles in each square pool.

b) One that shows the number of white tiles in each pool.

c) One that shows the number of all the tiles in each pool.

- As the number of the pool increases, how does the number of white tiles change? How does the number of black tiles change? How does this relationship show up in your table and in your graph?

- Find the number of black, white and total tiles, in the $10^{\text {th }}$ pool, the $25^{\text {th }}$ pool, the $100^{\text {th }}$ pool, and in the $n^{\text {th }}$ pool.

Figure 9. Tat Ming's pool. (Danielle's "good problem" from her initial interview.)

Michelle brought the Square Units problem shown in Figure 10. She likes it because students are given a limited amount of information and from that they have to figure out the dimensions and area of each square. She also comments that students often jump to the assumption that the figure is a square. Michelle tries to get students 
to use if-then statements in communicating their thinking about the problem. While she feels that there is really only one way to solve the problem, differing from the criteria she values, she likes that students can communicate their thinking in different ways. They could communicate in words or with math equations, giving her an opportunity to "teach different things."

The following diagram shows an arrangement of squares that appeared on the cover of the November issue of Scientific American. If the area of square $C$ is 64 square units and area of D is 81 square units, what are the areas of the other seven squares? List the dimensions and area of each interior square and the outside figure.

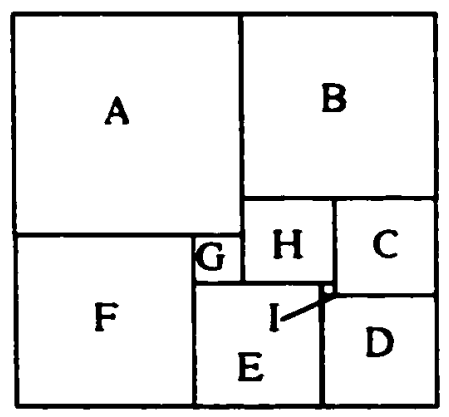

Figure 10. Square units. (Michelle's"good problem" from her initial interview.)

Quenton discussed a problem he had recently assigned for homework, related to a lesson they completed on transformational geometry. For this problem, students are given a set of conjectures to explore in order to prove whether or not they are true. The conjectures include:

If I draw two intersecting lines and reflect a shape, first over one of the lines and then over the other, I think the end result is the same as the result of a single rotation. The center and the measure of the rotation have a special relationship to the angle of the intersection of the lines. 
I can always locate two parallel lines so that the result of the translation is the same as the result of a reflection first across one of the parallel lines and then across the other.

He likes these problems because they represent a novel task where "students have to use what they have learned about the transformations and they also have to apply it because they never had done anything like that with it" (initial interview, 2/23/01, section 31-35). With this problem students have to explore a variety of different transformations and then determine if these different conjectures are true or not; it is not something they have memorized or completed previously.

During the prompted-response interview the teachers were asked to select from a group of tasks (Appendix F), problems that they might give to students in their classrooms. Following are criteria which are representative of that which these teachers used to make their decisions about problems they would give their students:

- connections to big ideas in the eighth grade (Darrin and Danielle)

- interesting, fun (Michelle and Quenton)

- complex, so students have to think and explore (Quenton)

In each case, the problems chosen were problems that represent "procedures with connections" and "doing mathematics" (Smith \& Stein, 1998).

They also described ways in which they might alter the task if they were to give them to students:

- add an extension, ask about train 10 , train 25 , and train $n$ (all)

- open it up, just give the situation and ask students to pose questions (Darrin and Quenton) 
- I might give them harder numbers (Michelle)

- I might ask if there are other ways to [level off stacks of cubes] (Michelle)

Of the problems these teachers felt they would use with their students, Michelle described using them either in class or as homework. None of the teachers suggested that they might use the tasks to assess problem solving abilities, instead the focus of the problem's use was connected to content understanding. Darrin, Danielle, and Quenton described how they would use the problems to review concepts the students had explored in previous lessons, as opposed to using the problems to teach concepts.

Another component of the prompted-response interview was when the teachers were asked to sort the set of tasks in some way. All of the teachers sorted the tasks both by cognitive demand of the task, or "what the task was like," and by content strand. These sorting methods, along with the comments above, suggest that these teachers are thinking about both the qualities and rigor of the task along with the task's alignment to state content standards. Danielle, Michelle, and Quenton each sorted by cognitive demand first and content strand second. While not conclusive information, the order in which they completed these sorts may suggest that these teachers consider cognitive demand of the task before they consider content alignment.

Quenton's good problem, emphasizing exploration and proof was drawn from the Visual Math curriculum. In the cases of Darrin, Danielle, and Michelle, the problems chosen as good problems were problems external to their curriculum but were aligned to what students are asked to do in Visual Math lessons. In each case, the problems ask students to move beyond finding a solution to developing 
generalizations and proof. Additionally, as teachers choose and/or adapt problems they attend to both the cognitive demand of the task and the content alignment.

These teachers are constantly making decisions that influence their instruction. They make decisions regarding their actions and expected student actions. In setting their goals for problem solving and determining which problems to pose, classroom instruction changes from a traditional "telling" approach to a reformed "investigative" approach. The section that follows explores the bases upon which these exemplary teachers make decisions about their problem solving instruction, considering what they emphasize and both how and when they teach problem solving.

Bases for Decisions about What to Emphasize in Problem Solving Instruction. As previously noted, these teachers view problem solving as the cornerstone of their curriculum. They see it as a life skill, the justification for learning math as well as a means for learning math. How does this relate to what they choose to emphasize in their instruction?

Each teacher describes the importance of developing students' communication skills. So, each teacher drew thinking out of students by asking them to talk out loud about what they were thinking as they solved the problem. Michelle and Quenton specifically asked students to think about ways to communicate their thinking to others. Michelle also described how she works with students to help them develop their communication skills with diagrams and/or mathematical equations.

An area where the teachers differed in their views was related to the teaching of problem solving strategies (e.g., make an organized list, draw a diagram, make a 
simpler problem). Two of the teachers, Darrin and Michelle, discuss methods for developing students' repertoire of problem solving strategies, while Danielle and Quenton explicitly stated that they do not teach problem solving strategies.

I try to model problem solving tactics. For instance, trying to get them to start with an easier problem or draw a picture. Oftentimes, their first instinct is to ask a friend or me. I want them to not only be okay with the struggle, but to enjoy it. (Darrin, initial interview, 2/13/01, section 184)

As we are going along in the Visual Math sometimes when we are looking at patterns I try to get them to organize it by putting it into a table, or to draw diagrams, you know use the equations to solve the problems. I also use the Lane County stuff to help them understand what are all the different problem solving strategies they have to choose from. We also have the Problem Solver books, I use problems out of there too. The Problem Solver is pretty direct and so when we are doing those, like the ones from the Problem Solver, sometimes I give each group a different one to work on. We might focus on a certain strategy for the day or we might have different groups use different strategies. It is pretty much directed what the different strategies are and showing them how to do it and then later, they get practice at different strategies. (Michelle, initial interview, 2/26/01, section 162-166)

Both Michelle and Darrin will, at times, suggest to students strategies they may want to try as they work on the problem. Michelle also directly teaches problem solving strategies and has students practice them. Danielle comments that now that she teaches Visual Math she no longer teaches problem solving; instead, the curriculum teaches it.

The teachers describe strategies they use to get students to explore more than one approach to problems. At times, the teacher presents the expectation in the task set-up and other times the teacher suggests it as an extension and/or as a means for students to verify their work. These exemplary teachers place an emphasis on various 
means of communication and the use of multiple methods for solving problems.

Darrin and Michelle also expose students to the various problem solving strategies by specifically suggesting their use.

Bases for Decisions about How to Teach Problem Solving. Influencing how these teachers teach problem solving is a common belief about how to develop students' problem solving expertise. Generally, they believe that when students are given lots of opportunities to solve problems, they learn to problem solve. In the process of solving problems, these teachers want students to see and accept different approaches to solving problems. They ask students to share their strategies and draw attention to the fact that the same answer can be obtained in more than one way.

While Michelle states that students leam to problem solve through exposure to problems, she also comments that exposure to problems, by itself, is not enough to develop problem solving skills in students. As a result, there are times where she does stop and teach problem solving. She describes how she approaches problem solving instruction early in the year.

We usually start out by doing a problem as a group. Oftentimes we just focus on one dimension, like maybe the communication or maybe the concept. Um. We might start out with just the math concept and the procedure and then add the communication part of it too. We work on the different dimensions, we do it in groups and then we talk about the different strategies that people use and make a poster out of them. We score each other's [work] with the scoring guide. We might do that once or twice and then move to one that they do on their own. And then we just try to give them problems like that to solve as we are going through the term as it fits into whatever curriculum we are doing... Some teachers give a problem solve every week. I don't do that. Not that I shouldn't, I just don't. It's overwhelming to do all the 
paperwork. They need to be practicing more, I think. (Michelle, initial interview, 2/26/01, section 213-217)

The process she describes is focused on helping students understand how to develop a problem to be scored with the state scoring guide. One might be left wondering to what extent students are learning how to problem solve by learning how to develop a response that scores well in each dimension. Instead, it may be that students are learning how to perform well when their work is scored with the state scoring guide. This approach to teaching problem solving may encourage an algorithmic view of problem solving in that the students have a recipe to follow as they approach a problem situation; first they show they understand the concept, then they decide on and use a strategy, and then they communicate what they did to solve the problem.

Even though these teachers share a common curriculum and common beliefs about problem solving, the tasks explored in their classrooms were not always implemented as intended by the curriculum developer, similar to teachers observed by Henningson and Stein (1997). Influencing student learning was not only the task setup (e.g., teacher goals, teacher knowledge about math, teacher knowledge about students), but also task implementation (e.g., classroom norms, task conditions, student/teacher dispositions). Darrin's behavior, in the following example, contradicts his wanting to develop students who are okay with struggling to understand a concept. Darrin explains how he helps students bridge their understanding into a new idea through giving a hint in anticipation of confusion.

My plan is to just pose it. And I'm going to give a hint, think about turning it into a square. But it will be a leap. So it will be interesting. 
At times when I've given situations like this, where it's been really big leaps, it hasn't worked as well as I would like. Because although the top five students get really into the challenge the bottom 10 just assume they can't get it and the middle 10 try and get kind of frustrated. (Darrin, pre-observation interview, 4/13/01, section 43)

I asked if he would give the hint to the whole class or just to those students who are showing signs of frustration. His response:

That's a good idea. Um. I just want to... the advantage to sharing it with the whole class is that everyone gets to hear it, whereas if 1 just go around to individuals I may not get around to every single person. The real go-getters won't want to hear that. They'll want to try to figure it out without my hint. But I think I will give the hint to the entire class. Just so people hear it. It doesn't really give it away. You still have to realize that you are adding something to both sides. And then I think I'll spend some sort of individual time with the other students, trying to get them to do it. But what I can see happening with this unfortunately, is that hopefully a student will get it but it may end up being me showing the first example and showing how it works. Then having them later today, when we get to another equation, practicing it, using that same approach. I'd much rather lead them to the point of discovery but for me, if it is a big enough jump, they might not get it on their own or so few will end up getting it on their own that it ends up being hard. I'm sort of planning on my hint and sort of some individual help. And eventually, after I show it, to really focus in on... I guess I'll ask students to really focus in on why this works. Try to get them to see that it is a square and how that is such a key to the chapter. Try to get them being the ones who are saying it so they can attach some meaning to it. (Darrin, pre-observation interview, $4 / 13 / 01$, section 50 )

Darrin also recognizes the potential conflict between his actions and those that are advocated by the curriculum. He states in his goals that he wants students to be okay with the struggle, the curriculum espouses disequilibrium as a sign of new learning, yet Darrin's actions eliminate any significant struggle.

Visual Math is open to any approach. When I ask questions to respond to students questions they say, "[Mr. Akers] talks in mystery." I worry 
that I'm compromising the curriculum by giving direct hints or showing them once how to do it. (Darrin, post-observation interview, 4/17/01, section 311)

On the one hand, Darrin feels as though the hint he provides does not take away the problematic aspects of the task since there are still "things" the student needs to figure out. Later he worries that his hints and his showing students his method compromises the curriculum and his goals. Are students engaged in problem solving after they receive this jumpstart with a strategy or when later they are applying the method that Darrin shared with them? Perhaps, instead of "doing mathematics" or problem solving, now students are completing a procedure with a connection to a visual model (Henningson \& Stein, 1997). In both this example and Michelle's, one must consider the extent to which students are engaged in problem solving, assuming that problem solving is analyzing a problematic situation, exploring a variety of strategies, and verifying results.

Bases for Decisions about When to Teach Problem Solving. As Michelle shared, some teachers in her building give problems of the week to teach problem solving. They set aside Fridays as problem solving day; a day in which they cease their normal routine and practice for the state assessment. Yet, all of these exemplary teachers say that they are teaching problem solving all the time through using the Visual Math curriculum.

Darrin states "the point of the whole year is to try to increase [the students'] problem solving... to get them better at solving things [that they don't know how to solve]. Probably mostly because of Visual Math I came to see it all as problem 
solving" (follow-up interview, 6/19/01, section 171). Danielle reflects on her new approach to problem solving, "I no longer teach problem solving, the curriculum teaches it... I never really spend a lot of time going through and doing those formula methods of problem solving. It is really coming from the lessons" (follow-up interview, 6/8/01, section). Both Darrin and Michelle feel that students need more problem solving experiences than what they are receiving through the curriculum. While Michelle articulates this feeling, Darrin suggests it through his action of bringing in a problem each day as a warm-up that is out of the context of the lesson.

Pacing Problem Solving Instruction. Throughout the interviews these teachers expressed a common struggle with pacing, their planned timing differing from the actual timing. Each teacher has found that the lessons take longer than they would expect. Even Quenton, with his level of experience, is surprised by the length of time some activities take. Darrin, Danielle, and Michelle comment that once they get to know the materials better they will have a better sense of where they can pick up the pace.

While appropriate pacing is a common struggle, the teachers also comment that the time spent on the lessons is worth it because of the level of the students' understanding.

[I]t takes us three weeks to get through something because it is such a long slow build. What we are doing right now is a sort of the culmination of what we've been doing with tiles and edges and arrays and patterns... the ownership the kids have in [the integer operations because of] what they are doing and knowing ... they know they've moved into another level of mathematics [understanding] and that whole celebration. When you are in the middle of that time factor 
you're going we're never going to get to the end of this but then you do and it's cause for celebration. (Danielle, follow-up interview, $6 / 8 / 01$, section 324)

Allowing the time beyond the "plan" allows students to dig more deeply into the ideas and develop their own understanding.

Ongoing decision-making is a part of teaching. These teachers have somewhat different lenses from the typical teacher through which to examine their practice. These teachers hold a view of problem solving that is unlike that of teachers who approach problem solving as another skill in a long list of skills to learn. Their decisions about what, how, and when to teach problem solving are influenced by their knowledge and beliefs which are explored more specifically in upcoming sections.

Classroom Action. These teachers hold a non-traditional view of their role in the classroom. Instead of acting as dispensers of knowledge, these teachers are facilitators. They pose problems, provide manipulatives, ask questions, encourage the use of multiple strategies, and place an emphasis on thinking and reasoning, not just a solution. The following section explores each dimension of the role of the teacher and provides either interview or observation excerpts that illustrates each behavior.

Finally, the role of the teacher is summarized through a look at the frequencies of the behaviors observed in each classrooms.

These exemplary teachers pose problems and provide manipulatives to students to help them think through the problems.

Today's [lesson] will be interesting ... I'm going to present to them one where they actually have to complete the square: one where they have to add to it. And we have not done that at all. And the first step 
just sort of has you set it up and then say, how do you think you can solve it? The equation is $\mathbf{n}^{2}-4 n+525$, I'm very curious to see how this goes. (Darrin, pre-observation interview, 4/13/01, section 39)

I will provide the pieces. I'll show them an array. Like today's lesson we are looking at an array and we're looking at the different operations that could represent that array. Um. You know the mathematical relationships that are going on. We are also looking at smaller arrays that will identify the multiplication of two positives, two negatives, or the multiplication of a positive and negative. (Danielle, preobservation interview, 4/10/01, section 47)

The teacher's role, while not "sage on the stage," is quite active. These teachers constantly move about the room asking questions of students while they work. The questions they ask function in different ways. At times these teachers' questions simply obtain finite responses (yes, seven, 6:25, coordinate) such as in the following examples from the classroom observations.

Darrin:

- Did anyone use the fact that the side is $\mathbf{n}-3$ ?

- If this whole shape has a value of 25, what's the length of the side?

- If from here to here [pointing to the edge of the square] is five, what does $n$ equal?

Danielle:

- Do you see this relationship [writes $5 \times 7=35$ on the board]?

- [Writes $35 \div 5=$ ] What would this be [pointing to the equal sign]?

- Matt, how are we going to write it?

Michelle:

- Is there anyone that had a low temperature that occurred in the afternoon?

- When exactly is sunrise?

- Does it change a lot?

Quenton:

- What do we call all these different formulas that represent the same pattem?

- What is the net value of the first six figures? 
- Do you remember what we call graphs like these?

Darrin's questioning was an attempt to help his students think through a visual solution to a problem that many students had chosen to solve using a "guess and check" method to find a solution. Danielle's questioning was intended to help students see how to accurately record their observations using numbers and math symbols. Michelle was asking questions to gather more information for the students so they could proceed with their data analysis. She posed these questions in response to a question one student posed to her. Similar to Danielle, Quenton's questioning is reminding students of the precise mathematical terminology that describes their observations.

Other times the intent of the questioning is to find out more about what students are thinking, as can be seen in the following questions.

Darrin:

- When you say it worked, what do you mean?

- How did you decide on this shape?

- How did you know to add four?

Danielle:

- What do you see?

- What do you think?

- Do you agree?

Michelle:

- What do you notice?

- That kind of confuses the data. What do you want to do?

Quenton:

- What do you do to find that difference [referring to the difference between successive steps in an arithmetic sequence the student had just modeled]?

- How did you see it? 
- Your thinking behind that was...? (From Classroom Observation.)

Often these teachers begin an activity with a chance for students to make observations about a model or problem situation, asking questions like "what do you notice?" and "what do you see?" Most of the time, when students share a solution or solution process without providing evidence of their reasoning, these teachers ask additional questions of students. They ask questions like "how did you know to ?" and "your thinking behind that was...?" Danielle asks questions of the class to check for agreement. Michelle gives students opportunities to decide what to do with the data they were analyzing.

Michelle describes an additional method she uses to draw out students' thinking. She asks students to talk aloud about what they are thinking while she transcribes what they say. She has found that this method serves as a helpful bridge between verbal and written communication.

[I am] trying really hard not to tell them how to do something and I'm not always $100 \%$ good on that one because when it gets pressed for time, I give in. If a kid asks me something and the bell is going to ring, sometimes I go ahead and show them how to do it. And I think, "I shouldn't have done that." I mean I know it right away that I shouldn't. But I work to try to be conscious of it and not do it. It's really hard not to take a pencil and do it. So lately, they come up to me and say, "I just really don't know how to do it," I say, "tell me what you're thinking and I'll write down what you think." I try to be the recorder of their thoughts and then I feel like I'm not doing it for them, but l've got that pencil in my hand [laugh]. But it kind of helps, you know. I say, "I'm not telling you what to do, you are telling me what you think you should do and I'm just writing down what you are saying." It's like they know in their mind, but they don't see it, then they draw it or something. But it's getting kids to talk out loud, sometimes I do the writing of their thinking to help them make that transition. (follow-up interview, 6/13/01, section 87) 
Sometimes the questions asked function to press the students to think further about their idea or solution. These questions encourage students to think beyond their solution and reasoning to the level of testing conjectures, making generalizations, and offering convincing proor.

Darrin:

- Why does that work to make this black [referring to positive numbers]?

Danielle:

- Melanie, you said something about the edges, would you explore that?

- How do you know you are right?

- How many other arrays can we make with the value of zero?

Michelle:

- Why is there a difference between this and Cole's group? [students share ideas] What else may cause the difference?

- What are some other ways that you might display the data visually?

Quenton:

- What is it about the picture that shows that it always works?

- How do you know? (From Classroom Observation.)

In the case of Darrin, Danielle, and Quenton the questions they ask direct the students back to the conceptual model they are building upon with their new lesson. They are being asked to consider a "visual proof" for how their thinking fits with what they discovered to be true in prior lessons. Rather, when Michelle was questioning about the difference between the groups she was trying to get the students "to at least define what the mistake was and what parameters they used to make their decision" (Michelle, post-observation interview, 4/6/01, section 99). She wanted them to analyze the situation and consider how and if both answers are reasonable. 
On a couple of occasions, questions were used to clear up a misunderstanding or misconceptions.

Darrin:

- There seems to be some confusion over the answer. Is it 25 or 21 for $\mathbf{n}$ ? Would someone else like to show?

Danielle:

- Does it matter which edge?

- It doesn't matter which is first?

Michelle:

- What is $5: 15$ [as a decimal]? What is 5.8 [as a time]? What is 5:30?

Quenton:

- What would Kevin's look like? (From Classroom Observation.)

Darrin draws his students' attention to discrepancies in the solutions that were shared, then elicits another volunteer to share to see if this discrepancy might be cleared up. Danielle, in an attempt to help them think more flexibly about their process, asked her students to consider the process they were using and if order made a difference in their solution. Michelle's students had found the mean for the daily time of low temperature over 30 days; they found 5.8 as the result and were struggling with how to record this as a time. Michelle asked questions about how to express some alternative, more straight-forward times as decimals (e.g., 5:15 and 5:30) to help them think about what is a reasonable estimate for 5.8 expressed as a time. Quenton was encouraging students to consider what the model for a student's solution would look like, hoping to clear up a misconception the student had about the area and dimensions of a rectangle constructed with algebra pieces. 
Figure 11 displays the frequencies of the question types asked by each teacher during the three days of classroom observation. Frequencies were determined by finding the relationship between the number of each of the question-types by the total number of questions asked. Darrin and Danielle most frequently asked questions simply yielding an answer. Darrin and Danielle ask this type of question more than twice as often as Michelle and Quenton. Michelle and Quenton most frequently asked questions to find out about student thinking. Quenton also frequently asked questions to press students for more thinking. There was at least one instance in all of the classrooms where questions were used to clear up a misconception. Quenton comments on this by saying, "I just talk to students a little bit and ask a couple questions, they usually see [their misconception]" (post-observation interview, 3/21/01, section 7).

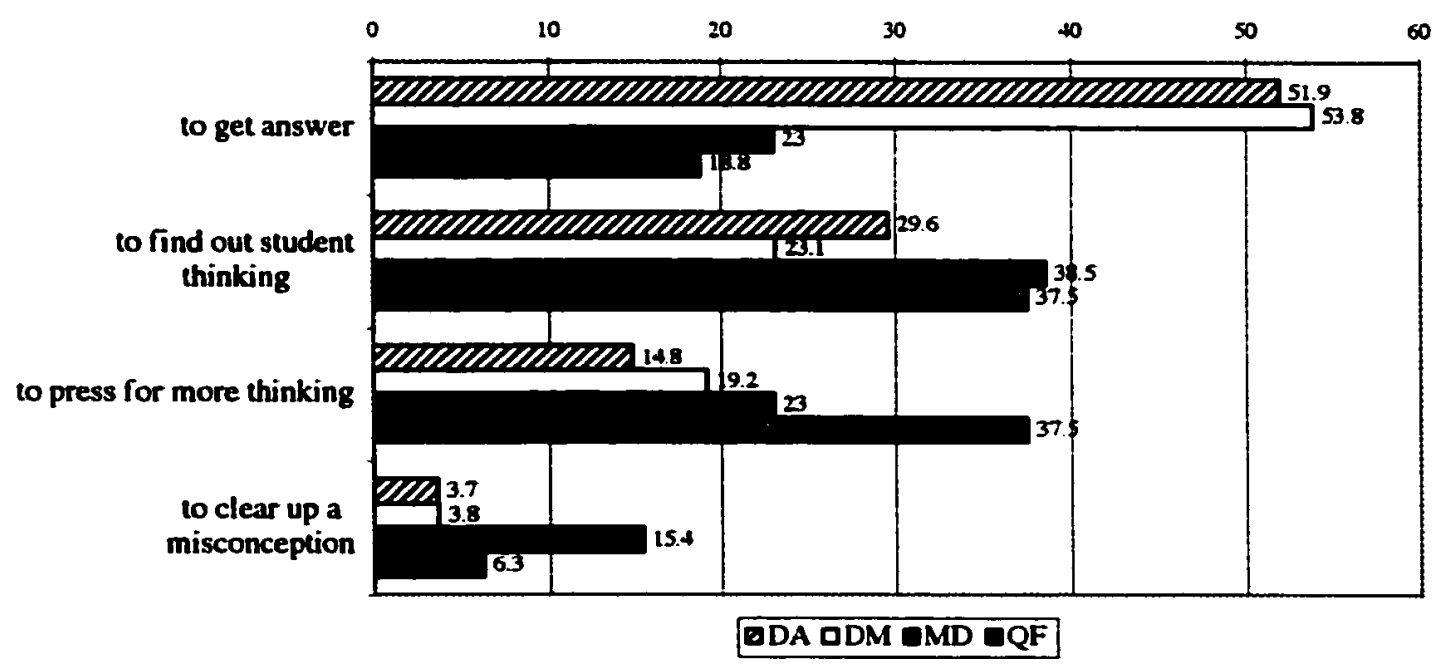

Figure 11. Frequency of question types (\%). (From Classroom Observations.) 
In addition to using questioning strategies that draw out students' thinking and reasoning, additional actions exhibiting these teachers' desire to draw out student thinking included (1) encouraging students to use multiple approaches to solving problems, (2) asking students to share their thinking and solutions with others, and (3) encouraging analysis and sensemaking of the various solution strategies. For example, when Darrin's class was solving quadratics he stated:

Some kids were really close [to developing the quadratic formula]. I got a small group to do it... They didn't come up with the exact quadratic formula but they came up with one that worked... I tried to end the whole [lesson with] take your pick [between guess and check. completing the square, factoring, etc.]. For some kids, they just thought that completing the square was the easiest, so they used that every time. Where some kids would say "on this one it is easier to use factoring and this one completing the square." So, that was like three weeks later, after you left. [laugh] We spent like a lot more time on it. (follow-up interview, 6/19/01, section 63)

Quenton describes how math looks different from what it did when he was in school.

Instead of everyone sitting quietly and solving the problem in one particular way he states:

I want kids to have a chance to look at what each other is doing and see the multiple approaches instead of just looking at methods that are correct. Kids learn from mistakes that they see. (Quenton, initial interview, 2/23/01, section 118)

Michelle describes how she encourages students not only to solve a problem but to also consider if their thinking makes sense.

I encourage them to ask their own questions. I encourage them to use what they know to solve the problems rather than just off the top of their heads. Sort of... asking them to verify their thinking in other ways and by asking what did you do to prove that to yourselr? (preobservation interview, 4/2/01, section 39) 
Checking to see if an answer makes sense and proving that it does, is the basis behind verification. Danielle recalls an experience illustrating the impact that verification can have on student's feelings of success.

In spending time doing problem solving and looking for ways of proving your answer is correct, doing that verification and having that strength in verifying ... you the performer know that your answer is right and true. You have all the confidence in the world and you can get up in front of anybody because you know you are right. It's no longer intimidating, it's like "oh my gosh, this is the right answer." If you know you have the right answer, it's easier. Standing in front of the group is easier. That really does break down the barriers. Being able to successfully verify was very powerful for this child. You're asking, "how do you know that?" "Are you sure?" And they say, "yes!" There is no doubt in their mind. (Danielle, initial interview, 1/9/01, section 140)

Summarized in Figure 12 are the interaction types that were observed in these teachers' classrooms. Frequencies were determined by finding the relationship between the number of each of the interaction-types by the total number of interactions observed. These indicate the role these exemplary teachers actually take in their classroom as opposed to what they say is ideal or what they believe they do. The majority of the teacher-initiated classroom interactions are the teacher asking questions, with detail regarding the questiun types offered in a previous section. All of the teachers posed problem(s) and three of the four spent time clarifying the task with students. Manipulatives were available for use in all the classrooms. However, in only two classrooms was manipulative use predominant. In the other two classrooms, the limited use of manipulatives was either related to the content of the lesson (weather pages were utilized to gather and study data) or the point in the lesson 
that was observed (manipulatives were used in prior lessons to provide scaffolding, but the days of the observation were during the culminating activity). Only two teachers offered praise or encouragement to students for their efforts as they worked. In the two classrooms without praise, the teachers' feedback was either nonjudgmental or the students' ideas were used as the building block for another idea or question. Students in all the classrooms were encouraged to reflect and to offer both reasoning and a solution. In two classrooms, specific strategies were encouraged and in one of these classrooms the teacher also presented his strategy. Students in all four classrooms were encouraged to participate. However, in two of the classrooms, Darrin's and Danielle's, the encouragement occurred too often and could be perceived as prodding.

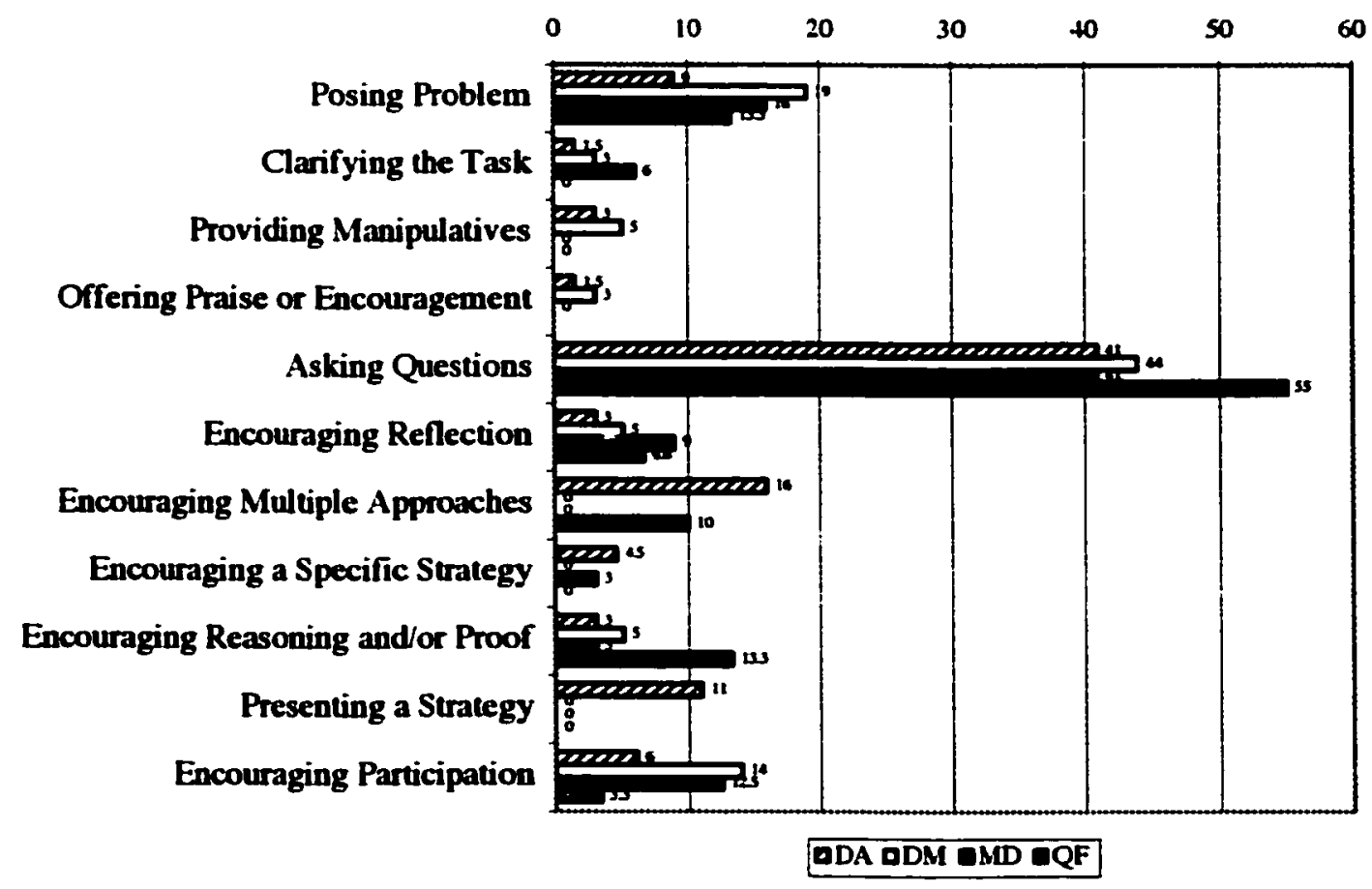

Figure 12. Frequency of interaction types $(\%)$ indicating role of teacher. From Classroom Observations. 
In conclusion, these teachers recognize their role is not to impart knowledge to the students; instead their role is to provide learning opportunities, listen carefully to students as they ponder ideas, and support them in making sense of ideas through providing manipulatives, questions, and opportunities to explain their thinking. Other comments that indicate how these teachers perceive their role and what they are learning about their role in the classroom include:

I need to follow [the students] lead more. (Darrin, follow-up interview, $6 / 19 / 01$, section 35)

I try really hard to just be curious about their thinking and help them make sense out of it. I try really hard not to tell them how to do something and I'm not al ways $100 \%$ good on that one because when it gets pressed for time, I give in. (Michelle, follow-up interview, 6/13/01, section 87)

[ will just stay out of their way [laugh]. Ask questions, go around and talk to them about what they are talking about. Ask them to summarize for me, what they've come up with so far, I'll ask them to think of ways to communicate their thinking to the others about their methods. (Quenton, pre-observation interview, 3/16/01, section 3)

Generally, these teachers see their role as one of allowing students the space to do the cognitive work they need to do.

Interrelationships between Beliefs and Actions. Summarized in Table 17 are the relationships among these exemplary teachers' goals in teaching problem solving, their beliefs regarding the results of engaging in problem solving, and their actions that support problem solving behaviors in the classroom. Reading across the table from left to right, suggests a link from the goals for instruction (e.g., confidence 
and eagerness to approach an unknown situation), to beliefs about problem solving opportunities (e.g., observe, invent, conjecture, generalize), to teachers' actions (e.g., encouraging reasoning and proof). For these teachers, decision-making and actions are closely aligned with their beliefs and goals related to problem solving. Their beliefs about the outcomes of engaging in problem solving also inform the problems they choose to have students explore.

\section{Table 17}

Interrelationships Between Teachers' Goals, Beliefs, and Actions

Regarding Problems and Problem Solving

\begin{tabular}{|c|c|c|}
\hline $\begin{array}{l}\text { Goals for Problem Solving } \\
\text { Instruction are to develop... }\end{array}$ & $\begin{array}{l}\text { Beliefs that engaging in Problem } \\
\text { Solving offers opportumity to*... }\end{array}$ & Related Teachers' Actions \\
\hline $\begin{array}{l}\text { - Iexible understanding of } \\
\text { mathematical concepts } \\
\text { - confidence and cagemess } \\
\text { to approach un'mown } \\
\text { situation } \\
\text { - metacognitive skills } \\
\text { - } \quad \text { oral and written } \\
\text { communication skills } \\
\text { acceptance for and } \\
\text { exploration of multiple } \\
\text { solution strategies }\end{array}$ & $\begin{array}{l}\text { leam concepts and apply } \\
\text { existing understanding } \\
\text { observe, invent, conjecture, } \\
\text { generalize } \\
\text { - see multiple approaches }\end{array}$ & $\begin{array}{l}\text { - poses problems and asks } \\
\text { questions } \\
\text { encourages } \\
\text { reasoning/proof } \\
\text { - encourages reflection } \\
\text { - discuss/share ideas } \\
\text { collaborate } \\
\text { encourages multiple } \\
\text { approaches }\end{array}$ \\
\hline
\end{tabular}

*Indicates that teachers also choose problems based on these criteria.

\section{Role of the Student}

The students in these exemplary teachers' classrooms also take on an active role. They interact with others, engage in problem solving, ask and answer questions, and present their results. The teacher-student and student-student dialogues are similar and consist of discussing problems and asking and answering questions. All of these areas are illustrated through an example from the classroom observations or the 
teachers' reflection on the classroom observation. Finally, the role of the students in these teachers' classrooms is summarized through a look at the frequencies of the behaviors observed in all of the classrooms and the level of engagement of the students in these classrooms.

In these exemplary teachers' classrooms, the students interact with the problem, their peers, and the teacher. The following example from Darrin's class (T indicates teacher) illustrates such interactions (Figure 13). Students were working on a problem in their small groups: the teacher was encouraging the students to look at the "square method" for solving the problem. Then Darrin pulls the class together to have students present strategies to the whole class. Pay particular attention to the students' actions and interactions. 
T: I want you to try using the square method for number 4. [To one pair that was working ahead]. How would you make it a square $\left[n^{2}-6 n+9=25\right]$ ?

[The discussion in one group]... I figured out where the 3 comes from [in $\left.n^{2}-6 n+9=25\right]$. When will it equal 121? 625? -62? It will never equal 62 since it's not a square.

T: I think the volume is too loud. How many have finished number 4? If you solved using guess and check, try to solve with the square method. I'm going to give you three minutes with this. [rang bell to signal] sh, sh, sh. [wait] Who will come up and show how they solved for 121 ?

Nathan: okay. $(-n+3)^{2}=\ldots$ I wanted to have 121 square rooted which is $11 .(-11+3)=-8$.

Maia: [to Nathan] I think of $\rightarrow \mathrm{n}$ as opposite of $\mathrm{n}$... I just have a really complicated way...

Maia: [to class] $\sqrt{121}=11,11+3=14,14 \times 14=196.196-84=112,112+9=121$. The 14 was for the 3 positives that I have to take off.

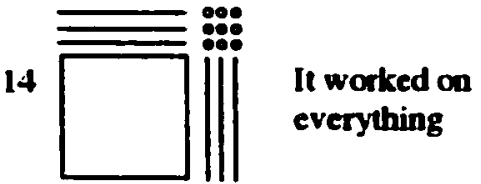

14

\section{Because}

$6 \times 14$ is 84

T: $\quad$ So far we've come up with this square [pointing to Maia's diagram]... when does it equal 121?... Alexis, do you want to show? Austin do you want to show?... control the urge to talk to your neighbor. If this is 121 , what would this length be? [pause] I'll show you my method so we bave another one.

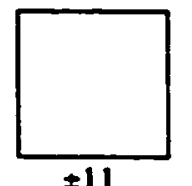

$$
\begin{array}{cc}
\mathbf{n}-3=11 & \mathbf{n}-3=-11 \\
+3+3 & +3+3 \\
\mathbf{n}=14 & \mathbf{n}=-8
\end{array}
$$

T: Who would like to show their way

Caleb: I did it the same as Nathan.

Julia: I can show Caleb's. $\sqrt{625}=-25,-25+3=-22$. The formula is the same as Nathan', $(-n+3)^{2}$

T: Could you find both answers with that method?

Julia, Caleb: No

T: Alexis, could you iell me what you did?

Alexis: $\sqrt{625}=25,25+3=28$.

T: When is this going to equal -62 ?

Ss: $\quad$ never... it keeps going positive... nothing times itself is negative, unless you use $i$

Figure 13. Completing the square.

This example shows the typical interchange in these classrooms in which students' work on a problem either individually, in groups, or a combination of the two. The students then have an opportunity to share their different ideas with the whole class. Often students approach this sharing as a chance to make their thinking 
public and to build on each other's thinking. In this example, Darrin also puts his ideas about the problem out for discussion.

A more specific example of a teacher-student interaction occurred in Quenton's class when a student was sharing his formula with Quenton and showing how it worked with specific examples (Figure 14). Quenton's questioning caused the student to step back and look at the formula alongside the model to determine how and why it works. While interacting around problems, these exemplary teachers push for high-level thinking including making conjectures, generalizations, and justifications; notice James' response to completing this level of analysis.

James had developed the following formula for finding the last term in an arithmetic sequence [ $(\mathrm{d} \times \mathrm{n})$ $+(\mathrm{a}-\mathrm{d})]$ where $d$ represents the common difference, $n$ represents the number of terms, and $a$ is the first term. He gave examples with the cubes, formed as a staircase showing that his formula worked [e.g. $(3 \times 3)+(1-3)=9+-2=7$ and $(1 \times 4)+(3-1)=4+2=6]$.

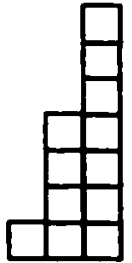

$(3 \times 3)+(1-3)=9+-2=7$

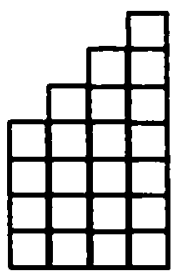

$(1 \times 4)+(3-1)=4+2=6$

$T$ was working with him to try to get him to reason with the model about why the formula works.

Captured below was his thinking and proof.
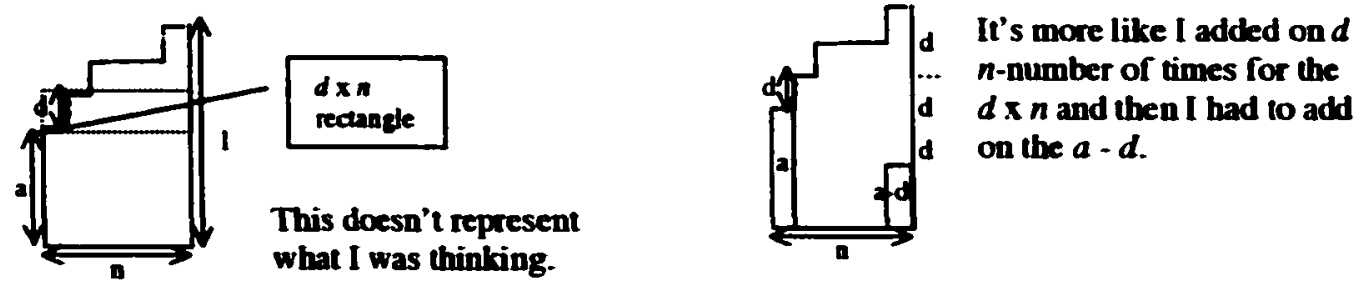

Fiqure 14. Arithmetic sequences. 
James talks through the possible connections between the model and his formula and determines that the multiplication portion of his equation relates to a repeated addition of $\boldsymbol{d}$ to create the last column rather than an area model for multiplication. Quenton's questioning moved him to a deeper level with his generalization. James initially could prove that his method always worked through example but persevered to develop an understanding of why it always worked.

Students in these classrooms also interact with their peers discussing the problems, and asking and answering questions. A second example from Quenton's class occurred when Quenton posed the first problem in their new lesson; the following discussion (Figure 15) occurred in one of the groups. 
On the overhead was the following:

- Skeich pattern

- Formula for $v(n)$

- Algebra piece model

- $v(1) \rightarrow v(6)$

- Sketch a coordinate graph of the first 8 to 10 arrangements

Dillon: II's $\mathrm{v}(n)=n \times 3+1 \ldots$ see [pointing to the dimensions]

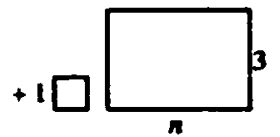

Kevin: I see $[(n+1) \times 3]-2$ [shows how be saw it]

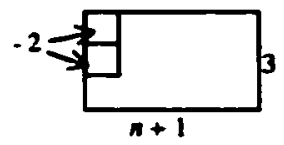

Dillon: What are we supposed to do for $v(1)$ through $v(6)$ ?

Matt: Those are the values of the arrangements. They are easy $v(1)=4, v(2)=7, v(3)=10, v(4)=13$, $v(5)=16 . .$. it just goes up by three each time.

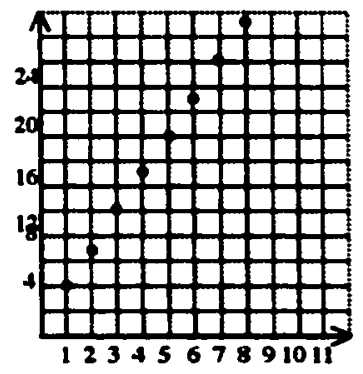

Figure 15. Algebraic representations.

This example shows how the culture in this classroom is such that students naturally share both their solution and their reasoning with each other. Dillon and Kevin do this by not just sharing their formula but also explaining how they "see" the formulas in the model. They also ask questions of each other instead of looking to the teacher as the only authority in the classroom. 
The students' discussions in these teachers' classrooms are centered on their thinking, possible strategies and solutions. The following example is from Danielle's classroom (Figure 16). Following an opportunity for her students to make observations about an array and to speculate about the relationships modeled and the possible edge pieces, students in the class were asked to use the pieces to model integer multiplication problems.

T: I'd like you to use your tile to model this [writes $+2 x+5$ on the overhead].

Mariah: It's kind of obvious that you are going to get black. [comes to the overhead to share] T: $\quad$ Our turn please. Mariah: This is 2 black because it says +2 . This is 5 black and you fill it all in with 10 black.

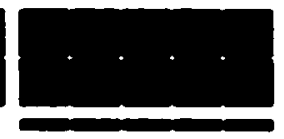

T: [writes $-3 \times-3$ on overhead] Ok. Build this one please.

[Quite a few students built a red area.] Rebekah: [to Mariah]... that's wrong. Mariah: No it's not. Rebekah: [built at overhead] Since you always lay them out black...

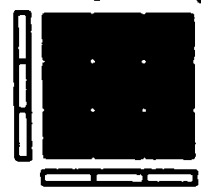

T: Can we listen to Rebekah?

Rebekah: We always start out black, this edge flips them... this edge flips them again, making them black again. so it's 9.

T: It doesn't matter which you do first does it?

Ss: No

Figure 16. Integer multiplication.

With the first problem, Mariah describes her model and the answer. She does not describe her process, other than saying "it's kind of obvious," nor is she asked to 
explain further. Rebekah, on the other hand, offers her thinking along the way and the reasoning behind what she was doing to obtain her solution.

The interactions these students have with their teacher include a form of dialogue similar to what the students have with their peers: discussing the problems, and asking and answering questions. Michelle's class provides an example of this such teacher-student and student-student interaction. Students were studying data from consecutive days of newspaper weather pages to determine if the daily low temperature occurs before or after sunrise.

T: May I have your attention? Shhh. We are now going to study the data collected. We need to determine if the low occurs before or after sunrise.

Gabe: How are we going to know if those on left occurred in the morning or the afternoon? They did not write it down [am and pm were not recorded next to the times].

T: We could ask them. Is there anyone that had a low temperature that occurred in the afternoon? [There was a specific question about the times recorded for March 7 and 8, was it $10 \mathrm{am}$ or pm?] Are there any other pieces of data that look odd to you?

Anna: Why are there so many blanks?

T: We only had enough people to go through the $28^{\text {th }}$.

Marc: Are we going to do mean, median, and mode?

T: How are we going to analyze it? I'm going to let your group decide and put a visual on the overhead to convince the class that you were right. I'm going to give you a blank copy of this [data table] to record your data on if you don't want to keep looking at the overhead.

[T distributes the blank overhead transparencies, overhead pens, and copy of the data table to each group.]

T: When you've made your decision you need to record it on here.

Anna: What time did the sunrise occur for each day? We need to know the time of sunrise.

T: There's a question to the class? When exactly is sunrise?

Ss: It changes.

T: Does it change a lot?

Elise: Ours are each two minutes earlier. 
[T asked various students what time sunrise was for their page.]

$\mathrm{T}$ : What happened over the course of the month?

Jon: It looks like it keeps going two minutes earlier.

T: We have another question. The class needs to make a decision about how to treat March 2 and 3. One has a range from 6 to 7, the other from 4 to 6 . Why do you think they did that?

Marc: It was at that temperature for a while.

T: That kind of confuses the data. What do you want to do?

Taylor. We should use the first time of low temperature.

As questions came from the students, Michelle in turn, posed them to the class much the same as if the questions were posed within their small groups. Instead of simply answering the students questions and/or telling the class that they will do things in a particular way, Michelle share the decision-making authority with the students. She asks the class to collectively gather the information and come to agreement about how to answer the question.

Figure 17 summarizes the frequency of the different interaction types within each teacher's classroom. These student interactions include:

- Problem solving behaviors

- Interactions with other students and/or the teacher

- Asking questions of other students

- Asking questions of the teacher

- Preserting results

- Answering questions with both a solution and reasoning

- Answering questions with solutions only. 


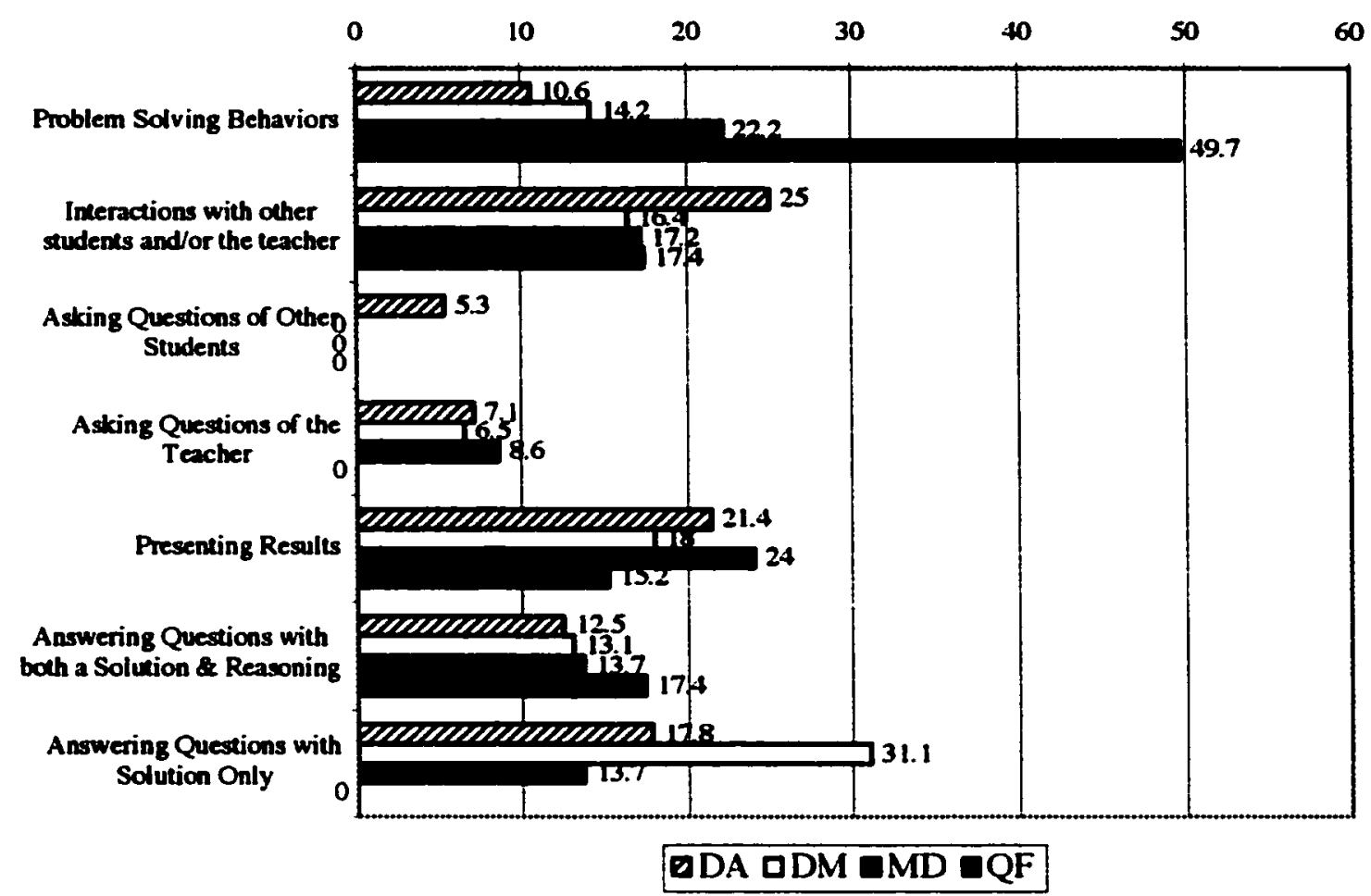

Figure 17. Frequency of interaction types (\%) indicating role of student. From the Classroom Observations.

Frequencies were determined by finding the relationship between the number of each of the student interaction-types by the total number of interactions observed. In all four classrooms students were engaged in problem solving behaviors. Those behaviors, as identified by the teachers, include:

- Discussing ideas with each other

- Discussing ideas with the teacher

- Observations

- Conjectures/predictions

- Generalizations 
- Testing generalizations/verifying.

These behaviors are clearly the most dominate in Quenton's classroom; $49.7 \%$ of the observed behaviors were problem solving behaviors. In all the classrooms students were interacting with the teacher and each other, presenting results, and answering questions. With the exception of Quenton's class, it is either as common or slightly more common for the students to answer questions with only a solution as it is for the student to answer with both a solution and reasoning. Students in Quenton's class were never observed answering a question with a solution only. The least dominate behaviors by the students in all the classrooms were asking questions of other students or the teacher.

As mentioned, problem solving behaviors are defined by these teachers as students discussing ideas about the problem and solution strategies with each other and the teacher; making observations, conjectures, and generalizations; and testing generalizations. Figure 18 displays the frequency of each of these student behaviors within each teacher's classroom during the observations. Frequencies were determined by finding the relationship between the number of each of the problem solving behaviors by the total number of problem solving behaviors. Students' discussing ideas with each other and/or the teacher were dominate behaviors in both Darrin and Danielle's classrooms. Making observations was a dominant behavior in both Danielle and Michelle's classrooms (e.g., what they could see in an array, what observations they could make about the data from the weather pages). Students in Michelle's classroom were at least twice as likely to make conjectures (sunrise is 
al ways two minutes earlier than it was the previous day, a mean time of 3.8 is equivalent to 4:20) than students in the other teacher's classrooms. Quenton's classroom was the only one in which making generalizations (e.g., inventing formulas for finding the missing information with certain givens) was the most dominate behavior. Students in all four classrooms were testing generalizations and/or verifying their work (e.g., in recalling how to find the area of a circle, students reconstructed two visual proofs for $\pi \pi^{2}$ ), however these behaviors were most prominent in Darrin's and Quenton's classrooms.

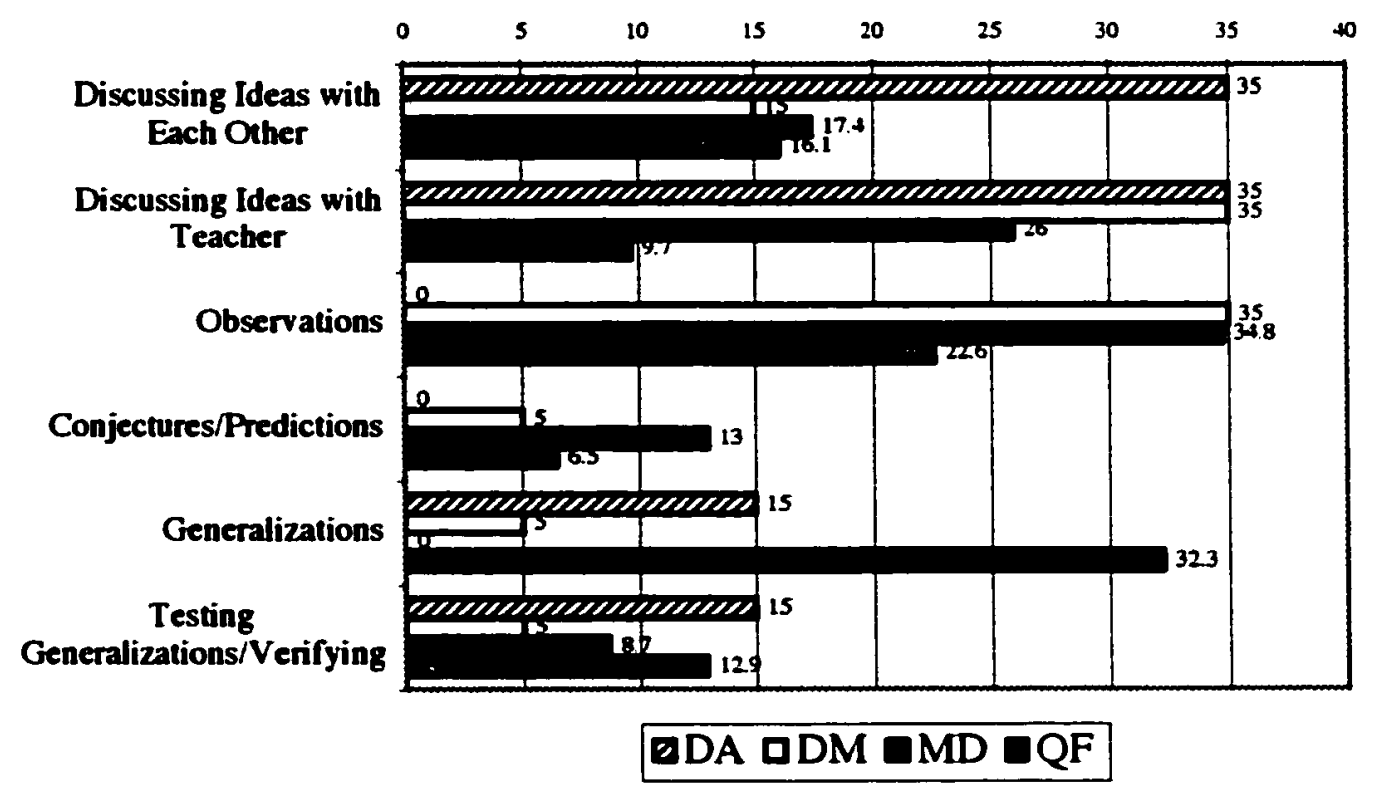

Figure 18. Frequency of problem solving behaviors (\%). From Classroom Observations.

As can be seen through these examples, the students in these classrooms take an active role in their learning. While the demand of the cognitive work that they are 
doing in the classrooms varies, there is evidence that in each classroom students are making sense of mathematics. Michelle describes this in the context of her lesson.

[Regarding the Weather Page] the kids are trying to make sense of what it all says....as you are looking at isolated data, it's not always clear how you might put it together in some way that makes sense. (Michelle, pre-observation interview, 4/2/01, section 47)

The students in these teachers' classrooms are given the opportunity to develop ideas on their own; instead of relying on the teacher as the authority, the students see themselves as capable mathematicians.

Interrelationships among Teachers, Students. and Mathematical Problem Solving

Students in these teachers' classrooms engage in problem solving to learn mathematics content. In doing so they are involved in a cyclical process that begins with them exploring the problem and from this exploration students develop models and methods of thinking about the problem. From these models and methods, students develop their reasoning and prove their thinking to be reasonable/valid. Also, in this process, students discuss their reasoning and their solution(s). Figure 19 shows this cyclical model representing mathematical problem solving process. The model is a circle indicating that the process is unending and the actions, while somewhat sequential, may not be brought to completion before engaging in the next action; some actions may occur simultaneously and not all students will be at the same place in the process as they engage in problem solving. For example, students may engage is discussing their reasoning as they are developing their models. Teachers engage in 
this process as problem solvers as well; they are asking questions to elicit student thinking, encouraging proof, making sense of multiple approaches, and reflecting.

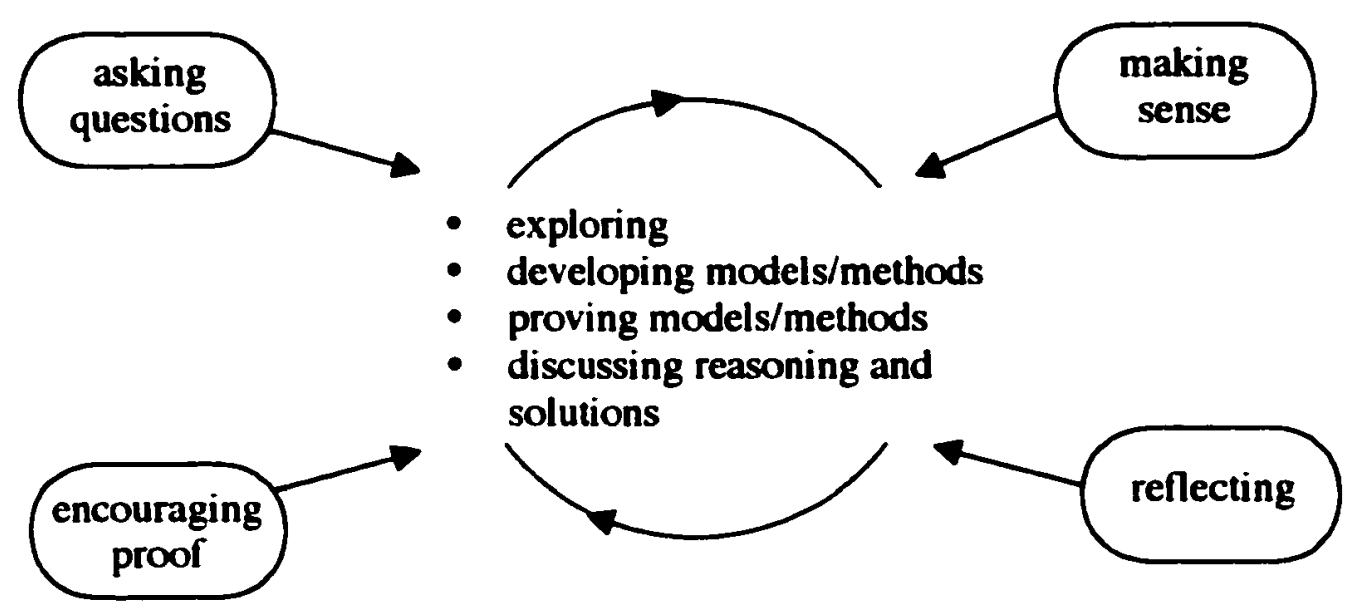

Figure 19. Mathematical problem solving process.

Bases for Decision-Making about Problem Solving Instruction

This section focuses on the internal and external conditions influencing these teachers as they make decisions about their problem solving instruction. In each subsection I will account for their instructional practice through explaining the knowledge and beliefs these teachers hold and how those knowledge and beliefs relate to their instructional practice.

\section{Internal Influences}

Explored in this section are the knowledge and beliefs these teachers hold about mathematical content, mathematical problem solving, students as learners, 
themselves as teachers of mathematics, pedagogy, and assessment. It concludes with a summary of how these internal influences shape these teachers' instructional practices.

Mathematical Content. These teachers' knowledge and beliefs about mathematics content can be summarized as viewing math as something to figure out, something to understand and not just do, and something that is uniquely understood by different individuals. They believe that mathematics content knowledge is developed through problem solving and making sense of it for yourself. They see the topics in math as being interconnected. These beliefs are articulated in the following ways:

Taking the middle school math classes at [the local university]... they made me see what I think to be the most important part of math, and that is problem solving. One reason that I liked math growing up was, I saw it as a game. I just solved problems with it but most people didn't look at it that way. Most people got frustrated with it and thought, "why do I have to learn this." I think Visual Math brings it to a point where problem solving is for everybody. So you don't have a choice but to look at math as problem solving. [n this program] every single time you bring up a new math idea the kids figure it out first. Instead of just saying "the area of a triangle is $1 / 2 \mathrm{bh}$, all right? Practice that 50 times," it's "what's the area here? Can you come up with a method to find out what the area is?" It's always presenting it in a manner where you have to figure it out. (Darrin, follow-up interview, 2/23/01, section 163-167)

It's kind of small and you have to sort of weave your way into it, but I find it for example, difficult to teach multiplication without doing division at the same time because of how interconnected those two operations are. That's kind of a nice example [from the classroom observation] of doing both those things in connection with each other. You know there is no reason to be fearful of division because it is just multiplication in reverse. So, ah, just incorporating both those operations. And I try to do that on other things, keep putting things together that make sense to me and maybe it will help the kids make the connection too. (Danielle, follow-up interview, 6/8/01, section 188) 
Well because [the models] put meaning behind what you were teaching and meaning behind what the kids were learning and a way of understanding rather than thinking this is something that is just done to them. I really felt that kids were just manipulating numbers without any understanding at all what it meant...they could punch a number into a calculator but they couldn't apply that to a problem. A good example is division, they didn't understand the concept of division, yet they could punch the numbers into a calculator but when you gave them a real-life problem, they wouldn't recognize it as a division problem. So what good was that little algorithm they learned? ... For that matter, [what good is] the calculator when they don't even know when to use it? I think [that with] what we are doing now, everything overlaps each other. When you are doing your numbers and your writing, you are doing your geometry, you are seeing the pictures, you are applying your algebra skills to your geometry. It's not like when we used to spend a year manipulating algebra symbols and never have any [meaning]. But now in algebra we might spend more of the period working on the problem solve and just a little bit of time working on the problems because you know they can practice that at home. It's definitely changed. (Michelle, initial interview, 2/26/01, section 285)

These teachers also describe how their own content knowledge has developed

both as a result of their having opportunities to learn math from a problem solving

approach as well as having opportunities to teach math through problem solving.

Really the key to all of these is turning [quadratics] into squares. That's not something that I really realized until I started looking through this. Um. I met with the other teacher last week and I was like, "wait, why are we doing this before we do factoring? Why are we doing completing the square? I remember doing that way after factoring." He's saying "we don't ever have to factor with this method. Sometimes it can be easier, but in general you can do this method every single time and you can get your answer." And that makes so much more sense because factoring it sort of guess and check and you are sort of figuring it out that way. They do have some factoring at the end of this chapter, but they teach it without that. (Darrin, preobservation interview, 4/13/01, section 31)

I think I too have seen visual connections that I never saw before. Um...the proportionality between diameter and circumference and exactly the function of pi. Looking at area and breaking that circle 
down and forming a rectangle using that. I had not done that. I guess it was something that I never really thought about it because I had been trained in what I call old school methods. I never thought about why or how it worked. It was that big why question, you've got a process, you've got a method, it works. How it was developed and all that stuff was, not. I never had really spent any time thinking about it before. (Danielle, follow-up interview, 6/8/01, section 220)

I really love being able to do the algebra pieces and it seems like each time that I do them I learn a little bit more. Like when I was talking about that part with minus three. That was when the problem was $2 n$ minus three, some kids were having problems with putting three red up there and I thought I should have just let them examine this a bit further and say, okay you've got $2 \mathrm{n}$ and you're supposed to take away three and you don't have those three, what do you think you should do? And then I think they would have put up zero pairs, they would put up the three red and three black and then they could take-away three black and then wha-la, they would have three red left. That would have put it together for them if I would have taken the time. (Michelle, follow-up interview, 6/13/01, section 95)

Darrin describes his new understanding of solving quadratics. He not only made sense of the "completing the square" method through use of a visual model, but he also came to understand factoring and its role in a different way. Danielle developed an understanding of pi, what it represents and how the area formula for a circle can be visually proven. She now understands why $\pi r^{2}$ works, instead of just doing it. Michelle, while using algebra pieces to solve equations, discusses how she has made sense of why adding negative three is the same as subtracting three.

Mathematical Problem Solving. As suggested in the previous section, these teachers view math as problem solving. They see it as a means to learn mathematics. They view problem solving as a life skill, therefore a valuable end in the curriculum. They have developed common classroom expectations regarding solving problems: 
asking that students solve problems in multiple ways, share their thinking with others, make and test conjectures, and develop generalizations. These behaviors are part of the normal classroom culture for these teachers. The beliefs these teachers hold about problem solving and problem solving instruction influence what these teachers do and do not do in the classroom. Even though these teachers hold common beliefs about problem solving, these teachers have made different decisions about whether or not to teach problem solving as a separate skill and how to treat problem solving strategies.

Danielle suggests that she no longer teaches problem solving as something separate; instead, the curriculum teaches it. While she attributes problem solving instruction to the curriculum, Danielle, in her actions and her expectations of students is also teaching students to problem solve. Her statement about "whose" teaching problem solving also suggests a shift in her thinking about problem solving instruction. Danielle used to teach problem solving in a formulaic way suggesting a strategy and telling students how to "write it up" and now she just asks students to engage in problem solving, similar to what Kilpatrick (1985) calls osmosis. Danielle believes that students learn to problem solve while they engage in solving problems that help them to learn mathematical content.

Michelle is the only teacher in this group who explicitly discussed teaching students problem solving as guided by the dimensions of the state scoring guide. That is, she focused on having students develop a write-up attending specifically to the various dimensions of the scoring guide. Kilpatrick (1985) would call this strategy memorization, as Michelle decomposes the solution into procedures that she teaches 
the students. While the other teachers also asked students to develop problems that could be scored with the state scoring guide, the scoring guide seemed to be used to guide conversations about "quality work" and as a means to provide feedback to students about their work, not as strict guidelines for the development of their work. Michelle's decision to teach problem solving through memorization is related to her beliefs about students and her beliefs about what represents problem solving. Michelle is the only teacher in this group that has significant doubts about what her students can do, as described in an upcoming section. This belief about students likely influences what she believes she needs to do for students so that they can "successfully" engage in problem solving. Since each time Michelle was asked to describe problem solving or problem solving instruction she turned the conversation to one about the state scoring guide, for her, teaching the students to successfully perform with the scoring guide is teaching them to problem solve. This focus on the scoring guide suggests that it has played a significant role in shaping her view of problem solving and problem solving instruction.

Quenton states that he does not value problem solving strategies, "things like make a chart, or work backwards, I don't really address those things in class" (initial interview, $2 / 23 / 01$, section 183 ). Instead he poses problems and asks students to explore the problems, try things out, and share their results. Quenton's descriptions of his problem solving instruction are akin to what Kilpatrick (1985) calls osmosis and cooperation; in addition to engaging in problem solving, he sees the sharing of ideas as key to the students' learning processes. As students share ideas with the class, they 
take on the role of a master problem solver, making imitation (Kilpatrick, 1985) a potential component of the learning process as well. Darrin and Michelle, on the other hand, teach problem solving strategies. However, they do so in different ways. Darrin suggests strategies to his students that they might use to solve problems and Michelle teaches them by both suggesting their use and directly teaching them. Darrin's method would ask students to imitate while Michelle's approach with directly teaching them, would again put students in the place where they were being asked to memorize. Another aspect of problem solving behavior discussed by these teachers was the aspect Schoenfeld (1985) refers to as control. Control is "the global decisions regarding the selection and implementation of resources and strategies" (p. 14). These teachers commented of ten about their students' reactions to being stuck and the strategies or lack of strategies they have for working through this. Danielle commented that her students are not coming in to her classroom ready to learn. When met with a challenge, many of her students "just shut down." Since Danielle believes that she should be teaching for understanding, and sees Visual Math as a tool for achieving this goal, she is pondering methods for getting past this struggle with students (e.g., staying with a group of students for more than one year so they "get used to having to think," and/or working with her colleagues to ensure that students are having consistent opportunities to think). Michelle found that it was when students were stuck that she had to work the hardest at not just telling them how they might solve the problem. She believes that she should allow students to solve problems on their own, yet recognizes her tendency to take away their opportunities to 
solve problems by telling them how to do so. Darrin, in his follow-up interview, described that for next year he would like to help students better know what they might do when they are stuck. He thought that he might have students generate ideas and strategies and then he would post these around the room so that students could refer to them as needed. In contrast, in the initial interview Darrin talks about how these strategies "seem to really slow down and not be the natural way that somebody goes about solving a problem" (2/13/01, section 31$)$. The strategy he describes using next year, with posting student-generated ideas around the room, would allow the students to control the amount of support and input they receive. His developing belief in what students can do allows him to consider methods of supporting students who need it while empowering students who do not need it to solve the problem with their own devices.

While these teachers' knowledge and beliefs about problem solving are similar, what they believe they need to do to support students in the problem solving process differs in important ways, suggesting some discontinuity between knowledge, beliefs, and practice. While there may be many explanations for this discrepancy, one explanation is offered in the next sections as we look at knowledge and beliefs about students as learners of mathematics.

Students as Learners. All of these teachers want to develop students who are curious and willing to investigate problem situations but find that not all students respond to problems with the same level of confidence or eagerness. These teachers want students to engage in learning activities without reliance on the teacher and three 
of the teachers believe that all students are capable mathematicians and can do this work without them taking away the demanding aspects of the task. These teachers expect students to do their own thinking and want them to move naturally toward generalizations. They have found that some students respond to the challenge, while others shut down. These teachers noted differences in the level of thinking and/or engagement among different students.

- Some students enjoy engaging in things they didn't understand. They would just come in and start to solve problems, responding to what is there to be figured out, others would be frustrated. (Darrin)

- Some students are self-assured others were worried about how they would look in front of their peers. There were students who were transferring what they knew about multiplication to division. They were really moving beyond the thinking of other students in the class. (Danielle)

- The low level kids need to do while the high level kids like to just listen and make observations. (Michelle)

- As smart as this group is, there are some kids that just struggle with the concepts. They just don't pay attention to what is going on, I don't know what to do for those. (Quenton)

During the pre-observation interview, both Darrin and Quenton, when commenting about their students as a whole, said that they have an inclination for good thinking and are willing to approach problems that they really do not know how to do. 
They are my class that is... the chattiest... but they work really well. They are really into their grades. They are really good thinkers and they really work well with each other. (Darrin, 4/13/01, section 81)

Some of them will exhibit some just incredibly good thinking, some of them already have a quite a bit done on this activity. And some nice stuff too. Some of them just pick up on things real quick. As a matter of fact, at the beginning of the lesson I had to put the brakes on a couple times because a couple of them were just about ready to just do the very last page of the lesson. [So to hold them back] I just kind of didn't make a big deal about it. I just let them share and said "hold that thought because it will be coming back up later." "That looks good, keep thinking about that as we go through the lesson." They are [confident]. They are not afraid to argue about stuff. They are not af raid to try things. They are pretty fun. (Quenton, 3/16/01, section 70-83)

Three of the four teachers see the potential in every student. For example,

Danielle comments about her frustration with her colleagues' lack of belief in

students. While she agrees that not all of her students are coming in to the classroom

ready to engage in learning, she believes they all have the ability to learn. She recalls

an experience in her first teaching situation:

There were times when I would say why am I doing this? Why am I making myself and them miserable? Will I ever teach these pigs to sing? Well, actually they did learn to sing. That comes from my first 6 months of teaching when I taught at [another] middle school and there was this teacher that had this sign above the door of why teach a pig to sing, it only makes you frustrated... I don't know I can't remember the full saying. I couldn't figure it out. I would just scratch my head. Why as a teacher, as an instructor, would you have that over your door? You know we are all pigs at times. You know, we are all asked to move in to an area that we are uncomfortable with and yea it makes you uncomfortable and them uncomfortable but when you learn to sing...I kind of felt like at times that I was teaching pigs to sing. But hey, we did it. They can sing and we are singing now. (postobservation interview, 4/12/01, section 288) 
Three weeks after the observed class sessions in Darrin's classroom he was completing work with the lesson on solving quadratics. As the lesson was drawing to a close, Darrin gave students the opportunity to self-differentiate as they solved problems; meaning, they chose problems based on what was appropriate for their level of understanding. His confidence in what the students could do allowed him to feel like he could let the them choose both the problems they solved and the methods they would use to solve the problems.

[After you were there,] I had to go back and do a lot more with dimensions. I started the class with having them practice "seeing" the dimensions. It was like $1 / 2$ the kids totally saw it and would just say oh, that's the dimension and they'd just know. Other kids were like going, where are you seeing this? ... how it ended up, I gave them problems that had sort of five levels of difficulty with completing the square. Starting off with ones that work out evenly and you can really see it, they are kind of already set of for you. Then they'd have to set it up. Then they'd have to add something was like three. Fourth was you know... all the way up to those that didn't work out evenly. They'd end up with like square roots to get the answer. Kids could start wherever they wanted and they didn't hand in any of it. It was all about how much knowledge they could gain and how far they could progress along this. It worked really well. (follow-up interview, $6 / 19 / 01$, section 51)

Michelle seemed less confident in her students' abilities, in fact, she commonly referred to her low class as her "guppy" group and doubted that they could succeed in an untracked classroom. She also had serious reservations about whether they could understand the content in Math Alive!: Course III (1998).

They just do not care about school. I'm still very confused about (how they would do if they weren't tracked], you know I think it just depends on the kid. I might have had less behavior problems but I don't think that they have necessarily learned anymore. I could see some of them just totally giving up because other kids get it and they 
just don't get it because they just really honestly are lacking some big skills. They don't conceptually see things the same way. Like when I did the areas of silhouettes with them. They would al ways count squares and 1/2-squares and even when I would present problems where they couldn't count halves anymore they kept trying to count. I got them up to the subdividing and the right triangles and about $3 / 4$ of them got that. But when it came to enclosing it in the larger square and subtracting the parts you don't need, they could not comprehend that. No matter how many times we did it, they'd go "why do you do that? Why do you subtract?" I just would say, "well, do you need that?" "No." "Then what would you do with that if you don't need it?" "I don't know." I mean that whole concept of subtraction was really hard for them. So sometimes I think even putting them with the kids that work harder, I don't think they'd necessarily get it. I have new group next year in the $7^{\text {th }}$ grade and they'll all be together again in $8^{\text {th }}$ and I'll have to make that decision again. But, I hope that I change my mind by the end of next year. But when I picture the kids I had doing VM 3 and understanding anything in it. You know, I just, I don't know. It's hard for me to believe. I'm not a believer yet. (follow-up interview, 6/13/01, section 79)

Yet she also sees that teaching math in this way empowers all students to develop understanding of mathematics. They develop this understanding through inquiry and problem solving just as mathematicians do.

Well, the fact that they can discover and create the mathematics themselves, I think that is a big change in my thoughts about students. I mean, gosh, when I was in school I never, I thought some great mathematician al ways did this and you know I wouldn't have come up with that on my own. And I think that it empowers kids, when they realize that hey you just figured out something that somebody else figured out. So I think that part is kind of neat. I don't know what else, the fact that they can do some of those algebra problems that there is no way that they could have done them symbolically from what I've had in the past. They could only do step-by-step what they had learned. But yet they can solve $n^{2}$, or whatever, they can solve more complicated problems without having to know all the techniques of it. I think it is kind of exciting to know they can do that. (Michelle, follow-up interview, 6/13/01, section 103) 
While Quenton's current teaching context is somewhat unique, with so many of his students labeled "Talented and Gifted," he reports having consistently held the belief that his students were smart enough to do math. He makes this comment about teaching students in Title I (initial interview, 2/23/01) as well as the students in his current teaching context. In this math/science magnet school he is eager to discover what is possible once he is able to work with a consistent group of students for three years. He is confident that what his students are doing is preparing them to enter high school at the Algebra 2 level.

All of these teachers know and believe that students can and do develop conceptual understanding through engaging in problem solving. They have found in their experiences that not all students approach the task with the same level of eagemess and the same depth of thinking. Darrin and Quenton specifically comment on their students' proclivity for good thinking. Danielle and Michelle work with higher need populations, as indicated by the SES rank for their schools. The varying characteristics of students have some influence on teacher behaviors, however it is unclear based on these four teachers if this is the best explanation of their behaviors (i.e., lack of experience with the curriculum and how students might respond to the lesson, may also explain the decisions the teachers make).

While all of these teachers seem willing to continue to empower students to explore and discover mathematics, there are differences among these teachers in what they believe students can do without their assistance. There is evidence provided by both comments and actions, as these teachers "support" students in a variety of ways. 
Table 18 shows the relationships between how these teachers choose to support their students and the beliefs they hold about problem solving, pedagogy, and students as learners.

Table 18

\section{Relationships Between Teachers' Beliefs and Chosen Strategies for Supporting Students}

\begin{tabular}{|l|l|}
\hline Belief that... & Supporting Students by... \\
\hline $\begin{array}{l}\text { Problem Solving is... } \\
\text { making observations, conjectures, and } \\
\text { generalizations }\end{array}$ & - $\begin{array}{l}\text { expecting them to make observations, } \\
\text { conjectures, and generalizations (all) }\end{array}$ \\
\hline $\begin{array}{l}\text { Pedagogy is... } \\
\text { recoggizing that there are many ways to } \\
\text { solve problems and expecting students } \\
\text { explore/consider them } \\
\text { exposure to solving problems teaches } \\
\text { students to problem solve } \\
\text { providing ways for student to control the } \\
\text { support they receive for solving problems }\end{array}$ & - $\begin{array}{l}\text { accepting and encouraging lots of different } \\
\text { approaches to solving problems (all) }\end{array}$ \\
\hline $\begin{array}{l}\text { Students are... } \\
\text { capable mathematicians }\end{array}$ & $\begin{array}{l}\text { giving students lots of opportunities to solve } \\
\text { problems (all) } \\
\text { posting strategies for dealing with being } \\
\text { stuck (Darrin) }\end{array}$ \\
$\begin{array}{l}\text { not ready to make this leap or carnot do it } \\
\text { without my help } \\
\text { not able to solve problems without knowing } \\
\text { specific strategies for doing so } \\
\text { not able to prepare problems for being } \\
\text { scored umless they are taught a format } \\
\text { within which to create a response }\end{array}$ & $\begin{array}{l}\text { - } \\
\text { asking students to develop their own } \\
\text { strategies for dealing with being stuck } \\
\text { (Darrin, Danielle and Quenton) } \\
\text { providing students with a strategy or a } \\
\text { "hint" about a strategy (Darrin and } \\
\text { Michelle) } \\
\text { leaching students each problem solving } \\
\text { strategies (Michelle) } \\
\text { teaching students a "how to" approach for } \\
\text { developing a response to a problem } \\
\text { (Michelle). }\end{array}$ \\
\hline
\end{tabular}

Themselves as Teachers of Mathematics. As discussed in the previous section, these teachers see themselves as learners of content; in this section, they see themselves as learners about teaching. While not asked specifically about their 
knowledge and beliefs about themselves as teachers, comments from the interviews offer a glimpse into what these teachers know and believe about themselves. The commonalities among these teachers are not as clear in this area so each teacher's story will be presented separately.

Darrin's comments in the initial interview suggest both how he likes to learn math and how he prefers to think about the teaching of math. His thinking about the teaching of math has been strongly influenced by how he viewed math as a learner and his experiences using Visual Math.

I really liked math in high school and liked to tutor people that were having trouble. I always thought of math as something to figure out, but other people had trouble understanding, they couldn't figure out what we were doing. Then I started taking the middle school math classes where we were presented with problems that we had to figure out and solve. We were never told how to do it, or given a rule, we were just solving problems for ourselves. The Visual Math curriculum bridges that gap. I guess it presents math in such a way that more people are going to look at it like I looked at it. It presents it as figuring it out and problem solving instead of being stuck up in the rules and the rote part of it. This was a huge part of it before when I was doing it. (Darrin, initial interview, 2/13/01, section 192)

Darrin comments on a struggle that occurred for him with the implementation of the observed lessons. He puzzles over how hard he should push the "completing the square" method of solving quadratics. He also recognized that decisions he made earlier in the year were impacting the implementation of this lesson and were causing him to rethink how to approach these lessons in his second year.

One thing that I've been sort of struggling with in these three days particularly is how much to push completing the square and how much to have them come to it naturally. It's like if you don't push it then I felt like so many of them would just keep doing the guess and check 
and by the time that you have to use completing the square then they haven't practiced completing the square on some basic easy ones. Which... it's like solve this completely hard one where you have to add all this stuff. They'd say, "what?" Whereas, if I really push them to look at it that way on the original ones, where it's set up that way already they can take these steps upward instead drifting into the one down here [referring to the later problems on the worksheet] and it's like, what? So then they have to try this other method, which is now where we've led up to advanced enough equations where it's going to be a really hard thing to fit in to. At the same point, I wanted them to be creating their own methods. Not, you do it this way. This is the way you have to do it. So, I don't know how I'll do it differently next year. I talked to David who is doing pretty much the same lesson but he was kind of leading it out for them. We ended up pretty much doing the same thing where he gave them some equations and said I want to you try completing the square on these. That's how I want you to solve them. He's like, I'm trying not to say they have to but I just hoping that eventually, they'll want to. [They'll see the power]... and just be woo'ed over [laugh]. That's a dilemma I had a lot this year where so much of my kids have a traditional background. I want it to be what they've constructed but for them to understand these later VM ideas I need them to sort of see it in this VM way too. Like in this chapter, I wished that I had pushed the n-strips a lot harder when I did the linear lesson at the beginning of the year. I don't know. It was a hard choice even then because it's like you know they know this other way... (Darrin, post-observation interview, 4/17/01, sections 187-195)

All of the teachers ask questions of students and are curious about student

thinking and reasoning. Danielle articulates that this aspect of her personality impacts

her actions as a teacher. She also feels that in reviewing the transcripts from the

interviews and observations that there is evidence that she is achieving her goal of

becoming more reflective and focusing on developing student understanding.

I think it comes down to basic personality, I'm more curious and I always want to know. I'm always looking and reflecting, reflecting on my kids, what do they know? What don't they know? What can I do? What can they do? How can I direct them? I hope this isn't true, but I'm not really sure that other teachers do that... especially teachers 
that open to the page in the book. (Danielle, initial interview, 1/9/01, section 164)

I think that one of the things that stands out as I read this is that one of my goals is to be a reflective teacher and it's apparent in reading this that I am reflective about what doing and impact it has. Um. The other thing that is so strongly one of my beliefs is in getting students to understand mathematics, understand the whys of what they do. Their conceptual understanding, from your observation those were lessons that I felt really exemplified that. So, not that I don't still have area to grow, but I do reflect and am working to become one of those teachers where kids know what they are doing, hopefully. (Danielle, follow-up interview, 6/8/01, section 11-12)

When Michelle took her first Visual Math class it helped her understand math concepts better. It is in using Visual Math with students that Michelle is leaming more about pedagogy. As she reflects on the "before" and "after" of her instructional practice, she comments that with regard to pedagogy, she is still developing. Upon thinking about the observed lessons, she felt that the lessons would have gone better if she had done some of the math ahead of time for herself. However, she was unclear about what she would have done differently if she had known the answers for herself.

I thought [Visual Math] was a better way of teaching the concepts whereas before we were more focused on teaching the skills. It helped me understand what I was doing. I learned a lot myself. In terms of pedagogy, I don't think I got that for years afterwards. I still don't totally get it. I just think that an ongoing development. I was more focused at that time on just ways of helping kids understand the concept and why things happened the way the did. Rather than, do this because I told you to. (Michelle, initial interview, 2/26/01, section 289)

I should have done some of the math ahead of time myself because it is really hard to know if the kids are doing it right or wrong [laugh] ... if you haven't done it yourself. I should have calculated the mean, median, and mode so that I had an idea. Instead, I had to wait until their presentations and see enough of them to know that there was a 
problem going on. I think I would have done a better job of questioning and stuff. Except, sometimes you need to let the kids figure that out too. I was kind of being like a kid. I don't know what I would have done differently if I did know. But at least I would have been aware. As it was, I was kind of in a fog... Now wait a minute, someone is going to have to help me straighten this out, I'm seeing all these different numbers, nobody is the same, why is that happening? (Michelle, post-observation interview, 4/6/01, section 275)

Quenton often shifted the conversation in the interviews to stories of what is going on for students. This may suggest that it is not his own actions that that are at the center of his attention rather it is the actions of students. This idea will be further developed in the next section. When Quenton was asked to reflect on his teaching he suggested that one aspect that he struggles with is how to get some groups to work together and how to get some kids to be productive. He described how he typically deals with this challenge so that it does not interfere with his instruction:

I just try to talk them into it. You know, I don't know what else to do. I could give them brownie points and put stars on posters but all that stuff, but it doesn't work for me. It takes too much time away from what I need to do. So I just try to talk them into it and then leave them to their own devices. I mean it's their poster, it's their job, it's not mine. I can say look at the other groups, they are all working, look at what they've got done. What have you guys got done? But other than what you think of to say at that particular moment to get them to do something... I know Johnson and Johnson have all these strategies for getting kids to work together but at that point the groupwork is taking more precedent than the content of what you are to teach. I just haven't bought into that whole system of stuff yet. You know, they are middle school kids. They can be fine with their group one day and then the next day they don't even want to sit at the table with them. So you deal with all that too. [laugh] [I remind them that] the seats are all full, there are none. We'll change seats next week. That's why I only have them in their seats for two weeks. At this age level... sometimes we go three if they are short weeks missing a day or two, here and there. Like the group in the corner, I just said you know you guys have to work together to get this done. I'm not going to do it for you 
and neither is anyone else. You've just got to do it. You're going to be together until spring break so either get over it or do your work. They finally eeked out some things and got through it all and finished. (post-observation interview, 3/21/01, section 123-125)

These teachers are in different places with regard to their knowledge and beliefs about themselves as learners and teachers of mathematics. Their comments suggest that, in the cases of Darrin, Danielle, and Michelle, they recognize that they still have room to grow with regard to their instructional practice. Quenton's comments suggest that there really is not currently anything he would do differently because he has consciously eliminated those strategies that he sees as alternatives. What can be said is these teachers' students and student learning have a great impact on these teacher's thinking and teaching. This confirms the need for the additional relationship arrows added to the conceptual framework offered in Chapter 1 , suggesting a two-way connection between teachers' decisions and teacher knowledge, between teachers' decisions and teacher beliefs, and between teachers' decisions and student behaviors (note the dashed arrows in Figure 20 shown below).

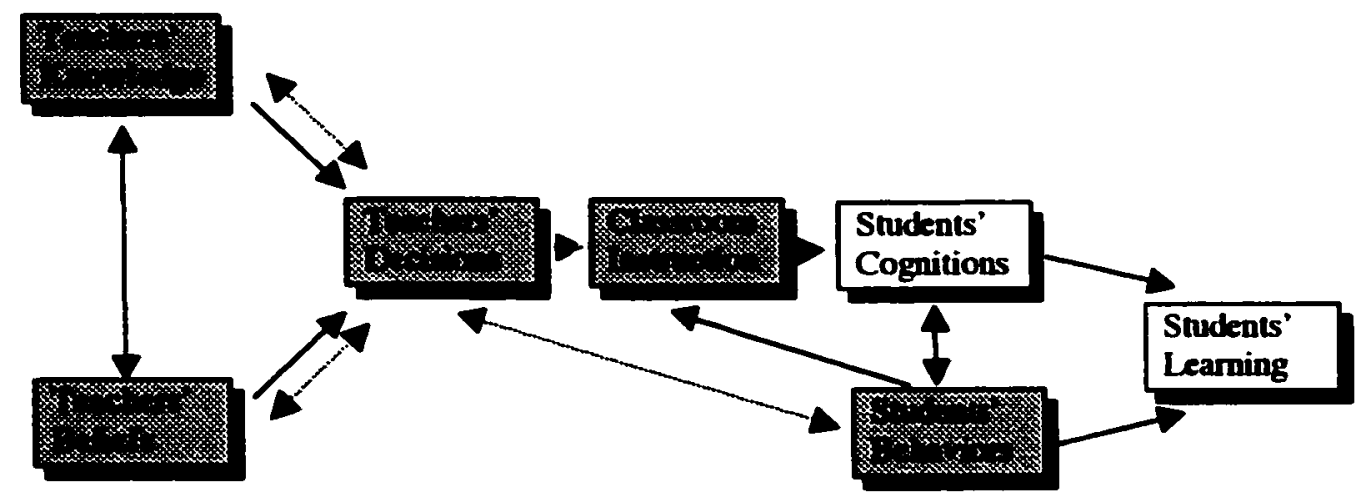

Figure 20. Revised model for research and curriculum development revisited. Adapted from Carpenter (1989, p. 193). 
Pedagogy. These teachers all focus on helping students develop understanding of concepts as opposed to teaching them how to perform algorithms. They view math as more than just a "black box" of rules and procedures to follow; they see instead math as something to understand and want to provide students with experiences that allow them to develop that understanding for themselves. This focus on teaching for understanding reflects their knowledge and beliefs about pedagogy, both general pedagogy and that which is specific to math instruction. Also, related to this desire to teach for understanding, three of the four teachers choose to teach Visual Mathematics; they choose this program even though it is not their district's adopted curriculum.

These teachers see their role as one where they educe or draw thinking out of students. They do this through posing problems that connect prior learning to new learning and exploring and discussing multiple approaches to solving problems. Their goal is to have students develop their own understanding of a concept not simply apply someone else's thinking.

Quenton views math as problem solving, so he develops the culture of his classroom to help students see it the same way. While he suggests that it is not necessarily something that he is doing in the activity that allows problem solving to occur, he did work with his students at the beginning of the year to help them understand that problem solving is what they do in his classroom. He poses problems, they learn through his questioning that they are expected to engage in solving them and share their thinking and reasoning with others. 
Well, I think it is the fact that they are doing it. They are trying to come up with... to solve these problems and find the information they need to find, they are just using what they already know. So really, it's the activity itself that promotes them thinking mathematically about what they've already done and applying it to new situations. It's nothing that I' $m$ specifically doing by setting up the activity that is causing that, other than it's just the normal culture of the classroom. It's what we do. (Quenton, pre-observation interview, 3/16/01, section 42)

Michelle also describes how her questioning helps students to understand her expectations of them. Because she wants students to understand math concepts for themselves, she looks for ways of drawing thinking and ideas out of them so they do not have to come from her.

I do it through questioning. I go around the room talking to groups individually. When they ask me a question, I try to get them to explain to me what they are trying to do and how that is going to accomplish what you want to accomplish. Because they tend to... like the boy who came up here and said "I'm going to add this up and add this up, will this get me this?" I didn't even know what they were talking about. I try to get them to tell me if they did that, what will that tell them, will it answer what you want to answer. A lot of times I try to answer questions with questions and that is frustrating them. When kids are stuck, I try to get them to start with what they do know. (Michelle, post-observation interview, 4/6/01, section 307)

Danielle also views math as problem solving and problems as something to work through and understand. She describes how taking a problem solving stance toward teaching allows her to work directly with students unlike what she can do when she takes on the role of a lecturer. She appreciates having opportunities to learn about her students' understanding and is freed up to have those conversations with students when she chooses to teach in this way. 
... for a teacher to be able to work directly with group of students, to get to know their thinking process, to get to work with them, you know to be able to work the classroom. You get much more individual time with kids. It is amazing how much more than if you stand in front of the room and be that lecture teacher. You also get to see the areas where students are stumbling, you get to see things that maybe I push through at a little bit faster pace. You see when the students are getting it and know when to move on. I think that one of the benefits for me and for the kids is being able to look at something in depth. We don't do something just because it's one page in the book and put it aside and don't come back to it. To be able to look at connections to things that we've done before, cyclical work, talk about concepts like proportional analysis, and sort of use that as this undercurrent the whole year long. (Danielle, follow-up interview, 6/8/01, section 288)

Danielle also comments that "there are times where I'd just like to take out the book and stand in front of the class, but it's just like, don't go there. Don't even go there" (post-observation interview, 4/12/01, section 292). Based on her comments from the follow-up interview, Danielle sees the benefits in teaching using a problem solving approach and it is those benefits that keep her from returning to a lecture approach.

Assessment. These exemplary teachers use a variety of assessment strategies because they see the purpose of assessment as way to understand students' understanding. Their methods are dominated by alternative assessment techniques such as curriculum embedded tasks, journal reflections, observations, and informal interviews. They focus on what students know and can do and then plan based on what they see and hear. All of the teachers utilize the lesson Follow-ups to determine individual students' understanding of the concepts and to have a written record of that understanding. In addition, Michelle develops quizzes and tests for the lessons, as she 
is concerned with evaluating student performance in more ways so that she has more grades in her gradebook.

These teachers assess students' understanding to help them make instructional decisions either for the whole class or for individual students. These decisions are made through observation and conversation with the students. These conversations involve listening carefully to students and gathering information regarding what they know and can do.

You just have that constant assessment of kids that's going on all the time. Some students are understanding it through doing a particular exercise or task. Some kids are still lost or in the dark. What can I do to help them? Is there another avenue that I can do? I find that that is really strong. Part of that assessment is listening to what they have to say. Listening to how they explain it. A question that sometimes I'll ask kids is "can you explain that to another person sitting in your group?" Through that explanation I will understand their understanding. (Danielle, initial interview, 1/9/01, section 60)

These teachers also make instructional decisions based on a more formalized assessment, reflective writing. This writing may be a component of an assignment or a question the teacher poses for students to respond to in their journal, in either case, the teacher is using this assessment information to make decisions about students' understanding and needs.

When I asked for a reflection or there is a piece in the work where a student has to reflect on what they can do or cannot do is so valuable to me now. I really use that as an assessment tool in duration of lesson or to decide if were are through with this and need to move on, or what do we need to review and talk about, what do we need to re-address. (Danielle, follow-up interview, 6/8/01, section 232) 
All of the lessons in the Visual Math curriculum have several worksheets.

These include: Focus Masters, Student Activity sheets, and Follow-up Activity sheets. The Focus Master and Student Activity sheets include problems that students explore in the context of the lesson, while they are learning the concepts. The Follow-up Activity sheets include problems that students solve to show their mastery of the concepts. These teachers use them as a culminating assessment for the lesson.

Darrin and Quenton assess student work on these worksheets in a similar fashion. Essentially, the Focus Master and Student Activity sheets are scored for effort and completion. The Follow-up Activity sheets are scored using a holistic scoring scale that looks at the level of the students' understanding of the concept, the thoroughness of the students' work, and how well students' thinking is communicated. Quenton also has students revisit the work on the Follow-ups once he has given them feedback on their first attempts on the problems. He asks that students choose problems from the Follow-up to develop more completely for inclusion in their "showcase portfolio." As they choose the problems he asks that they choose problems that reflect both their understanding of the concepts as well as their ability to apply the concepts.

Danielle and Michelle assign points to the Focus Masters, Student Activity sheets, and Follow-up Activity sheets. Michelle discusses her scoring system which begins with a holistic scoring guide:

On the daily basis I use a variation on the assessment form that is in the Visual Math. It has communication, it has visual models, it has symbols... so it kind of encompasses everything. If they get 
everything right and they've done everything that's asked of them, then I give them a " $Q+$." If they make some minor little errors or they leave some piece out, then I give them a "Q." I still think that meets my standards or my expectations for the class. Somebody that gets an "I" is somebody who misses quite a bit or has a big chunk that they left out. Somebody that gets an " $R$ " needs to rethink the whole thing because they've kind of missed the boat in understanding it. I also give an "NC" which is needs completion because I don't always think that rethink and needs completion are the same thing. There's not evidence that they need to rethink it, you just didn't finish it. They assess themselves. I look over that and reassess in most cases and write little notes about why I changed the grade. (initial interview, 2/26/01, section 86-88)

But changes to a point-based system.

But in my gradebook $I$ put in a number for that. So an " $E$ " is 10 out of 10 points, a "Q+" would be 9 out of $10 \ldots$ and the reason I did that is because I have a lot of kids and parents say "well they did their whole assignment, they didn't miss anything, they should get 100\%." I say "no, an ' $E$ ' means that you did something above and beyond what was requested and a ' $Q+$ ' says that you've done what was required, nothing more, nothing less." So I wanted to give that a value of an "A-." It means that you'll occasionally need to do an " $E$ " to guarantee that you have a strong " $A$," other than your test scores. (initial interview, 2/26/01, section 88-90)

Michelle's system is representative of a mix of the "old" with the "new," similar to the approaches observed by Cohen (1990) and Ball (1990) with early implementation of the Mathematics Framework for Califormia Public Schools (California State Department of Education, 1985). It seems as though Danielle is further along than Michelle the reform continuum with regard to student assessment. In addition to scoring the various worksheets with points, Danielle relies heavily of observation and student reflection. Whereas Michelle comments: 
... occasionally, I do observations, but my classes are so big that I don't do that... I do tests. But observations are something that I don't do as often as I wish I would. I wish I did a few more observations. (initial interview, 2/26/01, section 98)

When asked what she might look for when she observes students she comments that it:

... would probably be more participation. You know..., are they contributing to the group? In my middle block, are they doing anything they are supposed to be doing? It would probably be more of a behavioral training session than it would be actually assessing their math knowledge. (initial interview, $2 / 26 / 01$, section 122)

Darrin, Danielle, and Quenton view the opportunities for conversation about concepts during the lesson as opportunities for individual assessment and sites for decision-making about what to do next. Alternatively, Michelle essentially follows the curriculum as written, then stops for a test or quiz, and then makes a decision about whether or not to re-teach based on student performance. While all the teachers view assessment as a tool to guide instructional decision making, for Michelle some of that decision making is delayed until after a test or quiz. Also, with Michelle the discussions of assessment quickly turn to discussions about evaluation and grading.

Relationship of Internal Influences to Problem Solving Practice. Shown in Table 19 are the teachers knowledge and beliefs about math content, problem solving, students as leamers, themselves as teachers, pedagogy, and assessment and the related problem solving instructional practices. For example, what these teachers know and believe about math content is that math is something to figure out and understand; because these teachers believe that they give students opportunities to explore math concepts and develop their own models and methods for solving problems. 
Table 19

\section{Relationships of Internal Influences to Problem Solving Practice}

\begin{tabular}{|l|l|}
\hline Knowledge and Beliefs about... & Problem Solving Practice \\
\hline $\begin{array}{l}\text { Mathematics content as something to figure out } \\
\text { and understand }\end{array}$ & $\begin{array}{l}\text { exploring and developing models and } \\
\text { methods } \\
\text { observing, conjecturing, generalizing }\end{array}$ \\
- $\begin{array}{l}\text { mathem solving as a means to learn } \\
\text { Students as capable mathematicians }\end{array}$ & $\begin{array}{l}\text { proving models/methods, discussing } \\
\text { reasoning and solutions } \\
\text { - } \begin{array}{l}\text { Themselinesuish" control } \\
\text { mathematicians }\end{array}\end{array}$ \\
$\begin{array}{l}\text { Pedagogy and mathematics pedagogy as aiding } \\
\text { leamers with construction of knowledge } \\
\text { Assessment as a tool to guide instructional } \\
\text { decision-making }\end{array}$ & - $\begin{array}{l}\text { ask questions, provide manipulatives, and } \\
\text { have students engage in problem solving } \\
\text { observing and listening carefully to students }\end{array}$ \\
\hline
\end{tabular}

\section{External Influences}

This section continues the focus on the influences on these teachers' instructional practice. It explores the teachers' perspectives about the external influences on their practice including: curriculum, educational reform policy, instructional practice, and necessary support and leaming conditions. It concludes with a summary of how these external influences shape these teachers' instructional decision-making and therefore, instructional practices.

Curriculum. Echoed throughout these findings is the influence that the Visual Mathematics/Math Alive! (Foreman \& Bennett, 1996, 1998) curriculum has had on these exemplary teachers' thinking and practice. Already explored was what these teachers know and believe about math content, problem solving, and students including: (1) math is something to figure out and understand; (2) problem solving is a 
means for learning mathematics; and (3) students, while differing in their abilities and proclivities, are capable mathematicians. Explored in this section are what these teachers came to understand in the process of using the Visual Mathematics curriculum. These teachers also discuss the benefits and drawbacks of using the curriculum. Also presented are the results from their critique of two Standards-based curriculum samples alongside the Visual Math curriculum. We have already heard that these teachers feel as though it is not their actions that promote or teach mathematical thinking and problem solving, each states at some point that it is instead the curriculum that does it. In this section, and in previous sections, we see when these teachers review lessons and problems, they suggest adaptations of those lessons and problems to align with the format and rigor of Visual Math lessons. This shows that the curriculum accounts for much of what is observed in these teachers' practice and is able to have this influence because it is well aligned with their knowledge and beliefs about math, problem solving, pedagogy, and students.

Learning about Teaching and Learning. The teachers feel that using the Visual Math curriculum has helped them develop new understandings about teaching and learning. Darrin describes an instance of working with a colleague where he suggests changes in her lesson to make it come more from the students first, just as he has learned to do in Visual Math.

Has it influenced my teaching, yea, everyday, $100 \%$. I would say that at the core is that it is so based on constructivism. That it's not partially constructivism, it's not bringing in the idea of it. It all starts with the kids' knowledge and getting it to grow from there. I think it's fascinating. Obviously, you can use constructivism with anything, but 
I think because of Visual Math, I kind of naturally think of things that way, not that I've talked to teachers too much about their curriculums. I've certainly had my hands full this year. I did at one point talk to the social studies teacher who was trying to teach them about taking notes for something. She had this whole thing set up and $I$ just sort of brought up sort of inverting it started with the kids doing it. She was like, oh. Because of Visual Math that came really naturally to me, with the math everything always starts with that. (follow-up interview, $6 / 19 / 01$, section 135 )

Darrin describes this influence on lesson development, suggesting that he has realized that the learning process begins with what the students know and believe rather than the teacher's goals.

Danielle describes how implementing the program has influenced her thinking about the right questions to ask both during task development and while students are working. The questions she now asks help to move students forward with their understanding of the concepts.

I've learned more about how to write questions, when I'm asking questions for an assessment or something. I'm just thinking some of the really simple problem solving problems like you have a pool, you give the dimension, you are going to put a walkway around the pool, how many 12" tiles are you going to put around the pool? Why not ask them, how many other sizes of tile can you use where you never have to cut a tile? So we are looking at factors of 12. I ask that same first question, but I also ask, well what else can I use if all the tiles are exactly the same size? What if you mix tiles and use different sizes and still never have to cut a tile? Now see, before when I did a problem solving l'd never ask those further in depth questions because I was so used to following that state format. That says "this is a problem solving problem." (follow-up interview, 6/8/01, section 260276)

Oh gosh, I've really learned a whole lot. I've learned methods of working with students in groups, I have learned how to ask probing questions, I' $m$ constantly learning and thinking of ways to strengthen understanding and to ask questions to develop understanding. I think 
that is probably, a lot that it is curriculum directed. It put me on that pathway. About the questioning, asking those Socratic questions. I think that using that really as a teaching style. Sitting in [my professor's] classes, observing her style and observing how actively engaged people were in what they were doing. Trying to model some of that in my classroom. It wasn't only the curriculum, but also how the curriculum was initially presented to me. (follow-up interview, 6/8/01, section 224-228)

Danielle feels that her questioning skills developed in the context of using the curriculum. Also influential in developing her practice was observing the questioning used by her professors in her math courses.

Similarly, Michelle describes how she shows and tells less and asks questions more now that she is using the Visual Math materials.

Well, I've taught for 27 years, so there has been a big change. We used to just present and I'd have to find different ways to visually present it to the kids and I was inviting them to look at patterns, but I really wasn't giving them the experience of that. It was all pretty much "you pay attention to me and do what I do," you know the typical way of teaching. Now I try to develop their understanding, and of course the Visual Math lends itself to that. I think that having to ask more questions has definitely come out of it. Of course, there is lots more hands-on. I like it because it makes kids think, it's not just a... when I first started using Visual Math I'd get kids saying "you're making me think too hard." "Why do we have to think in here?" Because that's what math is all about. I mean how to think logically. (follow-up interview, 6/13/01, section 87)

As a result of using the Visual Math curriculum, Michelle describes a shift in her practice to the use of more hands-on approaches and asking students to do more thinking than they were accustomed to.

Quenton describes that through his experiences learning the hands-on approaches he learned that math could be fun, colorful, and interesting and students 
can still get to the same place mathematically (initial interview, 2/23/01). As he prepares to teach new lessons, he is amazed with how well aligned the possible solution strategies outlined in the manual are with what students actually come up with on their own.

It's like, "how do you know?" It's amazing to me. You look at it and you read the teacher comments and you say, "Oh geez, nobody is going to come up with that and the first thing that is out there is just like the book." It's because it is so valid. It stems from thinking. You start with the basic model and you think about it, there is pretty much some inescapable conclusions. And the kids come up with them, it's pretty cool. (Quenton, post-observation interview, 3/21/01, section 119)

While Quenton recognized the power of student discovery and hands-on approaches when he was first introduced to them, he is constantly reminded of the validity of these approaches as he uses the curriculum with students.

Through teaching using the Visual Mathematics curriculum, these teachers have learned lessons about both content and pedagogy. In an earlier discussion we learned about the content they came to better understand. In this section we learned that through the use of this curriculum, Darrin has learned that the learning process begins with what students know and believe; Danielle has become skilled at asking questions that uncover and develop students' understanding; Michelle has learned that hands-on approaches to teaching and learning really make students think; and Quenton has confirmed the power of student discovery of important math ideas through use of visual models and the validity of the Visual Math program. 
In the next three sections we explore the teachers' perceptions of the Visual Mathematics curriculum. Explored first are what the teachers perceive as benefits to using the program, followed by the drawbacks. Finally, teachers were asked to analyze two other curriculum samples relative to each other and then relative to their experiences using Visual Mathematics.

Benefits to Using Visual Mathematics. Common benefits noted by these teachers include that the lessons themselves promote mathematical thinking and problem solving. The lessons are sequenced in such a way that the concepts spiral and build on ideas already explored. The concepts are interconnected and explored in depth. Quenton comments that "This Visual Math thing is so powerful that it could be a total overhaul of mathematics" (initial interview, 2/23/01), the curriculum has that power. Two representative comments about benefits come from Danielle and Michelle. Both Danielle's and Michelle's comments relate to how learning takes place in a Visual Mathematics classroom. They pick up on both the social nature of learning and the inquiry-oriented approach to learning taken in the curriculum.

Students develop understanding. Students are able to construct their [understanding of] concepts. Students have tactile experiences. Students collaboratively learn in groups... they just learn to do that. They leam to pull ideas from other kids and they learn to share their own ideas. They learn some pretty incredible math along the way. I think the thing is that it takes us three weeks to get through something but it is such a long slow build. What we are doing right now is a sort of the culmination of what we've been doing with tiles and edges and arrays and patterns... the ownership the kids have in what they are doing and knowing... they know they've moved into another level of mathematics and that whole celebration. When you are in the middle of that time factor you're going we're never going to get to the end of this but then you do and it's cause for celebration. So yea, time, 
there's two sides to the time. [But if I did it from the book] would the kids really know it? Would they have that sense of ownership? Would they have that sense of celebration? No. No. There's no celebration when you teach a standard curriculum. I don't ever remember having an environment where kids would celebrate what they've leamed. We just turned the page and went on. There wasn't any of this cheerleading. [laugh.] (Danielle, follow-up interview, 6/8/01, section 323-329)

I think it leads to lots of good discussion about the math. I keep going back to that one problem with the algebra kids; having them try to figure out how something works rather than just showing them. You know, I think, number one, it makes them think. Two, they observe and use the scientific process. They daily use this as a thinking process, it's not rote learning. I think they have a more concrete, visual understanding of what the math is, but sometimes they don't make the transition to symbolic very easily. It might be that I am expecting them to make it too soon because they were only in the first half or first part of Volume Two. (Michelle, follow-up interview, $6 / 13 / 01$, section 114)

Drawbacks to Using Visual Mathematics. The comments regarding drawbacks

were more varied, ranging from concerns about content to concerns about support.

One concern was regarding the lack of real-world application problems:

... the real-world applications are not there or very rarely. So that complaint I have still sticks. I say to the kids a lot that "it is about thinking, it's not about you know, solving this equation, it's about being good thinkers." It's to help you. I gave an example with computers. Have you ever noticed that people who are good with computers are oftentimes good at math? There is nothing that is really in common between those two. There is nothing that you learn in math class that has anything to do with computers. It's the way that people approach computers, it's that way that you approach math. By taking a set of rules and working with it, coming at things from different directions. That would kind of work. They would be kind of like, "ok." They didn't have any response to that. But they nevertheless two weeks later would ask "why do we have to do fraction strips, when are we ever going see these?" You know, and especially eighth graders want to find things wrong. You know, algebra tiles, where are these from, my parents showed me a different 
way that is so much easier. I really would like there to be more focus on real-life applications. (Darrin, follow-up interview, 6/19/01, section 243)

Michelle noted that there was some content that was not explored this year because of how long it took to teach the lessons.

We didn't do any work with decimals, really. We did a little fraction, decimal and percent with the areas of silhouettes but not a lot. [Because] it's in Volume One. And it is in lessons we didn't get to. Scientific notation, not that that's a biggie, but they should have been exposed to it. Um, they had done some work with some formulas like the triangle area formula. They were looking at squares and rectangles and figuring out that it was one-half. They had that down pretty well. But sometimes I feel that I am leaving out some of the finer details. But, when it comes to statistics, I don't think we left anything out. We didn't do any box-and-whisker plots but they come later. (follow-up interview, 6/13/01, section 130-142)

Danielle feels as though the curriculum is lacking in teacher and student support. She presents two concerns, one regarding the necessary math background of the teacher and one related to the vocabulary used.

One of the things is that you really have to be strong mathematically to teach this program. I think that is a drawback. Either that or you have to have some kind of support group within your building where you go through and talk about doing the math. Another thing, the students are used to a particular word and you get to the follow-up and there is a word thrown in that they've never seen before. I don't remember the specific instances but I do know that that's happened. We have to spend some time talking about the vocabulary. Sometimes the vocabulary of the lessons gets in the way and it's not the level of the reading, it's the vocabulary. (Danielle, follow-up interview, 6/8/01, section 337)

Critiquing Other Curricula. In reviewing a sample lesson from two other

Standards-based curricula, the teachers gave their overall impressions of the lessons.

They also described similarities and differences between the lessons and compared the 
lessons to what they knew of the Visual Math lesson addressing the same content. Their comments are summarized in Table 20. Upon comparing the approach of these lessons to the approach taken in Visual Math, these teachers felt that the Visual Math lessons would go straight to the concept and promote more student thinking instead of guiding their thinking. The Visual Math lessons go into more depth and review old ideas while discovering new. Darrin stated that he noticed a lot of similarity between Visual Math and Nosing Around but said that Nosing Around really misses out by not looking at all the different units of measure (e.g., linear, area, volume). Danielle felt that the students leave the Visual Math lesson with a broader view of scaling, viewing it as a pattern progression versus simply viewing it as enlarging a figure. Darrin, Danielle, and Quenton each negatively commented on the context, saying it was silly, too much reading, and/or confusing. Michelle thought that the other Standards-based lessons were more fun and easier for her low achieving students to relate to. 
Table 20

\section{Comparing Visual Mathematics to Two Other Standards-based Curricula}

\begin{tabular}{|c|c|c|}
\hline & $\begin{array}{l}\text { Similarities between these two } \\
\text { Standards-based Lessons }\end{array}$ & $\begin{array}{l}\text { What these two Standards-based Lessons Do } \\
\text { Differently }\end{array}$ \\
\hline Footprints & \multirow[t]{2}{*}{$\begin{array}{l}\text { - uses patterns to explore } \\
\text { ratios } \\
\text { - provides a context } \\
\text { - } \quad \text { isolates ideas }\end{array}$} & $\begin{array}{l}\text { - Uses a double number line to explore the pattern } \\
\text { - Discovering a bit more } \\
\text { - Presents one pattern }\end{array}$ \\
\hline \multirow[t]{3}{*}{$\begin{array}{l}\text { Nosing } \\
\text { Around }\end{array}$} & & $\begin{array}{l}\text { - Using coordinates and a table to explore the } \\
\text { pattem } \\
\text { - Presents several patterns } \\
\text { - Asks students to do more thinking }\end{array}$ \\
\hline & Similarities to Visual Math & What Visual Math Does Difrerenuly \\
\hline & $\begin{array}{l}\text { - Provides a concrete visual } \\
\text { experience through } \\
\text { sketches on graph paper } \\
\text { - Uses pattems to explore } \\
\text { changes in } \\
\text { dimensions/lengths }\end{array}$ & $\begin{array}{l}\text { - Provides a concrete visual experience through use } \\
\text { of manipulatives } \\
\text { - Reviews work with perimeter, area, surface area. } \\
\text { volume, ratio and proportion } \\
\text { - Extends scale factor into 3D } \\
\text { - Uses patterns to explore changes in area, base } \\
\text { perimeter, surface area, volume... look at all } \\
\text { these ideas simultaneously } \\
\text { - Asks for observations, predictions and } \\
\text { generalizations }\end{array}$ \\
\hline
\end{tabular}

An additional comment that Darrin made once the researcher shared where the

Nosing Around lesson came from was:

That explains why Nosing Around was feeling like it was only "halfsies." They start with discovery, then practice it. Like their triangles lesson, at first I really liked it, I could see the discovery of $1 / 2$ bh but you turn the page and they give you the formula. If you have a belief of constructivism then go all the way, don't give it away as if there is one way. I just think that in going $1 / 2$ way they take the thinking from the kids. At times I struggle with no text. You know, not having that "official knowledge" but I wouldn't like this. (followup interview, 6/19/01, section 327) 
Darrin's comments suggest that he strongly values the opportunities for students to discover concepts and formulas for themselves. His complaint about the other curriculum was related to the fact that the text is structured in such a way that students do not have to construct understanding on their own, they can turn the page and find the "official knowledge," find the formula, find out how to do the problem, etc.

These exemplary teachers' perceptions of the Visual Mathematics curriculum are generally more positive than they are negative. This is particularly evident as they review other curricula and compare the approaches to the approach taken by Visual Math. They appreciate both the teaching approach and the rigor of the program, it is well aligned with their knowledge and beliefs about mathematics, problem solving, and pedagogy, that is why three of the four teachers choose to teach using these materials, as opposed to their district-adopted programs. Similarly, these teachers' knowledge beliefs about mathematics, problem solving, pedagogy, and effective curriculum are well aligned with perceptions about the educational reform policy. These relationships are explored in the next section.

Educational Reform Policy. The state reform policy, particularly the problem solving component of the state expectations is consonant with these teachers' knowledge and beliefs. Even though the policy is not the reason these teachers choose to teach math in the way they do, these teachers do see the policy offering them a justification for teaching math in the way they do and some see the policy as having afforded opportunities for new learning that they would not have otherwise had. 
Darrin comments that it would be harder to teach Visual Math if he did not have this philosophical backing from the state, as he sees the problem solving expectation as something that supports the work he is doing. Danielle feels that she would not have had all the exposure to problem solving she has had if it were not for the state expectations. It was this exposure and her using the Visual Math curriculum that has helped her develop a broader view of problem solving. Michelle admits that before the state had the problem solving expectation she would often skip over the problem solving sections in her book. Now she sees herself doing all the parts of problem solving on a daily basis. Quenton feels that the ideas coming from the state regarding an emphasis on problem solving and the development of worksamples are good, but he had really already changed his practice before the reform policy was in place.

When asked if their instructional practice would change if the state reform were not in place these teachers reiterated their goals in teaching problem solving and the role they feel it plays in their curriculum. All the teachers state that they would still emphasize problem solving but each offer a knowledge and/or belief justification for doing so.

Problem solving would still have a huge role. It would be just as important because the Visual Math curriculum is so heavily focused on thinking. (Darrin, initial interview, 2/13/01, section 180)

Knowing what I know now, about problem solving, I would still be doing the same thing. I'm still going to be emphasizing problem solving because to me it is the life skill of mathematics. (Danielle, initial interview, 1/9/01, section 124) 
I think I would still do problem solving. I would still do problem solving and I'd still emphasize all the strategies as we do in the Visual Math whether I'd score things with the scoring guide... I don't know... that's a good question. [laugh.] (Michelle, initial interview, 2/26/01, section 197-201)

Actually, probably not at all because they were kind of being developed at the same time we started working on the project at [another middle school] with [our university partner]. We always felt like we were 5 years ahead of where the state was at. Had the state done it or not, it wouldn't have mattered in my teaching. I would still be doing the things that I am now because of my experiences [with that project]. (Quenton, initial interview, 2/23/01, section 179)

Darrin and Michelle comment that they would still teach problem solving through their continued use of Visual Math, which they use because it meshes with their knowledge and beliefs about math and problem solving. Michelle's comments may lead us to believe that she would feel less constrained in her teaching of problem solving if the scoring guide were not in place. Danielle and Quenton attribute what they are doing in the çlassroom to what they have learned through their professional development. Now that their knowledge and beliefs have changed, there is no going back.

When asked for examples of ways that the state standards have impacted their instruction these teachers described preparing their students for the problem solving assessments by giving them opportunities to develop problems to be scored. In each case, the teacher is helping students develop a better understanding of the expectations of the scoring guide, these discussions and experiences influence their work.

The state expectations have impacted my teaching of problem solving in regards to the open-ended assessment. I prepared them for the test by having them work independently on work samples for a half-hour a 
week. I think having them answer a problem really well, by explaining, drawing diagrams, and verifying; it's a really important problem solving skill and has made their other work for me more comprehensive. (Darrin, initial interview, 2/13/01, section 176)

I don't even let them take them home to work on. My experience has been that their parents or older brother or sister help them too much, it's not their work. When you give them one on-demand in class and they can't do it at all. I usually make most of them on-demand and I don't even do a lot of rewrites unless they are just the tiniest little thing that needs to be fixed. When I go to have them rewrite them, they read them and say, "I don't even know what I was doing there." I say, "just think, if you don't know what you were doing, how am I supposed to know. You need to communicate so that we both know." Most of the time, rather than giving them the same problem to rewrite, although I think that is valuable, I've made them do it just because they learned, they had to do it over and over until they got it right. But it's very time consuming. But they leamed a lot by doing it. (Michelle, initial interview, 2/26/01, section 233)

It's hard for me to answer that. I mean, in terms of work samples we do a lot of work with discussing what is means to have a four in concept development. We talk about the scoring guide a lot. I haven't done a lot this year with the short periods. But when we had the longer periods we spent some time every couple of weeks working on problem solving stuff. They got their choice of problems and they write it up as if they were doing a work sample and then they score them. They do some self-scoring and they score other kids' paper using the scoring guide. (Quenton, initial interview, section 183)

Darrin stated, "I didn't do much for the multiple-choice. I mean I gave them a practice test. I don't know. I feel like those warm-up problems that I did today and I do every Tuesday and Wednesday, I feel like that's preparation for it" (Darrin, postobservation interview, 4/17/01, section 31-35).

When Quenton was asked about how what he does is aligned with the standards he responded with the following: 
I think [this "good" problem] is way above and beyond anything the state standards are concerned with. They would not even know how to approach looking at this. There is not one right answer that they can look at. Not that the people there don't understand that how would you even deal with scoring something like this. I think of this as problem solving. As far as the knowledge test, what do you call it, the multiple-choice test, there's nothing like this on the knowledge test. The concepts that we study in course 3 aren't even on the test. So we are working beyond them. (initial interview, 2/23/01, section 75)

Three of the four teachers say they emphasize problem solving more because of the policy. All of these teachers support the state reform policy but say that their instructional practice would not change if the reform were not in place; instead the policy serves as a justification for what they are doing in the classroom. One drawback of the reform policy, according to Quenton, is that it has "no teeth in it." He states:

The standards are just so lame. They don't mean anything. A kid could get $4 \mathrm{~s}$, or $3 \mathrm{~s}$, or $\mathbf{2 s}$ on that problem solving and it doesn't matter. They are still going to go on to the next grade and they are still going to get their high school diploma even if they don't get their CIM certificate. You know it's not like they have to pass the CIM to get anything. It's just there. We do all this paperwork and there is no teeth in it. They've watered it down, so you can actually get a 3 in one of the areas and still pass the test. It's used to put another article in the paper to show how many passed the test. I think the ideas are good. I like the problem solving thing, I think the kids should be able to do that. It's a standard part of being a mathematician but I really wish I could say this really counts. "You've got to get a good score on this." (initial interview, 2/23/01, section 91)

Instructional Practice. These teachers' knowledge and beliefs about mathematics teaching are developing through the act of teaching. Approaching mathematics instruction through problem solving has influenced both these teachers' beliefs and the beliefs of some of their students. Danielle and Michelle each describe 
a picture of their teaching practice "before" and "after" they changed their approach to teaching. The role of the teacher in the "after" classroom has the teacher posing problems and telling less.

I think before, before I really felt like I was tied to the curriculum and that I really did need to present it chapter, page, and verse on what was done. The more I stepped out of that realm and the more that I started looking for ways to step out of the realm, the more comfortable that felt in my classroom. I think the more productive of an instructor I was and my students were definitely more productive... If I was told I had to go back and teach math the other way, I'd find another place to teach. [Laugh.] I would. I'd teach reading or language arts where the kids have some choice in what they are doing. You don't have any choice when you are just doing memorization mathematics. There is not element of choice at all. It wouldn't matter that you found another way to solve the problem, you didn't do it right because you didn't do it the way the book told you. (Danielle, initial interview, 1/9/01, section 152-156)

But it's more interaction amongst each other than it is with me talling them what to do. Where in the past, it was more answer focused it is now process and thinking focused, if that makes sense. I remember when I was trying to make a change over from that and the kids would be saying, "well, what is the answer?" "I really don't care what they answer is, I care how did you get it? Can you tell me how you got it?" (Michelle, initial interview, 2/26/01, section 273)

While Darrin was not changing the way he had taught, his beliefs about the role of drill-and-practice were shifting as a result of teaching math using this approach.

Darrin's own learning experiences have focused on learning through practice. Now, as he uses the Visual Math curriculum he is wondering about the need for practice when concepts are explored again in later lessons. He comments, "I don't know if I need to give them more practice opportunities or if I just need to be more patient" (Darrin, follow-up interview, 6/19/01, section 267). 
Darrin and Michelle both commented on changes in beliefs held by students.

Darrin's comments were the result of a discussion with a student.

I think I' $d$ be a much less happy teacher [if I weren't teaching this way]. I think it is also more interesting for the students and more interesting for the teachers. I would teach $\mathbf{3}$ classes for $\mathbf{8 5}$ minutes on technically the exact same thing and it was never the same. Never. [laugh]. This was also the student feedback on it. It was interesting because a student one day was saying, "Man that must be so hard to teach the same class and read the same thing... well you're lucky, because with math it's always changing and stuff." And I'm thinking that is not something that I would have said about my eighth grade math class. I would have been like, with math you really have to do the same thing over and over again. But that was his impression of what math was. That's it's always changing and going in different directions. So I thought that was cool. (Darrin, follow-up interview, 6/19/01, section 139)

The students had an assignment to write a letter to a teacher who had an influence on

them. A couple students wrote their letters to Michelle.

[One student] says "before last year I was starting to hate math. You made it fun to go to and interesting. Most importantly, I think I learned a lot." [A nother student writes] "I've been in your class for the last two years and you've had a great impact on my life." This was pretty nice for him to write. They wrote some nice things, I think really meant it. "You've taught me a lot and have been exceedingly nice to people that don't deserve to be treated so well. I think your class is my favorite because of the way that you present the material that you teach and also that you are willing to help the people that are struggling." I liked the fact that he liked the method that I was using so well. (Michelle, follow-up interview, 6/13/01, section 91)

These teachers' knowledge and beliefs are clearly developing with their practice.

More specific influences on these teachers' problem solving practice are explored

further in two sections that follow. One section explores the dimensions of knowledge 
and beliefs impacting their practice and the second explores the external influences on teachers' knowledge, beliefs, and practice.

Necessary Support and Learning Conditions. This section explores the support and learning conditions that are necessary for teachers' continued development of their instructional practice. Both formal and informal professional development are considered. In the first part I will describe the role of formal professional development occurring through preservice and inservice coursework and field experiences. In the second, I will describe the informal support and learning opportunities that take place in the school setting through interactions with administrators and colleagues.

Professional Development. These exemplary teachers describe a formal professional development experience as their "critical moment" in changing their thinking and teaching of mathematics. For Darrin, it was his student teaching experience along with some math education courses that meshed with his view of mathematics. For Danielle, it was her math for elementary teachers course and realizing their was more to math than just memorizing. For Michelle and Quenton, it was attending a course/conference for inservice teachers that suggested a way of teaching math for understanding. For each, it was the hands-on approach that made the experience so powerful. Also powerful for Michelle and Quenton was the timing; they were searching for something to work more effectively with their students and the strategies suggested were ones they perceived would make a difference. 
Following are some representative quotes from these teachers describing other

formal professional development experiences these teachers have had. These include

30-hour courses, workshops, and opportunities for sharing and collaborating with colleagues.

[The district supports me] by providing classes... I think in order to become an even better teacher in problem solving I still have a ways to go. That is going to come from other colleagues and just being exposed to that environment, knowing what other people do. The district is very good about doing that. Giving me the opportunity, contractually being able to do that. (Danielle, initial interview, 1/9/01, section 148)

Well we've had quite a few inservices. They've dealt with mostly how to use the scoring guide and how to score. I serve on the district committee for CIM so I get it first-hand about things and I' $m$ usually showing other people what's required, what it means, what has to go in the portfolio and how, that kind of thing. In terms of actually teaching to problem solve, we haven't had a ton. I mean, in the beginning we did have some inservices that showed how to break it down in to the different dimensions and working on the different strategies, but it's been a long time ago. ...So not a lot of that. We've had some support in using the scoring guide and checking our inter-rater reliability, that kind of thing. [These took place] across the district. Now they just last week had new teachers and mentors work together on scoring. I took Molly and she scored my papers and we covered them up to check and see if we agreed on them. So trying to train new teachers that's ongoing. (Michelle, initial interview, 2/26/01, section 241)

The project [included] lots of staff development, lots of meeting time, and working together, lots of coursework and workshops that we went to. We were funded to do all that [through a grant]. We had lots of hours of training and exploration with the math, actually doing the math lesson and things like that. That was probably the Cadillac of all support programs. I doubt there will ever be anything like that again, just because it was so massive. We did like the Visual Math Course 1 and 2, Implementing Visual Math in the Classroom, and a couple of others that they changed the name to make them look different, but continuing on basically the same idea. The summer before we started implementing, we took Visual Math Course 1. And then during the 
year we did [course] 2 and then the next summer we did the Implementing class. That's the perfect experience. I don't think you could do any better than that. Of course that takes commitment on the part of the people that are in it as well. I know a lot of teachers would have never gone through that. (Quenton, initial interview, 2/23/01, section 229)

Darrin describes the professional development that would be most helpful to him.

I'd love to take more classes with the Math Learning Center. I'd love to have more trainings for VM, more [university] classes, which I plan to keep on taking, just not this year. [Laugh]. I don't know. The district has so many different styles and if I were to get support, I'd really like it to be specific to the VM curriculum. Not just some sort of general math stuff. This stuff is more useful to me. I would have loved to have... I did one Math Learning Center class this summer, but it was mostly work that we do here in the $7^{\text {th }}$ grade. I would have liked to have more experience with the upper stuff the course 3 stuff. It was really a course 2 training and I want course 3, upper course 3, the stuff I won't get to this year. I want to be one step ahead of them. [Laugh] Last year, what was nice was that I taught and observed [cooperating teacher] with $6^{\text {th }}, 7^{\text {th }}$, and $8^{\text {th }}$ grade and could see the whole spectrum. I think that if I didn't have all three that would really hurt me this year especially, just teaching $8^{\text {th }}$. I think being able to see what is going on at each level is really important. (Darrin, initial interview, 2/13/01, section 219-223)

For these teachers, it was a formal professional development experience that helped them create a vision for improving their mathematics teaching practice, and it is through continued professional development that they are able to sustain and cultivate their thinking and teaching of mathematics. Beyond the ongoing nature of these experiences, key characteristics are the hands-on opportunities for these teachers' own learning of mathematics and their opportunities for practice-based discussion with colleagues for learning about teaching. 
Administrators. Administrators also play a crucial role in developing their

teachers' knowledge and skills. These teachers describe how their administrators have supported them by sending them to classes, but they also see administrators as offering support through empowering them as teachers as well. Two examples come from

Danielle and Quenton; they were each given the freedom to use curriculum that is not their adopted curriculum.

Being able to experiment with some curriculum is incredibly supportive. If I was told that I had to teach [the adopted program] and only [the adopted program], I still wouldn't do it, but I'd give the façade that I would. I just cannot imagine not having that freedom to do some investigation in my own classroom. My principal has been very supportive in allowing me to do that, giving me freedom within my own classroom to do that. He's let me try things that I think are out of the norm of what is going on with other teachers who are teaching mathematics. (Danielle, initial interview, $1 / 9 / 01$, section 148)

Since I've been here I guess there hasn't been any real material support. I have the money to buy whatever materials, but we've had three different principals in five years. The first ones we had were a job-share thing, they were elementary people and they really didn't know math anyway, they thought what I was doing looked cool, so they were fine with it. Last year we had our second principal in her second year. I told her that I wasn't going to use the [adopted program] and she was fine with it, so I got support from her that way. Our new principal was at one of our feeder elementary schools when we had the [professional development] project going on, so she saw Visual Math in action and knew what it was. So she's okay with it to. So I don't feel pressure to defend it or act like I'm using [adopted program] when I'm really using Visual Math. So that's support I guess. (Quenton, initial interview, 2/23/01, section 206)

While Darrin and Michelle are teaching in situations where Visual Math is the adopted curriculum, Danielle and Quenton are not. Their administrators trust these teachers and allow them the freedom to teach in a way that they feel best serves their students. 
Colleagues. Colleagues, like administrators, influence these teachers through their support or lack of support for instructional practices they are using. While Darrin and Michelle are teaching in situations where there are other teachers using Visual Math, their colleagues vary in their use of and support for the program. Danielle and Quenton each teach in situations where they are the only teachers using Visual Math; Danielle has looked for support elsewhere and Quenton has withdrawn from support. Darrin's eighth grade teaching partner is using the program and has used it for the last several years. He and Darrin often plan and discuss the lessons together. The two of them are concerned that the sixth and seventh grade teachers are not implementing the program as whole-heartedly as they had hoped, but they do feel that their level of implementation is an improvement over years past.

Michelle is one of two identified math leaders in her building. She mentors half of the teachers in her building with the implementation of Visual Math and hopes that this collegial support will influence problem solving practice. Some concerns she raised after the first year of implementation were, that not all teachers completed the agreed upon lessons and the program does not provide enough drill-and-practice according to her teachers. It is in response to these concerns that Michelle hopes that a school-based Principles and Standards (NCTM, 2000) study group and opportunities to observe in other classrooms will help.

Danielle is struggling with teaching in a school where the norm is traditional practice. 
I'm really uncomfortable now, because I'm seeing a lot of [practice that reflects] the "before." I see people who have not really changed their practice over the last several years. And, um, I'm frustrated with those individuals. I'd like to know how to reach out and grab those individuals and shake them up a little bit. Not necessarily to convert them to my way of thinking, but just to get them to open their eyes and experience the things that I think are so productive. This year, one of my fellow teachers said to me "I don't see why you are having the kids draw all those pictures. If you just give them the formula then they'll know how to do it." Now obviously that still bothers me. I'm sorry, just because you've memorized a formula doesn't mean you necessarily know how to do it. I can see that. And I really do believe that I am right in my philosophy and the other person is wrong in their philosophy. I know that that is a personal prejudice. But I don't know how to open those doors. I'd really like to open the door so that this person can really see what the students are doing and maybe have their students experience that. (Danielle, initial interview, 1/9/01, section 160)

Quenton is struggling with being the only math teacher in his school, so he lacks

opportunities to collaborate with other math teachers. He also has added two electives to his teaching load causing him to feel overloaded with responsibilities, so much so that he does not take advantage of professional development opportunities that would help him continue to grow.

I go to the math training sessions that they are doing for [the adopted program] so I see some of my old math buddies. I' $m$ not there collegiality-wise or as a colleague. It's more of a social thing. I go just to see what they are doing and to learn a little bit about it. But as far as collegiality...there's not much. I don't have the time for it. I'm teaching four different levels of math and two electives. I've never gone to the [leadership development] institutes. I really want to, but I can't take the day off and blow off a whole weekend and have to plan for a sub and clean up and do all the work I didn't do. It's just too much. In that respect, I really haven't sought it out. Which is too bad. That was one of the things that I really enjoyed at my other school. I like to do a couple workshops in the summer to keep in touch with some people. So I really haven't done as much of that lately, plus I'm getting old enough now, and close enough to retirement that I'm just 
sort of an old flaky curmudgeon. [Laugh.] (Quenton, initial interview, 2/23/01, section 210)

Danielle and Quenton each comment about ongoing learning and how some teachers

are willing to do the extra work to grow and learn more, but others are not.

The other thing to is that... it really does boggle my mind that everyone has all these opportunities to take additional classes, but they don't take advantage of it. You know that whole thing where we talk to kids about being life-long learners. Well, don't we need to model that? I believe that there are teachers and there are educators. Someone gets his paycheck every month, those I consider to be teachers. And the ones that are educating are the ones educating not only their students, but also themselves [are educators]. They look at life as an educational experience. "What can I do to do my very best?" (Danielle, initial interview, 1/9/01, section 200)

The teachers that weren't involved [in the project], never would have been involved. They wouldn't have put in those kinds of hours even if they were getting paid for it. They just wouldn't have done it. So I guess part of it is having people who you are working with who are willing to do the things that you have to do to make things better, the extra work, the extra hours, and all that. I guess colleagues are a part of that support system. I just don't think about it because I don't have it here. [Laugh.] (Quenton, initial interview, 2/23/01, section 233)

These teachers, with the exception of Darrin. are not experiencing what Clarke calls the "spirit of collegiality, collaboration, and experimentation" (1997, p. 296).

They teach in situations where they have support from their administrators and have been given the opportunity for "experimentation" through use of innovative curriculum materials. These teachers are working toward outcomes they value (e.g., problem solving) and have available professional development opportunities that fit their needs. But once this researcher leaves, three of the four teachers no longer have an audience and critical friend that will ask hard questions that help them continue to 
grow. How will they reflect, plan, and obtain the emotional support needed to help them continue to construct their practice (Weissglass, 1994)? These teachers have some ideas about what would best suit their needs at this time. These are presented in the following section.

Teachers' Needs for Support. These exemplary teachers are not teaching in situations free from struggle. They each face challenges with teaching as they do. Regarding their teaching and learning philosophy, they are pleased with where they are but they each seek different support for their continued growth. When these teachers were asked about the "ideal" support conditions for them in their developing practice, three responded with suggestions for the establishment of collaborative learning communities within their schools, something that Quenton had experienced in his previous teaching environment.

For my first year, what I would really love is more time to observe. It's hard because I have three classes. It would almost make more sense if I had four 60 -minute classes. What would be nicest for me is if I had 3/4 load and I was able to spend the other 1/4 of it observing, maybe having someone come in more often to observe me. I would love that. I would really love it. I think that would be really great. I think that lessening the workload a bit, no one would complain about that, but that first year is a little overwhelming and you are doing the same work that people have been doing for a long time. Yeah, especially with the VM, I'd like to observe for classroom management things... just bring me out of the cocoon you get into in your classroom. I've been lucky that I've been able to do so much observation before becoming a teacher because the experiences I had as a student teacher and teacher's assistant got me in to see a lot of different people. But, now that I am teaching I would really get a lot out of that. (Darrin, initial interview, 2/13/01, section 204-206)

My ideal, I would have classes of no more than 24 or 25 students. I would have tables to work on. I would have room to walk about in my 
classroom. I would have all the manipulatives and supplies that I would need at any moment in time [laugh]. I would have colleagues to work with who would have not necessarily my philosophy, but a philosophy similar to mine. Ideally, I would like to have at least every day or maybe every other day to be able to have some common planning time with people, looking at what they are doing and how they are developing a particular lesson that maybe we are joint teaching. Some experiences that they've had, you know just that comparison and collaboration you get. That's one of the reasons that I wanted to come here, because I wanted some more collaboration. Ideally, I guess the money I need to go buy all these things. If I really look at the ideal, I'd like to start with the collaboration. I want to spend time with people who have a similar philosophy to mine. (Danielle, initial interview, 1/9/01, section 180)

I really enjoyed the observations we did with the math leaders group and the opportunity to talk about what they saw and what I saw in our visits. I also think that if we could get the teachers to spend the time doing it that they should read the NCTM Standards and talk about how they perceive the standards. What is the role of the middle school? I liked how in the study group we started by looking at geometry and talked about what is most interesting about what you've been reading? What is your main focus as a 4/5 teacher? 6-8 teacher? What should 4/5 students have in place before middle school? What is the high school expecting? Ideally, I would like to see all the 6-8 teachers have this experience. It was nice to have time to get together and share different ways to use the curriculum and talk about strategies for dealing with the same problem. I also think it would be helpful to have a class next year where we do the math and then go back and use it in our class. I don't think you can do Visual Math without a support class. Changing has been a slow process. We need long term support to continue, if no one is looking over our shoulders some might use direct instruction to do it. What is happening this year with the observations and classes is helpful. It makes us accountable to just do it. Next year I'd like all teachers to have time away from class for observations and discussion about what we saw. I'd like to form a study group with the Standards and tie it back to what they are doing in their classes. And I'd like to make sure that we have time to share ideas and put ideas to work. (Michelle, initial interview, 2/26/01, section 297)

[My ideal would be...] I guess first of all there would be academic freedom to choose my own curriculum and be trusted to use my 
knowledge as a professional to teach kids math without other people telling me what I should do. To have an administrator that supports that my class is noisy a lot of times and that it may not be all quiet and orderly. The support from parents who understand what it is that I'm trying to accomplish. They are supportive of me doing things in a little bit different way which here is... at the beginning was a little iffy, because it was new for them too. But it didn't take long for the parents at this school to see what was going on and really like it. They saw just a couple of the assignments coming home and they knew it was different. So, most of them really like it and are very supportive, well and they were at [my other school] too, the ones who were the most concerned about what the kids were doing in the sixth grade by the time their kids were in the eighth grade were our strongest supporters. We really went out of our way to get that support too. I haven't had to do that as much here. (Quenton, initial interview, 2/23/01, section 189-206)

Darrin suggests that he would learn a lot more by observing other teachers now than he did before he was teaching. He feels that it would be beneficial if observations were something that was just arranged, so that the time would not be used for something else. Danielle describes factors both in her physical teaching environment and with her relationships with colleagues that are impacting her teaching. Many of her concerns regarding the physical space she teaches in will be addressed next year when a new wing is added to her school and her portable classroom is eliminated. Danielle also feels that once she is in the building it will be more convenient to have conversations with colleagues. Michelle describes a district-based math leadership study group that has benefited her in developing her practice and she envisions that this type of work at the school level would be beneficial for the teachers in her building. Quenton's comments suggest that he already has much of his "ideal" in his current teaching situation, as he stresses the importance of academic freedom and 
support from his administrator and parents. These teachers' visions for the "ideal" address the struggles that are most critical to them as they implement and/or support others with implementing problem solving practice. To continue developing their practice these teachers would benefit from practice-based professional development that comes from studying their practice (e.g., lesson or task development, analyzing student work) with the colleagues. Development of collaborative learning communities within their schools would address most, if not all, of these support needs.

Relationship of External Influences to Problem Solving Practice. Shown in Table 21 are the teachers' knowledge and beliefs about curriculum, reform policy, instructional practice, necessary support and learning conditions and the related problem solving instructional practices. For example, what these teachers know and believe about their curriculum is that it aligns with a problem solving approach to teaching and learning and plays a key role in promoting mathematical thinking and problem solving in their classrooms; therefore, most of these teachers do not teach problem solving as something outsider their regular curriculum. 
Table 21

\section{Relationships of External Influences to Problem Solving Practice}

\begin{tabular}{|c|c|}
\hline Knowledge and Beliefs about... & Influenced Problem Solving Practice by... \\
\hline $\begin{array}{l}\text { - Curriculum representing a problem solving } \\
\text { approach to teaching and learning and } \\
\text { playing a key role in promoting } \\
\text { mathematical thinking and problem solving } \\
\text { Educational Reform Policy as a } \\
\text { justification for using the Visual Math } \\
\text { curriculum } \\
\text { Professional Development as providing the } \\
\text { "critical moment" in developing their } \\
\text { practice as well as helping to sustain and } \\
\text { cultivate their practice } \\
\text { Administrators as supporters of their } \\
\text { practice and of continued growth } \\
\text { Colleagues }\end{array}$ & $\begin{array}{l}\text { - most ( } 3 \text { of } 4) \text { believe that they do not need } \\
\text { to teach problem solving separately } \\
\text { - the teachers choose to teach the curriculum } \\
\text { because they feel it aligns well with the } \\
\text { policy } \\
\text { secing how use of manipulatives models } \\
\text { can help students understand math concepts } \\
\text { and/or understood concepts for themselves } \\
\text { - allowing them freedom to do what they feel } \\
\text { is best for students } \\
\text { varied }\end{array}$ \\
\hline
\end{tabular}

Summary and Discussion of the Data

The results presented above indicate that problem solving plays a significant role in these teachers' curricula. The goals of this study were to explore, describe, and account for the problem solving practice of four exemplary Oregon teachers'. Darrin, Danielle, Michelle, and Quenton were the teachers exhibiting characteristics most like the Classroom B teacher from Chapter 1 . Through a preliminary screening they showed evidence of utilizing pedagogical approaches that help students make sense of mathematics content while allowing all students access to meaningful mathematics curriculum. 
These exemplary teachers play an important role while engaging their students in mathematical problem solving. They develop an environment where mathematical thinking and problem solving are the norm by:

- consciously building a classroom culture that focuses on students developing their own concept understanding through problem solving, and

- explicitly planning for what they will do to engage students in mathematical problem solving on a daily basis (e.g., deciding what problems to pose, which manipulatives to provide, which questions to ask, how to encourage exploration of multiple approaches to solving problems).

The teachers' and students' roles are interrelated as they engage together in coconstructing the content. As students co-construct this problem solving environment they:

- discuss ideas with each other and the teacher,

- ask questions of each other and the teacher, and

- present their thinking.

As students engage in problem solving, they make observations, conjectures, and generalizations.

In the process of exploring and describing what these teachers do to promote mathematical thinking and problem solving, this researcher also investigated the influences on each teacher's practice and relationships among these influences. These teachers not only demonstrated many similarities in their practice and in their thinking 
about their practice but also demonstrated similarities in what is influencing their practice. Similarities in these teachers' knowledge and beliefs include views of:

- math as something to figure out and to understand,

- problem solving as a means to learn math where strategies are seen as a tool to help you when you are stuck, not as a skill to master,

- students as capable mathematicians ( 3 of the 4 ),

- themselves as developing teachers and capable mathematicians,

- pedagogy and math pedagogy as aiding learners with construction of knowledge (focused on exploring, developing models/methods, proving models/methods, and discussing reasoning and solutions), and

- assessment as a tool to guide instructional decision-making (3 of the 4), There were also similarities with the external influences on these teachers' practice and the relative power of those influences. These include a view of the:

- curriculum representing an approach to the teaching and learning of problem solving and playing a key role in promoting mathematical thinking and problem solving in their classrooms,

- reform policy as a justification for use of the Visual Math curriculum,

- formal and informal professional development as providing the "critical moment" in defining their practice as well as helping to sustain and cultivate their practice, and

- administrators as supporters through providing professional development opportunities and trusting these teachers to do what is best for students. 
Similar to Hawkins (1974) and others (Shulman, 1986a; Grossman et al., 1989), Cohen and Ball (2000) discuss the various types of teacher knowledge needed to teach for students' understanding. They suggest that there are three kinds of knowledge that are crucial for mathematics teaching: knowledge of mathematics, knowledge of students, and knowledge of instructional practices. These components of teacher knowledge are represented with Figure 21, an instructional triangle. This figure shows how $I$, Thou, and $I t$ (teacher, subject, and students, respectively) interact to produce teaching and learning. The top vertex of the triangle represents knowledge of mathematics, in this case mathematical problem solving. The lower left vertex represents the teacher. The lower right vertex represents knowledge of students. The arrows, indicating the interactions among the teacher, students, and content, represent knowledge of instructional practices. The present study examined these interactions as well as the influences on these interactions.

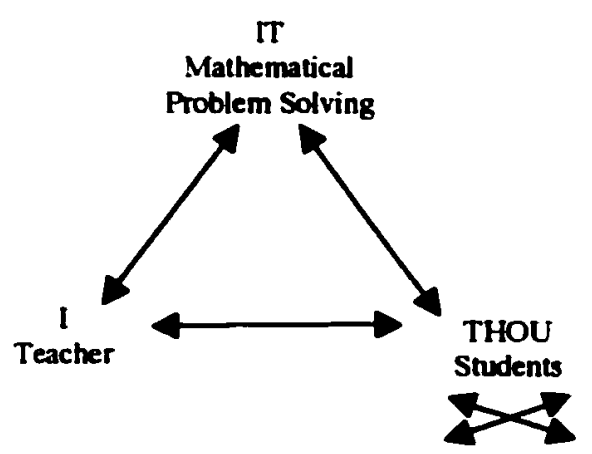

Figure 21. Revised instructional triangle. Adapted from Cohen \& Ball (2000). 
Figure 22 expands on this instructional triangle showing the interactions within and influences on teaching and learning in these exemplary teachers' classrooms. Influencing the content in these classrooms is the belief that math is something to figure out and problem solving is a means of learning mathematics - each shown within an oval, near the mathematical problem solving vertex. The ovals are overriding beliefs that influence classroom interactions and the other sets of knowledge and beliefs held by both teachers and students. Permeating the actions and interactions in the classroom is the teachers' generally shared belief that the students, and they themselves, are capable mathematicians. This belief in students is also shown with an oval due to its impact on both teachers and students. They are able to discover and make sense of mathematics in the same way that mathematicians do, through problem solving. Since the arrows, forming the triangle, represent the classroom interactions, the center of this figure specifies the actions and behaviors valued in these classrooms. In these classrooms, the actions of exploring, developing, proving, and discussing are circular and ongoing in this learning process. The teachers interact in this process by observing, listening, and asking questions, using these assessment strategies to guide their decision-making. The belief of using assessment in this way is also shown with an oval due to its effect on the teacher and the content explored. The external influences of curriculum, reform policy, professional development, administrators, and colleagues are shown acting on the teacher and impacting the teaching and learning process. These influences do not act with equal influence. Bold arrows are used to show that curriculum and professional 

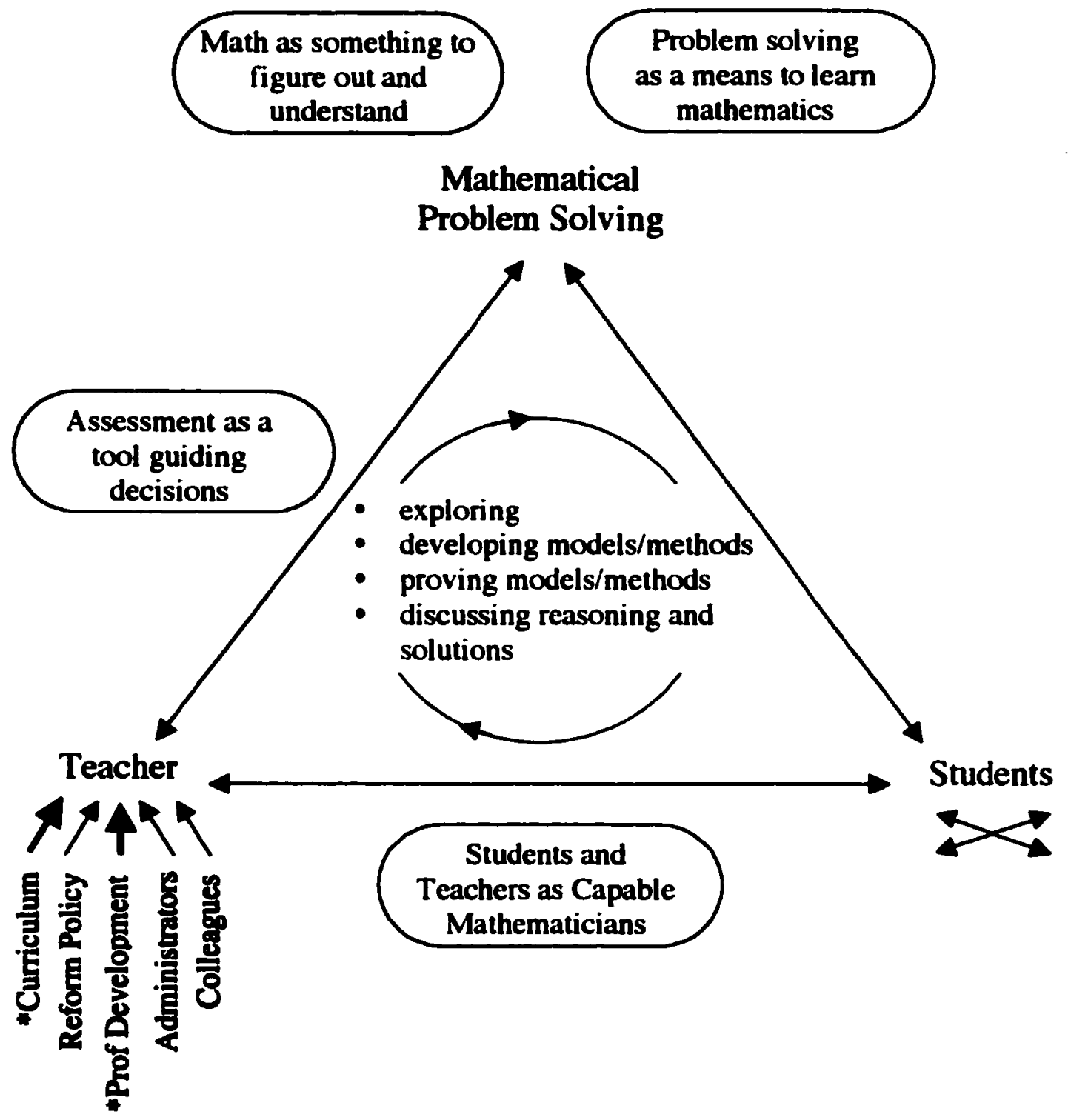

Figure 22. Instructional triangle specifying interactions within and influences on the teaching and learning process. * Indicates a stronger role in influencing these teachers' instructional decision-making and practice. 
development played a stronger role in influencing these teachers' instructional practices than the reform policy, administrators, or colleagues. These results indicate that teaching mathematical problem solving is complex and is influenced by many internal and external conditions. For these teachers, the strongest of these external influences is the use of the Visual Math curriculum and the related professional development experiences. The curriculum not only influences the teaching and learning process through its structure and the implied teacher/student roles but also influences the teachers' and students' beliefs about mathematics and mathematical problem solving. 


\section{CHAPTER V}

\section{CONCLUSIONS, FURTHER DISCUSSION, AND IMPLICATIONS}

This qualitative study helps to fill the gap in the research on problem solving instruction through using multiple data sources including teacher interviews and classroom observations. It provides a fuller description of Standards-based classroom practice than presently represented in the literature by offering both examples of problem solving practice and the related influences on that practice. The study also grounds the implementation of the Principles and Standards for School Mathematics (NCTM, 2000) in the work of practicing middle school teachers. Finally, the study shows how, for these teachers, their curriculum has played a significant role in developing their perspectives on learning, teaching, and the nature of math, which has in turn, influenced their knowledge, beliefs, and instructional practice.

The final chapter of this dissertation restates the research problem posed in Chapter 1 and reviews the major methods used to gather data in this study. The major sections of the chapter summarize and discuss the results presented in Chapter 4 including an interpretation of how these findings fit into the conceptual framework that guided the study and the existing literature. Finally, I offer a set of implications and recommendations based on the findings, as well as suggestions for further research. 


\section{Review of Research Questions and Research Methodology}

The research questions for this study arose from concerns regarding the implementation of Oregon's Educational Reform Act (HB 3565 and HB 2991), specifically mathematical problem solving. In my work as a district math specialist and teacher educator, I found that the reform influenced mathematics teaching and learning throughout the state in both positive and negative ways. In my view, the good news is that the majority of teachers now teach problem solving. The bad news is that many are not doing it well, for a variety of reasons, nor do they necessarily realize that this is the case. Many teachers have come to define problem solving and problem solving instruction relative solely to the dimensions of the state scoring guide, which does provide a rich description of the "product" of problem solving, but does not help teachers understand what students should experience in the process of becoming a mathematical problem solver. The scoring guide, taken alone, provides a limited view of problem solving with its focus on the valued end product, as seen in Classroom A, described in Chapter 1. Therefore, teachers need to consider the cognitive processes of problem solving and move away from instruction that reflects training students to be merely problem performers toward instruction that develops students as problem solvers.

To support teachers' attention to developing students' problem solving expertise, this study provides a vision for what is possible with problem solving instruction in light of current reform efforts and updates the literature by connecting to 
the recommendations for problem solving and problem solving instruction in NCTM's Principles and Standards for School Mathematics (2000). Therefore, the study was guided by the following questions:

1. What do the focus teachers do to engage students in mathematical problem solving?

a) What is the role of the teacher? How do these teachers see their role in problem solving instruction?

b) What is the role of the students? How do these teachers see the student's role?

c) What do these teachers emphasize in their problem solving instruction?

d) What role does problem solving play in their curriculum?

e) How do teachers choose problems for classroom investigation?

2. On what bases do teachers make decisions about -what to emphasize when teaching problem solving? -how to teach problem solving? -when to teach problem solving?

a) What dimensions of teacher knowledge, beliefs, and thinking (i.e., mathematics content, problem solving, pedagogy, mathematics pedagogy, themselves as teachers and learners, students as learners) account for the focus teachers' problem 
solving practice? Do these dimensions interact? If so, how and with what influence?

b) What external influences (i.e., curriculum, educational reform policies, formal and informal professional development) account for the focus teachers' problem solving practice? Do these dimensions interact? If so, how and with what influence?

The present study examines the thinking and practice of four exemplary middle school teachers focusing on what they do to promote mathematical thinking and problem solving in their classrooms. Also considered are the decisions made by these teachers regarding their problem solving instruction and the influences on these teachers' decisions and, therefore, their instructional practice.

The data was mainly derived from in-depth interviews with the teachers and classroom observations. The interviews were designed to determine (1) how the teachers view their role, their students' role, and the role of problem solving in the classroom, including how they choose problems and how they make decisions about problem solving instruction; and (2) what influences their decisions. The researcher observed three consecutive lessons in each teacher's classroom; the lessons were chosen by the teachers to represent lessons wherein they were promoting mathematical thinking and problem solving. Both before and after the classroom observations, there were interviews designed to determine the specific influences on the teachers' practice. 


\section{Summary and Conclusions}

These exemplary teachers play an important role in their classrooms as they engage their students in mathematical problem solving. The decisions they make about what types of problems to pose, what questions to ask, how to best support students, and so forth, impact the students' opportunities to learn during problem solving instruction (see comparison of Classroom A and Classroom B in Chapter 1). Students are actively engaged in this problem solving environment through making observations, conjectures, and generalizations. The teachers' and students' roles are interrelated as they engage together in making sense of the content.

Many common internal influences account for these teachers' problem solving practice. These teachers' view mathematics content as something to figure out and to understand; therefore, they have their students explore and develop their own models and methods for solving problems. They view problem solving as a means to learn math; therefore, they ask their students to observe, conjecture, and generalize. They view students as capable mathematicians ( 3 of the 4 teachers); therefore, they expect their students to discuss their reasoning with others and prove that their models/method work. They view themselves as developing teachers and capable mathematicians and, therefore, are willing to share control of the classroom with their students. They view pedagogy as aiding learners with construction of knowledge, thereby they ask-questions, provide manipulatives, and have students engage in problem solving. They view assessment as a tool to guide instructional decision- 
making ( 3 of the 4 teachers) and, therefore, observe and listen carefully to student thinking and reasoning.

Also, many common external influences account for these teachers' practice. The teachers' view of the curriculum as representing problem solving results in most of the teachers ( 3 of the 4 ) believing that they do not need to teach problem solving as a separate entity. The teachers' view of the reform policy as a justification for using the Visual Math curriculum suggests that their choice of curriculum is based on the curriculum's alignment with the policy. They view professional development (either preservice or inservice) as providing the critical moment defining their practice; such professional development helped them grasp how the use of manipulatives and models can help students understand math concepts and help even the teachers understand concepts for themselves. They also view professional development as helping them to sustain and cultivate their practice, most ( 3 of the 4 teachers) hoping that the development of a collaborative learning community could happen in their schools. They view administrators as supporters when those administrators provide professional development opportunities and trust these teachers to do what these teachers believe is best for students.

In conclusion, this study demonstrates that teachers are able to teach in ways consistent with the NCTM Standards when their knowledge and beliefs about practice align with the recommendations. Further, they teach in this manner when professional development experiences are geared toward understanding and developing Standardsbased instructional practice, curriculum is consistent with this vision of practice, and 
administrators and school cultures are supportive of such practice. When these internal and external conditions exist within and for teachers, their students have the opportunity to learn to become problem solvers, not just problem performers.

Finally, this study fills the gap that exists in the research on problem solving teaching and learning from 1985 to the present. While there are studies that explore reform-based instructional practice in general, there are no recent studies that are specific to problem solving: how teachers think about problem solving, how teachers choose problems, how teacher knowledge and beliefs influence problem solving instruction, etc. This study responds to these neglected and important aspects while considering the role that policy, curriculum, professional development, administrators, and colleagues have on teachers' developing practice. Additionally, while there are studies considering the relationships between teachers' knowledge, beliefs, and decision-making, they tend focus on either early career teachers or teacher researchers. This study is unique in its focus on "exemplary" teachers and the influences on their decision-making.

\section{Further Discussion}

This section discusses my conclusions in the context of the initial conceptual framework and the existing literature on developing teachers' knowledge, beliefs, and practice. Further, I offer a reconceptualized framework and elaborate on its connection to the findings of this study. 
This descriptive study cannot be generalized due to the small number of participants and its limited contexts. The upcoming discussion is limited by the teaching context in two ways: the nature of student assessment and the role of the curriculum. Oregon's high-stakes problem solving assessment is somewhat unique nationally, as most states administer only multiple-choice and constructed response (short answer) assessments; this study provides a picture of what happens to classroom practice when a problem solving assessment is on-demand and high stakes. In addition, all four teachers participating in the study were using the same curriculum, so there are aspects of their thinking and practice may be unique to that particular program.

\section{Reconceptualizing the Conceptual Framework}

The conceptual framework offered in Chapter 1 helped in designing the study, however that model offered by Carptenter, Fennema, and Peterson (1989) did not capture and communicate the dynamic relationships discovered in the context of the study. The instructional triangle offered by Hawkins (1974) and Cohen and Ball (2000) became more useful in accomplishing that purpose because the arrows connecting mathematical problem solving, the teacher, and the students suggest the interrelationships that exist in the teaching and learning process. I was also able to expand the instructional triangle to include the specific interactions between the teacher and the student that take place while engaged in problem solving represented in Figure 23 below. 


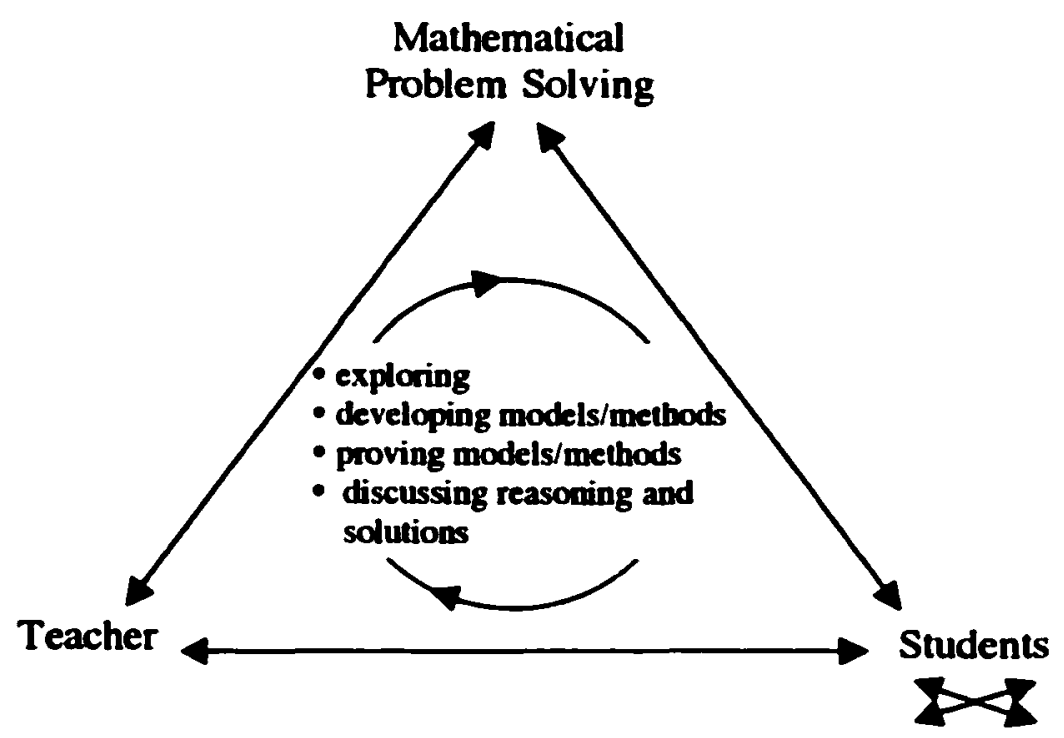

Figure 23. Instructional triangle specifying interactions while engaging in problem solving.

This model also allows for the presentation of the internal influences on teachers' decision-making and practice (added in Figure 24 below). These influences include teachers' knowledge and beliefs about math, problem solving, assessment, themselves as teachers and learners, and students as learners. Over time, the views held by these teachers became views that were shared by both the teachers and the students. 


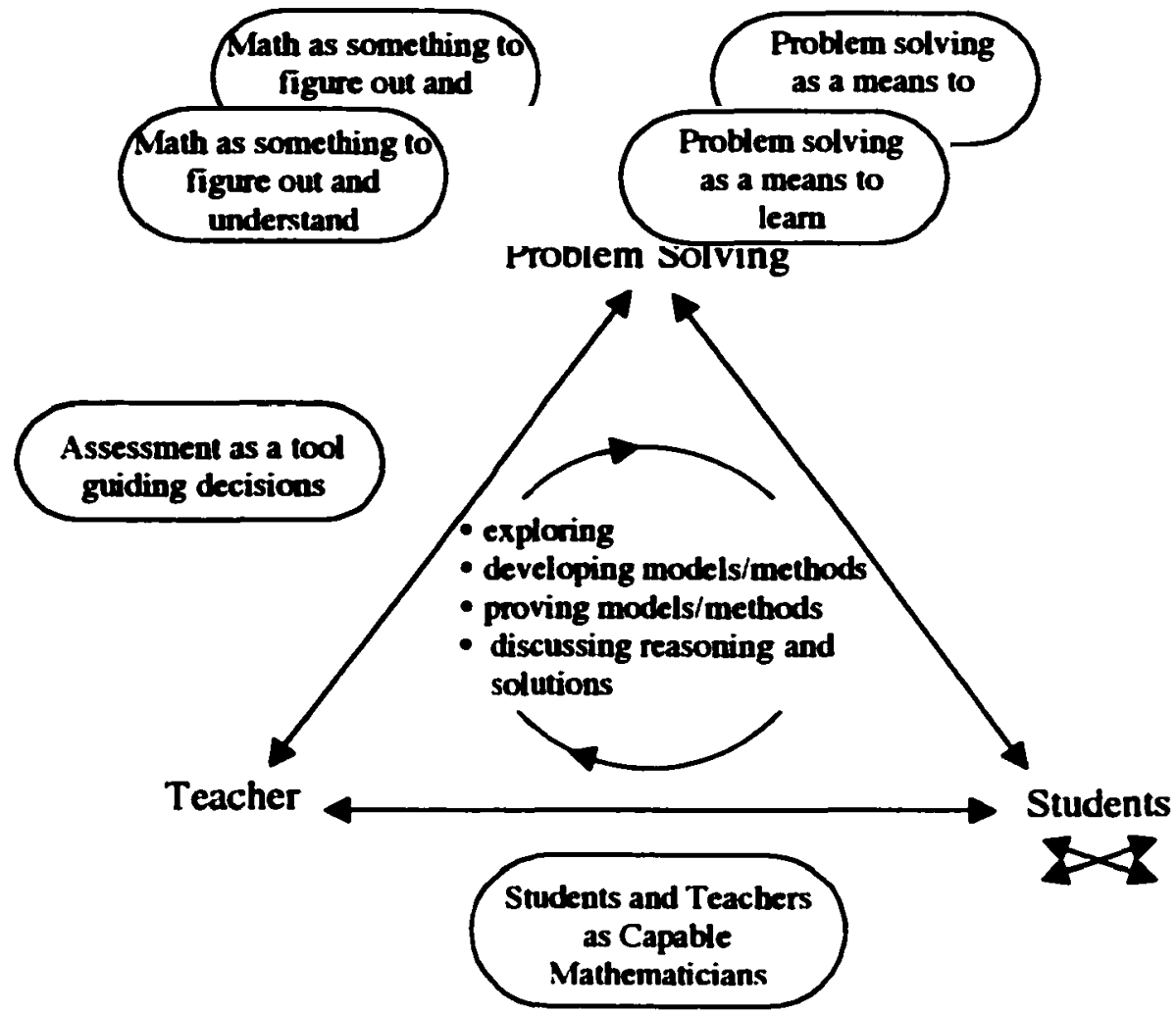

Figure 24. Instructional triangle specifying interactions within and influences (internal) on the teaching and learning process.

Finally, this model allows for the presentation of the external influences on teachers' decision-making and practice (added in Figure 25 below). These influences include the dimensions of curriculum, reform policy, professional development, administrators, and colleagues, each influencing teachers' decision-making and practice. 


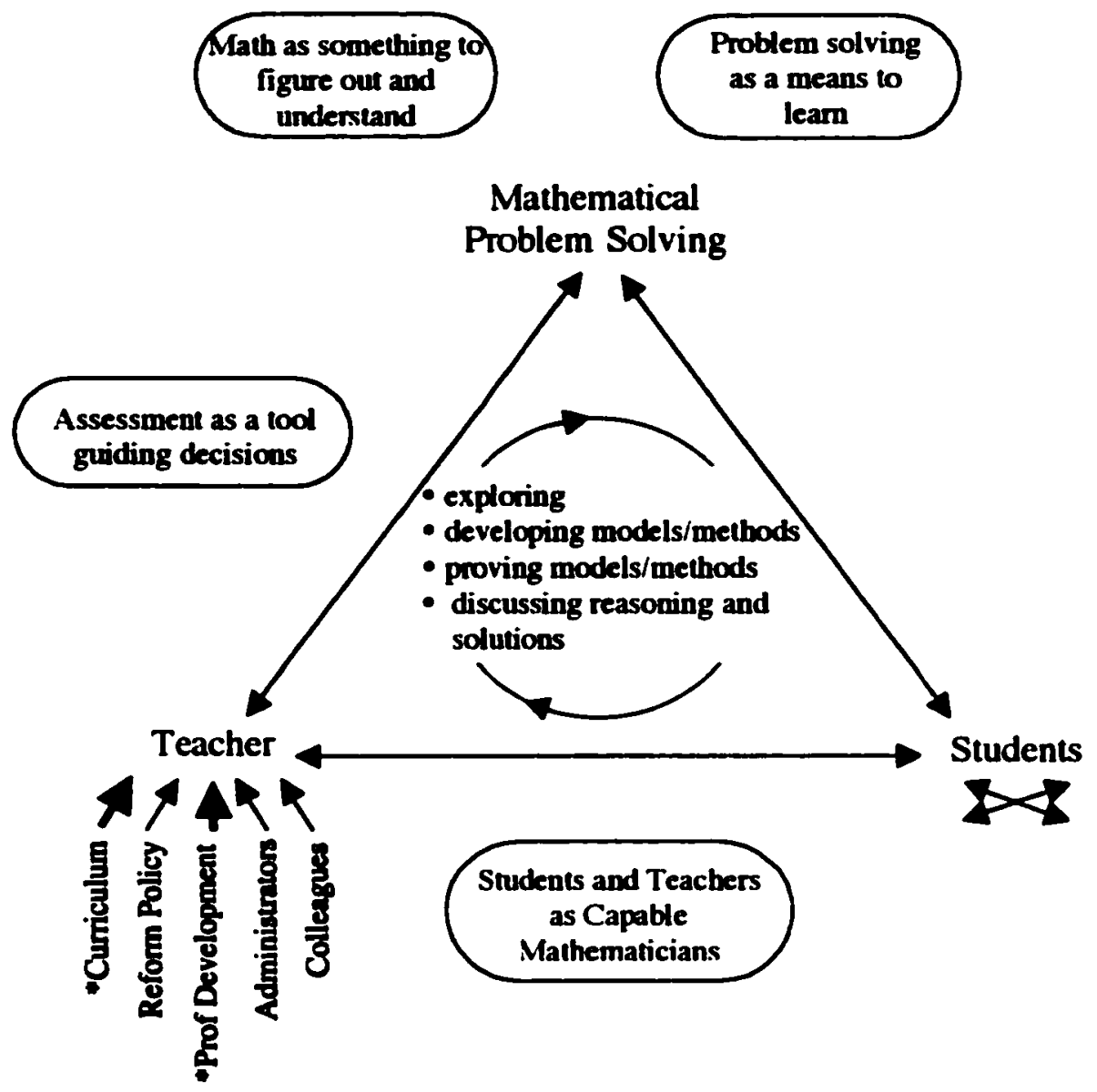

Figure 25. Instructional triangle specifying interactions within and influences (internal and external) on the teaching and leaming process. * Indicates a stronger role in influencing these teachers' instructional decision-making and practice.

The student-student and teacher-student interactions while engaged in mathematical problem solving are represented by the arrows in the instructional triangle and specifically described by the center circle shown above. The teachers in these classrooms rely on the social nature of learning to assist students while they engaged in problem solving; that is, these teachers encourage discussion of ideas and solutions as a means of bringing forward the resources and heuristics available to 
students as they work. This act of making student thinking public assists students in their problem solving performance (Schoenfeld, 1985) because it (1) exposes students' understanding and misunderstanding of concepts, (2) reveals strategies for dealing with being "stuck," (3) uncovers information that students may or may not have used, and (4) improves students' mathematical world view through collectively considering the ideas of others.

Intemal Influences on Problem Solving Instruction

The similarities in internal influences across the four teachers - that is, their knowledge and beliefs about math, problem solving, pedagogy, themselves, and students - confirm that there is a powerful relationship between knowledge and beliefs with instructional decision-making and practice such as that also discussed by Carpenter (1989), Lampert (1990), Lubinski and Vacc (1994), and Thompson (1989). What the teachers in the present study know and believe about teaching and learning is apparent and/or developing in their practice. For example, these exemplary teachers see mathematics as something to discover through problem solving; this syntactic knowledge helps them to interact with and develop their substantive knowledge (Grossman et al., 1989). For these teachers, there is a tight alignment between their beliefs about mathematics and their beliefs about pedagogy, as can be seen through the discussion about and the enactment of their role and their students' roles in the classroom. 
When classroom practice differed from espoused beliefs about math and pedagogy, the teachers attributed the difference to students, and what they believe students know and can do (as seen in Darrin's "hint" and Michelle's "algorithmic" approach to developing problem solving skills). These actions suggest that beliefs about students may be more powerful than the beliefs these teachers hold about math and pedagogy alone. What Darrin and Michelle believe is the right thing to do pedagogically is not yet stable; they "know what it looks like" but their everyday practice is not yet consistently reflective of this aspect of reformed practice (Hall, 1986). Instead of fostering healthy disequilibrium, Darrin and Michelle adjust the task during implementation to avoid disequilibrium and perhaps, in their minds, insure the success of all students.

\section{External Influences on Problem Solving Instruction}

External influences on these teachers' practice were consistent across teachers as well, with innovative curriculum materials and professional development having the most powerful influence on their practice.

Reform Policy. The influence of the educational reform policy on these teachers' instructional practice was not as strong as I would have expected. The good news is that

- these exemplary teachers support the policy as it aligns well with their beliefs about the nature of mathematics, and 
- the high stakes problem solving assessment has afforded these exemplary teachers opportunities to learn more about problem solving but is no longer the reason that they teach problem solving; they now see all of mathematics as problem solving.

While these exemplary teachers recognize that the emphasis on problem solving in the reform policy has afforded them learning opportunities, it is not the reason that they teach using a problem solving approach to instruction. Instead, the policy serves as a justification for these teachers' use of the Visual Mathematics curriculum.

Curriculum. Throughout the interviews and observations, teachers attributed their decision-making about problems to pose, next steps for instruction, and task and curriculum revision, to their experiences using Visual Mathematics curriculum. These decisions are likely related to the fact that there is also tight alignment between these teachers' knowledge and beliefs about teaching, learning, and assessment and the beliefs about teaching, learning, and assessment advocated by the curriculum. This alignment is apparently one of the reasons why these teachers choose to teach using these materials. Another reason for this choice is these teachers recognize how the implementation of this curriculum has helped them grow as a teacher and learner of math along with the growth they see in their students' conceptual understanding and attitudes toward math.

The good news is that the Visual Mathematics/Math Alive! $(1996,1998)$ curriculum and its implementation have served as powerful tools for teacher development. These exemplary teachers' knowledge and beliefs have been altered 
through their experience with using the materials. The teachers in this study describe both the mathematical content and the pedagogical techniques they have learned in the context of implementing the curriculum. This curriculum supported these teachers' content knowledge development through its discussions about math content and possible solution strategies. It supported teachers' development of pedagogical knowledge through the stance it takes toward teaching, learning, assessment, and the power of student thinking and reasoning.

The not-so-good news relative to these teachers has been that the curriculum is a necessary, but not a sufficient condition in developing their instructional practice. Indeed, I wonder whether or not teachers using the Visual Mathematics or other curricula become teachers dependent on them. Moreover, I wonder whether all of these teachers would be able to sustain exemplary instructional practices without the day-to-day support of the Visual Mathematics curriculum. Unfortunately, my guess is "no," at least, "not yet." Three of the teachers were teaching Visual Math as their full curriculum for the first time. Even though they could describe how to improve tasks and curricula, suggesting that they could use any materials and make them better, it was the subtle, day-to-day interactions with students that cause me to doubt their ability to sustain such teaching without the support of the curriculum. Darrin's "hint" and Michelle's overly "supportive" behaviors each represent a downward shift in the cognitive demand of the proposed tasks. These teachers know what the cognitive demand should be, but they do not yet know how to keep it there. With time and experience, they will. 
An additional concem leading from dependence on a curriculum is that teachers may not listen as carefully as they should to where students are and where they need to be. This happens in many ways, sometimes intentionally and sometimes not. For example, a teacher may have one student share their thinking with the class and hear that that particular student understands the concept and make the assumption that either everyone else also understands it or now understands based on the student's explanation. Not listening to students can impact students' mathematical thinking and learning on many levels. It can send the message to students that the teacher does not care about what they understand, how they think, or what they can do. Implicitly, it can communicate to students that the teacher cares more about "covering the curriculum, controlling the discourse, and showing one correct way to think about the problem. These messages to students can translate into negative experiences or beliefs about math, as in the following:

- "covering" the curriculum leading students to a superficial understanding of concepts,

- controlling the discourse leading students to believe that the teacher is the locus of authority in the classroom, and/or

- showing one correct way to think about the problem leading students to believe there is one right way to do math.

These views about mathematics and learning, developed as a result of not being listened to, are not reflective of the beliefs espoused in the Standards.

Also influencing these teachers' curriculum implementation are their 
professional development experiences prior to contact with this curriculum and the students with whom they work. So, we need to help teachers understand, recognize, and consistently implement Standards-based instructional practices without dependence on a curriculum. Ideally, teachers could articulate and consistently implement those aspects of practice as described in Classroom B (choosing the right problem, eliciting student thinking, and reflection and scnsemaking) without the support of a curriculum.

Professional Development. These teachers each identify a professional development (either inservice or preservice) experience as providing for them a critical moment in their development as teachers and learners. These experiences were ones where teachers engaged in learning about math content and pedagogy through "doing." All of the teachers experienced new understandings about the nature of math and math content. Consequently, their substantive and syntactic knowledge developed simultaneously. Their pedagogical knowledge also developed through those experiences because in each case, the professors/instructors were asking teachers to engage in learning math through hands-on problem-oriented instruction.

The teachers also developed professionally in the context of their own classrooms as suggested by Fennema and Franke (1992). As the teachers in the present study used the Visual Math curriculum, they learned more about math, pedagogy, and student thinking. The knowledge they gained through the curriculum implementation influences their beliefs about math, pedagogy, and students. The combination of the learning that takes place in formal professional development 
experiences (described above) and that which occurs through experimenting in the classroom helps the teacher construct professional knowledge that is resistant to fads and external mandates, because the knowledge is personally constructed (Castle \& Aichele, 1994; Schifter \& Fosnot, 1993). These exemplary teachers are apparently building resistance basing their decision-making not only on their curriculum, the reform policy, and positive professional development experiences, but also on what they have come to believe about "effective" mathematics instruction. These teachers now have a vision for problem solving instruction that serves as a critical filter for their decision-making and practice.

School Culture. Administrators and colleagues help to support a school culture that allows these teachers to teach for mathematical thinking and problem solving like the teacher in Classroom B. All of these teachers report that they feel supported by their administrators who allow them to teach in a way that the teachers believe is best for students. These administrators supported professional development for these teachers and allowed them to use a curriculum that was not the adopted curriculum. They encouraged collaboration with colleagues and showed interest in what was happening in these teachers' classrooms (see also, Hord \& Hall, 1987; Hyde et al., 1994). In at least one of the settings, the participating teacher serves as the "expert peer" in his/her school and the administrator finds ways to facilitate collaboration and observation among the teachers (Hall, 1988).

Researchers (e.g., Clarke, 1997; Driscoll \& Lord, 1990; Weissglass, 1994) suggest that also critical to supporting teachers' developing practice is the opportunity 
to reflect on classroom events. Similarly, as three of these teachers describe their “ideal" support conditions they suggest that collaborative discussion about and focused reflection on their practice is what they need to continue to develop their instructional practice.

As seen in this discussion, the findings of this study are consistent with the existing literature regarding internal and external influences which account for teachers' decision-making and practice. For these teachers, the intemal influences are developing as their knowledge and beliefs about math, pedagogy, problem solving, assessment, themselves, and students grow and change through their experiences in the classroom. Differing are the relative power of the external influences on these teachers. For these teachers, their professional development experiences and their curriculum are the strongest influences on their practice, with the reform policy and colleagues and administrators serving as support for their "experimentation" with practice.

Implications and Recommendations

While Oregon's reform policy accomplished getting problem solving instruction into K-12 classrooms around the state, the instruction that is occurring may not be preparing students to become expert problem solvers. One of the original intents of this study was to help teachers and administrators around the state of Oregon develop a vision for what is possible with regard to problem solving instruction. This perceived need was in response to my experiences in working with numerous 
preservice and inservice teachers around the state who see problem solving as a skill to teach separate from content and guided solely by the mathematics problem solving scoring guide. The cases of the exemplary teachers in this study do help in creating a vision for what is possible, while also raising additional questions about teacher development and the influences on classroom teachers' decision-making and practice.

Beginning, then, with teacher educators and professional developers, I relate my research conclusions to several audiences for their pragmatic consideration. Finally, I close with recommendations for further research.

\section{Teacher Educators and Professional Developers}

Teacher educators and professional developers need to help teachers confront and develop their views of teaching, learning, students, and the nature of mathematics. Given that these teachers' learning occurred through coursework or workshops, observation and reflection on practice, conversation with colleagues, and/or implementation of a curriculum, teacher educators and professional developers should provide learning experiences that

- help teachers develop a "vision" for Standards-based instruction,

- engage them in learning in the way they will teach,

- give them opportunities to "try out" their learning, and

- provide opportunities to discuss their learning with others.

Indeed, teacher educators and professional developers need to prepare teachers to be problem solvers in the context of their classroom instruction, flexible and fluent 
users of all their knowledge and beliefs that inform teaching, leaming, and assessment. Given that these teachers see professional development and collegial support as the key to helping them sustain and further develop their practice, teacher educators and professional developers should provide ongoing, professional development experiences that engage teachers within schools in productive dialogue and reflection about instructional practice. They should give teachers the tools that they need to continue development through establishing a professional learning community within their schools.

Specifically, how might teacher educators and professional developers go about providing such experiences? This research provides teacher educators and professional developers with examples of classroom practice where mathematical thinking and problem solving are the norm. For one idea, teacher educators and professional developers can use these descriptions of practice with prospective and practicing teachers to help them understand

(1) what students can do relative to mathematical thinking and problem solving, and

(2) what kinds of teacher actions are necessary to cultivate such mathematical thinking and problem solving in their own classroom (e.g., maintaining the cognitive demand of task through providing appropriate support, questioning to draw out student thinking, listening carefully to students to understand and appropriately challenge and extend their current understanding). 
Analysis of cases encourages discussion about practice in a non-threatening way since it is external to one's own practice. Parallel cases dealing with implementation of the same task in two different ways (like Classroom A and B) can bring forward a specific aspect of practice for discussion, for example, use of questioning or teacher support. Once a group of teachers has positively engaged in analysis of external cases then they could move into discussions about their own practice, perhaps reviewing videotapes, audiotapes, and/or student work as a group. A safe way to begin discussions of practice is by looking only at what the students are saying and doing. Later discussions can shift toward consideration of what influence the teacher actions had on students' actions.

A three-pronged approach to professional development can be powerful. Teachers need experiences in which they engaged in leaming mathematics reflecting the criteria outlined above, this may be curriculum or content specific (i.e., Visual Mathematics, Connected Math, Algebra, Data Analysis). Such experiences, in combination with case discussions and analysis of one's own practice, help teachers develop critical filters for instructional practice thereby helping them mindfully implement curriculum as opposed to just tuming to the next page. The goal of professional development should be to assist teachers with understanding, recognizing, and consistently implementing effective instructional practices without dependence on a particular curriculum. Such instructional practices are stable and useable in a variety of contexts. 


\section{Teachers}

For teachers, there is still the need to recognize that students develop as problem solvers through engaging in problem solving - where problem solving is defined as exploration of (making observations, conjectures, and generalizations) a situation that lacks an immediately obvious strategy or solution while making use of mathematical knowledge, strategies/techniques, metacognitive skills, and beliefs. Teachers can develop students' problem solving expertise through asking them to engage in problem solving and while doing so, students develop understanding of mathematics content. Therefore, teachers need to attend to what students are saying and doing and consider ways to support and extend student thinking so that the task is problematic for all students. Teachers must also consider how their actions impact what students are saying and doing and consider what type of support empowers students to truly engage in problem solving.

What should teachers do to empower students to engage in problem solving? Teachers should pay attention to what students are saying and doing. When they do so, they are more likely to

- choose problems that meet the students where they are and then plan for ways to extend appropriately for each student

- structure ways of helping students make sense of concepts and reflect on their understanding 
- plan for how they will handle student questions about the problem so their actions lead to the maintenance of the cognitive demand of the task rather than the decline

- ask questions that show their genuine interest in how the student thought about the problem instead of looking for a particular answer.

\section{Curriculum Developers}

Curriculum developers need to be aware of the power of a curriculum on teachers' knowledge, beliefs, and classroom instruction. They must be aware that curriculum sends a powerful message about teaching, learning, assessment, students' abilities, and the nature of mathematics. To be most effective these messages need to be consistent with each other and consistent with the vision of the Principles and Standards for School Mathematics (NCTM, 2000).

What should curriculum developers do to support teachers' listening to students? For example, curriculum developers should help teachers understand their role and their students' roles in a Standards-based classroom, through providing

- examples of how a discussion of an idea or task might play-out in the classroom,

- an implementation guide that provides a philosophical basis for the program and suggests that it is this philosophy that should be used as a filter for teacher decision-making, and

- professional development that models these roles. 
They should support appropriate teacher decision-making through inclusion (both in print and embedded in the professional development) of discussions about

- choosing problems that are mathematically worthwhile (leading to discovery or application of big mathematical ideas),

- planning for allowing students to make sense of concepts while maintaining higher-order thinking, and

- utilizing questioning strategies that draw out student thinking.

What difficulties do these suggestions hold for curriculum developers? How might curriculum developers help teachers hold, manage, or deal with them? Such discussions, as I suggest, may be left unread or they may be discounted with the response from teachers that "my students couldn't do that" Curriculum developers and professional developers should challenge teachers to implement the materials as written for a period of time. This would allow students to rise to the challenge of their new roles while also giving teachers a chance to practice their own new roles. Once teachers see that this type of thinking is possible for their students, they are more likely to value the discussions about instructional practice and decision-making, while also being more ready to make appropriate decisions when they deviate from lessons or units as written. Curriculum developers can help teachers in developing the critical filters described in the previous section 


\section{Policymakers}

For policymakers, there is a need to recognize the successes and pitfalls of the state-level policy as it is currently implemented around the state as a whole. Already noted is the dilemma that many teachers around the state who are incorporating problem solving into their instruction are really training students as problem performers instead of developing students as problem solvers. What changes in the curriculum and assessment system might cause positive shifts in instructional practice toward problem solving instead of problem performing? Policymakers should help all teachers develop a vision for effective problem solving instruction through these actions:

- They should consider the "placement" of the problem solving standard in the curriculum framework. As suggested previously, it is problematic to just list problem solving as if it is just another strand area, not to mention the dilemmas around listing it last. Problem solving should be front and forward for teachers. It should be considered, as these exemplary teachers considered it, a means to learn mathematics content.

- They should also explore what impact redesigning the test might have on views of problem solving teaching and learning. I recommend shifting from a one-day, single answer problem toward a design similar to the writing assessment, of several days duration, using an open-ended problem (multiple approaches and multiple correct conclusions). 
- They should consider revising the scoring guide or perhaps redesigning the student checklist to reflect problem solving as a process, not just a product. This change would take the focus off the product while solving the problem and place it on the process.

Students and teachers alike need to view problem solving as a process and as a means to leam mathematics. Reexamining the content standards, scoring guide, and the assessment and refining them to reflect problem solving as a "process" would make a difference in how teachers perceive what it means to prepare students for such work.

\section{Suggestions for Further Research}

From this research, additional questions regarding teacher development surface. These include:

- What influence does the curriculum have on decision making and practice for other exemplary middle school teachers (e.g., those using Connected Math, Math In Context, MaThematics)?

- How do teachers explain "points of decision making" (e.g., planning, teacher-student/student-student interactions, feedback and assessment)?

- How do beliefs about what students can do influence teachers' abilities to listen carefully? What filters (objectives, curriculum, time, content understanding, student ability), if any, influence what teachers attend to when listening? How do these filters shape student learning opportunities and their performance? 


\section{Conclusion}

When initially planning this study, my desire was to explain what teacher knowledge and beliefs are necessary for classroom instruction to focus on developing students as mathematical thinkers and problem solvers. I knew that effective problem solvers possess habits of mind which include:

- Ilexible and fluent thinking

- confident use of mathematical knowledge and processes

- willingness to persevere and make sense of a situation

- curiosity, and

- reflective thinking.

I also knew how important it is for individuals to be effective problem solvers because it is then easier for them to learn new things and to make sense of existing knowledge. Thus, effective problem solvers may gain better access and more opportunities in higher education, as well as being better prepared for "real" problems and citizenship in a democracy. What I also knew was that effective teachers must also possess the same habits of mind, not only with regard to mathematics, but also with regard to their teaching. What was unclear to me was how to move from this ideal to classroom practice that can support that kind of desired learning. In other words, how do teachers become Classroom B teachers who

- possess a rich understanding of math content which includes how knowledge is created in the discipline, 
- utilize pedagogical approaches that help students make sense of mathematics content, through confronting existing conceptions, and realizing connections both within and outside the field of mathematics,

- believe that all students can understand mathematics and should have access to meaningful mathematics curriculum, and

- are confident and flexible in their teaching and are curious about student thinking and the subject.

The four exemplary teachers who participated in this study and their stories illustrate how they became and how they are becoming the kind of teachers they want to be. Their teaching and experiences suggest ways that other teachers may also be encouraged to develop into Classroom B teachers. 


\section{REFERENCES}

Ball, D. L. (1990). Reflections and deflections of policy: The case of Carol Tumer. Educational Evaluation and Policy Analysis, 12 (3), 247-259.

Ben-Chaim, D., Fey, J., Fitzgerald, W., Benedetto, C., \& Miller, J. (1997, March). Development of proportional reasoning in a problem-based middle school curriculum. Paper presented at the meeting of the American Educational Research Association, Chicago.

Bidwell, J. K., \& Clason, R. G. (Eds.). (1970). Readings in the history of mathematics education. Washington, DC: National Council of Teachers of Mathematics.

Borasi, R. (1990). The invisible hand operating in mathematics instruction: Students' conceptions and expectations. In T. J. Cooney \& C. R. Hirsch (Eds.), Teaching and learning mathematics in the 1990's: 1990 Yearbook (pp. 174-182). Reston, VA: National Council of Teachers of Mathematics.

Borko, H. \& Elliott, R. (1998, June). Tensions between competing pedagogical and accountability commitments for exemplary teachers of mathematics in Kentucky. Paper presented at the National Conference on Large-Scale Assessment of the Council of Chief State School Officers, Colorado Springs, CO.

Branca, N. A. (1980). Problem solving as a goal, process, and basic skill. In S. Krulik \& R. E. Reys (Eds.). Problem solving in school mathematics (pp. 3-8). Reston, VA: National Council of Teachers of Mathematics.

Brannan, R., \& Schaaf, O. (1983). An instructional approach to problem solving. In G. Shufelt \& J. R. Smart (Eds.), The agenda in action (pp. 41-59). Reston, VA: National Council of Teachers of Mathematics.

Bruni, J. V. (1982) Problem solving for the primary grades. Arithmetic Teacher, 29 (6), 10-15.

Califomia State Department of Education. (1985). Mathematics framework for California public schools, kinderparten through grade twelve. Sacramento, CA: Author. 
Callahan, R. (1996). Daily problems and weekly puzzlers: $180 \mathrm{mind}$-stretching math problems. Alsip, IL: Ideal School Supply Company.

Carpenter, T. P. (1989). Teaching as problem solving. In R. I. Charles \& E. A. Silver (Eds.), The teaching and assessing of mathematical problem solving: Volume 3 (pp. 187-202). Reston, VA: National Council of Teachers of Mathematics.

Carpenter, T. P., Fennema, E., Peterson, P. L., Carey, D. A. (1988). Teachers' pedagogical content knowledge of students' problem solving in elementary arithmetic. Journal of Research in Mathematics Education, 19 (5), 499-532.

Castle, K. \& Aichele, D. B. (1994). Professional development and teacher autonomy. In D. B. Aichele \& A. F. Coxford (Eds.). Professional development for teachers of mathematics: 1994 Yearbook (pp. 1-8). Reston, VA: National Council of Teachers of Mathematics.

Clarke, D. M. (1994). Ten key principles from research for the professional development of mathematics teachers. In D. B. Aichele \& A. F. Coxford (Eds.), Professional development for teachers of mathematics: 1994 Yearbook (pp. 37-48). Reston, VA: National Council of Teachers of Mathematics.

Clarke, D. M. (1997). The changing role of the mathematics teacher. Journal for Research in Mathematics Education, 28 (3), 278-308.

Cobb, P. (1994). Where is the mind? Constructivist and sociocultural perspectives on mathematics development. Educational Researcher, $\underline{23}$ (7), 13-20.

Cobb, P., Wood, T., \& Yackel, E. (1990). Classrooms as learning environments for teachers and researchers. In R. B. Davis, C. A. Maher, \& N. Noddings (Eds.), Constructivist views on the teaching and learning of mathematics: Journal for Research in Mathematics Education Monograph, 4 (pp. 125-146). Reston, VA: National Council of Teachers of Mathematics.

Cohen, D. K. (1988). Teaching practice: Plus que ca change... . In P. W. Jackson (Ed.), Contributing to educational change (pp. 27-84). Berkley, CA: McCutchan Publishing Company.

Cohen, D. K. (1990). Revolution in one classroom: Or then again was it? Educational Evaluation and Policy Analysis, 12 (3), 311-338.

Cohen, D. K. \& Ball, D. L. (1990). Policy and practice: An overview. Educational Evaluation and Policy Analysis, 12 (3), 233-239. 
Cohen, D. K. \& Ball, D. L (2000, April). Instructional innovation: Reconsidering the story. Paper presented at the meeting of the American Educational Research Association, New Orleans, LA.

Confrey, J. (1990). What constructivism implies for teaching. In R. B. Davis, C. A. Maher, \& N. Noddings (Eds.), Constructivist views on the teaching and learning of mathematics: Journal for Research in Mathematics Education Monograph. 4 (pp. 107-122). Reston, VA: National Council of Teachers of Mathematics.

Cooney, T. J. (1985). A beginning teacher's view of problem solving. Journal for Research in Mathematics Education, 16 (4), 324-336.

Darling-Hammond, L., (1990). Instructional policy into practice: "The power of the bottom over the top." Educational Evaluation and Policy Analysis, 12 (3), 339-347.

Dewey, J. (1970). Extracts from Dewey. In M. Skilbeck (ed.) John Dewey London: Collier-Macmillan Limited. (Reprinted from How we think, 1933, New York: D. C. Heath and Co.)

Driscoll, M. \& Lord, B. (1990). Professionals in a changing profession. In T. J. Cooney \& C. R. Hirsch (Eds.), Teaching and learning mathematics in the 1990's, 1990 Yearbook (pp. 237-245). Reston, VA: National Council of Teachers of Mathematics.

Fennema, E., \& Franke, M. L. (1992). Teachers' knowledge and its impact. In D. A. Grouws (Ed. ), Handbook of research on mathematics teaching and learning (pp. 147-164). New York: Macmillan.

Fernandez, E. (1997, March). The "'standards'-liken" role of teachers' mathematical knowledge in responding to unanticipated student observations. First Draft. Paper presented at the Annual Meeting of the American Educational Research Association, Chicago.

Foreman, L. C., \& Bennett, A. B., Jr. (1995). Visual mathematics: Course I. Salem, OR: Math Learning Center.

Foreman, L. C., \& Bennett, A. B., Jr. (1996). Visual mathematics: Course II. Salem, OR: Math Learning Center.

Foreman, L. C., \& Bennett, A. B., Jr. (1998). Math alive!: Course III. Salem, OR: Math Leaming Center. 
Fraenkel, J. R. \& Wallen, N. E. (1996). How to design and evaluate research in education (3rd Edition). New York: McGraw-Hill.

Goldin, G. A. (1982). The measure of problem solving outcomes. In F. K. Lester \& J. Garofalo (Eds.), Mathematical problem solving: Issues in research (pp. 87101). Philadelphia: Franklin Institute Press.

Griffin, L., \& Demoss, G. (1998). Problem of the week: A fresh approach to problem solving. Grand Rapids, MI: Instructional Fair TS Denison.

Grossman, P. L., Wilson, S. M., \& Shulman, L. S. (1989). Teachers of substance: Subject matter knowledge for teaching. In M. C. Reynolds (Ed.), Knowledge base for the beginning teacher (pp. 23-36). New York: Pergammon Press.

Grouws, D. A. (1985). The teacher and classroom instruction: Neglected themes in problem-solving research. In E. A. Silver (Ed.), Teaching and learning mathematical problem solving: Multiple research perspectives (pp. 295-308). Hillsdale, NJ: Lawrence Erbaum.

Hall, G. E. (1986, April 16-20). Deriving teaching skill from studies of the implementation of innovations in education. Paper presented at the Annual Meeting of the American Educational Research Association, San Francisco.

Haimes, D. H. (1996). The implementation of a "function" approach to introductory algebra: A case study of teacher cognitions, teacher actions, and the intended curriculum. Journal for Research in Mathematics Education, 27 (5), 582-602.

Hall, G. E. (1988). The principal as leader of the change facilitating team. Journal of Research and Development in Education, 22 (1), 49-59.

Hall, G. E. (1992). The local educational change process and policy implementation. Journal of Research in Science Teaching, 29 (8), 877-904.

Hawkins, D. (1974). The informed vision: Essays on learning and human nature. New York: Agathon Press.

Hall, G. E. \& Rutherford, W. L. (1983). Client concerns: A guide to facilitating institutional change. Washington, DC: National Institute of Education.

Henningson, M. \& Stein, M. K. (1997). Mathematical tasks and student cognition: Classroom-based factors that support and inhibit high-level mathematical thinking and reasoning. Journal of Research in Mathematics Education, 28 (5), 524549. 
Hiebert, J., Carpenter, T. P., Fennema, E., Fuson, K., Human, P., Murray, H., Olivier, A., \& Wearne, D. (1996). Problem solving as a basis for reform in curriculum and instruction: The case of mathematics. Educational Researcher, 25 (4), 1221.

Hord, S. M. \& Hall, G. E. (1987). Three images: What principals do in curriculum integration. Curriculum Inquiry, 17 (1), 55-89.

House, P. A., Wallace, M. L., \& Johnson, M. A. (1983). Problem solving as a focus: How? When? Whose responsibility? In G. Shufelt \& J. R. Smant (Eds.), The agenda in action (pp. 9-19). Reston, VA: National Council of Teachers of Mathematics.

Hyde, A. A., Ormiston, M., \& Hyde, P. (1994). Building professional development into the culture of schools. In D. B. Aichele \& A. F. Coxford (Eds.), Professional development for teachers of mathematics (pp. 49-53). Reston, VA: National Council of Teachers of Mathematics.

Jennings-Wiemers, N. (1990). Transformation and accommodation: A case study of Joe Scott. Educational Evaluation and Policy Analysis, 12 (3), 281 -292.

Kantowski, M. G. (1980). Some thoughts on teaching for problem solving. In S. Krulik \& R. E Reys (Eds.), Problem solving in school mathematics (pp. 195203). Reston, VA: National Council of Teachers of Mathematics.

Kilpatrick, J. (1985). A retrospective account of the past 25 years of research on teaching mathematical problem solving. In E. A. Silver (Ed.), Teaching and learning mathematical problem solving: Multiple research perspectives (pp. 115). Hillsdale, NJ: Lawrence Eribaum.

Lamper, M. (1990). When the problem is not the question and the solution is not the answer: Mathematical knowing and teaching. American Educational Research Journal, 27 (1), 29-63.

Leinhardt, G. (1992). What research on learning tells us about teaching. Educational Leadership, 49 (7), 20-25.

Loucks-Horsley, S., Hewson, P. W., Love, N., Stiles, K. E. (1998). Designing professional development for teachers of science and mathematics. Thousand Oaks, CA: Corwin Press. 
Lovitt, C., Stephens, M., Clarke, D., \& Romberg, T. A. (1990). Mathematics teachers reconceptualizing their roles. In T. J. Cooney \& C. R. Hirsch (Eds., Teaching and learning mathematics in the 1990's: 1990 Yearbook (pp. 229-236). Reston, VA: National Council of Teachers of Mathematics.

Lubinski, C. A. (1992). Teacher change K-8. In Methodologies for studying teacher change in the reform of school mathematics, Volume II. Papers presented for the working group, Studying Teacher Change in Reform of School Mathematics, Nashville, TN.

Lubinski, C. A. \& Vacc, N. N. (1994). The influence of teachers' beliefs and knowledge on learning environments. Arithmetic Teacher 41 (8), 476-479.

Merriam, S. B. (1988). Case study research in education: A qualitative approach. San Francisco: Jossey Bass.

National Center for Educational Statistics. (2002). Educational information for students across the nation: Find your school [Online]. Available: hilp://nces.ed.gov/nceskids/Allschool/

National Center for Research in Mathematical Science Education and Educational Development Center. (1992, March 30). Methodologies for studying teacher change in the reform of school mathematics. Volume II. Papers presented for the working group, Studying Teacher Change in Reform of School Mathematics, Nashville, TN.

National Commission of Educational Excellence. (1983). A nation at risk: The imperative for educational reform. Washington, DC: Government Printing Office.

National Council of Supervisors of Mathematics. (1977, October). Position paper on basic mathematical skills. Arithmetic Teacher, 25 (1), 19-22.

National Council of Teachers of Mathematics. (1970). 32nd yearbook: A history of mathematics education in the United States and Canada. Washington, DC: Author.

National Council of Teachers of Mathematics. (1980). An agenda for action. Reston, VA: Author.

National Council of Teachers of Mathematics. (1989). Curriculum and evaluation standards for school mathematics. Reston, VA: Author. 
National Council of Teachers of Mathematics. (1991). Professional standards for teaching mathematics. Reston, VA: Author.

National Council of Teachers of Mathematics. (1995). Assessment standards for school mathematics. Reston, VA: Author.

National Council of Teachers of Mathematics. (2000). Principles and standards for school mathematics. Reston, VA: Author.

National Research Council. (1985). Everybody counts: A report to the nation on the future of mathematics education. Washington, DC: National Academy Press .

Noddings, N. (1990). Constructivism in mathematics education. In R. B. Davis, C. A. Maher, \& N. Noddings (Eds.), Constructivist views on the teaching and learning of mathematics: Journal for Research in Mathematics Education Monograph 4 (pp. 7-18). Reston, VA: National Council of Teachers of Mathematics.

Nolan, J. \& Francis, P. (1992). Changing perspectives in curriculum and instruction. In C. D. Glickman (Ed.) Supervision in transition: 1992 yearbook (pp. 44-61). Alexandria, VA: Association for Supervision and Curriculum Development.

Oregon Department of Education. (2001). Teaching and learning to standards [Online]. Available: http://www.ode.state.or.us/us/mathematics/

Oregon Department of Education. (2002). Oregon statewide assessment results [Online]. Available: http://www.ode.state.or.us/asmu/results/

Oregon Department of Education, Office of Curriculum, Instruction, and Field Services and Office of Assessment and Evaluation. (2000). Worksample study: A report to the department of education. Salem, OR: Author.

Peterson, P. L. (1990). Doing more in the same amount of time. Educational Evaluation and Policy Analysis, 12 (3), 261-280.

Pólya, G. (1945). How to solve it: A new aspect of mathematical method. Princeton, NJ: Princeton University Press.

Pólya, G. (1954). Mathematics and plausible reasoning. Princeton, NJ: Princeton University Press. 
Pólya, G. (1980). On solving mathematical problems in high school. In S. Krulik \& R. E. Reys (Eds.), Problem solving in school mathematics (pp. 1-2). Reston, VA: National Council of Teachers of Mathematics.

Raymond, A. M. (1997). Inconsistency between a beginning elementary school teacher's mathematics beliefs and teaching practice. Journal for Research in Mathematics Education 28(5), 550-576.

Resnick, L. (1988). Treating mathematics as an ill-structured discipline. In R. Charles \& E. Silver (Eds.), The teaching and assessing of mathematical problem solving (pp. 32-60). Reston, VA: National Council of Teachers of Mathematics.

Richards, L. \& Richards, T. (1994). Q.S.R. nudoist: Qualitative data analysis software [Computer software]. Melbourne, AU: Qualitative Solutions and Research Limited.

Rickard, A. (1995). Teaching with problem-oriented curricula: A case study of middle-school mathematics instruction. Journal of Experimental Education, 64, (1), 5-26.

Romberg, T. A. (1992). Problematic features of the school mathematics curriculum. In P. W. Jackson (Ed.), Handbook of research on curriculum (pp. 749-788). New York: Macmillan.

Rowland, G. (1993). Making change our friend: The design perspective. Educational Technology, 33(7), 29-31.

Sawada, D. (1997). NCTM's standards in Japanese elementary schools. Teaching Children Mathematics, 4 (1), 20-23.

Scanlin, A., Hoogeboom, S., \& Goodnow, J. (1998). The problem solver : Activities for learning problem-solving strategies. Palo Alto, CA: Creative Publications.

Schaaf, O., \& Brannan, R. (1983). Problem solving in mathematics. Palo Alto, CA: Dale Seymour.

Schifter, D. \& Fosnot, C. T. (1993). Reconstructing mathematics education: Stories of teachers meeting the challenge of reform. New York: Teachers College Press. 
Schoenfeld, A. H. (1982). Some thoughts on problem-solving research and mathematics education. In F. K. Lester \& J. Garofalo (Eds.), Mathematical problem solving: Issues in research (pp. 27-37). Philadelphia: Franklin Institute Press.

Schoenfeld, A. H. (1985). Mathematical problem solving. Orlando, FL: Academic Press.

Schoenfeld, A. H. (1992). Learning to think mathematically: Problem solving, metacognition, and sensemaking in mathematics. In D. A. Grouws (Ed.), Handbook of research on teaching and learning (pp. 334-370). New York: Macmillan.

School Mathematics Study Group. (1972). Correlates of mathematics achievement: Teacher background and opinion variables. In J. W. Wilson \& E. A. Begle (Eds.), NLSMA Reports (No. 23, Part A). Palo Alto, CA: Author.

Schwab, J. J. (1978). Science, curriculum and liberal education. Chicago: University of Chicago Press.

Secada, W. \& Byrd, L. (1993). Classroom observation scales: School level reform in the teaching of mathematics. Madison, WI: National Center for Research in Mathematical Sciences Education, Wisconsin Center for Education Research, School of Education.

Shulman, L. S. (1970). Psychology and mathematics education. In E. G. Begle (Ed.), Mathematics education: 69th yearbook of the national society for the study of education.Pt. 1 (pp. 23-71). Chicago: University of Chicago Press.

Shulman, L.S. (1986a). Those who understand: Knowledge growth in teaching. Educational Researcher, 12(2), 4-14.

Shulman, L. S. (1986b). Paradigms and research programs in the study of teaching: A contemporary perspective. In M. Wittrock (Ed.) Handbook of research on teaching, (3rd ed.) (pp. 3-36). New York: Macmillan.

Silver, E. A. (1982). Knowledge organization and mathematical problem solving. In F. K. Lester \& J. Garofalo (Eds.), Mathematical problem solving: Issues in research (pp. 15-25). Philadelphia: Franklin Institute Press. 
Silver, E. A. (1985). Research on teaching and mathematical problem solving: Some underrepresented themes and needed directions. In E. A. Silver (Ed.), Teaching and learning mathematical problem solving: Multiple research perspectives (pp. 247-266). Hillsdale, NJ: Lawrence Erlbaum.

Silver, E. A. (1990). Contributions of research to practice: Apply findings, methods and perspectives. In T. J. Cooney \& C. R. Hirsch (Eds.), Teaching and learning mathematics in the 1990s: 1990 yearbook (pp. 1-11). Reston, VA: National Council of Teachers of Mathematics.

Silver, E. A. \& Lane, S. (1995). Can instructional reform in urban middle schools help students narrow the mathematics performance gap? Some evidence from the QUASAR project. Research in Middle Level Education Quarterly, 18 (2), 4970.

Smith, M. S. \& Stein, M. K. (1998). Selecting and creating mathematical tasks: From research to practice. Mathematics Teaching in the Middle School, 3 (5), 344 350.

Stanic, G. M. A., \& Kilpatrick, J. (1989). Historical perspectives on problem solving in the mathematics curriculum. In R. I. Charles \& E. A. Silver (Eds.), The teaching and assessing of mathematical problem solving. Volume 3 (pp. 1-22). Reston, VA: National Council of Teachers of Mathematics.

Steen, L. A. (1990). On the shoulders of giants. Washington, DC: National Academy Press.

Stein, M. K., Smith, M. S., Henningsen, M. A., \& Silver, E. A. (2000). Implementing standards-based mathematical instruction: A casebook for professional development. New York: Teachers College Press.

Strauss, A. \& Corbin, J. (1990). Basics of qualitative research: Grounded theory techniques and procedures. Newbury Park, CA: Sage.

Sykes, G. (1990). Organizing policy into practice: Reactions to the cases. Educational Evaluation and Policy Analysis, 12(3), 349-353.

Thompson, A. G. (1985). Teachers' conceptions of mathematics and the teaching of problem solving. In E. A. Silver (Ed.), Teaching and learning mathematical problem solving: Multiple research perspectives (pp. 281-294). Hillsdale, NJ: Lawrence Erlbaum. 
Thompson, A. G. (1989). Learning to teach mathematical problem solving: Changes in teacher's conceptions and beliefs. In R. I. Charles \& E. A. Silver (Eds.), The teaching and assessing of mathematical problem solving. Volume 3 (pp. 232-243). Reston, VA: National Council of Teachers of Mathematics.

von Glasersfled, E (1990). A exposition of constructivism: Why some like it radical. In R. B. Davis, C. A. Maher, \& N. Noddings (Eds.), Constructivist views on the teaching and learning of mathematics: Journal for Research in Mathematics Education Monograph 4 (pp. 19-29).

Vygotsky, L. S. (1978). Mind in society: The development of higher psychological processes. Cambridge, MA: Harvard University Press.

Weissglass, J. (1994). Changing mathematics teaching means changing ourselves: Implications for professional development. In D. B. Aichele \& A. F. Coxford (Eds.), Professional development for teachers of mathematics (pp. 67-78). Reston, VA: National Council of Teachers of Mathematics.

Wilson S. M. (1990). A conflict of interests: The case study of Mark Black. Educational Evaluation and Policy Analysis, 12(3), 293-310. 
APPENDIX A

TIMELINE 


\begin{tabular}{|c|c|}
\hline Month & Activity \\
\hline $\begin{array}{l}\text { August- } \\
\text { September } 2000\end{array}$ & - Identify approximately 16 teachers for initial screening \\
\hline $\begin{array}{l}\text { September 22, } \\
2000\end{array}$ & $\begin{array}{l}\text { - Attend training session on the use of the Classroom } \\
\text { Observation Scales }\end{array}$ \\
\hline $\begin{array}{l}\text { Late September- } \\
\text { Early November } \\
2000\end{array}$ & $\begin{array}{l}\text { - Contact teachers and schedule initial screening } \\
\text { observation } \\
\text { - Conduct initial screening observations }\end{array}$ \\
\hline December 2000 & $\begin{array}{l}\text { - Select } 4 \text { teachers best fitting the selection criteria } \\
\text { - Obtain consent from each participant and schedule initial } \\
\text { interview } \\
\text { - Administer teacher questionnaire }\end{array}$ \\
\hline $\begin{array}{l}\text { Early January- } \\
\text { Early March } 2001 \\
\end{array}$ & $\begin{array}{l}\text { - Conduct Initial Interviews and Prompted-Response } \\
\text { Interviews }\end{array}$ \\
\hline $\begin{array}{l}\text { Late March - } \\
\text { April } 2001\end{array}$ & $\begin{array}{l}\text { - Conduct 3-day Observations and Pre- and Post- } \\
\text { Observation Interviews }\end{array}$ \\
\hline April 2001 & - Preliminary data analysis identifying themes \\
\hline May 2001 & - Generate protocol for Follow-up Interview \\
\hline June 2001 & - Conduct Follow-up Interviews \\
\hline $\begin{array}{l}\text { July } 2001- \\
\text { March } 2002\end{array}$ & - Data Analysis and writing \\
\hline
\end{tabular}


APPENDIX B

INFORMED CONSENT 


\section{TEACHING MATHEMATICAL PROBLEM SOLVING IN THE CONTEXT OF OREGON'S EDUCATIONAL REFORM}

You are invited to participate in a research study conducted by Nicole Miller Rigelman, a doctoral student from Portland State University, in the Department of Curriculum and Instruction. The researcher hopes to learn more about what is happening in middle-level mathematics classrooms where teachers are mindful of reform implementation. This research is being conducted in partial fulfillment of the requirements for a doctoral degree under the supervision of Dr. Karen NoordhofT. School of Education. You were selected as a possible participant in this study because of your leadership in mathematics education at the building district. and/or state levels.

If you decide to participate, you will be asked to take part in several interviews as well as allow classroom observations. There will be two 1-hour. two 30 to 40 -minute, and one 15 minute audiotaped interviews. Three of the interviews will occur prior to the classroom observations, one will immediately follow the observations, and a follow-up interview will lake place in Febnuary. The interviews are designed to find out about your experiential background, your beliefs about mathematics and problem solving, and how you make decisions in your instruction. The observations will take place on three consecutive days of math instruction for one your classes. The researcher is trying to better understand how teachers promote mathematical thinking and problem solving in their classrooms. She wants to capture your work at its best so you will have freedom in choosing the lessons observed and may choose to increase the number of lessons observed if the initial lesson does not transpire as planned. You will also have an opportunity to discuss your perceptions of the lessons in an interview following the observations. You may not receive any direct benefit form taking part in this study, but the study may help to increase knowledge that may help others in the future. At the same time, you may experience an opportunity to reflect on your own practice with the possibility of furthering your personal and professional development.

Any information that is obtained in connection with this study and that can be linked to you or identify you will be kept confidential. This information will be kept confidential through use of a pseudonym. The pseudonym will be used to label all data collected and will be used in written reports. The information will not be shared with your supervisor or impact your job in any way. The audiotapes will only be used by the researcher to accurately capture the data and to provide a more thorough report than can be achieved through note-laking alone.

Your participation is completely voluntary. You do not have to take part in this study, and it will not affect your relationship with Portland State University. You may also withdraw from this study at any time without affecting your relationship with Portland State University, your school district, and the researcher.

If you have concems of problems about your participation in this study or your rights as a research subject, please call the Human Subjects Research Review Committee, Office of Research and Sponsored Projects, 111 Cramer Hall, Portland State University, (503) 725-8182. If you have any questions about the study itself, contact Dr. Karen Noordhoff at (503) 725-4692 or Nicole Miller Rigelman at 112 NE 63rd A venue, Portland, (503) 236-1097.

Your signature indicates that you have read and understand the above information and agree to take part in this study. Please understand that you may withdraw your consent at any time without penalty, and that, by signing you are not waiving any legal claims, rights or remedies. The researcher should provide you with a copy of this form for your own records. 


\section{APPENDIX C}

\section{MATHEMATICS TEACHER QUESTIONNAIRE}

Adapted from: Horizon Research, Inc. (1999). Local Systemic Change Teacher Questionnaire [Online]. Available: http://www.horizonresearch.com/LSC/manual/0102/tab5/teacher questionnaire0001 k8m.pdf 
Teacher Demographic Information

1. Name

2. District

3. School

4. What grade(s) do you teach? (Check all that apply.)
Q $5^{\text {th }}$
0 $6^{\text {th }}$
a $7^{\text {th }}$
0 $8^{\text {th }}$

5. What percent of your teaching assignment is math?
- $100 \%$
$75-99 \%$
व 25-49\%
$50-74 \%$
$24 \%$ or lower

6. How many college mathematics courses have you completed?
$\square$ None
0 4- 5 semesters
1 semester
0 6-9 semesters
2-3 semesters
Q 10 or more semesters

7. Describe your educational background: (Check all that apply.)

- Undergraduate major in mathematics or mathematics education

- Undergraduate minor in mathematics or mathematics education

- Graduate-level major or minor in mathematics or mathematics education

a Certification to teach advanced secondary mathematics

- Elementary education teaching certificate

None of the above

8. When did you last complete a mathematics course for college credit?
In the last 5 years
a 11-20 years ago
6-10 years ago
a. More than 20 years ago

9. Did your college mathematics coursework include the equivalent of at least one semester of: (Check one $D$ on each line.)
Number system concepts
Y Yes
No
Concepts in algebra
QYes
No
Concepts in geometry
Yes
No

10. How many years have you taught prior to this school year? 
Please rate the effect of each of the following on your mathematics instruction.

Inhibits Neutral Encourages NA

effective or mixed Effective don't
inseruction

11. State and/or district curriculum frameworks.

12. State and/or district testing policies and practices.

13. Quality of available instructional materials.

14. Access to calculators for mathematics instruction.

15. Access to computers for mathematics instruction.

16. Funds for purchasing math materials and manipulatives.

17. Instructional materials at the district or school level.

18. Time available for teachers to plan and prepare lessons.

19. Time available for teachers to work with other teachers.

20. Time available for teacher professional development.

21. Importance that the school places on mathematics.

22. Consistency of mathematics reform efforts with other state/district educational reforms.

23. Public attitudes toward educational reform.

Please answer the following questions regarding the class that will be observed.

24. What grade level(s) is this class? (Check all that apply.)
口 $5^{\text {th }}$
a $6^{\text {th }}$
D $7^{\text {th }}$
$8^{\text {th }}$

25. How many times per week do you typically teach mathematics to this class?

26. What is the approximate number of minutes in a typical period of this class?

27. What is the name of this class? (e.g., Grade 6; Geometry; Advanced Problem Solving; Title 1 Math; etc.)

28. How is this class grouped?

Heterogeneously a Tracked by ability

Other (please explain 


\section{Professional Development}

29. Approximately how many hours have you spent on formal professional development in mathematics/mathematics education during the past 2 years?
0
$1-9$
10-19
20-39
40-59
$60-79$
80 or more

30. What percentage of the above hours were provided by your school or district?
0
$1-9$
10-19
20-39
40-59
$60-79$
$80-100$

In general, to what extent is each of the following true of mathematics-related professional development that you have experienced in your distriet?

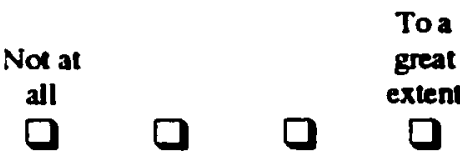

31. I am involved in planning my mathematics-related professional development.

32. I am encouraged to develop an individual professional plan to address my needs and interests related to mathematics education.

33. I am given time to work with other teachers as part of my professional development.

34. I am given time to reflect on what l've learned and how to apply it to the classroom.

35. I receive support as I try to implement what I have learned.

Please indicate the number of times you have participated in each of the following activities during this school year.

$$
\begin{array}{lllll}
0 & 1-2 & 3-4 & 5-6 & 7+
\end{array}
$$

\section{Formal Activities}

36. Participated in a study group/discussion group.

37. Was "coached" on my teaching by a teacher/staff person based on a classroom observation. 
Informal Activities

38. Received assistance from a "lead teacher" in my school.

39. Received assistance from a staff person in my district.

40. Received assistance from a designated mathematician/mathematics educator from a college/university/ professional organization/industry.

41. Read messages in a Listserv mathematics discussion.

42. Posted messages to a Listserv mathematics discussion.

$$
\begin{array}{lllll}
0 & 1-2 & 3-4 & 5-6 & 7+
\end{array}
$$

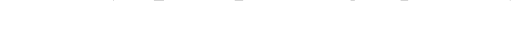


APPENDIX D

INITIAL INTERVIEW PROTOCOL 
Time: $60-90$ minutes

1. As you know, I asked you to be part of my study because of what I saw in your class this fall (or because you were identified as an exemplary math teacher). What has been most influential to you in developing your teaching practice?

2. What instructional materials do you use for math?

3. Tell me about the problem you brought. In your opinion, what makes it a "good" problem? What kind of student responses does this problem elicit? Why do you think so? Given Oregon's performance expectations, how does this problem prepare students to meet the standard?

4. How would you assess student learning on this problem? Why? Are there other ways you assess student leaming?

5. We are hearing a lot about the importance of promoting mathematical thinking and problem solving in our students. What does this mean to you? Can you give an example of that?

6. What role does problem solving take in your curriculum? What are your goals in teaching problem solving? When do you teach problem solving?

7. In what ways have the state expectations impacted your teaching of problem solving?

8. Imagine the state reform were not in place, what role would problem solving take in your curriculum? Why?

9. What are some things you do to develop students' problem solving expertise? Can you give an example of that?

10. What support (professional development, resources, time, collegial sharing) have you received in implementing the state expectations? What has had the most influence on your practice? Can you give an example of your classroom practice before and after? Your school before and after?

11. Have there been critical moments/experiences or turning points that caused you to change your thinking about math teaching/learning? Why do you suppose that experience/event was so powerful?

12. For you, what would "ideal" support conditions look like? Why? 


\section{APPENDIX E}

PROMPTED-RESPONSE INTERVIEW PROTOCOL 
Time: $60-90$ minutes

Tell teachers that I have a group of tasks that can be sorted in a variety of ways and that I am interested in how they think the tasks go together. Let teachers know that I would like them to show how the tasks could go together and talk about the categories they decide upon. (Sorting methods would include critical distinctions among problem types... e.g., task content, task difficulty.)

Once teachers finish sorting the tasks, ask:

1. How would you describe these groups? How did you decide to put the tasks together in the way you did?

2. Can you sort the tasks in another way? How would you describe these groups? How did you decide to put the tasks together in this way?

If it does not come out in the initial sorts, ask:

1. Which problems would you would give your students? Why?

2. In what context would you use the task?

3. What would you like to learn from your students by giving the task?

Finally, ask the teacher to choose a problem that they would most likely give to their students. Ask the teacher to solve the problem talking aloud about what he/she is thinking. Ask:

1. What do you think your students might do with this problem?

2. What approaches might they use? Are there any others?

3. Are there other tasks that you would give your students? Why? 


\section{APPENDIX F}

\section{TASKS FOR SORTING}

From: Stein, M. K., Smith, M. S., Henningsen, M. A., \& Silver, E. A. (2000). Implementing standards-based mathematical instruction: A casebook for professional development. New York: Teachers College Press. 


\section{Task A}

Manipulatives/tools: pattem blocks

$1 / 2$ of $1 / 3$ means one of two equal parts of one-third.<smiles>C1CCC2CCCC(CC1)CC2</smiles>

one-third<smiles>C1CCC2CC3CC(C1)C2C3</smiles>

$1 / 2$ of $1 / 3$ or $1 / 2 \times 1 / 3=1 / 6$
Find $1 / 3$ of $1 / 4$. Use pattern blocks. Draw your answer.

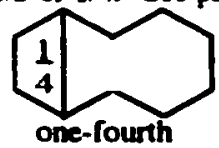

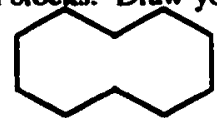
$1 / 3$ of $1 / 4$ or $1 / 3 \times 1 / 4=$

\section{Task B}

Manipulatives/tools: counters

For homework, Mark's teacher asked him to look at the pattem below and draw that figure that should come next.

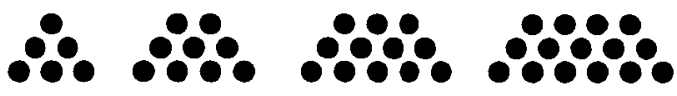

Mark does not know how to draw the next figure.

1. Draw the next figure for Mark

2. Write a description for Mark telling him how you knew which figure comes nexl.

Find 1/4 of 1/3. Use pattern blocks. Draw your answer.<smiles>CC1(C)C2CCCC1C1CCCC2C1</smiles><smiles>CC1CCCCCCCCCC1</smiles>

Task C

Manipulatives/tools: $10 \times 10$ square grid

Shade $1 / 3$ of the decimal square and express as a decimal. Use the decimal square to explain to your partner why the fraction and the decimal are equivalent.

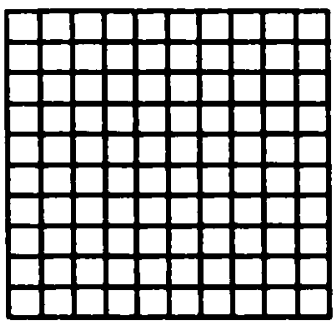

\section{Task D}

Manipulatives/tools: none

Evaluate each expression when $x=3$.

$$
\begin{aligned}
& 3 x \\
& 5+x \\
& x+21 \\
& 18-x \\
& x+6
\end{aligned}
$$




\section{Task E}

Manipulatives/tools: calculator

Divide using paper and pencil. Check your answer with a calculator and round the decimal to the nearest thousandth.

\section{$\mathbf{5 2 5}$ \\ 1.3 \\ $\mathbf{5 2 . 7 5}$ \\ 7.25 \\ 30.459 \\ .12}

\section{Task G}

Manipulatives/tools: Base Ten Blocks, grid paper

$$
\begin{array}{llll}
.08 & 8 & .080 & .008000
\end{array}
$$

Make three observations about the relative size of the above 4 numbers. Be sure to explain your observations as clearty as possible. Feel free to illustrate your observations if you feel it would help others understand them.

\section{Task F}

Manipulatives/tools: none

Match the property name with the appropriate equation.

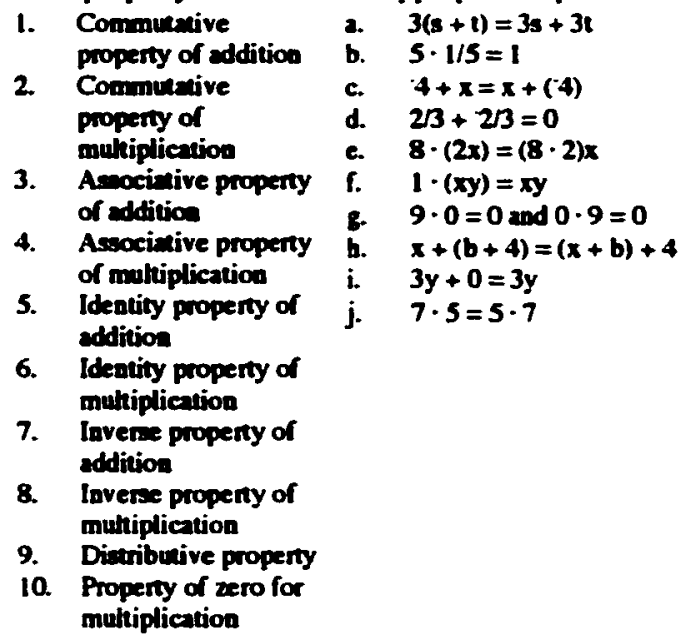

\section{Task H}

Manipulatives/tools: grid paper

The pairs of numbers in a-d below represent the heights of stacks of cubes to be leveled off. On grid paper, sketch the front views of columns of cubes with these heights before and after they are leveled off. Write a statement under the sketches that explains how your method of leveling off is related to finding the average of the two numbers.

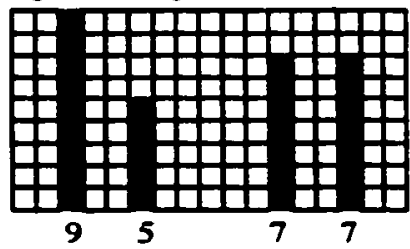

By taking 2 blocks off the first stack and giving them to the second stack, I've made the two stacks the same. So the total of cubes is not distributed into 2 columns of equal height. And that is what average means.
a) 14 and 8
b) 16 and 7
c) 7 and 12
d) 13 and 15 


\section{Task 1}

Manipulatives/tools: none

Write and solve a proportion for each.

17 is what percent of 68 ?

What is $15 \%$ of 60 ?

8 is $10 \%$ of what number?

24 is $25 \%$ of what number?

28 is what percent of 140 ?

What is $60 \%$ of 45 ?

36 is what percent of 90 ?

What is $80 \%$ of 120 ?

21 is $30 \%$ of what number?

Manipulatives/tools: none

\section{Task K}

The Georgetown University basketball team had a total of 252 free throws in 14 games. Find the average number of free throws per game.

\section{Task M}

Manipulatives/tools: none

Write three different mathematical problems that can be solved using the information below.

Jerome. Elliot, and Arturo took turns driving home from a trip. Arturo drove 80 miles more than Eliot. Eltiot drove twice as many miles as Jerome. Jerome drove 50 miles.

Question 11

Question 2

Question 13
Manipulatives/tools: none

\section{Task J}

One method of mentally computing $7 \times 34$ is illustrated in the diagram below:

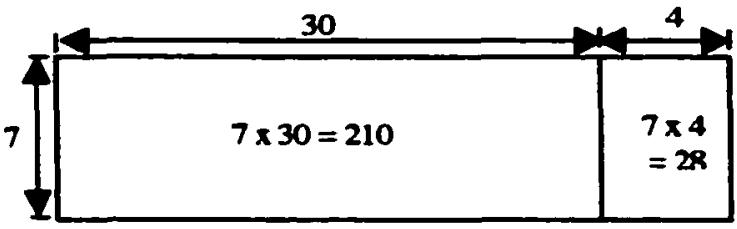

Mentally compute these products. Then sketch a diagram that describes your methods for each.

1. $27 \times 3$

2. $325 \times 4$

\section{Task L} Manipulatives/lools: Base Ten Blocks

Using Base Ten blocks, how could you show that 0.292 is less than 0.3 ?

\section{Task $\mathbf{N}$}

Manipulatives/tools: none

The cost of a sweater at J. C. Penney's was \$45.00. At the "Day and Night Sale" it was marked $30 \%$ off the original price. What was the price of the sweater during the sale? Explain the process you used to find the sale price. 


\section{Task O}

Manipulatives/tools: none

Give the fraction and percent for each decimal.

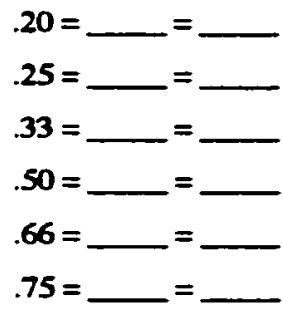

Task Q

Manipulatives/tools: calculator with scientific functions

Penny's mother told her that several of her great-greatgreat-grandparents fought in the Civil War. Penny thought this was interesting and she wondered how many great-great-great-grandparents that she actually had When she found that number, she wondered how many generations back she'd have to go until she could count over 100 ancestral grandparents or 1000 . or 10,000 . or even 100,000. When she found out she was amazed and she was also pretty glad she had a calculator. How do you think Penny might have figured out all of this information? Explain and justify your method as clearly and completely as possible.

\section{Task S}

Manipulatives/tools: Square Tiles

Use the side of a square pattem tile as a measure. find the perimeter (i.e., distance around) of each train in the pattem block figure shown below.

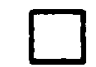

Train I

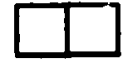

Train 2

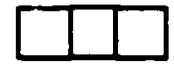

Train 3
Manipulatives/tools: none

Use the following information and the graph to write a story about Tony's walk-

At noon. Tony started walking to his grandmother's house. He arrived at her house at 3:00. The graph below shows Tony's speed in miles per hour

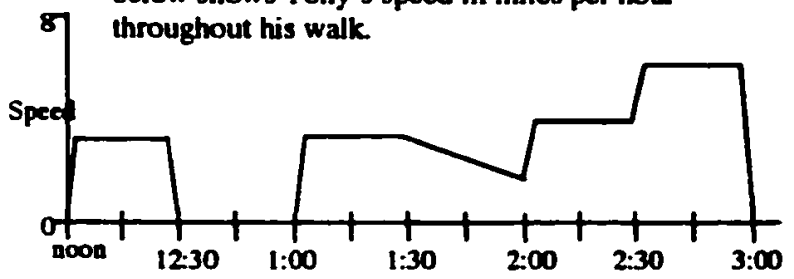

Write a story about Tony's walk. In your story, describe what Tony might have been doing at the different times.

Manipulatives/tools: none

\section{Task R}

Part A: After the first two games of the season, the best player on the girl's basketball team had made 12 out of 20 free throws. The best player on the boy's basketball team had made 14 out of 25 free throws. Which player had made the greater percent of free throws?

Pan B: The "better" player had to sit out the third gams due to an injury. How many baskets (out of an additional 10 free throw "tries") would the other player need to make in order to take the lead in terms of greatest percentage of free throws?

\section{Task T}

Manipulatives/tools: calculator

Your school's science club has decided to do a special project on nature photography. They decided to take a little over 300 outdoor photos in a variety of natural settings and in all different types of weather. Eventually they want to organize some of the best photos into a display and enter the State nature photography contest. The club was thinking of buying a $35 \mathrm{~mm}$ camera, but someone suggested that it might be better to buy disposable cameras instead. The regular camera with autofocus and automatic light meter would cost about $\$ 40.00$ and film would cost $\$ 3.98$ for 24 exposures and $\mathbf{5 5 . 9 5}$ for 36 exposures. The disposable cameras could be purchased in packs of three for $\$ 20.00$ with two of the three taking 24 pictures and the third one taking 27 pictures. Single disposables could be purchased for 58.95. The club officers have to decide which would be the best option and they have to justify their decisions to the club advisor. Do you think they should purchase the regular camera or the disposable cameras? Write a justification that clearly explains your reasoning 
APPENDIX G

\section{CLASSROOM OBSERVATION SCALES}

From: Secada, W. \& Byrd, L. (1993). Classroom observation scales: School level reform in the teaching of mathematics. Madison, WI: National Center for Research in Mathematical Sciences Education, Wisconsin Center for Education Research, School of Education. 
Use of Mathematical Analysts

This scale is intended to measure the extent to which students are engaged in mathematical analysis (e.g., searching for mathematical patterns, making conjectures, and justifying those conjectures).

1. Students receive, recite, or perform routine procedures. In no activities during the lesson do students engage in mathematics analysis.

2. Students primarily receive, recite, or perform routine procectures. But at some point during the lesson, they engage in mathematical analysis as a minor diversion.

3. There is a least one significant activity involving mathematical analysis in which some students engage. OR, mathematical analysis that is primarily diversionary in nature occurs throughout the lesson.

4. There is at least one major activity in which students engage in mathematical analysis; this activity occupies a substantial portion of the lesson: and many students are engaged in it.

5. Most students, for most of the time, are engaged in mathematical analysis.

\section{Depth of Knowledge and Student Understanding}

This scale measures the depth of mathematical knowledge as evidenced by opportunities for students to produce new knowledge by discovering relationships. justifying their hypotheses, and drawing conclusions.

1. Knowledge is very thin because concepts are treated trivially or presented as non-problematic: students are involved in the coverage of information which they are to remember. For example. students apply an algorithm for factoring binomials or they use the FOIL method of multiplication - in either case with no altention to the underlying concepts.

2. Knowledge remains superficial or fragmented. Underlying or related concepts and ideas might be mentioned or covered, but only a superficial acquaintance or trivialized understanding of these ideas is evident. For example, a teacher might explain why we factor binomials or why the FOIL method works, but the focus remains on students mastering these procedures.

3. Knowledge is treated unevenly during instruction; deep understanding of some mathematics concepts is countered by superficial understanding of some other ideas. At least one idea may be presented in depth and its significance grasped by some students, but in general the focus is not sustained.

4. Knowledge is relatively deep because the students provide information, arguments or reasoning that demonstrate the complexity of one or more ideas. The teacher structures the lesson so that many students do at least one of the following: sustain a focus on a sigmificant topic for a period of time; or demonstrate their understanding of the problematic nature of information and/or ideas: or demonstrate understanding by arriving at a reasoned, supported conclusion; or explain how they solved a relatively complex problem.

5. Knowledge is very deep because the teacher successfully stnuctures the lesson so that almost all students do at least one of the following: sustain a focus on a significant lopic; or demonstrate their understanding of the problematic nature of information and/or ideas; or demonstrate complex understanding by arriving at a reasoned, supported conclusion; or explain bow they solved a complex problem. In gencral, students' reasoning. explanations and arguments demonstrate fullness and complexity of understanding. 
Mathematieal Diseourse and Communieation

This scale assesses the extent to which talking is used to learn and understand mathematics in the classroom.

1. Virtually no features of mathematical discourse and communication occur.

2. Sharing and the development of collective understanding among a few students (or between a single student and the (eacher) occur briefly.

3. There is at least one sustained episode of sharing and developing collective understanding about mathematics that involves (a) a small group of students or (b) a small group of students and the reacher. Or, brief episodes of sharing and developing collective understandings occur sporadically throughout the lesson.

4. There are many sustained episodes of sharing and developing collective understandings about mathematics in which many students participate.

5. The creation of and maintenance of collective understandings permeates the entire lesson. This could include the use of common terminology and the careful negotiation of meanings. Almost everyone participates.

Locus of Mathematical Authority

The intent of this scale is 10 determine the extent 10 which the lesson supports a shared sense of authority for validating students' mathematical reasoning.

1. Students rely on the teacher and/or text as the legitimate source of mathematical authority. Students will accept an answer as correct only if the teacher says it is correct or if it is found in the back of the book. If stuck on a problem, students will almost always ask the teacher for belp.

2. Students rely on the teacher and some of their more capable peers (who are clearly recognized as being better at math) as the legitimate source of mathematical authority. The teacher will often rely on this more capable group of students to provide the right answer when pacing the lesson or to correct an erroneous answer. As a result. other students will often rely on these students for correct solutions, verification of right answers, or belp when stuck

3. Many students share mathematical authority among themselves. They tend to rely on the soundness of their own mathematical arguments for verification of an answer, however. they still look to the teacher as the authority for making the final decisions. The teacher may intervene with the answer in an effort to speed things up when students seem to be getting bogged down in the details of an argument.

4. Most students share in the mathematical authority of the class. Though the teacher might intervene when they are getting bogged down. she does so with a question that focuses their attention or helps them to see a contradiction that they were missing. The leacher often answers a question with a question, though from time to time, she may provide the students with an answer.

5. Almost all the students share in the mathematical authority for the class. Students rely on the soundness of their own arguments and reasoning. The teacher almost always answers a question with a question. It is not uncommon to see students leaving a class still arguing about one or more mathematical points in their lesson. 


\section{Soctal Support}

This scale measures the extent to which the teacher supports students by conveying high expectations for all students (e.g., taking risks, trying hard to master challenging academic work).

1. Social support is negative; action/comments by teacher or students result in "put-downs;" classroom atmosphere is negative.

2. Social support is mixed. Both negative and positive behaviors or comments by teachers or students are observed.

3. Social support is neutral or mildly positive. Evidence may be mainly in the form of verbal approval for student effort and work. However, such support tends to be given to students who are already taking initiative in the class, and it tends not to be given to those who are reluctant participants or less articulate or skilled in the subject.

4. Social support from the teacher is clearly positive and there is some evidence of social support among students for their peers. Evidence of special efforts by the teacher take the form of expressions that convey high expectations for all; mutual respect; a need to ury hard and risk initial failure.

5. Social support is strong; the class is characterized by high expectations, challenging work, strong effort, mutual respect and assistance in achievement for all students. Both teacher and students demonstrate a number of these attitudes by soliciting and welcoming contributions from all snidents who are expected to put forth their best efforts. Broad participation may be an indication that low achieving students receive social support for learning.

Student Engagement in Mathematics

This scale measures the extent to which students are engaged in the lesson (e.g., attentiveness, doing the assigned work, showing enthusiasm for work by taking initiative to raise questions, contribuse to group lasks and help peers.

1. Disruptive disengagement: students are frequently off-task as evidenced by gross inattention or serious disnuptions by many; this is the central characteristic during much of the class.

2. Passive disengagement; students appear lethargic and are only occasionally on-task carrying out assigned activities; for substantial portions of time, many students are either clearly off-task or nominally on-task but not orying very hard.

3. Sporadic or episodic engagement; most students, some of the time, are engaged in class activities. but this engagement in uneven. mildly enthusiastic or dependent on frequent prodding from the teacher.

4. Engagement is widespread: most students, most of the time, are on-task pursuing the substance of the lesson; most students seem to be taking the work seriously and trying hard.

5. Serious engagement: almost all students are deeply involved. almost all of the time, in pursuing the substance of the lesson. 
APPENDIX $\mathrm{H}$

PRE- AND POST - OBSERVATION INTERVIEW PROTOCOLS 


\section{PRE-OBSERVATION INTERVIEW}

Time:15-20 minutes

After expression of appreciation to the teacher for allowing me to observe the class, ask the following questions:

1. What have you been doing in your math class recently?

2. What are the BIG mathematical ideas of the lessons I will observe? What do you hope students will learn? Why?

3. How will you promote mathematical thinking and problem solving in this lesson? Why? What is it about that structure that promotes mathematical thinking and problem solving?

4. Is there anything in particular that I should know about the group of students that I will be observing?

\section{POST-OBSERVATION INTERVIEW}

Time: $40-60$ minutes

Thank the teacher for his/her willingness to let me observe their class and let me know about his/her thinking:

1. How do you feel about the lessons I observed?

2. Were there any ways in which the lessons differed from your original plan? If yes, how did it differ? What caused you to make the changes?

3. Do you feel as though the lesson was successful in promoting mathematical thinking and problem solving the way you thought it would? What did you do or not do? What would you have done differently?

4. What did you learn about what your students know and can do? What do your students still need to learn? Were there any surprises?

5. What is the next step for this class?

6. Did you encounter any challenges in these lessons? How did you handle these challenges?

7. Are there other challenges you have faced? How did you handle these challenges? What kind of support would help you with these challenges? 


\section{APPENDIX I}

\section{CHARACTERISTICS OF MATHEMATICAL INSTRUCTIONAL TASKS}

From: Smith, M. S. \& Stein, M. K. (1998). Selecting and creating mathematical tasks: From research to practice. Mathematics Teaching in the Middle School, 3(5), 344-350. 


\section{Memoribation}

- Involve either reproducing previously learned facts, rules, formulas, or derinitions or committing facts, rules, formulas or definitions to memory.

- Camnot be solved using procedures because a procedure does not exist or because a time frame in which the task is being completed is 100 shont to use a procedure.

- Are not ambiguous. Such tasks involve exact reproduction of previously seen material, and what is to be reproduced is clearly and directly stated.

- Have no connection to the concepts or meaning that underlie the facts, rules, formulas, or definitions being learned or reproduced.

\section{Procedures without Connections}

- Are algorithmic. Use of the procedure either is specifically called for or is evident from prior instruction, experience, or placement of the lask.

- Require limited cognitive demand for successful completion. Litle ambiguity exists about what needs to be done and how to do it.

- Have no comnection to the concepts or meaning that underlic the procedure being used.

- Are focused on producing correct answers instead of on developing mathematical understanding.

- Require no explanations or explanations that focus sole on describing the procedure that was used.

\section{Procedures with Connections}

- Focus students' attention on the use of procedures for the purpose of developing deeper levels of understanding of mathematical concepts and ideas.

- Suggest explicitly or implicitly pathways to follow that are broad general procechures that have close comections to underlying concepts.

- Usually are represented in multiple ways, such as visual diagrams, manipulatives, symbols, and problem situations. Making comections among multiple representations helps develop meaning.

- Require some degree of cognitive effort. Although general procedures may be followed, they cannot be followed mindlessly. Students need to engage with conceptual ideas that underlie the procedures to complete the task successfully and that develop understanding.

\section{Dolng Mathematies}

- Require complex and non-al gorithmic thinking -- a predictable, well-rebearsed approach or pathway I not explicitly suggested by the task, task instructions, or a worked-out example.

- Require students to explore and understand the nature of mathematical concepts. processes, or relationships.

- Demand self-monitoring or self-regulation of one's own cognitive processes.

- Require students to access relevant knowledge and experiences and make appropriate use them in working through the task.

- Require students to analyze the task and actively examine task constraints that may limit possible solution strategies and solutions.

- Require considerable cognitive effort and may involve some level of anxiety for the student because of the unpredictable nature of the solution process required. 
APPENDIX J

FOLLOW-UP INTERVIEW PROTOCOL 
Time: $60-90$ minutes

1. After reviewing your transcripts, what stands out for you about your thinking and teaching practice? Were there any surprises? Is there anything you wish to add or clarify?

2. What specific segments of the classroom observations show interactions that reflect what you strive for in your classroom? (Will you show me where it starts and stops?) What does this segment illustrate about your thinking and practice?

3. Has using the Visual Mathematics/Math Alive! Curriculum influenced your thinking and teaching? If so, how? Can you give me an example of that? If not, why do you think that it may not have had much influence?

4. What, if anything have you learned as a result of using the Visual Mathematics/Math Alive!? (probe for specific examples as appropriate) What have you learned about:
a. math?
b. students?
c. student learning?
d. problem solving?
e. teaching problem solving?
f. assessing problem solving?

5. In your opinion, what are some benefits of using the Visual Mathematics/Math Alive! curricula (e.g., teachers, students)? How would you compare these benefits to other curricula you've used before?

6. In your opinion, what are some drawbacks of using the Visual Mathematics/Math Alive! curricula (e.g., teachers, students)? How would you compare these drawbacks to other curricula you've used before?

7. Here are examples of how two programs approach the teaching of scale factor. Take your time and look them over. Let me know when you are ready to talk about them, ['ll be interested in hearing your impressions. What are your impressions of these lessons? What similarities, if any, do you notice to Visual Mathematics/Math Alive!? What differences, if any, do you notice? How might you approach the teaching of this concept? Can you talk a little about the reasons you'd teach it this way? Have you taught the concept of scale factor using Visual Mathematics/Math Alive!?

Would you like to have a copy of this transcript as well? Can I send it to you by email? 


\section{APPENDIX K \\ CURRICULUM SAMPLES FOR FOLLOW-UP INTERVIEW}

Footprints and Theola's T-Shirt from

National Center for Research in Mathematical Sciences Education and the Freudenthal Institute (eds.). (1998). Mathematics in context. Chicago: Encyclopedia Britannica.

Nosing Around from

Lappan, G., Fey, J. T., Fitzgerald, W. M., Friel, S., \& Phillips, E. D. (1997). Connected mathematics. Palo Alto, CA: Dale Seymour Publications. 
Ms. Maestro's choral class is planning to put on a musical for the local communits The room that they will use is at the far end of the building and is rather difficult to find. To of fect audience to the performance room, Mabel suggests that they place footprints along the fait frofn the front door to the room. Ms. Maestro thinks that is a great idea and makes a pattern of a fow ó ysen. Cliff suggests that since the musical is about giants, the class should eniarge the pattern and make. int footpints.

The pattem of the footprint is drawn on 1-centimeter gridadraw grid.

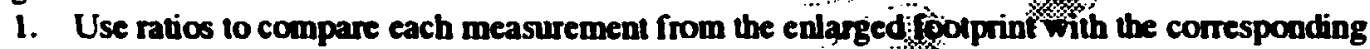
measurement from the original footprint. Describe what yo find.

2. Use the double number line to find the relationship fivetwe the original and the enlarged footprint by filling in the missing numbers.

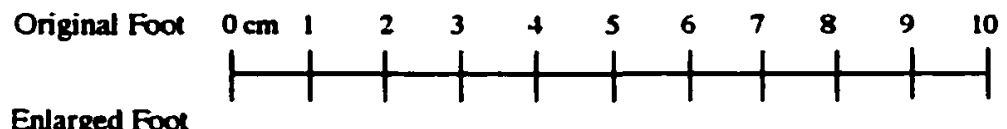

3. What is the ratio between the area of the original footprint to the area of the enlarged footprint? Compare this ratio to the relationship you found in problem $b$. What do you observe?

Theole's T.Shirt

Theola is eleven, and ber favorite animal is a cat. On a T-shirt, she wants to paint an enlargement of a drawing of a cat. She takes the original picture of the cat and draws a half-centimeter grid on it.

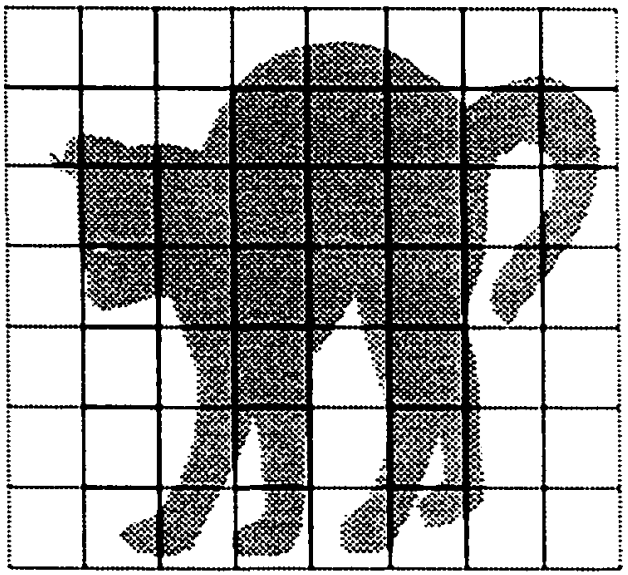

a. How big should she make each square of the enlarged grid so that the total enlargement will fit nicely on ber T-shirt?

b. Make a double number line to show the relationship between the length measurements of the original and the enlarge cat drawing.

Another way to show the relationship between an original and an enlarged drawing is to describe it in terms of scale factor. The scale factor tells you bow many times you enlarge every measurement of the original picture. You can think about scale factor in tems of arrow language.

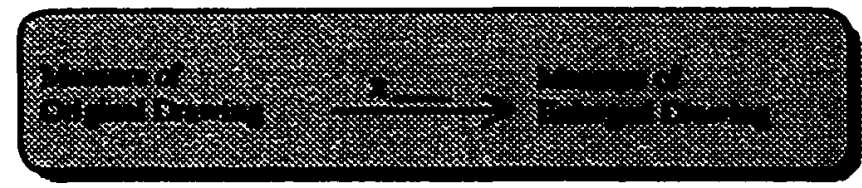

c. What is the scale factor you chose for Theola's enlarged drawing?

d. What is the scale factor for the enlarged footprint? 
Nosing Around, Part 1

Zack and Marta's computer game involves a family called the Wumps. The members of the Wump family are various sizes, but they all have the same shape. Mug Wump is the game's main character. By enlarging or reducing Mug, a player can transform him into other Wump family members

Look at the chart below. The Wumps in the chart are numbered according to their size. Mug is Wump 1. Since the segments that make up Zug are twice as long a s the segments that make up Mug. Zug is Wump 2. Since the segments that make up Bug

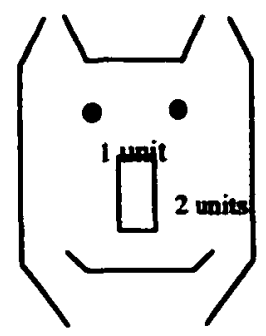
are three times as long as the segments that make up Mug. Bug is Wump 3.

The Womp Noses (Plus Lug and Thug)

\begin{tabular}{|l|c|c|c|c|}
\hline \multicolumn{1}{|c|}{ Wump } & $\begin{array}{c}\text { Width } \\
\text { of Nose }\end{array}$ & $\begin{array}{c}\text { Leagh } \\
\text { of Nose }\end{array}$ & $\begin{array}{c}\text { Width } \\
\text { Leagh }\end{array}$ & $\begin{array}{c}\text { Perimet } \\
\text { er }\end{array}$ \\
\hline Wump 1 (Mug) & 1 & 2 & $1 / 2$ & 6 \\
Wump 2 (Zug) & 2 & & $2 / 4$ & \\
Wump 3 (Bug) & 3 & 6 & & \\
Wump 4 & & & & \\
Wump 5 & & & & \\
Wump 10 & & & & \\
Wump 20 & & & & \\
Wump 100 & & & & \\
Lus & 1 & 6 & $1 / 6$ & \\
Thus & 3 & 2 & $3 / 2$ & \\
\hline
\end{tabular}

a. Look at the data. What panterns do you see? Explain bow the values in each column change as the Wumps get bigger. Look for relationships between the values of the different columns.

b. The rule for making Wump 4 is $(4 x, 4 y)$. The rule for making Wump 5 is $(5 x, 5 y)$. Add data to the chart for Wumps 4 and 5. Do their noses fit the patterns you notice in part A?

c. Use the patterns you found to add data for Wumps 10, 20, and 100 to the chart. Explain your reasoning.

d. Do Lug's nose and Thug's nose seem to fit the patierns you found for the Wumps? If not, what makes them different?

Nosing Around, Part 2

To find the length, width and perimeter of Zug's nose, we can multiply the length, width, and perimeter of Mug's nose by 2. The number 2 is called the scale factor from Mug's nose to Zug's nose. The seale feetor is the number that we multiply the dimension of an original figure by to the get the dimensions of an enlarged or rectuced figure.

The scale factor from Mug to Bug is 3. You can multiply the side lengths of Mug's nose by 3 to find the side lengths of Bug's nose. We can also say that the side lengths and perimeters grow by a scale factor of 3.

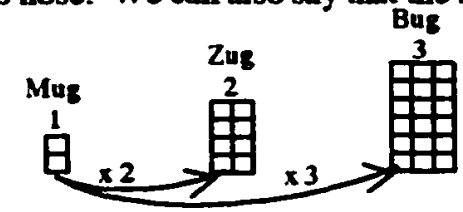

1. Is there a scale factor from Mug's nose to Wump 4's nose? Why or why not?

2. Is there a scale factor from Mug's nose to Thug's nose? Why or why not?

3. The dimensions of Bug's nose are $3 \times 6$. Suppose this nose is enlarged by a scale factor of 3 .

a. What are the dimensions of the new nose?

b. What is the perimeter of the new nose?

4. a. What is the scale factor from Wump 2 to Wump 10 ?

b. What is the scale factor from Wump 10 to Wump 2? 
APPENDIX L

\section{RESEARCH QUESTION AND METHODS}

ALIGNMENT MATRIX 
I. What do the focus teachers do to engage students in mathematieal problem solving? In answering this question, I will look at relationships among the teacher, student. and the content. specifically, problem solving. I will describe what teachers and students are doing as they engage in problem solving. I will also describe what teachers emphasize as they teach problem solving, the role problem solving plays in their curriculum. and how teachers chose the problems they do.

a) What is the role of the teacher? How do these teachers see their role in problem solving instruction?

a) What is the role of the students?

a) What do these teachers emphasize in their problem solving instruction?

a) What role does problem solving play in their curriculum?

a) How do teachers choose the problems for classioom investigation?
Initial Intervlew: Teachers will bring a "good" problem to the initial interview and discuss what makes it a "good" problem, How do teachers choose the problems for classroom investigation? Interview Questions: What is problem solving? What role does problem solving take in your curriculum? What are your goals in teaching problem solving? Imagine the state reform were not in place, what role would problem solving take in your curriculum? What are some things you do to develop students' problem solving expertise? Answering: What role does problem solving play in their curriculum?

Prompled-Response Intervikw: task sorting activity will engage teachers discussion about what strikes them as the salient features of problem and will help the researcher determine what the teacher considers a "problem" in general and what is a "problem" for his/her students. It gives insight into how a teacher makes decisions about which problems to give to his/ber students Answering: How do teachers choose the problems for classtoom investigation?

Clnstoom Observallons: observe the role of teacher and student during problem solving instruction. Answering: What is the role of the teacher? What is the role of the students? What do these teachers emphasize in their problem solving instruction?

Pre- and Post-Observation Interviews:

Pre-Interview Questions: What are the BIG mathematical ideas of the lesson I will observe? What do you hope students will learn? Why? How will you promote problem solving during in this lesson? Why? What is it about what you' ve planned that promotes problem solving? Post-Interview Questions: Do you feel the lesson was successful in promoting problem solving in the way that you thought it would? What did you do...? -or- What would you do difrerently...? What did you leam about what your students know and can do? What do you students still need to leam with regard to...? What are your next steps for this class? Answering: How do teachers choose the problems for classroom investigation? How do these teachers see their role in problem solving instruction? 
What do I want to know? Research Questions
How will I study it?

Comnections to Methods
II. On what besces do texchers make decisions about
- what to emphsoize when tenching problem solving?
- how to teach problem solving?, and
- when to leach problem solving?
Questionnaire: Questions regarding internal and external influences (c.g., curriculum. policy, resources, support time, philosophy) and their impact on instruction. Questions regarding the type and scope of formal and informal professional development experiences and the impact of those experiences on leachers' knowledge and beliefs. Answering: What dimensions of teacher knowledge, beliefs, and thinking (mathematics content, problem solving, pedagogy, mathematics pedagogy) account for the focus teachers' problem solving practice? What external influences (i.e., curriculum, echucational reform policies, formal and informal professional development) account for the focus teachers' problem solving practice? In answering this question I will look at the internal and external conditions influencing leachers as they make decisions about what lo emphasize as they teach problem solving. how to leach problem solving, and when 10 teach problem solving. This study will allow me to account for and explain the internal (knowledge, beliefs, and thinking) and external (curriculum, policy, professional development) conditions that influence teachers' problem solving practice. It will provide stories of how teachers come to teach problem solving the way they do.
Initial Interview: Teachers will bring a "good" problem to the initial interview and discuss what makes it a "good" problem. Answering: -what to emphasize when teaching problem solving? Interview Questions: Generally, this line of questions is getting on how teachers are making decisions about their problem solving instruction... What is problem solving? What role does problem solving take in your curriculum? What are your goals in teaching problem solving? When do you teach problem solving? Imagine the state reform were not in place, what role would problem solving take in your curriculum? What are some things you do to develop students' problem solving expertise? Answering: - what to emphasize when teaching problem solving? - how to teach problem solving? -when to teach problem solving? Additional Interview Questions: What instructional materials do you use for math? Imagine the state reform were not in place, what role would problem solving take in your curriculum? Why? What support (professional development, resources, time, collegial sharing) have you received in implementing the state expectations? What has had the most influence on your practice? Can you give an example of before and after? Were there critical moments that caused you to change your thinking about math teaching/learning? Why do you suppose that experience/event was so powerful? What would be included in the "ideal" support conditions? Why?

Answering: What external infuences (i.e., curriculum, educational reform policies, formal and informal professional development) account for the focus teachers' problem solving practice?

Prompled-Response Intervlew: task sorting activity gives insight into how a teacher makes decisions about which problems to give to his/her students. Following the sorting, the researcher will ask the teacher to solve one of the problems the teacher identified as a problem he/she would give his/ber students and to discuss all the approaches that could be used to solve the problem.

Answering: What dimensions of teacher knowledge, beliefs, and thinking (mathematics content, problem solving, pedagogy, mathematics pedagogy, themselves as teachers and learners, students as learners) account for the focus teachers' problem solving practice? 
What do I want to know?

Research Questions

a) What dimensions of teacher knowledge. beliefs, and thinking (mathematics content, problem solving, pedagogy. mathematics pedagogy, themselves as reachers and learners, students as learners) account for the focus teachers' problem solving practice? Do these dimensions interact? If so, how and with what influence?

b)What external influences (i.e. curriculum, educational reform policies, formal and informal professional development) account for the focus reachers' problem solving practice? Do these dimensions interact? If so, how and with what influence?
How will I study it? Comections to Methods
Classroom Observations: observe the role of teacher and student during problem solving instruction. Answering: What dimensions of teacher knowledge, beliefs, and thinking (students as learners) account for the focus teachers' problem solving practice?

Pre- and Poat-Observation Interviews:

Pre-Interview Questions: What are the BIG mathematical ideas of the lesson I will observe? What do you bope students will leam? Why? How will you promote problem solving during this lesson? Why? What is it about that structure that promotes problem solving? Post-Interview Questions: Do you feel the lesson was successful in promoting problem solving in the way that you thought it would? What did you do...? - or- What would you do differently...? What did you learn about what your students know and can do? What do you students still need to learn with regard to...? What are your next steps for this class? Did you encounter any challenges in these lessons? How did you handle these challenges? Are there any other challenges you have faced? How did you handle these challenges? What kind of support would help you with these challenges? Answering: What dimensions of teacher knowledge. beliefs, and thinking (mathematics content, problem solving, pedagogy. mathematics pedagogy, themselves as teachers and learners, students as learners) account for the focus teachers' problem solving practice? What external influences (i.e.. curriculum, educational reform policies) account for the focus teachers' problem solving practice? 